Cochrane Database of Systematic Reviews

\title{
Aromatase inhibitors (letrozole) for subfertile women with polycystic ovary syndrome (Review)
}

Franik S, Eltrop SM, Kremer JAM, Kiesel L, Farquhar C

Franik S, Eltrop SM, Kremer JAM, Kiesel L, Farquhar C.

Aromatase inhibitors (letrozole) for subfertile women with polycystic ovary syndrome.

Cochrane Database of Systematic Reviews 2018, Issue 5. Art. No.: CD010287.

DOI: 10.1002/14651858.CD010287.pub3.

www.cochranelibrary.com 
TABLE OF CONTENTS

HEADER

ABSTRACT

PLAIN LANGUAGE SUMMARY

SUMMARY OF FINDINGS

BACKGROUND

OBJECTIVES

METHODS

RESULTS

Figure 1.

Figure 2.

Figure 3.

Figure 4.

Figure 5.

Figure 6.

DISCUSSION

AUTHORS' CONCLUSIONS

ACKNOWLEDGEMENTS

REFERENCES

CHARACTERISTICS OF STUDIES

DATA AND ANALYSES

Analysis 1.1. Comparison 1 Letrozole compared to placebo, Outcome 1 Live birth rate.

Analysis 1.2. Comparison 1 Letrozole compared to placebo, Outcome 2 Ovarian hyperstimulation syndrome rate. ..................

Analysis 1.3. Comparison 1 Letrozole compared to placebo, Outcome 3 Clinical pregnancy rate.

Analysis 1.4. Comparison 1 Letrozole compared to placebo, Outcome 4 Miscarriage rate by woman randomised.

Analysis 1.5. Comparison 1 Letrozole compared to placebo, Outcome 5 Miscarriage rate by pregnancies.

Analysis 1.6. Comparison 1 Letrozole compared to placebo, Outcome 6 Multiple pregnancy rate.

Analysis 2.1. Comparison 2 Letrozole compared to selective estrogen receptor modulators with or without adjuncts, followed by timed intercourse, Outcome 1 Live birth rate.

Analysis 2.2. Comparison 2 Letrozole compared to selective estrogen receptor modulators with or without adjuncts, followed by timed intercourse, Outcome 2 Live birth rate by BMI.

Analysis 2.3. Comparison 2 Letrozole compared to selective estrogen receptor modulators with or without adjuncts, followed by timed intercourse, Outcome 3 Live birth rate by first- or second-line treatment.

Analysis 2.4. Comparison 2 Letrozole compared to selective estrogen receptor modulators with or without adjuncts, followed by timed intercourse, Outcome 4 Impact of allocation bias for live birth rate.

Analysis 2.5. Comparison 2 Letrozole compared to selective estrogen receptor modulators with or without adjuncts, followed by timed intercourse, Outcome 5 Impact of detection bias for live birth rate.

Analysis 2.6. Comparison 2 Letrozole compared to selective estrogen receptor modulators with or without adjuncts, followed by timed intercourse, Outcome 6 Impact of attrition bias for live birth rate.

Analysis 2.7. Comparison 2 Letrozole compared to selective estrogen receptor modulators with or without adjuncts, followed by timed intercourse, Outcome 7 Ovarian hyperstimulation syndrome rate.

Analysis 2.8. Comparison 2 Letrozole compared to selective estrogen receptor modulators with or without adjuncts, followed by timed intercourse, Outcome 8 Ovarian hyperstimulation syndrome rate per BMI.

Analysis 2.9. Comparison 2 Letrozole compared to selective estrogen receptor modulators with or without adjuncts, followed by timed intercourse, Outcome 9 Clinical pregnancy rate.

Analysis 2.10. Comparison 2 Letrozole compared to selective estrogen receptor modulators with or without adjuncts, followed by timed intercourse, Outcome 10 Impact of allocation bias for clinical pregnancy rate.

Analysis 2.11. Comparison 2 Letrozole compared to selective estrogen receptor modulators with or without adjuncts, followed by timed intercourse, Outcome 11 Miscarriage rate by woman randomised.

Analysis 2.12. Comparison 2 Letrozole compared to selective estrogen receptor modulators with or without adjuncts, followed by timed intercourse, Outcome 12 Miscarriage rate by pregnancies.

Analysis 2.13. Comparison 2 Letrozole compared to selective estrogen receptor modulators with or without adjuncts, followed by timed intercourse, Outcome 13 Multiple pregnancy rate. 
Analysis 3.1. Comparison 3 Letrozole compared to clomiphene citrate, followed by IUI, Outcome 1 Ovarian hyperstimulation syndrome rate.

Analysis 3.2. Comparison 3 Letrozole compared to clomiphene citrate, followed by IUI, Outcome 2 Clinical pregnancy rate. .... Analysis 3.3. Comparison 3 Letrozole compared to clomiphene citrate, followed by IUI, Outcome 3 Miscarriage rate by woman randomised.

Analysis 3.4. Comparison 3 Letrozole compared to clomiphene citrate, followed by IUI, Outcome 4 Miscarriage rate by pregnancies.

Analysis 3.5. Comparison 3 Letrozole compared to clomiphene citrate, followed by IUI, Outcome 5 Multiple pregnancy rate. ... Analysis 4.1. Comparison 4 Letrozole compared to laparoscopic ovarian drilling, Outcome 1 Live birth rate.

Analysis 4.2. Comparison 4 Letrozole compared to laparoscopic ovarian drilling, Outcome 2 Ovarian hyperstimulation syndrome rate.

Analysis 4.3. Comparison 4 Letrozole compared to laparoscopic ovarian drilling, Outcome 3 Clinical pregnancy rate. ............. Analysis 4.4. Comparison 4 Letrozole compared to laparoscopic ovarian drilling, Outcome 4 Miscarriage rate by woman randomised.

Analysis 4.5. Comparison 4 Letrozole compared to laparoscopic ovarian drilling, Outcome 5 Miscarriage rate by pregnancies. .. Analysis 4.6. Comparison 4 Letrozole compared to laparoscopic ovarian drilling, Outcome 6 Multiple pregnancy rate. ............ Analysis 5.1. Comparison 5 Letrozole compared to FSH, Outcome 1 Ovarian hyperstimulation syndrome rate. ....................... Analysis 5.2. Comparison 5 Letrozole compared to FSH, Outcome 2 Clinical pregnancy rate.

Analysis 5.3. Comparison 5 Letrozole compared to FSH, Outcome 3 Miscarriage rate by woman randomised.

Analysis 5.4. Comparison 5 Letrozole compared to FSH, Outcome 4 Miscarriage rate by pregnancies.

Analysis 5.5. Comparison 5 Letrozole compared to FSH, Outcome 5 Multiple pregnancy rate.

Analysis 6.1. Comparison 6 Letrozole compared to anastrozole, Outcome 1 Ovarian hyperstimulation syndrome rate. .............

Analysis 6.2. Comparison 6 Letrozole compared to anastrozole, Outcome 2 Clinical pregnancy rate.

Analysis 6.3. Comparison 6 Letrozole compared to anastrozole, Outcome 3 Miscarriage rate by woman randomised. ..............

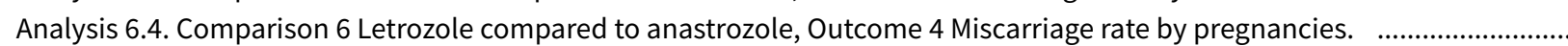

Analysis 6.5. Comparison 6 Letrozole compared to anastrozole, Outcome 5 Multiple pregnancy rate.

Analysis 7.1. Comparison 7 Different administration protocols of letrozole, Outcome 1 Ovarian hyperstimulation syndrome rate.

Analysis 7.2. Comparison 7 Different administration protocols of letrozole, Outcome 2 Clinical pregnancy rate.

Analysis 7.3. Comparison 7 Different administration protocols of letrozole, Outcome 3 Miscarriage rate by woman randomised.

Analysis 7.4. Comparison 7 Different administration protocols of letrozole, Outcome 4 Miscarriage rate by pregnancies. ........

Analysis 7.5. Comparison 7 Different administration protocols of letrozole, Outcome 5 Multiple pregnancy rate. .....................

Analysis 8.1. Comparison 8 Dosage studies of letrozole, Outcome 1 Ovarian hyperstimulation syndrome rate. ........................

Analysis 8.2. Comparison 8 Dosage studies of letrozole, Outcome 2 Clinical pregnancy rate.

Analysis 8.3. Comparison 8 Dosage studies of letrozole, Outcome 3 Miscarriage rate by woman randomised. ..........................

Analysis 8.4. Comparison 8 Dosage studies of letrozole, Outcome 4 Miscarriage rate by pregnancies.

Analysis 8.5. Comparison 8 Dosage studies of letrozole, Outcome 5 Multiple pregnancy rate. 
[Intervention Review]

\title{
Aromatase inhibitors (letrozole) for subfertile women with polycystic ovary syndrome
}

\author{
Sebastian Franik ${ }^{1}$, Stephanie M Eltrop ${ }^{1}$, Jan AM Kremer ${ }^{2}$, Ludwig Kiesel ${ }^{1}$, Cindy Farquhar ${ }^{3}$
}

1Department of Obstetrics and Gynaecology, University Hospital Münster, Münster, Germany. 2Department of Obstetrics and Gynaecology, Radboud University Nijmegen Medical Center, Nijmegen, Netherlands. 3Department of Obstetrics and Gynaecology, University of Auckland, Auckland, New Zealand

Contact address: Sebastian Franik, Department of Obstetrics and Gynaecology, University Hospital Münster, Albert-Schweitzer-Campus 1, Münster, 48149, Germany. Sebastian.Franik@UKMuenster.de, S.Franik@gmx.de.

Editorial group: Cochrane Gynaecology and Fertility Group.

Publication status and date: New search for studies and content updated (no change to conclusions), published in Issue 5, 2018.

Citation: Franik S, Eltrop SM, Kremer JAM, Kiesel L, Farquhar C. Aromatase inhibitors (letrozole) for subfertile women with polycystic ovary syndrome. Cochrane Database of Systematic Reviews 2018, Issue 5. Art. No.: CD010287. DOI: 10.1002/14651858.CD010287.pub3.

Copyright @ 2018 The Cochrane Collaboration. Published by John Wiley \& Sons, Ltd.

\section{A B S T R A C T}

\section{Background}

Polycystic ovary syndrome (PCOS) is the most common cause of infrequent periods (oligomenorrhoea) and absence of periods (amenorrhoea). It affects about $4 \%$ to $8 \%$ of women worldwide and often leads to anovulatory subfertility. Aromatase inhibitors (Als) are a class of drugs that were introduced for ovulation induction in 2001. Since about 2001 clinical trials have reached differing conclusions as to whether the Al letrozole is at least as effective as the first-line treatment clomiphene citrate (CC).

\section{Objectives}

To evaluate the effectiveness and safety of aromatase inhibitors for subfertile women with anovulatory PCOS for ovulation induction followed by timed intercourse or intrauterine insemination (IUI).

\section{Search methods}

We searched the following sources from inception to November 2017 to identify relevant randomised controlled trials (RCTs): the Cochrane Gynaecology and Fertility Group Specialised Register, the Cochrane Central Register of Controlled Trials, MEDLINE, Embase, PsycINFO, Pubmed, LILACS, Web of Knowledge, the World Health Organization (WHO) clinical trials register and Clinicaltrials.gov. We also searched the references of relevant articles. We did not restrict the searches by language or publication status.

\section{Selection criteria}

We included all RCTs of Als used alone or with other medical therapies for ovulation induction in women of reproductive age with anovulatory PCOS.

\section{Data collection and analysis}

Two review authors independently selected trials, extracted the data and assessed risks of bias. We pooled studies where appropriate using a fixed-effect model to calculate odds ratios (ORs) and 95\% confidence intervals (Cls) for most outcomes, and risk differences (RDs) for ovarian hyperstimulation syndrome (OHSS). The primary outcomes were live birth and OHSS. Secondary outcomes were clinical pregnancy, miscarriage and multiple pregnancy. We assessed the quality of the evidence for each comparison using GRADE methods.

\section{Main results}

This is a substantive update of a previous review. We identified 16 additional studies for the 2018 update. We include 42 RCTs (7935 women). The aromatase inhibitor letrozole was used in all studies. 


\section{Letrozole compared to clomiphene citrate (CC) with or without adjuncts followed by timed intercourse}

Live birth rates were higher with letrozole (with or without adjuncts) compared to clomiphene citrate (with our without adjuncts) followed by timed intercourse (OR 1.68, 95\% $\mathrm{Cl} 1.42$ to $1.99 ; 2954$ participants; 13 studies; $\mid 2=0 \%$; number needed to treat for an additional beneficial outcome (NNTB) =10; moderate-quality evidence). There is high-quality evidence that OHSS rates are similar with letrozole or clomiphene citrate $(0.5 \%$ in both arms: risk difference $(\mathrm{RD})-0.00,95 \% \mathrm{Cl}-0.01$ to $0.00 ; 2536$ participants; 12 studies; $12=0 \%$; high-quality evidence). There is evidence for a higher pregnancy rate in favour of letrozole (OR 1.56, 95\% Cl 1.37 to 1.78; 4629 participants; 25 studies; $\left.\right|^{2}=1 \%$; NNTB $=10$; moderate-quality evidence). There is little or no difference between treatment groups in the rate of miscarriage by pregnancy (20\% with CC versus $19 \%$ with letrozole; OR $0.94,95 \%$ Cl 0.70 to $1.26 ; 1210$ participants; 18 studies; $12=0 \%$; high-quality evidence) and multiple pregnancy rate $(1.7 \%$ with CC versus $1.3 \%$ with letrozole; OR $0.69,95 \% \mathrm{Cl} 0.41$ to $1.16 ; 3579$ participants; 17 studies; $12=0 \%$; high-quality evidence). However, a funnel plot showed mild asymmetry, indicating that some studies in favour of clomiphene might be missing.

\section{Letrozole compared to laparoscopic ovarian drilling}

There is low-quality evidence that live birth rates are similar with letrozole or laparoscopic ovarian drilling (OR $1.38,95 \% \mathrm{Cl} 0.95$ to 2.02 ; 548 participants; 3 studies; $I^{2}=23 \%$; low-quality evidence). There is insufficient evidence for a difference in OHSS rates (RD $0.00,95 \% \mathrm{Cl}$ -0.01 to $0.01 ; 260$ participants; 1 study; low-quality evidence). There is low-quality evidence that pregnancy rates are similar (OR $1.28,95 \%$ $\mathrm{Cl} 0.94$ to $1.74 ; 774$ participants; 5 studies; $\mathrm{I}^{2}=0 \%$; moderate-quality evidence). There is insufficient evidence for a difference in miscarriage rate by pregnancy (OR $0.66,95 \% \mathrm{Cl} 0.30$ to $1.43 ; 240$ participants; 5 studies; $\mathrm{I}^{2}=0 \%$; moderate-quality evidence), or multiple pregnancies (OR $3.00,95 \% \mathrm{Cl} 0.12$ to $74.90 ; 548$ participants; 3 studies; $1^{2}=0 \%$; low-quality evidence).

Additional comparisons were made for Letrozole versus placebo, Selective oestrogen receptor modulators (SERMS) followed by intrauterine insemination (IUI), follicle stimulating hormone (FSH), Anastrozole, as well as dosage and administration protocols.

There is insufficient evidence for a difference in either group of treatment due to a limited number of studies. Hence more research is necessary.

\section{Authors' conclusions}

Letrozole appears to improve live birth and pregnancy rates in subfertile women with anovulatory polycystic ovary syndrome, compared to clomiphene citrate. There is high-quality evidence that OHSS rates are similar with letrozole or clomiphene citrate. There is high-quality evidence of no difference in miscarriage rates or multiple pregnancy rates. There is low-quality evidence of no difference in live birth and pregnancy rates between letrozole and laparoscopic ovarian drilling, although there were few relevant studies. For the 2018 update, we added good-quality trials, upgrading the quality of the evidence.

\section{PLAIN LANGUAGE SUMMARY}

\section{Aromatase inhibitors for subfertility treatment in women with polycystic ovary syndrome}

Review question: Cochrane authors examined the evidence about aromatase inhibitors (Als) for subfertile women with polycystic ovary syndrome (PCOS).

Background: PCOS is the most common cause of infrequent or absent menstrual periods, and affects about $4 \%$ to $8 \%$ of women worldwide. It often causes anovulatory subfertility (subfertility related to failure to ovulate). Als are used to make ovulation happen. Since about 2001 clinical trials have reached differing conclusions as to whether the Al letrozole is at least as effective for treating subfertility as the most commonly used treatment, clomiphene citrate (CC).

Study characteristics: The review includes clinical studies where participants were randomly assigned to the intervention or to the comparison group (randomised controlled trials, RCTs). Our review includes 42 RCTs with 7935 women. In all trials the aromatase inhibitor used was letrozole. Comparators included CC, which was used in 25 of the RCTs, and laparoscopic ovarian drilling (a surgical technique to puncture the membrane surrounding the ovary), which was used in five RCTs. Several studies included other treatments in one or both arms.

Key results: Letrozole appears to improve live birth and pregnancy rates compared to CC when used to cause ovulation and timed intercourse. The quality of this evidence was moderate and seems to be reliable. There appeared to be no difference for miscarriage rate or multiple pregnancy rate. There appeared to be no difference between letrozole and laparoscopic ovarian drilling for any observed outcomes, although there were few relevant studies. Ovarian hyperstimulation syndrome (OHSS), a serious adverse event of hormonal stimulation, was a very rare event and in most studies it did not occur. The evidence is current to January 2018.

Quality of the evidence: The overall quality of the evidence ranged from moderate to high. Some studies in favour of clomiphene citrate may never have been published. It appears that studies that reported live births report higher clinical pregnancy rates in the letrozole group than studies that failed to report live births. This suggests that results might be somewhat less favourable to letrozole if all studies reported live births. 


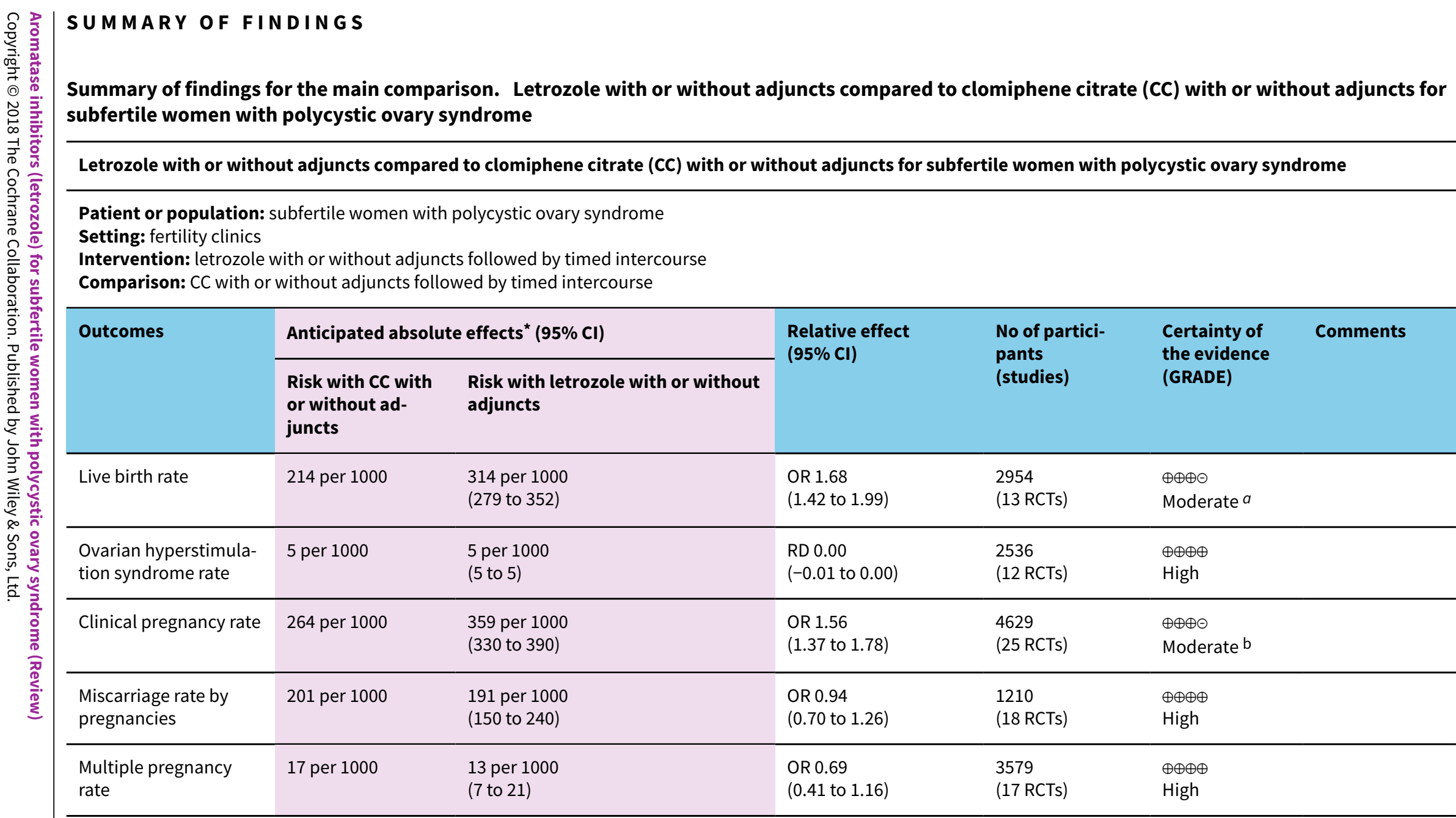

${ }^{\star}$ The risk in the intervention group (and its $95 \%$ confidence interval) is based on the mean risk in the comparison group and the relative effect of the intervention (and its $95 \% \mathrm{Cl})$.

CI: Confidence interval; RD: Risk difference: OR: Odds ratio;

\section{GRADE Working Group grades of evidence}

High certainty: We are very confident that the true effect lies close to that of the estimate of the effect

Moderate certainty: We are moderately confident in the effect estimate: The true effect is likely to be close to the estimate of the effect, but there is a possibility that it is

substantially different

Low certainty: Our confidence in the effect estimate is limited: The true effect may be substantially different from the estimate of the effect 
aDowngraded one level for serious risk of bias associated with potential selective reporting: Studies that reported live birth tended to report higher clinical pregnancy rates in the letrozole group than studies that failed to report live birth, suggesting that results might be less favourable to letrozole if all studies reported live birth.

bDowngraded one level for serious risk of publication bias: a funnel plot analysis strongly suggests that there might be more publications without a significant effect which were not published.

Summary of findings 2 . Letrozole compared to laparoscopic ovarian drilling for subfertile women with polycystic ovary syndrome

\section{Letrozole compared to laparoscopic ovarian drilling compared to placebo for subfertile women with polycystic ovary syndrome}

Patient or population: Subfertile women with polycystic ovary syndrome

Setting: Fertility clinics

Intervention: Letrozole with or without adjuncts followed by timed intercourse

Comparison: Laparoscopic ovarian drilling (LOD) followed by timed intercourse

\begin{tabular}{|c|c|c|c|c|c|c|}
\hline \multirow[t]{2}{*}{ Outcomes } & \multicolumn{2}{|c|}{ Anticipated absolute effects ${ }^{\star}(95 \% \mathrm{Cl})$} & \multirow{2}{*}{$\begin{array}{l}\text { Relative effect } \\
(95 \% \mathrm{CI})\end{array}$} & \multirow{2}{*}{$\begin{array}{l}\text { No of partici- } \\
\text { pants } \\
\text { (studies) }\end{array}$} & \multirow{2}{*}{$\begin{array}{l}\text { Certainty of the } \\
\text { evidence } \\
\text { (GRADE) }\end{array}$} & \multirow[t]{2}{*}{ Comments } \\
\hline & Risk with LOD & Risk with letrozole & & & & \\
\hline $\begin{array}{l}\text { Ovarian hyperstimula- } \\
\text { tion syndrome rate }\end{array}$ & 0 per 1000 & $\begin{array}{l}0 \text { per } 1000 \\
(0 \text { to } 0)\end{array}$ & $\begin{array}{l}\text { RD } 0.00 \\
(-0.01 \text { to } 0.01)\end{array}$ & $\begin{array}{l}260 \\
(1 \mathrm{RCT})\end{array}$ & $\begin{array}{l}\oplus \oplus \ominus \ominus \\
\text { Low } c\end{array}$ & \\
\hline Clinical pregnancy rate & 284 per 1000 & $\begin{array}{l}336 \text { per } 1000 \\
\text { ( } 271 \text { to } 408)\end{array}$ & $\begin{array}{l}\text { OR } 1.28 \\
(0.94 \text { to } 1.74)\end{array}$ & $\begin{array}{l}774 \\
(5 \mathrm{RCTs})\end{array}$ & $\begin{array}{l}\oplus \oplus \oplus \ominus \\
\text { Low a,b }\end{array}$ & \\
\hline $\begin{array}{l}\text { Miscarriage rate by preg- } \\
\text { nancies }\end{array}$ & 145 per 1000 & $\begin{array}{l}101 \text { per } 1000 \\
\text { (49 to } 196)\end{array}$ & $\begin{array}{l}\text { OR } 0.66 \\
\text { (0.30 to } 1.43)\end{array}$ & $\begin{array}{l}240 \\
\text { (5 RCTs) }\end{array}$ & $\begin{array}{l}\oplus \oplus \oplus \ominus \\
\text { Moderate } a\end{array}$ & \\
\hline Multiple pregnancy rate & 0 per 1000 & $\begin{array}{l}0 \text { per } 1000 \\
(0 \text { to } 0)\end{array}$ & $\begin{array}{l}\text { OR } 3.00 \\
\text { (0.12 to } 74.90)\end{array}$ & $\begin{array}{l}548 \\
\text { (3 RCTs) }\end{array}$ & $\begin{array}{l}\oplus \oplus \ominus \ominus \\
\text { Low } a, b\end{array}$ & \\
\hline
\end{tabular}

${ }^{\star}$ The risk in the intervention group (and its 95\% confidence interval) is based on the assumed risk in the comparison group and the relative effect of the intervention (and its $95 \% \mathrm{Cl})$.

Cl: Confidence interval; RD: Risk difference; OR: Odds ratio;

\section{GRADE Working Group grades of evidence}

High certainty: We are very confident that the true effect lies close to that of the estimate of the effect 
Moderate certainty: We are moderately confident in the effect estimate: The true effect is likely to be close to the estimate of the effect, but there is a possibility that it is substantially different

Low certainty: Our confidence in the effect estimate is limited: The true effect may be substantially different from the estimate of the effect

Very low certainty: We have very little confidence in the effect estimate: The true effect is likely to be substantially different from the estimate of effect

a Insufficient data to allow judgement of risk of bias in some studies - downgraded one level for serious risk of bias.

bThere is insufficient data to determine if there is a difference as opposed to no evidence of a difference - downgraded one level for imprecision.

CEvidence is based on a single study and there were no events, which may increase the likelihood of imprecision - downgraded two levels. 


\section{B A C K G R O U N D}

\section{Description of the condition}

Polycystic ovary syndrome (PCOS) is the most common cause of infrequent periods (oligomenorrhoea) and absence of periods (amenorrhoea), affecting about $4 \%$ to $8 \%$ of women worldwide in their fertile years (Abu 2012). Many of these women are subfertile, but for most of them it just takes longer to become pregnant naturally and only a small percentage need fertility treatment.

The mechanisms causing PCOS are very complex and the exact pathogenesis remains unknown, but some of the symptoms are believed to be caused by abnormal levels of the pituitary hormones luteinizing hormone (LH) and of the male hormones (androgens) which interfere with the normal function of the ovaries (Azziz 2006).

The diagnosis can be made based on the 'Rotterdam criteria 2003', jointly proposed by the European Society for Human Reproduction and Embryology and the American Society for Reproductive Medicine (Rotterdam 2003). The woman must have two of the following three criteria to be diagnosed with PCOS:

- Oligoovulation (infrequent ovulation) or anovulation (absence of ovulation), or both

- High male hormone levels (hyperandrogenism) diagnosed either clinically (excessive hair growth, hirsutism) or biochemically (raised serum testosterone levels)

- Ovaries which appear to be polycystic on vaginal sonogram, defined by the presence of 12 or more antral follicles in an ovary or an ovarian volume of more than $10 \mathrm{~mL}$. Antral follicles are defined as measuring between 2 and $9 \mathrm{~mm}$ in diameter.

Other definitions of PCOS include the National Institutes of Health Criteria (NIH), defined in 1990. They include only the presence of clinical and/or biochemical hyperandrogenism and oligo/amenorrhoea anovulation (Zawadski 1992).

The Androgen Excess Society defines PCOS as hyperandrogenism with ovarian dysfunction or polycystic ovaries (Azziz 2006).

\section{Description of the intervention}

There are many possible options for treatment of subfertility in women with anovulatory PCOS.

Clomiphene citrate (CC) is a selective oestrogen receptor modulator (SERM), and is the most common medication used for treating the condition. It was first introduced in 1960 for treatment of World Health Organization (WHO) type II anovulation (a type of subfertility where hormone levels stay normal) in subfertile women, and has been the first-line treatment ever since. CC is given orally and is relatively safe and inexpensive, but there are also adverse effects associated with it, such as negative changes in endometrium and cervical mucus due to the down-regulation of oestrogen receptors that might impair implantation after successful induction of ovulation (Casper 2006).

Aromatase inhibitors (Als) are a newer class of drugs that were introduced for ovulation induction in 2001 by Mitwally and Casper (Mitwally 2001). Since about 2001 data from many clinical trials have been collected and there is evidence that the Al letrozole might be as effective as CC, but the outcome data vary. Als are administered orally, but due to their short half-life elimination time of 48 hours there are fewer adverse effects on oestrogen target tissues such as the endometrium and cervix compared with CCs (Baruah 2009; Jirge 2010; Samani 2009). Despite evidence of effectiveness and safety in well-designed large randomised controlled trials (RCTs), letrozole is still used off-label for ovulation induction, since it has not been approved by the US Food and Drug Administration (FDA) for this indication (Amer 2017; Legro 2014). A 2005 study (Biljan 2005), including 150 babies, raised some concerns about the teratogenicity of letrozole, but there were major methodological flaws in this study as the intervention group was not well controlled. Two other large studies, including 911 and 470 infants respectively, compared the use of letrozole to CC and spontaneously-conceiving women. Both reported no higher levels of minor or major congenital malformations or cardiac abnormalities in newborns after use of letrozole for ovulation induction (Forman 2007; Tulandi 2006).

Due to the short half-life elimination time of letrozole it should be completely cleared out of the system before implantation takes place. Some clinicians recommend testing the blood levels of $B$ hCG prior to treatment with letrozole to exclude pregnancy (Casper 2011). CC and Als are usually both given for five days, starting on day three of the cycle. The dose for CC ranges from $50 \mathrm{mg}$ to $150 \mathrm{mg}$ a day, and for letrozole from $2.5 \mathrm{mg}$ to $7.5 \mathrm{mg}$ a day (Lee 2011).

Since many women with PCOS experience insulin resistance or impaired glucose tolerance, metformin and other insulinsensitising agents were thought to be a superior drug for treatment of ovulation induction (Velázquez 1997). However, the latest version of the Cochrane Review on oral agents for ovulation induction concludes that the use of metformin and other insulin sensitising agents as an adjunct is limited and might be favourable only in women who are resistant to CC alone (Brown 2016).

Human menopausal gonadotropins (hMG) were introduced into clinical practice in 1961 for ovulation induction. They exert a central role in ovulation induction in CC-resistant subfertile normogonadotropic anovulatory women (Lunenfeld 2004). However, women with PCOS are at particular risk for complications such as ovarian hyperstimulation syndrome (OHSS) and multiple pregnancies, and a low-dose step-up protocol was introduced to reach the follicle stimulating hormone (FSH) threshold gradually in order to minimise the risks of OHSS and multiple pregnancies (White 1996). Use of FSH for ovulation induction in women with PCOS appears to be safe and effective (Homburg 2011).

For all the above-mentioned drugs for ovulation induction, follicular growth should be monitored during a stimulation cycle to reassure effectiveness and also to minimise the occurrence of adverse events, such as multiple pregnancy (Von Hofe 2015).

Finally, another possible option for ovulation induction in cases of CC resistance is laparoscopic ovarian diathermy (or drilling, LOD), during which the damaging of localised areas in the ovarian cortex and stroma seems to have similar success rates compared with gonadotropin therapy (Farquhar 2002). It is not fully understood how the partial destruction of the ovary results in follicle development and ovulation induction (Farquhar 2012). However, long-term outcomes of a study with eight to 12 years of follow-up indicate that LOD is safe and effective (Nahuis 2011). 


\section{How the intervention might work}

Als down-regulate the production of oestrogen by inhibiting the cytochrome P450 isoenzymes 2A6 and 2C19 of the aromatase enzyme complex (Cole 1990). They inhibit the negative feedback loop of oestrogen in the hypothalamus, and result in stronger gonadotropin-releasing hormone $(\mathrm{GnRH})$ pulses. The elevated levels of GnRH stimulate the pituitary gland to produce more $\mathrm{FSH}$, which induces development of follicles in the ovaries. Because Als do not deplete oestrogen receptors, in contrast to CC, the central feedback mechanism remains intact and as the dominant follicle grows and oestrogen levels rise, normal negative feedback occurs centrally. This results in suppression of FSH and the smallergrowing follicles will undergo atresia, leading to a single dominant follicle and mono-ovulation (ovulation of a single egg) in most cases (Casper 2006; Lee 2011). Therefore, by leaving the central mechanism intact, the Als might lower the risk of high multiple ovulation and OHSS compared to CC.

\section{Why it is important to do this review}

Because evidence for and against the effectiveness and safety of Als has fluctuated over the last decade, and new data based on recent RCTs have become available, an update of the existing Cochrane Review was necessary to provide up-to-date information for daily practice.

This review evaluates the effectiveness and safety of Als compared to other agents for ovulation induction or laparoscopic ovarian drilling, to provide evidence about whether or not Als should be used in subfertile women with PCOS who are trying to conceive.

\section{O B JECTIVES}

To evaluate the effectiveness and safety of aromatase inhibitors for subfertile women with anovulatory PCOS for ovulation induction followed by timed intercourse or intrauterine insemination (IUI).

\section{METHODS}

\section{Criteria for considering studies for this review}

\section{Types of studies}

We considered randomised controlled trials (RCTs) for inclusion in the review. We excluded cross-over trials unless phase one data were available separately.

\section{Types of participants}

Women of reproductive age with anovulatory PCOS (WHO type II anovulation in women with normogonadotropic normoestrogenic anovulation), diagnosed according to the Rotterdam Criteria (Rotterdam 2003), the NIH consensus criteria (Zawadski 1992) or the AES criteria (Azziz 2009).

\section{Exclusion criteria}

We excluded RCTs of women with hyperprolactinaemia or Cushing's syndrome, or both. We also excluded trials covering women with WHO type I anovulation (hypogonadotropic hypogonadal anovulation). Women in this group have amenorrhoea, low or low-normal serum FSH concentrations and low serum estradiol concentrations due to decreased hypothalamic secretion of gonadotropin-releasing hormone $(\mathrm{GnRH})$ or pituitary unresponsiveness to $\mathrm{GnRH}$. We excluded studies using methods other than ovulation induction followed by intercourse or IUI, for example 'in vitro fertilisation' (IVF).

\section{Types of interventions}

We considered for inclusion aromatase inhibitors for ovulation induction, alone or in conjunction with medical adjuncts, e.g. metformin or FSH, followed by sexual intercourse or IUI in women with anovulatory subfertility. Als were compared to each other and to other choices of treatment, including CC, tamoxifen, recombinant and urinary gonadotropin (FSH), insulin-sensitising agents such as metformin, and laparoscopic ovarian drilling.

\section{Types of outcome measures}

\section{Primary outcomes}

\section{Effectiveness:}

1. Live birth rate by woman randomised, defined as delivery of a live fetus after 20 completed weeks of gestational age.

\section{Adverse effects:}

2. OHSS rate by woman randomised, as defined by the study authors.

\section{Secondary outcomes}

3. Clinical pregnancy rate by woman randomised, defined as the presence of a gestational sac on ultrasound.

4. Miscarriage rate by woman randomised, defined as the involuntary loss of a clinical pregnancy before 20 weeks of gestation, including partial loss of a multiple pregnancy.

5. Miscarriage rate by pregnancies, defined as the involuntary loss of a clinical pregnancy before 20 weeks of gestation, including partial loss of a multiple pregnancy.

6. Multiple pregnancy rate by woman randomised, defined as more than one intrauterine pregnancy, confirmed by ultrasound or delivery.

\section{Search methods for identification of studies}

We searched for all published and unpublished RCTs of the use of Als for ovulation induction in anovulatory women with PCOS. We consulted the Cochrane Gynaecology and Fertility Group Information Specialist. We used the following search strategy, without language restriction:

\section{Electronic searches}

1. Cochrane Gynaecology and Fertility Group Specialised Register (CGFG) (inception to 6 November 2017; Appendix 1)

2. The Cochrane Central Register of Controlled Trials (CENTRAL) (inception to 6 November 2017; Appendix 2)

3. $\operatorname{MEDLINE}(\mathrm{R})$ In-Process \& Other Non-Indexed Citations, Ovid MEDLINE(R) Daily and Ovid MEDLINE(R) (inception to 6 November 2017; Appendix 3)

\section{Embase (inception to 6 November 2017; Appendix 4)}

\section{PsycINFO (inception to 6 November 2017; Appendix 5)}


We combined the MEDLINE search with the Cochrane highly sensitive search strategy for identifying randomised trials which appears in theCochrane Handbook of Systematic Reviews of Interventions (Cochrane Handbook) (Version 5.1.0, Section 6.4.11). We combined the Embase search with trial filters developed by the Scottish Intercollegiate Guidelines Network (SIGN) (www.sign.ac.uk/mehodology/filters.html\#random). There was no language restriction in these searches.

\section{Searching other resources}

We checked the references of relevant systematic reviews and RCTs obtained by the search and contacted experts in the field and manufacturers of aromatase inhibitors, to pick up any additional, relevant data. We also searched the databases of the WHO, clinicaltrials.gov, Web of Knowledge, PubMed and LILACS, Google and Google Scholar, up to January 2018.

\section{Data collection and analysis}

We conducted data collection and analysis in accordance with the Cochrane Handbook (Higgins 2011).

\section{Selection of studies}

For this update of the review, two review authors (SF and SE ) independently selected the trials to be included, in accordance with the aforementioned criteria. We excluded trials from the review if they made comparisons other than those specified above. Studies from non-English language journals were translated if necessary. If a trial was published more than once, we only included the most complete and up-to-date data. We contacted authors of primary studies if papers did not contain enough information to enable an accurate assessment of eligibility for inclusion. We provide a list of excluded studies, showing the reasons for exclusion in the Characteristics of excluded studies table.

\section{Data extraction and management}

For this update of the review, two review authors (SF and SE) independently extracted the data, resolving any disagreements by recourse to a third party. We used a data extraction form designed and piloted by the review authors. All data collected for our analyses were dichotomous. If studies had multiple publications, we included only the main trial report. The review authors contacted study investigators to resolve any data queries, as required.

\section{Assessment of risk of bias in included studies}

We assessed the included studies for risks of bias, using the Cochrane 'Risk of bias' tool. We evaluated seven domains of possible biases:

- Random sequence generation

- Allocation concealment

- Blinding of participants and personnel

- Blinding of outcome assessment

- Incomplete outcome data

- Selective reporting

- Other potential bias

We judged the different types of bias using the criteria from the Cochrane Handbook Table 8.5.d: Criteria for judging risk of bias in the 'Risk of bias' assessment tool (Higgins 2011). Two review authors (SF and SE) checked these domains of bias independently and rated them as being at high, low or unclear risk of bias. The assessments were compared and any disagreements resolved by consensus or by discussion with a third review author (CF). The conclusions are presented in the 'Risk of bias' table and were incorporated into the interpretation of the review findings by means of sensitivity analyses.

\section{Measures of treatment effect}

Where dichotomous data measures were used, we have expressed the results in the control and intervention groups of each study as odds ratios (ORs) with $95 \%$ confidence intervals ( $\mathrm{Cls}$ ). For the very rare outcome OHSS we have used a risk difference (RD) analysis to allow Cls for the difference in percentage points. Based on the specified outcomes, there were no continuous data measures.

\section{Unit of analysis issues}

The primary analysis was by woman randomised. The secondary outcome of miscarriage rate was also analysed by pregnancies. We contacted authors of studies that used cycles as the denominator rather than women, for additional information; if we could not obtain it we did not include the trial in the analysis. If there were multiple cycles, the unit of analysis remained as the woman randomised. We used only the first phase of cross-over-trials in the analysis, as successful treatment prevents a cross-over. We treated multiple live births as one event.

\section{Dealing with missing data}

If data were missing from included studies, we contacted the investigators to request the relevant missing data. If this was not possible, we imputed individual values for the primary and secondary outcomes. In participants without a reported outcome we assumed that live births had not occurred. For other outcomes, we analysed only the available data. We subjected any imputation to sensitivity analysis. We analysed the data on an intention-totreat (ITT) basis, as far as possible.

\section{Assessment of heterogeneity}

We tested the results of the included studies for heterogeneity by measuring the scatter in the data points on the graph and the overlap in their $\mathrm{Cls}$. We used the $\mathrm{I}^{2}$ statistic, which describes the percentage of total variation across the trials that is due to heterogeneity rather than to chance (Higgins 2011). The values of the $1^{2}$ statistic lie between $0 \%$ (no heterogeneity) and $100 \%$ (extreme heterogeneity). We take values above $50 \%$ to indicate moderate heterogeneity and we explored them within sensitivity and subgroup analyses.

\section{Assessment of reporting biases \\ In view of the difficulty of detecting and correcting for publication bias and other reporting biases, we aimed to minimise their potential impact by ensuring a comprehensive search for eligible studies and by being alert to duplication of data. We compared all outcome measures stated in the Methods section to the outcomes reported in the Results section, to ensure comparability. If there were more than 10 trials included in a comparison, we produced a funnel plot to test for reporting bias.}




\section{Data synthesis}

We used a fixed-effect model to combine the data from the primary studies if they were sufficiently similar. We conducted statistical analysis with Review Manager 5, in accordance with the guidelines for statistical analysis developed by Cochrane (Higgins 2011).

\section{Our comparisons were:}

1. Letrozole compared to placebo;

2. Letrozole compared to other ovulation induction agents followed by intercourse;

3. Letrozole compared to other ovulation induction agents followed by IUI;

4. Letrozole compared to laparoscopic ovarian drilling;

5. Letrozole compared to FSH;

6. Letrozole compared to anastrozole;

7. Comparison of different administration protocols of letrozole;

8. Dosage studies of letrozole.

Increases in the odds of an outcome, either beneficial (e.g. live birth) or detrimental (e.g. OHSS) are shown in the forest plots of the meta-analysis to the right of the centre-line.

\section{Subgroup analysis and investigation of heterogeneity}

We performed subgroup analysis for primary outcomes only, to evaluate the evidence for a study population with an average body mass index (BMI) above 25 compared to women with an average BMI below 25 within their study group. We conducted a further subgroup analysis comparing women with no previous treatment for ovulation induction to women that were CC-resistant. We intended to perform subgroup analyses on other parameters, such as the age of the woman, the duration of subfertility and the duration and drug dosages, but this was not possible due to the lack of data.

\section{Sensitivity analysis}

We conducted a sensitivity analysis for the primary outcomes to evaluate whether the conclusions are robust to arbitrary decisions made about the eligibility and analysis of studies. This analysis includes consideration of whether the review conclusions would have differed if:

1. Eligibility was restricted to studies without high or unclear risk of bias;
2. We had used a random-effects model;

3. We had implemented alternative imputation strategies;

4. The summary effect measure had been the risk ratio instead of the odds ratio.

\section{Overall quality of the body of evidence: 'Summary of findings' table}

We generated 'Summary of findings' tables using GRADEpro software. The first table evaluates the overall quality of the body of evidence for the main review comparison (aromatase inhibitors compared to selective oestrogen receptor modulators, with or without adjuncts), using GRADE criteria, i.e. study limitations (risk of bias), consistency of effect, imprecision, indirectness and publication bias. Judgements about evidence quality (high, moderate, low or very low) were justified, documented and incorporated into the reporting of results for each outcome.Two review authors independently evaluated the overall quality of the evidence for the main outcomes of the review (live birth rate, miscarriage rate, clinical pregnancy rate, multiple pregnancy rate, and OHSS by woman randomised). We produced a second 'Summary of findings' table for the comparison 'Letrozole compared to laparoscopic ovarian drilling'. There are no 'Summary of findings' tables for the remaining comparisons of the review, because we considered them less clinically important. The results of these comparisons are discussed within the text of the review.

\section{RES U L T S}

\section{Description of studies}

\section{Results of the search}

The previous version of this review included 26 trials. The searches for the 2018 review update resulted in the retrieval of 38 full-text papers (Figure 1). We included 16 new studies (Characteristics of included studies). We excluded 10 new studies (Characteristics of excluded studies). Two new studies are awaiting classification (Characteristics of studies awaiting classification); we have contacted their authors and still await a response. We have moved five studies from ongoing to excluded (NCT01679574; NCT01793038; NCT01431352;Palihawadana 2015; Sarvi 2010), and three studies from ongoing to included (Amer 2017; Liu 2017; Wu 2016). Four studies have been moved from awaiting classification to excluded (Al-Hussaini 2014; NCT01577017; NCT00610077; Sharma 2010). We classify one new study as ongoing (NCT03009838; Characteristics of ongoing studies). 
Figure 1. Study flow diagram for update 2018

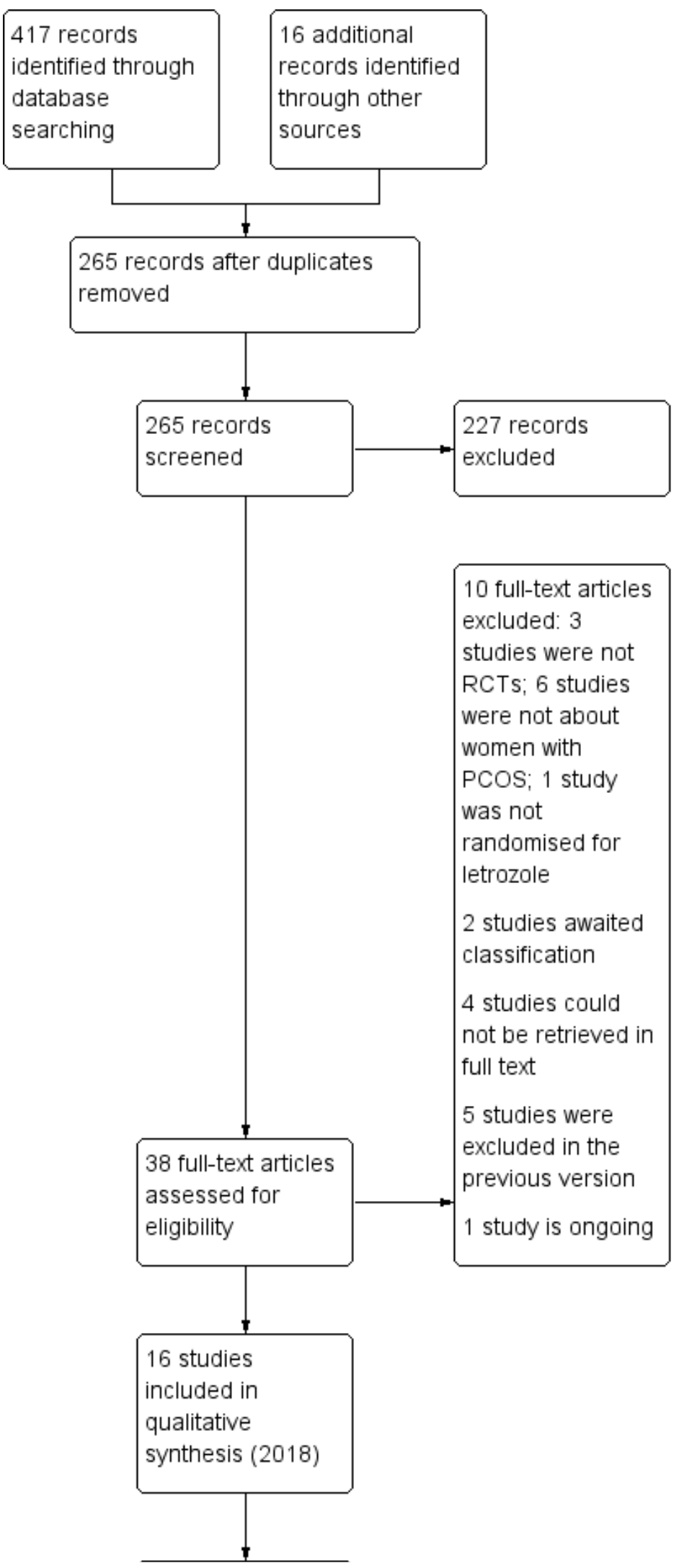


Figure 1. (Continued)

\begin{tabular}{|l|}
16 new studies \\
(2018) and 26 \\
original studies \\
included in \\
quantitative \\
synthesis \\
(meta-analysis)
\end{tabular}

\section{Included studies}

\section{Study design and setting}

We include 42 parallel-designed randomised controlled trials (RCTs) in this 2018 updated review.

The studies were done in different parts of the world:

- China (Chen 2016; Liu 2015; Liu 2017; Wu 2016)

- Egypt (Abdellah 2011; Abu Hashim 2010a; Abu Hashim 2010b; Badawy 2008; Badawy 2009a; Badawy 2009b; El-Gharib 2015; ElKhayat 2016; Elgafor 2013; Hassan 2017; Hendawy 2011; Ibrahim 2017; Moussa 2016; Selim 2012)

- India (Begum 2009; Ganesh 2009; Kamath 2010; Kar 2012; Ray 2012; Roy 2012; Sh-El-Arab Elsedeek 2011)

- Iraq (Al-Omari 2004; Sharief 2015)

- Iran (Davar 2011; Dehbashi 2009; Foroozanfard 2011; Ghahiri 2016; Ghomian 2015; Ramezanzadeh 2011; Seyedoshohadaei 2016; Sohrabvand 2006; Zarei 2015; Zeinalzadeh 2010)

- Turkey (Atay 2006; Bayar 2006; Nazik 2012)

- United Kingdom (Amer 2017)

- USA (Legro 2014)

The following different settings recruited women into the trials:

- Not stated (Atay 2006; Ray 2012; Roy 2012; Selim 2012).

- Subfertility clinic (Amer 2017; Begum 2009; Davar 2011; Dehbashi 2009; Foroozanfard 2011; Ghahiri 2016; Ganesh 2009; Kar 2012; Nazik 2012; Ramezanzadeh 2011; Sh-El-Arab Elsedeek 2011; Seyedoshohadaei 2016; Sohrabvand 2006; Zeinalzadeh 2010).

- Outpatient clinic (Abu Hashim 2010a; Abu Hashim 2010b; Badawy 2008; Badawy 2009a; Badawy 2009b; Bayar 2006; ElGharib 2015; Ibrahim 2017).

- Department of obstetrics and gynaecology (Al-Omari 2004; Chen 2016; Elgafor 2013; Legro 2014).

- Division of reproductive endocrinology (Kamath 2010).

- Maternity and child hospital (Seyedoshohadaei 2016; Zarei 2015).

- University hospital (El-Khayat 2016; Ghomian 2015; Hassan 2017; Hendawy 2011; Liu 2015; Liu 2017; Moussa 2016; Wu 2016).

- Women's health institute (Abdellah 2011).

Drs Abu Hasim and Badawy confirmed to us that their five studies, conducted from 2008 until 2010, were independent and did not include the same women.

\section{Participants}

The studies included 7935 women who were subfertile due to anovulatory PCOS. The ages of the women ranged from 18 to 40 years.

\section{Interventions}

- 2/42 studies compared letrozole versus placebo (Kamath 2010; Zarei 2015).

- 26/42 studies compared letrozole to other ovulation induction agents followed by intercourse (Abu Hashim 2010b; Amer 2017; Atay 2006; Badawy 2009b; Bayar 2006; Begum 2009; Chen 2016; Davar 2011; Dehbashi 2009; El-Gharib 2015; El-Khayat 2016; Foroozanfard 2011; Ghahiri 2016; Hendawy 2011; Legro 2014; Liu 2017; Moussa 2016; Nazik 2012; Ray 2012; Roy 2012; Selim 2012; Seyedoshohadaei 2016; Sharief 2015; Sh-El-Arab Elsedeek 2011; Sohrabvand 2006; Wu 2016).

- 3/42 studies compared letrozole to other ovulation induction agents followed by IUI (Ganesh 2009; Kar 2012; Zeinalzadeh 2010).

- 5/42 studies compared letrozole versus laparoscopic ovarian drilling (Abdellah 2011; Abu Hashim 2010a; Elgafor 2013; Ibrahim 2017; Liu 2015).

- $1 / 42$ studies compared letrozole versus FSH (Hassan 2017).

- 2/42 studies compared letrozole versus anastrozole (Al-Omari 2004; Badawy 2008).

- 2/42 studies compared different administration protocols of letrozole (Badawy 2009a; Ghomian 2015).

- $1 / 26$ studies compared different doses of letrozole (Ramezanzadeh 2011).

(See Characteristics of included studies)

\section{Outcomes}

- $16 / 42$ studies reported live birth rate by woman randomised (Abdellah 2011; Abu Hashim 2010a; Abu Hashim 2010b; Amer 2017; Bayar 2006; Begum 2009; Dehbashi 2009; Foroozanfard 2011; Legro 2014; Liu 2015; Liu 2017; Kamath 2010; Ray 2012; Roy 2012; Seyedoshohadaei 2016; Wu 2016).

- 21/42 studies reported OHSS rate by woman randomised (Abu Hashim 2010a; Abu Hashim 2010b; Badawy 2008; Badawy 2009a; Badawy 2009b; Bayar 2006; Begum 2009; Chen 2016; El-Khayat 2016; Foroozanfard 2011; Ganesh 2009; Ghahiri 2016; Hassan 2017; Kamath 2010; Legro 2014; Nazik 2012; Ramezanzadeh 2011; Roy 2012; Selim 2012; Zarei 2015; Zeinalzadeh 2010). 
- 41/42 studies reported clinical pregnancy rate by woman randomised (Abdellah 2011; Abu Hashim 2010a; Abu Hashim 2010b; Al-Omari 2004; Amer 2017; Atay 2006; Badawy 2008; Badawy 2009a; Badawy 2009b; Bayar 2006; Begum 2009; Chen 2016; Davar 2011; Dehbashi 2009; El-Gharib 2015; El-Khayat 2016; Elgafor 2013; Foroozanfard 2011; Ganesh 2009; Ghahiri 2016; Ghomian 2015; Hassan 2017; Ibrahim 2017; Kamath 2010; Kar 2012; Legro 2014; Liu 2015; Liu 2017; Moussa 2016; Nazik 2012; Ramezanzadeh 2011; Ray 2012; Roy 2012; Selim 2012; ShEl-Arab Elsedeek 2011; Seyedoshohadaei 2016; Sharief 2015; Sohrabvand 2006; Wu 2016; Zarei 2015; Zeinalzadeh 2010).

- 30/42 studies reported miscarriage rate by woman randomised and by pregnancies (Abdellah 2011; Abu Hashim 2010a; Abu Hashim 2010b; Badawy 2008; Badawy 2009a; Badawy 2009b; Bayar 2006; Begum 2009; Chen 2016; Davar 2011; Dehbashi 2009; El-Khayat 2016; Elgafor 2013; Foroozanfard 2011; Ganesh 2009; Ghahiri 2016; Hassan 2017; Ibrahim 2017; Kamath 2010; Kar 2012; Liu 2015; Liu 2017; Nazik 2012; Ramezanzadeh 2011; Ray 2012; Roy 2012; Seyedoshohadaei 2016; Sohrabvand 2006; Wu 2016; Zarei 2015).

- 30/42 studies reported multiple pregnancy rate by woman randomised (Abdellah 2011; Abu Hashim 2010a; Abu Hashim 2010b; Al-Omari 2004; Amer 2017; Atay 2006; Badawy 2008; Badawy 2009a; Badawy 2009b; Bayar 2006; Begum 2009; Chen 2016; Dehbashi 2009; El-Khayat 2016; Foroozanfard 2011; Ganesh 2009; Hassan 2017; Hendawy 2011Kamath 2010; Kar 2012; Legro 2014; Liu 2015; Nazik 2012; NCT00610077; Ramezanzadeh 2011; Roy 2012; Selim 2012; Sharief 2015; Wu 2016; Zeinalzadeh 2010).

(See Characteristics of included studies)

\section{Excluded studies}

We exclude 30 trials from the review. Sixteen of these were identified for the 2018 update (Al-Hussaini 2014; AlShaikh 2017; Angel 2014; Azmoodeh 2015; Khanna 2013; Li 2016; NCT01431352; NCT01577017; NCT01679574; NCT01793038; Pakrashi 2014; Palihawadana 2015; Pourali 2017; Sharma 2010; Xi 2015; Yun 2015). The primary reasons for exclusion of the studies were inclusion criteria, interventions, inability to obtain study data and no randomisation. (See Characteristics of excluded studies)

\section{Risk of bias in included studies}

See Characteristics of included studies; Figure 2; Figure 3. 
Figure 2. Risk of bias summary: review authors' judgements about each risk of bias item for each included study.

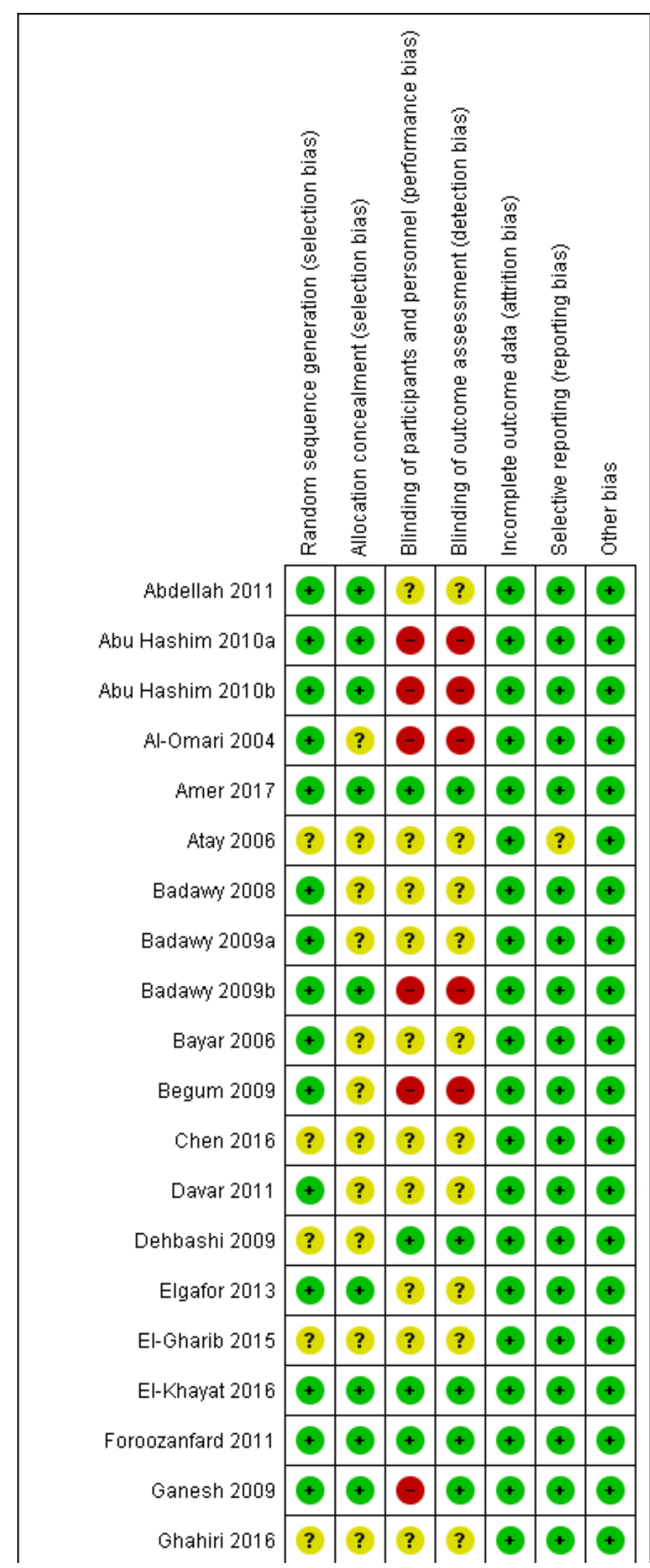


Figure 2. (Continued)

\begin{tabular}{|c|c|c|c|c|c|c|c|}
\hline Ghahiri 2016 & $?$ & $?$ & $?$ & $?$ & $\odot$ & + & + \\
\hline Ghomian 2015 & $?$ & $?$ & $?$ & $?$ & + & $\oplus$ & $\odot$ \\
\hline Hassan 2017 & + & + & $?$ & $?$ & + & + & + \\
\hline Hendawy 2011 & $\odot$ & $?$ & $?$ & ? & + & $?$ & $?$ \\
\hline Ibrahim 2017 & $\odot$ & $?$ & $\Theta$ & + & $\odot$ & ? & $\odot$ \\
\hline Kamath 2010 & $\odot$ & + & + & + & + & + & + \\
\hline Kar 2012 & $?$ & $?$ & $?$ & $?$ & + & + & + \\
\hline Legro 2014 & $\odot$ & + & $\odot$ & + & $\odot$ & + & $\odot$ \\
\hline Liu 2015 & $?$ & ? & $?$ & + & $\odot$ & ? & ? \\
\hline Liu 2017 & + & $?$ & $\odot$ & $\odot$ & $\Theta$ & + & $\odot$ \\
\hline Moussa 2016 & 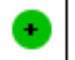 & $?$ & $?$ & $?$ & + & $?$ & + \\
\hline Nazik 2012 & $\odot$ & $?$ & - & - & $\odot$ & + & $\odot$ \\
\hline Ramezanzadeh 2011 & $\odot$ & $?$ & $?$ & $?$ & - & + & + \\
\hline Ray 2012 & $?$ & ? & $?$ & $?$ & $?$ & ? & $\odot$ \\
\hline Roy 2012 & + & $?$ & $?$ & $?$ & $\odot$ & + & + \\
\hline Selim 2012 & $\odot$ & + & $\Theta$ & $\odot$ & $\odot$ & $\odot$ & 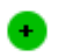 \\
\hline Seyedoshohadaei 2016 & $\odot$ & $?$ & $?$ & $?$ & + & $?$ & $\odot$ \\
\hline Sharief 2015 & $?$ & $?$ & $?$ & $?$ & $?$ & $?$ & $\oplus$ \\
\hline Sh-El-Arab Elsedeek 2011 & + & $?$ & $?$ & $?$ & + & $?$ & + \\
\hline Sohrabvand 2006 & $\odot$ & $?$ & $\odot$ & - & $\oplus$ & $\oplus$ & + \\
\hline Wu 2016 & $\odot$ & + & $\oplus$ & + & 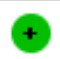 & $\oplus$ & + \\
\hline Zarei 2015 & $?$ & $?$ & $?$ & $?$ & + & $?$ & $\odot$ \\
\hline Zeinalzadeh 2010 & $?$ & $?$ & $?$ & $?$ & $\oplus$ & + & $\odot$ \\
\hline
\end{tabular}


Figure 3. Risk of bias graph: review authors' judgements about each risk of bias item presented as percentages across all included studies.

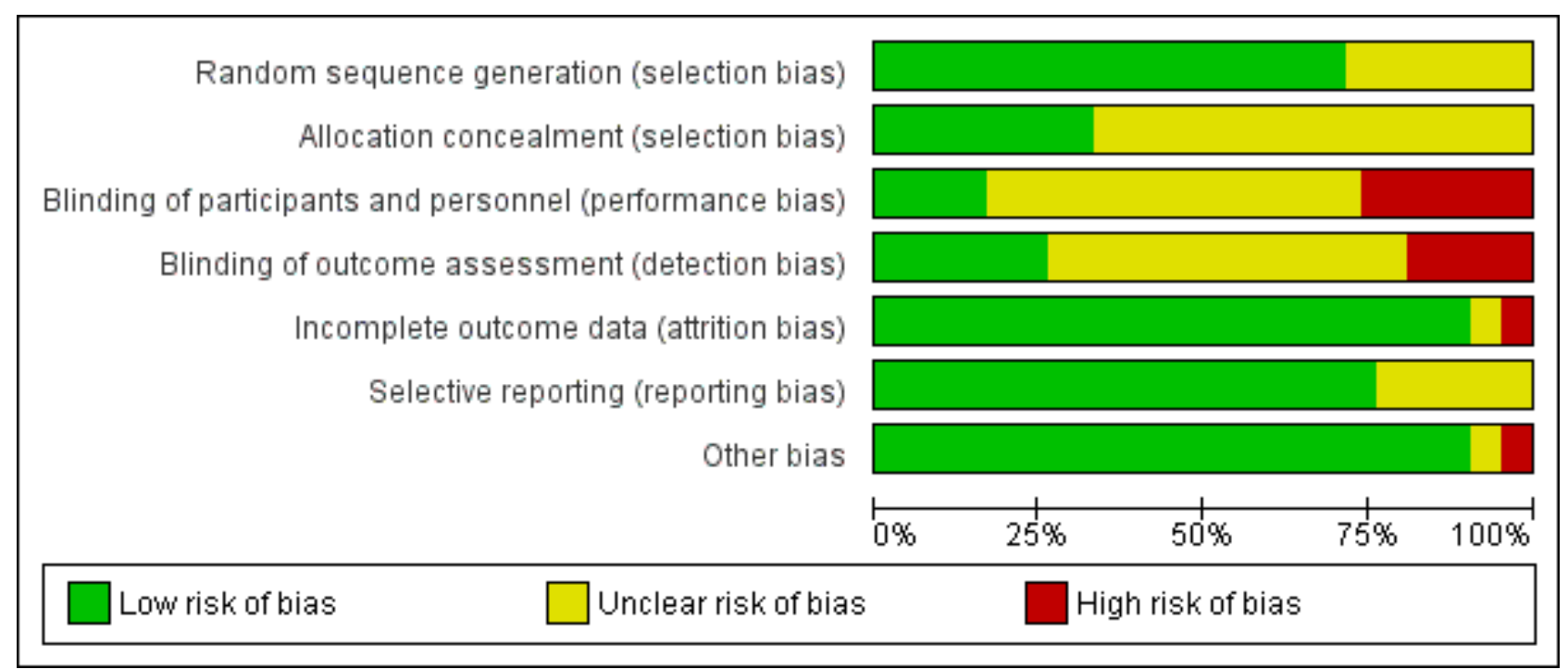

\section{Allocation}

Thirty studies were at low risk of selection bias related to sequence generation. They used computer randomisation, a random-number table or lottery. The remaining 12 studies did not fully describe their method of randomisation and the contacted authors did not respond, so we rated them at unclear risk of this bias (Figure 2).

Fourteen studies were at low risk of selection bias related to allocation concealment. They used sequentially-numbered, sealed (opaque) envelopes and the list was kept by a third party during the procedure. The other 28 studies did not describe allocation concealment sufficiently and the authors did not respond to our emails, so we rated them at unclear risk of bias (Figure 2).

\section{Blinding}

Seven out of 42 studies described the blinding of participants and personnel, and were thus rated tat low risk of performance bias. Twenty-five studies did not mention blinding of participants of personnel and the authors did not respond to our emails, so we rated them at unclear risk of bias. Ten studies stated that there was no blinding of participants or personnel or both, and were at high risk of bias (Figure 2).

Eleven of 42 studies reported that the outcome assessors were blinded and were therefore at low risk of bias. Twenty-three studies did not mention blinding of outcome assessors and the authors did not respond to our email contact, so were rated at unclear risk of bias. Four studies were at high risk of detection bias, because they reported that the outcome assessors were not blinded. Another four studies were also at high risk of bias because the participants were not blinded and it is therefore not plausible that the outcome assessors were blinded. (Figure 2).

\section{Incomplete outcome data}

Thirty-eight of 42 studies included all or nearly all women they had randomised (more than 90\%) and were therefore at low risk of attrition bias. Two studies were at unclear risk of attrition bias. One study had peculiar group numbers and none of the other biases were addressed, so we tried without success to contact the authors (Ray 2012). Another study did not report how many women were originally randomised (Sharief 2015). Two studies were at high risk of attrition bias: one study because 13 of 80 women were not analysed. Four women were excluded after randomisation due to an ovarian cyst on sonography on day three. Nine more women were lost to follow-up without any reasons given (Ramezanzadeh 2011). The second study excluded 28 of 268 women from analysis; 13 were lost to follow-up, three were excluded, and 12 had complications (Liu 2017; Figure 2).

\section{Selective reporting}

Thirty-nine of the 42 included studies reported the outcomes they had stated in the Methods section, and we therefore judged them to be at low risk of bias. In three of the 42 studies only a few outcomes were presented and the contacted authors did not respond, so we rated them at unclear risk of reporting bias (Figure 2).

\section{Other potential sources of bias}

In one study there were substantial baseline differences in age and duration of infertility between the two groups and we deemed the risk of bias to be high (Nazik 2012). In another study, the methods were not well described and the clinical trial registration number led to a different trial (Zarei 2015). We found no potential sources of within-study bias in the other 40 studies (Figure 2).

\section{Effects of interventions}

See: Summary of findings for the main comparison Letrozole with or without adjuncts compared to clomiphene citrate (CC) with or without adjuncts for subfertile women with polycystic ovary syndrome; Summary of findings 2 Letrozole compared to laparoscopic ovarian drilling for subfertile women with polycystic ovary syndrome

\section{Letrozole compared to placebo}

Two trials including 167 participants compared an aromatase inhibitor (letrozole) and placebo (Kamath 2010; Zarei 2015). Only 
one trial reported live birth rate, and there was insufficient evidence to suggest a difference in live birth rate $(\mathrm{OR} 3.17,95 \% \mathrm{Cl} 0.12$ to 83.17 ; 36 participants; 1 study; Analysis 1.1). A risk difference analysis for OHSS rate showed insufficient evidence of a difference in frequency of this adverse event (RR $0.00,95 \% \mathrm{Cl}-0.05$ to 0.05 ; 167 participants; 2 studies; $1^{2}=0 \%$; Analysis 1.2). Pregnancy rate was higher using letrozole compared to placebo (OR 2.88, 95\% $\mathrm{Cl} 1.08$ to $7.66 ; 167$ participants; 2 studies; $\mathrm{I}^{2}=0 \%$; Analysis 1.3 ). A risk difference analysis for miscarriage rate showed insufficient evidence of a difference in frequency of this adverse event (OR $1.60,95 \% \mathrm{Cl} 0.26$ to 9.89; 167 participants; 2 studies; Analysis 1.4). Multiple pregnancy rate was not estimable because there were no cases reported.

\section{Letrozole compared to clomiphene citrate (CC) with or without adjuncts, followed by intercourse}

25 trials including 4629 women compared letrozole to selective oestrogen receptor modulators with or without adjuncts (Abu Hashim 2010b; Amer 2017; Atay 2006; Badawy 2009b; Bayar 2006; Begum 2009; Chen 2016; Davar 2011; Dehbashi 2009; El-Gharib 2015; El-Khayat 2016; Foroozanfard 2011; Ghahiri 2016; Legro 2014; Liu 2017; Moussa 2016; Nazik 2012; Ray 2012; Roy 2012; Selim 2012;
Seyedoshohadaei 2016; Sharief 2015; Sh-El-Arab Elsedeek 2011; Sohrabvand 2006; Wu 2016).

- Letrozole (2.5 mg to $7.5 \mathrm{mg} /$ day) versus clomiphene citrate (50 mg to $150 \mathrm{mg} /$ day), either alone or in combination with metformin (1000 mg to $1500 \mathrm{mg}$ daily); 75 to 150 IU hMG in one or both arms; estradiol valerate $4 \mathrm{mg} /$ day or berberine $1.5 \mathrm{~g}$ for 6 months.

\section{Primary outcomes}

\subsection{Live birth}

Thirteen studies including 2954 women compared letrozole to CC, with or without adjuncts in one or both arms, and reported live birth (Abu Hashim 2010b; Amer 2017; Bayar 2006; Begum 2009; Dehbashi 2009; Foroozanfard 2011; Legro 2014; Liu 2017; Ray 2012; Roy 2012; Seyedoshohadaei 2016; Sohrabvand 2006; Wu 2016). Letrozole resulted in an increased live birth rate compared to CC for ovulation induction (OR $1.68,95 \% \mathrm{Cl} 1.42$ to 1.99 ; 2954 participants; 13 studies; $1^{2}=0 \%$; number needed to treat for an additional beneficial outcome (NNTB) = 10; moderate-quality evidence; Figure 4; Analysis 2.1). 
Figure 4. Forest plot of comparison: 2 Aromatase inhibitors compared to other ovulation induction agents, outcome: 2.1 Live birth rate.

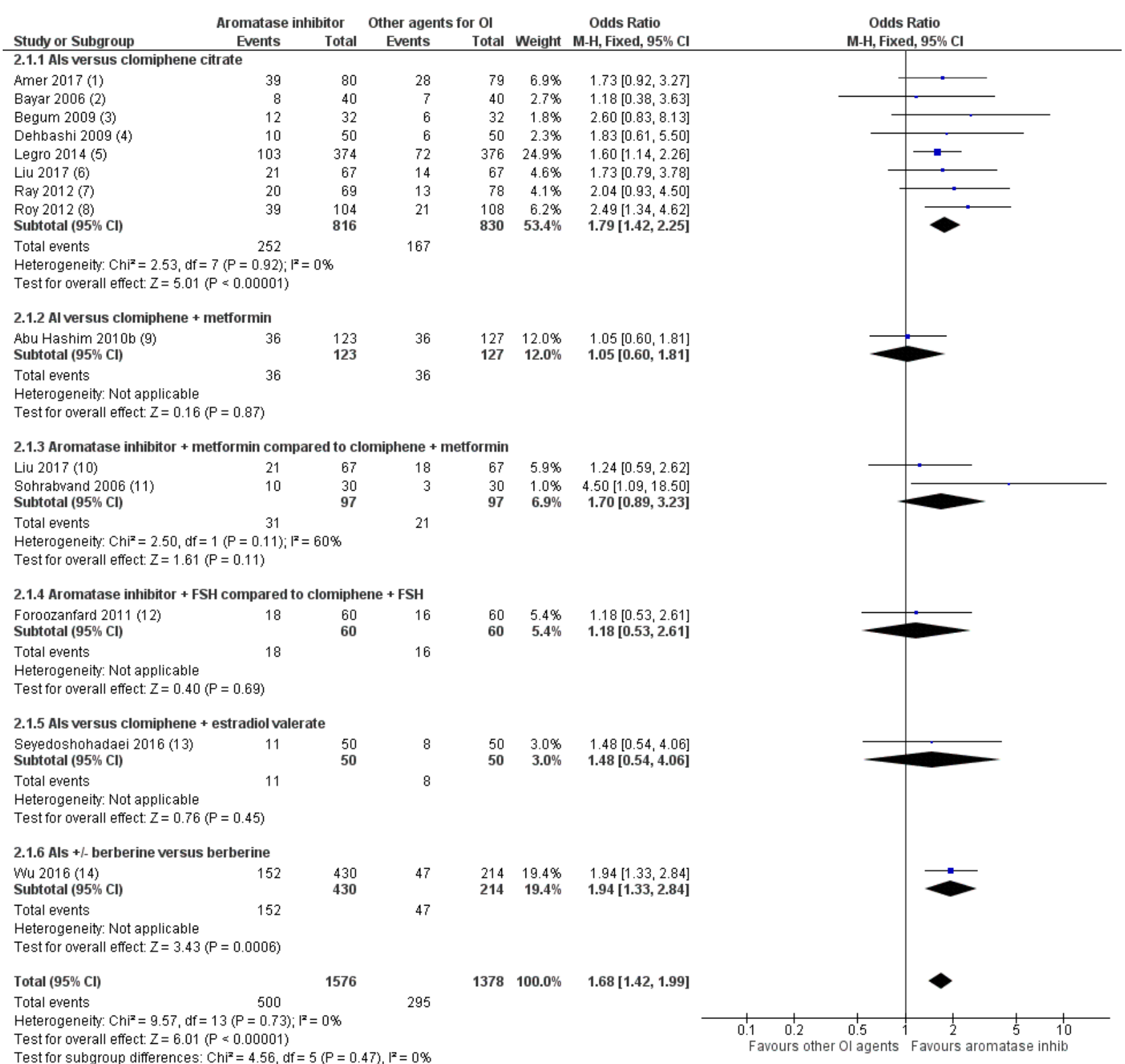

Test for subgroup differences: $\mathrm{Chi}^{2}=4.56, \mathrm{df}=5(\mathrm{P}=0.47), \mathrm{I}^{\mathrm{2}}=0 \%$

Footnotes

(1) Previous subfertility treatment unknown; starting dose $2.5 \mathrm{mg}$ letrozole vs $50 \mathrm{mg}$ clomiphene citrate/day

(2) No previous ovulation induction; letrozole, $5 \mathrm{mg} /$ day versus clomiphene $100 \mathrm{mg} / \mathrm{day}$

(3) CC-resistant women; letrozole, $7.5 \mathrm{mg} /$ day versus clomiphene, $150 \mathrm{mg} / \mathrm{day}$

(4) No previous ovulation induction; letrozole, $5 \mathrm{mg} /$ day versus clomiphene $100 \mathrm{mg} /$ day

(5) Cumulative live birth rate; treatment naïve patients; letrozole $2.5 \mathrm{mg} /$ day vs clomiphene $50 \mathrm{mg} /$ day starting dose

(6) Previous treatment for subfertility unknown; clomiphene 50 - $150 \mathrm{mg}$ versus letrozole $5 \mathrm{mg}$

(7) Unknown if primary fertility treatment or CC-resistant; letrozole, $2.5 \mathrm{mg} /$ day versus clomiphene $100 \mathrm{mg} / \mathrm{day}$

(8) Unknown if primary fertility treatment or CC-resistant; letrozole, $2.5-5 \mathrm{mg} /$ day versus clomiphene $50-100 \mathrm{mg} / \mathrm{day}$

(9) $30 \%$ of the women were CC-resistant; letrozole, $2.5 \mathrm{mg} / \mathrm{day}$ versus clomiphene $150 \mathrm{mg} / \mathrm{day}$ with metformin, $1500 \mathrm{mg} / \mathrm{day}$

(10) Previous treatment for subfertility unknown; clomiphene $50-150 \mathrm{mg}$ versus letrozole $5 \mathrm{mg}$; both groups received $1000-1500 \mathrm{mg}$ metformin daily

(11) Clomiphene-resistant women; letrozole, $2.5 \mathrm{mg} /$ day + metformin, $1500 \mathrm{mg} /$ day versus clomiphene, $100 \mathrm{mg} / \mathrm{day}+\mathrm{metformin}, 1500 \mathrm{mg} / \mathrm{day}$

(12) Clomiphene-resistant women; letrozole, $5 \mathrm{mg} / \mathrm{day}+150 \mathrm{UI} \mathrm{hMG}$ versus clomiphene $100 \mathrm{mg} / \mathrm{day}+150 \mathrm{UI} \mathrm{hMG}$

(13) Clomiphene-resistant women; letrozole $5 \mathrm{mg} /$ day versus clomiphene $100 \mathrm{mg} / \mathrm{day}+$ estradiol valerate $4 \mathrm{mg}$

(14) Previous subfertility treatment unknown; letrozole $2.5 \mathrm{mg}-5 \mathrm{mg} / \mathrm{day} \pm$ berberine $1.5 \mathrm{~g}$ for 6 months (50\%) versus berberine for 6 months

Subgroup analysis showed insufficient evidence to suggest a difference by mean BMI $(P=0.87)$ or in study populations that were CC-resistant or had no previous treatment for ovulation induction $(P=0.85)$ (analysis not shown). Sensitivity analysis excluding one study (Begum 2009) with high risk of detection bias showed no substantive influence on the treatment effect. A sensitivity analysis comparing studies with unclear and low risk for allocation bias also showed insufficient evidence for a difference in treatment 
effect between the two subgroups $(P=0.34)$. Subgroup analysis by $\mathrm{CC}$ resistance showed insufficient evidence for a difference in treatment effect for live birth.

In our sensitivity analyses, findings for live birth were not influenced by the use of a random-effects model, alternative imputation strategies, or risk ratio rather than odds ratio. An additional sensitivity analysis showed that studies that reported live births tended to report higher clinical pregnancy rates in the letrozole group than studies that failed to report live birth, suggesting that results might be less favourable to letrozole if all studies reported live birth, with a more modest treatment effect. However, a funnel plot for live birth rate was symmetrical, indicating that our findings might not be influenced by publication bias (Figure 5).

\section{Figure 5. Funnel plot of comparison: 2 Aromatase inhibitors compared to selective estrogen receptor modulators} with or without adjuncts, followed by timed intercourse, outcome: 2.1 Live birth rate.
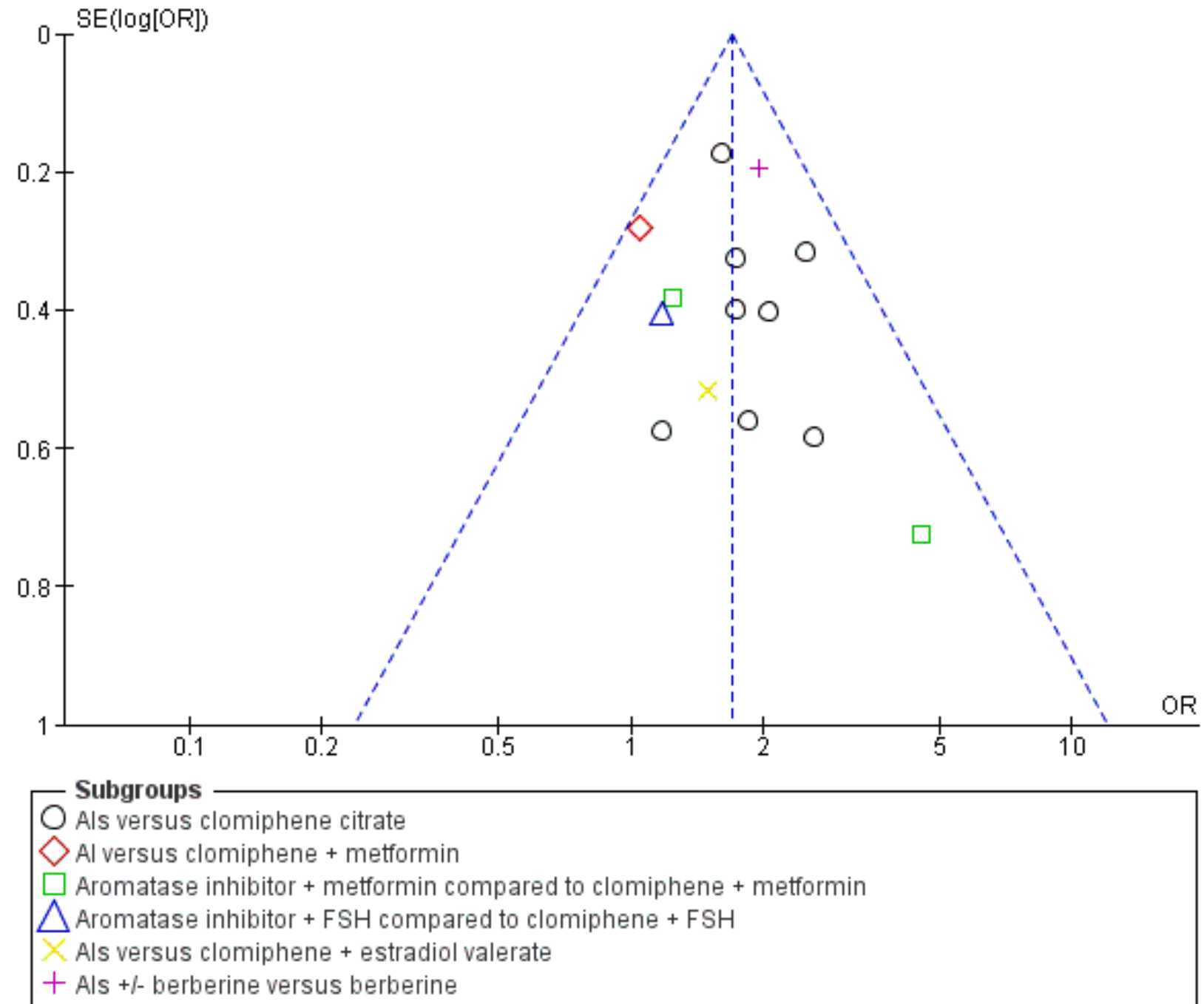

\subsection{Ovarian hyperstimulation syndrome (OHSS)}

Twelve studies including 2536 women compared letrozole to CC, with or without adjuncts in one or both arms, and reported the occurrence of ovarian hyperstimulation syndrome (Abu Hashim 2010b; Badawy 2009b; Bayar 2006; Begum 2009; Chen 2016; ElKhayat 2016; Foroozanfard 2011; Ghahiri 2016; Legro 2014; Nazik 2012; Roy 2012; Selim 2012). Our risk-difference analysis showed that there is high-quality evidence of a similar frequency of this adverse event in both groups (RD $-0.00 ; 95 \% \mathrm{Cl}-0.01$ to $0.00 ; 2536$ participants; 12 studies; $\mathrm{I}^{2}=0 \%$; high-quality evidence; Figure 6 ; Analysis 2.7). A subgroup analysis showed insufficient evidence to suggest a difference by BMI mean $(P=0.79)$ (analysis not shown). A funnel plot for OHSS was insufficient for detection of a potential publication bias because there were no events in most of the studies (analysis not shown). 
Figure 6. Forest plot of comparison: 2 Aromatase inhibitors compared to other ovulation induction agents, outcome: 2.6 Ovarian hyperstimulation syndrome rate.

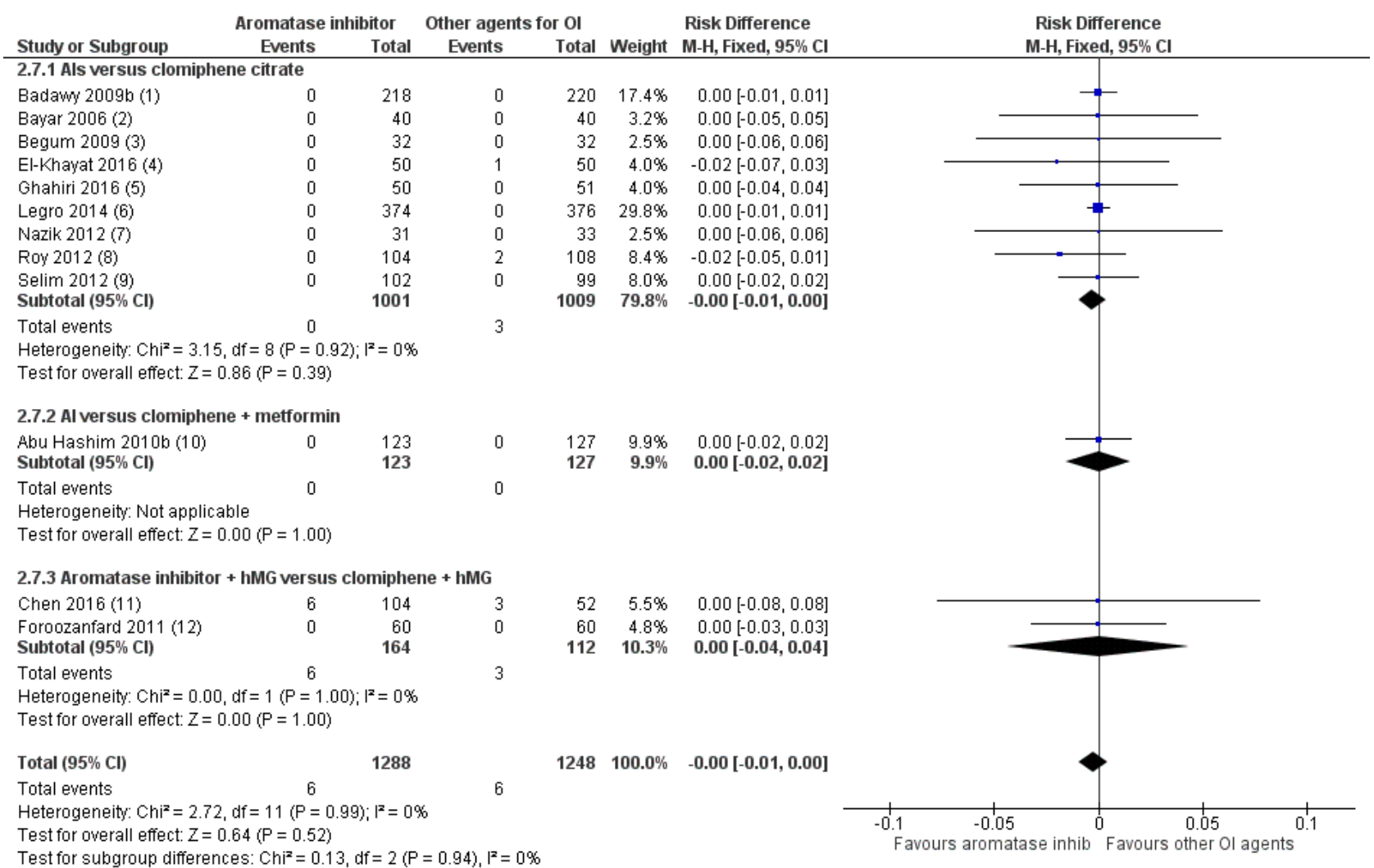

Footnotes

(1) No previous ovulation induction; letrozole, $5 \mathrm{mg} /$ day versus clomiphene, $100 \mathrm{mg} / \mathrm{day}$

(2) No previous ovulation induction; letrozole, $5 \mathrm{mg} /$ day versus clomiphene, $100 \mathrm{mg} / \mathrm{day}$

(3) CC-resistant women; letrozole, $7.5 \mathrm{mg} /$ day versus clomiphene, $150 \mathrm{mg} / \mathrm{day}$

(4) Unknown if previously treatet for subfertility; $5 \mathrm{mg}$ letrozole versus $100 \mathrm{mg}$ clomiphene/day

(5) Previous subfertility treatment unknown; $5 \mathrm{mg}$ letrozole versus $100 \mathrm{mg}$ clomiphene/day

(6) Treatment naive patients; letrozole $2.5 \mathrm{mg} /$ day vs clomiphene $50 \mathrm{mg} /$ day starting dose

(7) No previous ovulation induction; letrozole, $2.5 \mathrm{mg} /$ day versus clomiphene, $100 \mathrm{mg} / \mathrm{day}$

(8) Unknown if primary fertility treatment or CC-resistant; letrozole, $2.5-5 \mathrm{mg} /$ day versus clomiphene, $50-100 \mathrm{mg} /$ day

(9) Unknown if primary fertility treatment or CC-resistant; letrozole, $5 \mathrm{mg} /$ day versus clomiphene, $100 \mathrm{mg} /$ day

(10) $30 \%$ of the women were CC-resistant

(11) Previous treatment unknown; letrozole $2.5-5 \mathrm{mg}+/-75$ IU hMG versus CC $50-100 \mathrm{mg} / \mathrm{day}$

(12) Clomiphene resistant women; letrozole, $5 \mathrm{mg} / \mathrm{day}+150 \mathrm{UI} \mathrm{hMG}$ versus clomiphene, $100 \mathrm{mg} / \mathrm{day}+150 \mathrm{UI} \mathrm{hMG}$

\section{Secondary outcomes}

\subsection{Clinical pregnancy}

Clinical pregnancy rate was reported in 25 studies, including 4629 women (Abu Hashim 2010b; Amer 2017; Atay 2006; Badawy 2009b; Bayar 2006; Begum 2009; Chen 2016; Davar 2011; Dehbashi 2009; El-Gharib 2015; El-Khayat 2016; Foroozanfard 2011; Ghahiri 2016; Legro 2014; Liu 2017; Moussa 2016; Nazik 2012; Ray 2012; Roy 2012; Selim 2012; Seyedoshohadaei 2016; Sharief 2015; Sh-El-Arab Elsedeek 2011; Sohrabvand 2006; Wu 2016). Use of letrozole resulted in a higher clinical pregnancy rate compared to clomiphene citrate, with or without adjuncts in one or both arms (OR $1.56,95 \% \mathrm{Cl} 1.37$ to $1.78 ; 4629$ participants; 25 studies; $12=1 \%$; NNTB $=10$; moderate-quality evidence; Analysis 2.9).

\subsection{Miscarriage rate by woman randomised and by pregnancies}

Miscarriage rate was reported in 18 studies, including 3754 women (Abu Hashim 2010b; Badawy 2009b; Bayar 2006; Begum 2009; Chen 2016; Davar 2011; Dehbashi 2009; El-Khayat 2016; Foroozanfard
2011; Ghahiri 2016; Legro 2014; Liu 2017; Nazik 2012; Ray 2012; Roy 2012; Seyedoshohadaei 2016; Sohrabvand 2006; Wu 2016). The analysis of miscarriage rate by woman randomised showed little evidence for a difference in favour of clomiphene citrate, with or without adjuncts in one or both arms (OR 1.39, 95\% Cl 1.07 to 1.81 ; 3754 participants; 18 studies; $\left.\right|^{2}=0 \%$; Analysis 2.11). However, the results of the analysis of miscarriage rate by pregnancies showed no evidence of a difference between the groups (OR 0.94, 95\% Cl 0.70 to $1.26 ; 1210$ participants; 18 studies; $\left.\right|^{2}=0 \%$; high-quality evidence; Analysis 2.12).

\subsection{Multiple pregnancy rate}

Multiple pregnancy rate was reported in 16 studies, including 3519 women (Abu Hashim 2010b; Amer 2017; Atay 2006; Badawy 2009b; Bayar 2006; Begum 2009; Chen 2016; Dehbashi 2009; El-Khayat 2016; Foroozanfard 2011; Legro 2014; Nazik 2012; Roy 2012; Selim 2012; Sharief 2015; Wu 2016). The analysis of multiple pregnancy rate by woman randomised showed high-quality evidence of no difference in multiple pregnancy rate for letrozole compared to CC 
(OR $0.73,95 \%$ Cl 0.43 to $1.24 ; 3519$ participants; 16 studies; $\mid 2=0 \%$; Analysis 2.13).

\section{Publication bias}

We produced a funnel plot for both primary outcomes and for the outcome of pregnancy rate. A funnel plot for live birth rate was symmetrical, indicating that our findings might not be influenced by publication bias (Figure 5). A funnel plot for OHSS was insufficient for detection of a potential publication bias because there were no events in most of the studies (analysis not shown). The funnel plot for the secondary outcome pregnancy rate showed some asymmetries, with a gap on the left side. This indicates that there were possibly some studies with significant effects in favour of CC which were not reported, and therefore the results of our meta-analysis might have overestimated the effect of letrozole on pregnancy rate.

\section{Letrozole compared to clomiphene citrate for ovulation induction followed by IUI}

Three studies including 1597 women compared use of letrozole with or without adjuncts to other agents for ovulation induction followed by IUI (Ganesh 2009; Kar 2012; Zeinalzadeh 2010).

- Letrozole (2.5 mg to $5 \mathrm{mg}$ daily, cycle days 3 to 7 or 2 to 6 ) versus clomiphene citrate (50 mg to $150 \mathrm{mg}$ daily, cycle days 3 to 7 or 2 to 6) with or without adjuncts or rFSH only (rFSH 75 IU to $100 \mathrm{IU}$ from day 2 until the day of hCG administration).

\section{Primary outcomes}

\subsection{Live birth}

No studies comparing letrozole to clomiphene reported live birth rate.

\subsection{Ovarian hyperstimulation syndrome}

Two studies reported ovarian hyperstimulation syndrome rate comparing use of letrozole to CC (Ganesh 2009; Zeinalzadeh 2010). Our risk-difference analysis showed insufficient evidence of a difference in frequency of this adverse event between the two treatment groups (RD $-0.00,95 \% \mathrm{Cl}-0.01$ to $0.00 ; 1494$ participants; 2 studies; $12=0 \%$; Analysis 3.1 ). Subgroup analyses were not possible because there were too few studies.

\section{Secondary outcomes}

\subsection{Clinical pregnancy}

Clinical pregnancy rate was reported in three studies comparing letrozole to CC (Ganesh 2009; Kar 2012; Zeinalzadeh 2010). The analysis showed evidence in favour of letrozole compared to CC for ovulation induction followed by IUI (OR 1.71, 95\% CI 1.30 to 2.25; 1597 participants; 3 studies; $12=0 \%$; Analysis 3.2).

\subsection{Miscarriage rate by woman randomised and by pregnancies}

Miscarriage rate was reported in two studies comparing letrozole to CC (Ganesh 2009; Kar 2012). There was insufficient evidence of a difference between the two groups for miscarriage rate by woman randomised (OR 1.22, 95\% Cl 0.62 to 2.40; 1490 participants; 2 studies; $1^{2}=0 \%$; Analysis 3.3 ) or by pregnancies (OR $0.76,95 \% \mathrm{Cl}$ 0.37 to $1.57 ; 260$ participants; 2 studies; $\left.\right|^{2}=30 \%$; Analysis 3.4 ).

\subsection{Multiple pregnancy rate}

Multiple pregnancy rate was reported in three studies comparing letrozole to CC, with or without adjuncts (Ganesh 2009; Kar 2012; Zeinalzadeh 2010). There was insufficient evidence of a difference between the two groups (OR $1.03,95 \% \mathrm{Cl} 0.49$ to $2.13 ; 1597$ participants; 3 studies; $\left.\right|^{2}=0 \%$; Analysis 3.5 ).

\section{Letrozole compared to laparoscopic ovarian drilling}

Five studies including 774 women compared letrozole with or without metformin to laparoscopic ovarian drilling (Abdellah 2011; Abu Hashim 2010a; Elgafor 2013; Ibrahim 2017; Liu 2015).

- Letrozole (2.5 mg to $5 \mathrm{mg}$ daily, cycle days 3 to 7 ) with or without metformin ( $850 \mathrm{mg}$ to $1700 \mathrm{mg}$ daily for 6 to 8 weeks) versus laparoscopic ovarian drilling.

\section{Primary outcomes}

\subsection{Live birth}

Live birth rate was reported in three studies including 548 women, comparing letrozole to laparoscopic ovarian drilling (Abdellah 2011; Abu Hashim 2010a; Liu 2015). There was low-quality evidence of no difference in live birth rate between the two treatment groups (OR 1.38, 95\% Cl 0.95 to 2.02; 548 participants; 3 studies; $\left.\right|^{2}=23 \%$; Analysis 4.1). Subgroup analyses were not possible because there were only three studies.

\subsection{Ovarian hyperstimulation syndrome}

Only one study including 260 women comparing use of letrozole to laparoscopic ovarian drilling reported ovarian hyperstimulation syndrome rate (Abu Hashim 2010a). Our risk-difference analysis showed insufficient evidence of a difference in frequency of this adverse event for the two treatment groups (RD 0.00; $95 \% \mathrm{Cl}-0.01$ to $0.01 ; 260$ participants; 1 study; Analysis 4.2).

\section{Secondary outcomes}

\subsection{Clinical pregnancy}

Clinical pregnancy rate was reported in five studies including 774 women, comparing letrozole with or without metformin to laparoscopic ovarian drilling (Abdellah 2011; Abu Hashim 2010a; Elgafor 2013; Ibrahim 2017; Liu 2015). There was low-quality evidence of no difference between the two groups (OR 1.28, 95\% Cl 0.94 to $1.74 ; 774$ participants; 5 studies; $1^{2}=0 \%$; Analysis 4.3 ).

\subsection{Miscarriage rate by woman randomised and by pregnancies}

Miscarriage rate was reported in five studies including 774 women, comparing letrozole with or without metformin to laparoscopic ovarian drilling (Abdellah 2011; Abu Hashim 2010a; Elgafor 2013; Ibrahim 2017; Liu 2015). There was moderate-quality evidence of no difference between the two groups for miscarriage rate by woman randomised (OR $0.81,95 \% \mathrm{Cl} 0.38$ to $1.70 ; 774$ participants; 5 studies; $\mathrm{I}^{2}=0 \%$; Analysis 4.4 ) and by pregnancy (OR 0.66; $95 \% \mathrm{Cl}$ 0.30 to $1.43 ; 240$ participants; 5 studies ; $\left.\right|^{2}=0 \%$; Analysis 4.5 ).

\subsection{Multiple pregnancy rate}

Multiple pregnancy rate was reported in three studies including 548 women, comparing letrozole to laparoscopic ovarian drilling (Abdellah 2011; Abu Hashim 2010a; Liu 2015). There was lowquality evidence of no difference between the two groups for 
multiple pregnancy rate by woman randomised (OR 3.00, 95\% Cl 0.12 to $74.90 ; 548$ participants; 3 studies; $12=0 \%$; Analysis 4.6).

\section{Letrozole compared to follicle stimulating hormone (FSH)}

One study including 140 women compared use of letrozole to FSH (Hassan 2017).

- Letrozole $2.5 \mathrm{mg}$ twice daily for 5 days versus uFSH $75 \mathrm{IU}$ a day for 7 days, both groups starting on the third day of menstruation.

\section{Primary outcomes}

\subsection{Live birth}

No studies comparing letrozole to FSH reported live birth rate.

\subsection{Ovarian hyperstimulation syndrome}

Only one study comparing letrozole to FSH reported no occurrence of ovarian hyperstimulation syndrome (Hassan 2017). A riskdifference analysis showed insufficient evidence of a difference between the two treatment groups (RD $0.00,95 \% \mathrm{Cl}-0.03$ to 0.03 , 140 participants; 1 study; Analysis 5.1)

\section{Secondary outcomes}

\subsection{Clinical pregnancy}

Clinical pregnancy rate was reported in one study comparing letrozole to FSH (Hassan 2017). There was insufficient evidence of a difference between the two groups (OR $0.82,95 \% \mathrm{Cl} 0.40$ to 1.67 ; 140 participants; 1 study; Analysis 5.2)

\subsection{Miscarriage rate by woman randomised and by pregnancies}

Miscarriage rate was reported in one study comparing letrozole to FSH (Hassan 2017). There was insufficient evidence of a difference between the two groups for miscarriage rate by woman randomised (OR 0.66, 95\% Cl 0.11 to 4.06; 140 participants; 1 study; Analysis 5.3) or by pregnancies (OR $0.74,95 \% \mathrm{Cl} 0.11$ to $4.90 ; 140$ participants; 1 study; Analysis 5.4).

\subsection{Multiple pregnancy rate}

Multiple pregnancy rate was reported in one study comparing letrozole to FSH (Hassan 2017). There was insufficient evidence to suggest a difference between the two treatment groups (OR 0.19, $95 \% \mathrm{Cl} 0.01$ to $4.12 ; 140$ participants; 1 study; Analysis 5.5).

\section{Letrozole compared to anastrozole}

Two studies including 270 women compared letrozole to the $\mathrm{Al}$ anastrozole (Al-Omari 2004; Badawy 2008).

- Letrozole $2.5 \mathrm{mg} /$ day versus anastrozole $1 \mathrm{mg} /$ day for 5 days, both starting on cycle day 3 .

\section{Primary outcomes}

\subsection{Live birth}

No studies comparing letrozole to anastrozole reported live birth rate.

\subsection{Ovarian hyperstimulation syndrome}

Only one study comparing letrozole to anastrozole reported the occurrence of ovarian hyperstimulation syndrome (Badawy 2008). A risk difference analysis showed insufficient evidence of a difference between the two treatment groups (RD $0.00,95 \% \mathrm{Cl}$ -0.02 to $0.02 ; 220$ participants; 1 study; Analysis 6.1 )

\section{Secondary outcomes}

\subsection{Clinical pregnancy}

Clinical pregnancy rate was reported in two studies comparing letrozole to anastrozole (Al-Omari 2004; Badawy 2008). There was insufficient evidence of a difference between the two groups (OR $0.85,95 \% \mathrm{Cl} 0.51$ to $1.43 ; 260$ participants; 2 studies; $\left.\right|^{2}=12 \%$; Analysis 6.2).

\subsection{Miscarriage rate by woman randomised and by pregnancies}

Miscarriage rate was reported in one study comparing letrozole to anastrozole (Badawy 2008). There was insufficient evidence of a difference between the two groups for miscarriage rate by woman randomised (OR 0.98, 95\% Cl 0.24 to 4.03; 220 participants; 1 study; Analysis 6.3 ) or by pregnancies (OR $1.19,95 \% \mathrm{Cl} 0.27$ to $5.13 ; 220$ participants; 1 study; Analysis 6.4).

\subsection{Multiple pregnancy rate}

Multiple pregnancy rate was reported in two studies comparing letrozole to anastrozole (Al-Omari 2004; Badawy 2008). One study did not report any cases of multiple pregnancies and an odds ratio was therefore not estimable (Al-Omari 2004). The other study showed insufficient evidence to suggest a difference between the two treatment groups (OR 5.00, 95\% Cl 0.24 to 105.35; 220 participants; 1 study; Analysis 6.5).

\section{Different administration protocols of letrozole}

\subsection{Five days compared to 10 days administration protocol of letrozole}

There was one trial comparing a five-day letrozole administration protocol to a 10-day letrozole administration protocol (Badawy 2009a). This study did not report live birth rate. A risk-difference analysis on the OHSS rate showed insufficient evidence to suggest a difference in occurrence of OHSS between the two treatment groups (RD $0.00,95 \% \mathrm{Cl}-0.02$ to $0.02 ; 220$ participants; 1 study; Analysis 7.1). The analysis showed insufficient evidence of a difference between the groups in clinical pregnancy rate (OR $0.63,95 \% \mathrm{Cl} 0.35$ to $1.13 ; 220$ participants; 1 study; Analysis 7.2 ), miscarriage rate by woman randomised (OR $0.69,95 \% \mathrm{Cl} 0.21$ to 2.24; 220 participants; 1 study; Analysis 7.3), miscarriage rate by pregnancies (OR $0.96,95 \% \mathrm{Cl} 0.27$ to $3.42 ; 220$ participants; 1 study; Analysis 7.4 ) or multiple pregnancy rate (OR $0.32,95 \% \mathrm{Cl} 0.01$ to 8.05; 220 participants; 1 study; Analysis 7.5).

\subsection{Letrozole day 3 - 7 administration versus day 5 - 9 administration}

There was one trial including 70 women comparing starting letrozole on day 3 versus day 5 administration protocol (Ghomian 2015). This study did not report live birth rate, OHSS rate, miscarriage rate or multiple pregnancy rate. The analysis showed insufficient evidence of a difference between the two groups in clinical pregnancy rate (OR $1.38,95 \% \mathrm{Cl} 0.28$ to 6.66 ; 70 participants, 1 study; Analysis 7.2).

\section{Dosage studies of letrozole}

There was only one trial comparing a $5 \mathrm{mg} /$ day administration of letrozole to a $7.5 \mathrm{mg} /$ day administration protocol (Ramezanzadeh 
2011). This study did not report live birth rate. A risk-difference analysis on OHSS rate showed insufficient evidence to suggest a difference in occurrence of OHSS between the two treatment groups (RD $0.00,95 \% \mathrm{Cl}-0.05$ to $0.05 ; 80$ participants; 1 study; Analysis 8.1). Their results show insufficient evidence of a difference between the groups in clinical pregnancy rate (OR 1.00, 95\% Cl 0.32 to $3.17 ; 80$ participants; 1 study; Analysis 8.2), miscarriage rate by woman randomised (OR $0.33,95 \% \mathrm{Cl} 0.01$ to $8.22 ; 80$ participants; 1 study; Analysis 8.3 ), miscarriage rate by pregnancies (OR $0.29,95 \%$ $\mathrm{Cl} 0.01$ to 8.39 ; 80 participants; 1 study; Analysis 8.4) or multiple pregnancy rate (OR $1.00,95 \% \mathrm{Cl} 0.06$ to $16.56 ; 80$ participants; 1 study; Analysis 8.5).

\section{DISCUSSION}

\section{Summary of main results}

\section{Letrozole compared to placebo}

Two trials compared Letrozole to placebo. There is a lack of adequate studies with a large number of participants and a low risk of bias.

\section{Letrozole compared to clomiphene citrate followed by timed intercourse}

The results of our analysis of 25 trials comparing letrozole to CC followed by timed intercourse suggest that letrozole improves the live birth rate and pregnancy rate compared to CC (Summary of findings for the main comparison).

However, we note that studies that reported live birth tended to report higher clinical pregnancy rates in the letrozole group than studies that failed to report live birth, with insufficient evidence of a difference in miscarriage rates by pregnancies. This suggests that findings might be less favourable to letrozole if all studies reported live birth. However, a funnel plot for live birth rate was symmetrical, indicating that our findings might not be influenced by publication bias (Figure 5).

A risk-difference analysis suggested that letrozole and clomiphene citrate are equally safe in terms of ovarian hyperstimulation and miscarriage. (Summary of findings for the main comparison).

The funnel plot for clinical pregnancy rate was asymmetrical, suggesting that our findings might be influenced by publication bias in favour of letrozole. A funnel plot investigating the impact of possible allocation bias on clinical pregnancy rate also showed some asymmetry, suggesting that the results might be influenced by allocation bias in favour of letrozole.

All analyses had absent or low levels of statistical heterogeneity ( 12 less than $25 \%$ ).

Seven of our 25 studies in this analysis included women that were resistant to clomiphene citrate (Abu Hashim 2010b; Begum 2009; Davar 2011; El-Gharib 2015; Foroozanfard 2011; Seyedoshohadaei 2016; Sohrabvand 2006); the other 18 studies included women who were not resistant to clomiphene citrate (Badawy 2009b; Bayar 2006; Dehbashi 2009; Legro 2014; Nazik 2012; Sh-El-Arab Elsedeek 2011) or it was not mentioned (Amer 2017; Atay 2006; Chen 2016; El-Khayat 2016; Ghahiri 2016; Liu 2017; Moussa 2016; Selim 2012; Sharief 2015; Ray 2012; Roy 2012; Wu 2016).
Data based on findings from Legro 2014 found that the interventions had comparable treatment costs. This suggests that, given its higher effectiveness, letrozole is more cost-effective than clomiphene citrate (Reproductive Medicine Network 2013).

\section{Letrozole compared to other agents for ovulation induction followed by IUI}

Three trials compared letrozole to clomiphene citrate for ovulation induction followed by IUI. None reported live birth. Two reported OHSS: only three cases occurred and there was insufficient evidence of a difference despite a study population of 1494 women. Clinical pregnancy rates were increased in women treated with letrozole, compared to CC and FSH. There was insufficient evidence of a difference in rates of miscarriage or multiple pregnancy.

\section{Letrozole compared to laparoscopic ovarian drilling}

Five trials compared letrozole to laparoscopic ovarian drilling in clomiphene citrate-resistant women (Summary of findings 2). OHSS was reported only in Abu Hashim 2010a, but no cases of OHSS were found despite a study population of 260 women. There was low- to moderate-quality evidence of no difference in rates of live birth, pregnancy, miscarriage or multiple pregnancy rate.

\section{Letrozole compared to FSH}

A single study including 140 women compared use of letrozole to FSH (Hassan 2017). Live birth rate was not reported and there were no events of OHSS. There was insufficient evidence of a difference for clinical pregnancy, miscarriage or multiple pregnancy rate.

\section{Letrozole compared to anastrozole}

Letrozole was compared to anastrozole in two studies including 260 women (Al-Omari 2004; Badawy 2008). Neither study reported live birth and OHSS was only reported in Badawy 2008 but with no events. Rates of clinical pregnancy and multiple pregnancies were compared in both trials, but there was insufficient evidence of a difference. Miscarriage rates were reported only in Badawy 2008, with insufficient evidence of a difference between the groups.

\section{Different administration protocols of letrozole}

\section{Five days compared to 10 days letrozole administration protocol}

A single study including 218 women compared a five-day administration protocol to a 10-day administration protocol for letrozole. There was insufficient evidence of increased effectiveness or reduced side effects for any of our outcomes.

\section{Letrozole day 3-7 administration versus day 5-9 administration protocol}

A single study including 70 women compared a day 3 to 5 versus day 5 to 9 administration protocol. Only pregnancy rate was reported and there was insufficient evidence for a difference.

\section{Dosage studies of letrozole}

We intended to analyse different doses of letrozole in the range from 2.5 to $5 \mathrm{mg} / \mathrm{day}$, but we found only one study including 80 women comparing a dosage of $5 \mathrm{mg} /$ day to $7.5 \mathrm{mg} /$ day. There was insufficient evidence of a difference in effectiveness as only seven pregnancies were reported in each group. There was also insufficient evidence of a difference in adverse events, but the size of the study population might have been too small because only 
one or no cases were reported in each group for OHSS, miscarriage and multiple pregnancy rate.

\section{Overall completeness and applicability of evidence}

For our main comparison of letrozole compared to other agents for ovulation induction, we found sufficient studies for our analysis of live birth and OHSS to answer our research question.

Most of the studies included were conducted in Egypt or the Middle East. There are, however, two large studies from the USA and Europe confirming the results (Amer 2017; Legro 2014).

\section{Quality of the evidence}

We included 42 studies with 7935 women. The overall quality of the evidence varied and was rated as moderate to high for our main comparison (Summary of findings for the main comparison). The reasons for downgrading the evidence included possible publication bias. Moreover, there was a tendency for studies that reported live birth to report higher clinical pregnancy rates in the letrozole group than studies that failed to report live birth, suggesting that results might be somewhat less favourable to letrozole if all studies reported live birth. However, based on the large numbers of participants and the addition of trials at low risk of bias in this update, it is unlikely that additional studies are going to alter the effect estimates of our main comparison of letrozole versus clomiphene citrate, with or without adjuncts.

The other comparisons included only one to five studies. We downgraded much of the evidence for risks of bias and imprecision (Summary of findings 2).

\section{Potential biases in the review process}

We conducted a comprehensive search with the help of an experienced Information Specialist, and ran extensive manual searches in order to identify all relevant studies and in an effort to minimise the risk of publication bias. However, we generated a funnel plot for the outcome of pregnancy rate in the comparison of aromatase inhibitors versus other ovulation induction agents, which indicated that there might be some studies not published that reported results in favour of clomiphene citrate. There are five studies awaiting classification, which could also have an influence on our results. There might therefore be some publication bias in this review.

We followed Cochrane guidelines to select studies, extract data and assess the quality and potential risks of different types of biases in all our included studies, in order to minimise the chance of error and bias by the review authors.

\section{Agreements and disagreements with other studies or reviews}

Our meta analysis shows evidence for increased live birth rates in favour of letrozole when compared to clomiphene citrate in women with PCOS. This differs from a previous review, which did not detect a difference (Misso 2012). This is most likely due to the limited number of studies included in the previous review. Another recent meta analysis (Roque 2015) is in accordance with our findings of increased live birth and pregnancy rates, as well as no difference for miscarriage and multiple pregnancy rates in our meta-analysis. In addition, our meta-analysis showed no evidence for a difference in effect between letrozole and laparoscopic ovarian drilling for subfertility treatment in women who are resistant to clomiphene citrate, which is in agreement with the results of an earlier metaanalysis (Misso 2012).

\section{AUTHORS' CONCLUSIONS}

\section{Implications for practice}

Letrozole appears to improve live birth and pregnancy rates in subfertile women with anovulatory polycystic ovary syndrome (PCOS), compared to clomiphene citrate (CC). There is high-quality evidence that OHSS rates are similar with letrozole or clomiphene citrate. There was high-quality evidence of no difference in miscarriage rate and multiple pregnancy rate. There is low-quality evidence of no difference in live birth and pregnancy rates between letrozole and laparoscopic ovarian drilling, although there were few relevant studies. In the 2018 update, we added trials of good quality, thereby upgrading the quality of the evidence base.

\section{Implications for research}

For letrozole compared to placebo, additional studies may not be necessary, since there is evidence in favour of letrozole compared to clomiphene citrate $(\mathrm{CC})$, which was proven to be more effective compared to placebo for live birth and pregnancy rates (Badawy 2009b; Bayar 2006; Dehbashi 2009; Nazik 2012; Sh-El-Arab Elsedeek 2011).

Further research including large studies is needed to compare letrozole with clomiphene citrate specifically in women with PCOS who have had no previous treatment for ovulation induction, to help determine whether letrozole or CC should be a first-line medical ovulation induction agent in women with anovulatory PCOS. Furthermore, large studies are needed in Asia, Europe and America to investigate possible ethnic differences. More large studies of high quality are needed for our comparisons four to eight, as there was very limited evidence available.

More randomised clinical trials (RCTs) could also be conducted, investigating a five- or 10-day administration protocol and day 3 to 5 or day 5 to 9 administration of letrozole, but with caution because of the concerns of teratogenic effects of letrozole. Based on these concerns, outcomes on neonatal birth defects should also be reported.

\section{ACKNOWLEDGEMENTS}

We would like to thank Marian Showell (Information Specilaist) for writing and running the search, Vanessa Jordan for assistance with methodological questions, Helen Nagels (Managing Editor of CGFG) for helping us to develop the protocol and answering our questions, and Julie Brown for assistance with writing the full review. We would like to thank our peer reviewers for giving very constructive feedback, leading to great improvement of the review.

The authors of the 2018 update thank Dr. Willianne Nelen for her contributions to the previous version of this review. 


\section{R E F E R E N C E S}

\section{References to studies included in this review}

Abdellah 2011 \{published data only\}

Abdellah MS. Reproductive outcome after letrozole versus laparoscopic ovarian drilling for clomiphene-resistant polycystic ovary syndrome. International Journal of Gynecology and Obstetrics 2011;113(3):218-21.

\section{Abu Hashim 2010a \{published data only\}}

Abu Hashim H, Mashaly AM, Badawy A. Letrozole versus laparoscopic ovarian diathermy for ovulation induction in clomiphene-resistant women with polycystic ovary syndrome: a randomized controlled trial. Archives of Gynecology and Obstetrics 2010;282(5):567-71.

\section{Abu Hashim 2010b \{published data only\}}

Abu Hashim H, Shokeir T, Badawy A. Letrozole versus combined metformin and clomiphene citrate for ovulation induction in clomiphene-resistant women with polycystic ovary syndrome: a randomized controlled trial. Fertility and Sterility 2010;94(4):1405-9.

\section{Al-Omari 2004 \{published data only\}}

Al-Omari WR, Sulaiman WR, Al-Hadithi N. Comparison of two aromatase inhibitors in women with clomiphene-resistant polycystic ovary syndrome. International Journal of Gynecology \& Obstetrics 2004;85(3):289-91.

Amer 2017 \{published data only\}

Amer SA, Smith J, Mahran A, Fox P, Fakis A. Double-blind randomized controlled trial of letrozole versus clomiphene citrate in subfertile women with polycystic ovarian syndrome. Human Reproduction 2017;32(8):1631-8. [CENTRAL: 01405506]

\section{Atay 2006 \{published data only\}}

Atay V, Cam C, Muhcu M, Cam M, Karateke A. Comparison of letrozole and clomiphene citrate in women with polycystic ovaries undergoing ovarian stimulation. Journal of International Medical Research 2006;34(1):73-6.

\section{Badawy 2008 \{published data only\}}

Badawy A, Mosbah A, Shady M. Anastrozole or letrozole for ovulation induction in clomiphene-resistant women with polycystic ovarian syndrome: a prospective randomized trial. Fertility and Sterility 2008;89(5):1209-12.

\section{Badawy 2009a \{published data only\}}

Badawy A, Mosbah A, Tharwat A, Eid M. Extended letrozole therapy for ovulation induction in clomiphene-resistant women with polycystic ovary syndrome: a novel protocol. Fertility and Sterility 2009;92(1):236-9.

\section{Badawy 2009b \{published and unpublished data\}}

Badawy A, Abdel Aal I, Abulatta M. Clomiphene citrate or letrozole for ovulation induction in women with polycystic ovarian syndrome: a prospective randomized trial. Fertility and Sterility 2009;92(3):849-52.
Bayar 2006 \{published data only\}

Bayar U, Basaran M, Kiran S, Coskun A, Gezer S. Use of an aromatase inhibitor in patients with polycystic ovary syndrome: a prospective randomized trial. Fertility and Sterility 2006;86(5):1447-51.

\section{Begum 2009 \{published and unpublished data\}}

Begum MR, Ferdous J, Begum A, Quadir E. Comparison of efficacy of aromatase inhibitor and clomiphene citrate in induction of ovulation in polycystic ovarian syndrome. Fertility and Sterility 2009;92(3):853-7.

\section{Chen 2016 \{published data only\}}

Chen Z, Zhang M, Qiao Y, Yang J. Effects of letrozole in combination with low-dose intramuscularinjection of human menopausal gonadotropin on ovulationand pregnancy of 156 patients with polycystic ovary syndrome. Pakistanian Journal of Medical Sciences 2016;32(6):1434-8.

\section{Davar 2011 \{published data only\}}

Davar R, Javedani M, Fallahzadeh MH. Metformin-letrozole in comparison with metformin-clomiphene citrate in clomipheneresistance PCOS patients undergoing IUI. Iranian Journal of Reproductive Medicine 2011;9(1):31-6.

Dehbashi 2009 \{published data only\} Dehbashi S, Kazerooni T, Robati M, Alborzi S, Parsanezhad ME, Shadman A. Comparison of the effects of letrozole and clomiphene citrate on ovulation and pregnancy rate in patients with polycystic ovary syndrome. Iranian Journal of Medical Sciences 2009;34:23-8.

\section{Elgafor 2013 \{published data only\}}

Elgafor IA. Efficacy of combined metformin-letrozole in comparison with bilateral ovarian drilling in clomipheneresistant infertile women with polycystic ovarian syndrome. Archives of Gynecology and Obstetrics 2013;288(1):119-23. [DOI: 10.1007/s00404-013-2714-2]

\section{El-Gharib 2015 \{published data only\}}

EL-Gharib MN, Mahfouz AE, Farahat MA. Comparison of letrozole versus tamoxifen effects in clomiphene citrate resistant women with polycystic ovarian syndrome. Journal of Reproduction and Infertility 2015;16(1):30-5.

\section{El-Khayat 2016 \{published data only\}}

El-Khayat W, Abdel Moety G, Mohammady MA, Hamed D. A randomized controlled trial of clomifene citrate, metformin, and pioglitazone versus letrozole, metformin, and pioglitazone for clomifene-citrate resistant polycystic ovary syndrome. International Journal of Gynaecology and Obstetrics 2016;132(2):206-9.

\section{Foroozanfard 2011 \{published data only\}}

Foroozanfard F, Mahdian M, Mousavi Gl, Pejmanmanesh M, Soleimani A. Use of letrozole versus clomiphene citrate combined with gonadotropins in patients with clomiphene resistant polycystic ovarian syndrome: A comparative study. Pakistan Journal of Medical Sciences 2011;27(5):967-70. 


\section{Ganesh 2009 \{published data only\}}

Ganesh A, Goswami SK, Chattopadhyay R, Chaudhury K, Chakravarty B. Comparison of letrozole with continuous gonadotropins and clomiphene-gonadotropin combination for ovulation induction in 1387 PCOS women after clomiphene citrate failure: a randomized prospective clinical trial. Journal of Assisted Reproduction and Genetics 2009;26(1):19-24.

\section{Ghahiri 2016 \{published data only\}}

Ghahiri A, Mogharehabed N, Mamourian M. Letrozole as the first-line treatment of infertile women with poly cystic ovarian syndrome (PCOS) copared with clomiphene citrate: a clinical trial. Advanced Biomedical Research 2016;5(6):1-4.

\section{Ghomian 2015 \{published data only\}}

Ghomian N, Khosravi A, Mousavifar N. A randomized clinical trial on comparing the cycle characteristics of two different initiation days of letrozole treatment in clomiphene citrate resistant PCOS patients in IUI cycles. International Journal of Fertility and Sterility 2015;9(1):17-26.

\section{Hassan 2017 \{published data only\}}

Hassan A, Shehata N, Wahba A. Cost effectiveness of letrozole and purified urinary FSH in treating women with clomiphene citrate-resistant polycystic ovarian syndrome: a randomized controlled trial. Human Fertility 2017;20(1):37-42.

\section{Hendawy 2011 \{published data only\}}

Hendawy SF, Samaha HE, Elkholy MF. Letrozole versus clomiphene citrate for induction of ovulation in patients with polycystic ovarian syndrome undergoing intratuerine insemination. Clinical Medicine Insights: Reproductive Health 2011;5:11-6.

\section{Ibrahim 2017 \{published data only\}}

Ibrahim MH, Tawfic M, Hassan MM, Sedky OH. Letrozole versus laparoscopic ovarian drilling in infertile women with PCOS resistant to clomiphene citrate. Middle East Fertility Society Journal 2017;22(4):251-4

\section{Kamath 2010 \{published and unpublished data\}}

Kamath MS, Aleyamma TK, Chandy A, George K. Aromatase inhibitors in women with clomiphene citrate resistance: a randomized, double-blind, placebo-controlled trial. Fertility and Sterility 2010;94(7):2857-9.

\section{Kar 2012 \{published data only\}}

Kar S. Clomiphene citrate or letrozole as first-line ovulation induction drug in infertile PCOS women: a prospective randomized trial. Journal of Human Reproductive Sciences 2012;5(3):262-5. [DOI: 10.4103/0974-1208.106338]

\section{Legro 2014 \{published and unpublished data\}}

* Legro RS, Brzyski RG, Diamond MP, Coutifaris C, Schlaff WD, Casson P, et al. NICHD Reproductive Medicine Network. Letrozole versus clomiphene for infertility in the polycycstic ovary syndrome. New England Journal of Medicine 2014;371(2):119-29.

Legro RS, Kunselman AR, Brzyski RG, Casson PR, Diamond MP, Schlaff WD, et al. Effect of letrozole versus clomiphene on live birth in women with anovulatory infertility due to polycystic ovary syndrome (PCOS): A randomized double-blind multicenter trial. Fertility and Sterility 2013; Vol. 100, issue 3:S51.

Liu 2015 \{published data only\}

Liu W, Dong S, Li Y, Shi L, Zhou W, Liu Y, et al. Randomized controlled trial comparing letrozole with laparoscopic ovarian drilling in women with clomiphene citrate-resistant polycstic ovary syndrome. Experimental and Therapeutic Medicine 2015;10(4):1297-302.

\section{Liu 2017 \{published data only\}}

Liu C, Feng G, Huang W, Wang Q, Yang S, Tan J, et al. Comparison of clomiphene citrate and letrozole for ovulation induction in women with polycystic ovary sndrome: a prospective randomized trial. Gynecological Endocrinology 2017;33(11):872-6.

\section{Moussa 2016 \{published data only\}}

Moussa AA, Torky H, Dief O, Elwahed AA, Senna HA. The effect of clomiphene citrate versus tamoxifen versus letrozol on endometrial thickness and blood flow in ovulation induction in women with polycystic ovaries. Acta Medica International 2016;3(2):88-92.

\section{Nazik 2012 \{published data only\}}

Nazik H, Kumtepe Y. Comparison of efficacy of letrozole and clomiphene citrate in ovulation induction for women with polycystic ovarian syndrome. HealthMED Journal 2012;6(3):879-83.

\section{Ramezanzadeh 2011 \{published data only\}}

Ramezanzadeh F, Nasiri R, Yazdi MS, Baghrei M. A randomized trial of ovulation induction with two different doses of Letrozole in women with PCOS. Archives of Gynecology and Obstetrics 2011;284(4):1029-34.

\section{Ray 2012 \{published data only\}}

Ray PB, Ray A, Chakraborti PS. Comparison of efficacy of letrozole and clomiphene citrate in ovulation induction in Indian women with polycystic ovarian syndrome. Archives of Gynecology and Obstetrics 2012;285(3):873-7.

\section{Roy 2012 \{published data only\}}

Roy K, Baruah J, Singla S, Sharma JB, Singh N, Jain SK, et al. A prospective randomized trial comparing the efficacy of letrozole and clomiphene citrate in induction of ovulation in polycystic ovarian syndrome. Journal of Human Reproductive Sciences 2012;5(1):20-5.

Selim 2012 \{published data only\}

Selim MF, Borg TF. Letrozole and clomiphene citrate effect on endometrial and subendometrial vascularity in treating infertilityin women with polycystic ovary syndrome. Journal of Gynaecologic Surgery 2012;28(6):405-10. [DOI: 10.1089/ gyn.2012.0033]

\section{Seyedoshohadaei 2016 \{published data only\}}

Seyedoshohadaei F, Tangestani L, Zandvakili F, Rashadmanesh N. Comparison of the effect of clomipheneestradiol valerate vs letrozole on endometrial thickness, 
abortion and pregnancy rate in infertile women with polycystic ovarian syndrome. Journal of Clinical and Diagnostic Research 2016;10(8):QC10-3.

\section{Sharief 2015 \{published data only\}}

Sharief M, Nafee NR. Comparison of letrazole and clomiphene citrate in women with polycystic ovaries undergoing ovarian stimulation. Journal of Pakistani Medical Association 2015;65(11):1149-1152.

\section{Sh-El-Arab Elsedeek 2011 \{published data only\}}

Sheikh-El-Arab Elsedeek M, Elmaghraby HA. Predictors and characteristics of letrozole induced ovulation in comparison with clomiphene induced ovulation in anovulatory PCOS women. Middle East Fertility Society Journal 2011;16(2):125-30

\section{Sohrabvand 2006 \{published data only\}}

Sohrabvand F, Ansari SH, Bagheri M. Efficacy of combined metformin-letrozole in comparison with metformin-clomiphene citrate in clomiphene-resistant infertile women with polycystic ovarian disease. Human Reproduction 2006;21(6):1432-5.

\section{Wu 2016 \{published data only\}}

Wu X, Wang Y, Liu J, Liang R, Xue H, Ma H, et al. Randomized controlled trial of letrozole, berberine, or a combination for infertility in the polycystic ovary syndrome. Fertility and Sterility 2016;106(3):757-66.

\section{Zarei 2015 \{published data only\}}

Zarei A, Shabahrami TB, Dadras N. Effects of letrozole in prevention of premature luteinizing hormone $(\mathrm{LH})$ surge in infertile women with clomiphene citrate resistant polycystic ovary syndrome (PCOS) undergoing intrauterine insemination. Galen Medical Journal 2015;4(3):104-11.

\section{Zeinalzadeh 2010 \{published data only\}}

Zeinalzadeh M, Basirat Z, Esmailpour M. Efficacy of letrozole in ovulation induction compared to that of clomiphene citrate in patients with polycystic ovarian syndrome. Journal of Reproductive Medicine 2010;55(1-2):36-40.

\section{References to studies excluded from this review}

\section{Akbari 2012 \{published data only\}}

Akbari S, Ayazi Roozbahani M, Ayazi Roozbahani F. Comparing of letrozole versus clomiphene citrate combined with gonadotropins in intrauterine insemation cycles. Iranian Journal of Reproductive Medicine 2012;10(1):29-32.

\section{Al-Hussaini 2014 \{published data only\}}

Al-Hussaini T, Mohammed S, Abdellah M, Abdel Aleem A. Letrozole versus combined clomiphene citrate and metformin as a first line treatment in women with polycystic ovarian syndrome. British Journal of Obstetrics and Gynaecology 2014;EPosters:EP6.13.

\section{Al-Shaikh 2017 \{published data only\}}

Al-Shaikh SF, Al-Mukhatar EJ, Al-Zubaid AA, Al-Rubaie BJ, AlKhuzaee $\mathrm{L}$. Use of clomiphene or letrozole for treating women with polycystic ovary syndrome related subfertility in Hilla city. Middle East Fertility Society Journal 2017;22:105-10.
Angel 2014 \{published data only\}

Angel M, Ghose S, Gowda M. A randomized trial comparing the ovulation induction efficacy of clomiphene citrate and letrozole. Journal of Natural Science Biology \& Medicine 2014;5(2):450-2.

Anwary 2012 \{published data only\}

Anwary SA, Alfazzaman M, Bar, N, Islam MR. Outcome of metformin treatment in polycystic ovary syndrome. Mymensingh Medical Journal 2012;21(1):60-5.

\section{Azargoon 2012 \{published data only\}}

Azargoon A, Toussy JA, Darbanan FF. Pregnancies following the use of sequential treatment of metformin and incremental doses of letrozole in clomiphene-resistant women with polycystic ovary syndrome. Iranian Journal of Reproductive Medicine 2012;10(1):33-40.

\section{Azmoodeh 2015 \{published data only\}}

Azmoodeh A, Pejman Manesh M, Akbari Asbagh F, Ghaseminejad A, Hamzehgardeshi Z. Effects of letrozole-HMG and clomiphene-HMG on incidence of luteinized unruptured follicle syndrome in infertile women undergoing induction ovulation and intrauterine insemination: a randomised trial. Global Journal of Health Science 2015;8(4):244-52.

\section{Badawy 2009c \{published data only\}}

Badawy A, Abdel Aal I, Abulatta M. Clomiphene citrate or anastrozole for ovulation induction in women with polycystic ovary syndrome? A prospective controlled trial. Fertility and Sterility 2009;92:860-3.

Baruah 2009 \{published data only\}

Baruah J, Roy KK, Rahman SM, Kumar S, Sharma JB, Karmakar D. Endometrial effects of letrozole and clomiphene citrate in women with polycystic ovary syndrome using spiral artery Doppler. Archives of Gynecology \& Obstetrics 2009;279(3):311-4.

\section{El Bigawy 2008 \{published data only\}}

El Bigawy AF, Fouda UMF, Wahab HAE. A randomized trial of letrozole versus clomiphene citrate in induction of ovulation in patients with polycystic ovary syndrome (PCOS). Middle East Fertility Society Journal 2008;13(1):52-6.

\section{Foroozanfard 2013 \{published data only\}}

Foroozanfard F, Saberi H, Moravvegi A, Kazemi M. Pregnancy rate following luteal phase support in polycystic ovarian syndrome using combination therapies for ovulation induction: A randomized clinical trial.. Human Reproduction 2013;28(Suppl 1):i311-56.

\section{Khanna 2013 \{published data only\}}

Khanna SC, Kumar A, Joy SG, Tanwar R, Sharma S, Prasad S. Is letrozole superior to clomiphene for ovarian stimulation priorto intrauterine insemination?. Archives of Gynaecology and Obstetrics 2013;287(3):571-5.

\section{Li 2016 \{published data only\}}

Li J, Ng EH, Stener-Victorin E, Hu Z, Wu W, Ai M, et al. Comparison of acupuncture pre-treatment followed by letrozole versus letrozole alone on live birth in anovulatory 
infertile women with polycystic ovary syndrome:a study protocol for a randomised controlled trial. BMJ Open 2016;6(10):e010955.

\section{Mittal 2004 \{published data only\}}

Mittal S, Kamthane VP, Goswami SK, Ghosh S, Chakravarty BN. Comparative evaluation of different stimulation protocols in CC resistant P.C.O women undergoing IUI. 20th Annual Meeting of the ESHRE, Berlin, Germany, 200406 27-30. 2004:i122.

\section{Nahid 2012 \{published data only\}}

Nahid L, Sirous K. Comparison of the effects of letrozole and clomiphene citrate for ovulation induction in infertile women with polycystic ovary syndrome. Minerva Ginecologica 2012;64(3):253-8.

\section{NCT00610077 \{published data only\}}

NCT00610077. An open, randomized, parallel-group, multicentric, comparative study of letrozole with clomiphene citrate for induction of ovulation in anovulatory infertility.. clinicaltrials.gov/ct2/show/NCT00610077 (first posted 07 February 2008). [NCT00610077]

\section{NCT01315912 \{published data only\}}

NCT01315912. Dosage optimization for letrozole treatment. clinicaltrials.gov/ct2/show/NCT01315912 (first posted 16 March 2011). [NCT01315912]

\section{NCT01431352 \{published data only\}}

NCT01431352. Letrozole versus chinese herbal medicine on polycystic ovary syndrome (PCOS). clinicaltrials.gov/ct2/show/ NCT01431352 (verified November 2013). [NCT01431352]

\section{NCT01577017 \{published data only\}}

NCT01577017. The effects of letrozole and clomiphene citrate for induction of ovulation in polycystic ovarian syndrome (PCOS). clinicaltrials.gov/ct2/show/NCT01577017 (first posted 13 April 2012).

\section{NCT01679574 \{published data only\}}

NCT01679574. Letrozole or combined clomiphene citrate metformin as a first line treatment in women with polycystic ovary syndrome. clinicaltrials.gov/ct2/show/NCT01679574 (first posted 96 September 2012). [NCT01679574]

\section{NCT01793038 \{published data only\}}

NCT01793038. Clomiphene citrate plus UFSH versus aromatase inhibitor plus UFSH in clomiphene resistant infertile PCOS women. clinicaltrials.gov/ct2/show/NCT01793038 (verified March 2013). [NCT01793038]

\section{Ozdemir 2013 \{published data only\}}

Ozdemir U, Ozaksit G, Cakir Gungor AN, Aydogan M. Letrozole usage adjuvant to gonadotropins for ovulation induction for patients with clomiphene citrate failure. Archives of Gynecology and Obstetrics 2013;288(2):445-8.

Pakrashi 2014 \{published data only\}

Pakrashi T, Baydoun H, Bocca S, Oehninger S, Stadtmauer L. Luteral phase supplementation with vaginal progesterone in women with Polycystic ovary syndrome and ovulatory
Dysfunction undergoing ovulation induction with letrozole: a randomized controlled trial.. Fertility and Sterility

2014;102(3):Supplement, e237.

Palihawadana 2015 \{published data only\}

Palihawadana TS, Wijesinghe PS, Seneviratne HR. A comparison of endometrial thickness following augmentation of ovulation with clomifene citrate or letrozole in women with ovulatory infertility. Ceylon Medical Journal 2015;60(2):48-52.

Pourali 2017 \{published data only\}

Pourali L, Ayati S, Tavakolizadeh S, Soleimani H, Sani FT. Clomiphene citrate versus letrozole with gonadotropins in intrauterine insemination cycles: a randomized trial. International Journal of Reproductive Biomedicine 2017;15(1):49-54.

\section{Sarvi 2010 \{published data only\}}

Sarvi F. The effect of metformin in different phenotypes of poly cystic ovary syndrome according to Rotterdam criteria criteria. Iranian Registry of Clinical Trials 2010. [IRCT201103146063N1]

\section{Sharma 2010 \{published data only\}}

Sharma S, Goswami SK, Rajani S, et al. Efficacy of letrozolegonadotropin, clomiphene-gonadotropin and only gonadotropin in clomiphene and letrozole resistant PCOS women undergoing IUI. Human Reproduction 2010;25(Suppl 1):i46.

\section{Xi 2015 \{published data only\}}

Xi W, Liu S, Mao H, Yang Y, Xue X, Lu X. Use of letrozole and clomiphene citrate combined with gonadotropins in clomiphene-resistant infertile women with polycystic ovary syndrome: a prospective study. Drug Design, Development and Therapy 2015;9:6001-8.

\section{Yang 2008 \{published data only\}}

Yang M, Quan S, Li H, Song Y, Xing F. Effect of two different doses of letrozole in promoting ovulation in infertile women with polycystic ovarian syndrome. Journal of Southern Medical University 2008;28(11):2060-2.

\section{Yun 2015 \{published data only\}}

Yun BH, Chon SJ, Park JH, Seo SK, Cho S, Choi YS, et al. Minimal stimulation using gonadotropin combined with clomiphene citrate or letrozole for intrauterine insemination. Yonsei Medical Journal 2015;56:490-6.

\section{References to studies awaiting assessment}

Aygen 2007 \{published data only\}

Aygen EM, Guzel Z, Ozgun T, Atakul T, Sahin Y. The use of letrozole for ovulation induction in infertile women with polycystic ovarian syndrome. Erciyes Tip Dergisi 2007;29:195-200.

\section{Lorzadeh 2011 \{published data only\}}

Lorzadeh N, Kazemirad S, Mohammadi Z. Comparison of effects letrozole and clomiphene citrate for ovulation induction in women with polycystic ovary syndrome. Iranian Journal of Obstetrics, Gynecology and Infertility 2011;14(3):13-9. 


\section{NCT02551367 \{published data only\}}

NCT02551367. Letrozole versus clomiphene citrate for ovulation induction in women with polycystic ovary syndrome (PCOS). clinicaltrials.gov/ct2/show/NCT02551367 (verified September 2015). [NCT02551367]

\section{Safdarian 2012 \{published data only\}}

Safdarian L, Dibazar NS, Ahmadzadeh A, Yekta BG. Comparing two ovulation induction methods by brachial artery ultrasonography in infertile women with polycystic ovary syndrome. Tehran University Medical Journal 2012;70:242-9.

\section{Shirin 2009 \{published data only\}}

Shirin G, Mehran A, Maryam B, Maryam G, Masoumeh M. Comparing the effects of clomiphene-HMG and letrozoleHMG on ovulation Induction in infertile women. Journal of Reproduction and Infertility 2009;10(2):109-14.

\section{References to ongoing studies}

\section{NCT03009838 \{published data only\}}

NCT03009838. Letrozole versus laparoscopic ovarian drilling in polycystic ovary syndrome. clinicaltrials.gov/ct2/show/ NCT03009838 (first posted 04 January 2017).

\section{Additional references}

\section{Abu 2012}

Abu Hashim H. Clomiphene citrate alternatives for the initial management of polycystic ovary syndrome: an evidencebased approach. Archives of Gynecology and Obstetrics 2012;285(6):1737-45.

\section{Azziz 2006}

Azziz R, Carmina E, Dewailly D, Diamanti-Kandarakis E, EscobarMorreale HF, Futterweit W, et al. Androgen Excess Society. Positions statement: criteria for defining polycystic ovary syndrome as a predominantly hyperandrogenic syndrome: an androgen excess society guideline. Journal of Clinical Endocrinology and Metabolism 2006;91(11):4237-45.

\section{Azziz 2009}

Azziz R, Carmina E, Dewailly D, Diamanti-Kandarakis E, EscobarMorreale HF, Futterweit W, et al. Task Force on the Phenotype of the Polycystic Ovary Syndrome of The Androgen Excess and PCOS Society. The androgen excess and PCOS society criteria for the polycystic ovary syndrome: the complete task force report. Fertility and Sterility 2009;91(2):456. [PUBMED: 18950759]

\section{Biljan 2005}

Biljan MM, Hemmings R, Brassard N. The outcome of 150 babies following the treatment with letrozole or letrozole and gonadotropins. Fertility and Sterility 2005;84(Supplement 1):s95.

\section{Brown 2016}

Brown J, Farquhar C. Clomiphene and other antioestrogens for ovulation induction in polycystic ovarian syndrome.
Cochrane Database of Systematic Reviews 2016, Issue 12. [DOI: 10.1002/14651858.CD002249.pub5]

\section{Casper 2006}

Casper RF, Mitwally MF. Review: aromatase inhibitors for ovulation induction. Journal of Clinical Endocrinology and Metabolism 2006;91(3):760-71.

\section{Casper 2011}

Casper RF, Mitwally MF. Use of the aromatase inhibitor letrozole for ovulation induction in women with polycystic ovarian syndrome. Clinical Obstetrics and Gynaecology 2011;54(4):685-95.

\section{Cole 1990}

Cole PA, Robinson $\mathrm{CH}$. Mechanism and inhibition of cytochrome P-450 aromatase. Journal of Medical Chemistry 1990;33(11):2933-44.

\section{Farquhar 2002}

Farquhar CM, Williamson K, Gudex G, Johnson NP, Garland J, Sadler L. A randomized controlled trial of laparoscopic ovarian diathermy versus gonadotropin therapy for women with clomiphene citrate-resistant polycystic ovary syndrome. Fertility and Sterility 2002;78(2):404.

\section{Farquhar 2012}

Farquhar C, Brown J, Marjoribanks J. Laparoscopic drilling by diathermy or laser for ovulation induction in anovulatory polycystic ovary syndrome. Cochrane Database of Systematic Reviews 2012, Issue 6. [DOI: 10.1002/14651858.CD001122.pub4]

\section{Forman 2007}

Forman R, Gill S, Moretti M, Tulandi T, Koren G, Casper R. Fetal safety of letrozole and clomiphene citrate for ovulation induction. Journal of Obstetrics and Gynaecology Canada 2007;29(8):668

\section{Higgins 2011}

Higgins JPT, Green S, editor(s). Cochrane Handbook for Systematic Reviews of Interventions Version 5.1.0 (updated March 2011). The Cochrane Collaboration, 2011. Available from handbook.cochrane.org.

\section{Homburg 2011}

Homburg R, Hendriks ML, König TE, Anderson RA, Balen AH, Brincat M, et al. Clomifene citrate or low-dose FSH for the firstline treatment of infertile women with anovulation associated with polycystic ovary syndrome: a prospective randomized multinational study. Human Reproduction 2011;27(2):468-73.

\section{Jirge 2010}

Jirge PR, Patil RS. Comparison of endocrine and ultrasound profiles during ovulation induction with clomiphene citrate and letrozole in ovulatory volunteer women. Fertility and Sterility 2010;93(1):174-83.

\section{Lee 2011}

Lee VC, Ledger W. Aromatase inhibitors for ovulation induction and ovarian stimulation. Clinical Endocrinology 2011;74(5):537-46. 


\section{Lunenfeld 2004}

Lunenfeld B. Historical perspectives in gonadotrophin therapy. Human Reproduction Update 2004;10(6):453-67.

\section{Misso 2012}

Misso ML, Wong JL, Teede HJ, Hart R, Rombauts L, Melder AM, et al. Aromatase inhibitors for PCOS: a systematic review and meta-analysis. Human Reproduction Update 2012;18(3):301-12.

\section{Mitwally 2001}

Mitwally MF, Casper RF. Use of an aromatase inhibitor for induction of ovulation in patients with an inadequate response to clomiphene citrate. Fertility and Sterility 2001;75(2):305-9.

\section{Nahuis 2011}

Nahuis MJ, Kose N, Bayram N, Van Dessel HJ, Braat DD, Hamilton $\mathrm{CJ}$, et al. Long-term outcomes in women with polycystic ovary syndrome initially randomized to receive laparoscopic electrocautery of the ovaries or ovulation induction with gonadotrophins. Human Reproduction 2011;26(7):1889-904.

\section{Reproductive Medicine Network 2013}

Reproductive Medicine Network. Letrozole versus clomiphene citrate in anovulatory PCOS women: A cost-effectiveness analysis. Fertility and Sterility 2013; Vol. 100, issue 3:S128.

\section{Roque 2015}

Roque M, Tostes AC, Valle M, Sampaio M, Geber S. Letrozole versus clomiphene citrate in polycystic ovary syndrome: systematic review and meta-analysis. Gynaecological Endocrinology 2015;31(12):917-21. [DOI: 10.3109/09513590.2015.1096337]

\section{Rotterdam 2003}

Rotterdam ESHRE/ASRM-Sponsored PCOS consensus workshop group. Revised 2003 consensus on diagnostic criteria and long-

\section{CHARACTERISTICS OF STUDIES}

Characteristics of included studies [ordered by study ID] term health risks related to polycystic ovary syndrome (PCOS). Human Reproduction 2004;19(1):41.

\section{Samani 2009}

Samani FG, Farzadi L, Nezami N, Tarzamni MK, Soleimani F. Endometrial and follicular development following letrozole intervention in unexplained infertile patients failed to get pregnant with clomiphene citrate. Archives of Gynecology and Obstetrics 2009;280(2):201-5.

\section{Tulandi 2006}

Tulandi T, Martin J, Al-Fadhli R, Kabli N, Forman R, Hitkari J, et al. Congenital malformations among 911 newborns conceived after infertility treatment with letrozole or clomiphene citrate. Fertility and Sterility 2006;85(6):1761-5.

\section{Velázquez 1997}

Velázquez E, Acosta A, Mendoza SG. Menstrual cyclicity after metformin therapy in polycystic ovary syndrome. Obstetrics and Gynecology 1997;90(3):392-5.

\section{Von Hofe 2015}

Von Hofe J, Wright Bates G. Ovulation Induction. Obstetrics and Gynecoly Clinics of North America 2015;42:27-37.

\section{White 1996}

White DM, Polson DW, Kiddy D, Sagle P, Watson H, GillingSmith C, et al. Induction of ovulation with low-dose gonadotropins in polycystic ovary syndrome: an analysis of 109 pregnancies in 225 women. Journal of Clinical Endocrinology and Metabolism 1996;81(11):3821-4.

\section{Zawadski 1992}

Zawadski JK, Dunaif A. Diagnostic criteria for polycystic ovary syndrome: Towards a rational approach. Boston: Blackwell Scientific Publications 1992:377-384.

* Indicates the major publication for the study

Abdellah 2011

Methods $\quad$ Randomised controlled trial

Duration and location of the trial: quote: "The present study was conducted from July 15,2007 , to February 28, 2010, at the Women's Health Center, Assiut University, Assiut, Egypt, after approval was received from the Ethics Committee of Assiut University."

Participants

Inclusion criteria: all participants met the Rotterdam consensus criteria for the diagnosis of PCOS. Other inclusion criteria included primary or secondary infertility because of anovulation for at least 1 year and clomiphene resistance. Clomiphene resistance was defined as lack of ovulation after 6 consecutive induction cycles with $50 \mathrm{mg}$ of CC, then with $150 \mathrm{mg}$ of CC each day for 5 days in each cycle. The male partner of each participant was required to have a normal result on semen analysis and each woman was required to have patent tubes on hysterosalpingography or on a diagnostic laparoscopy.

Exclusion criteria: exclusion criteria included age below 20 years or above 35 years; hormonal treatment within 3 months prior to the study; hyperprolactinaemia (morning plasma prolactin concentra- 
tion $30 \mathrm{ng} / \mathrm{ml}$ or more); any other endocrine, hepatic, or renal disorder; presence of an organic pelvic mass; and a history of abdominal surgery that might have caused pelvic factor infertility.

Number of women randomised: 147,74 in the letrozole group and 73 in the LOD group

Number of women analysed: 70 in the letrozole group and 70 in the LOD group

Number of withdrawals/exclusions/loss to follow-up and reasons: 7 women were lost to follow-up.

Number of centres: 1, Women's Health Center, Assiut University, Assiut

Age (y): group A letrozole: $23.9 \pm 3.2$, group B LOD: $23.6 \pm 3.2$

BMI (kg/m²): group A letrozole: $27.3 \pm 2.6$, group B LOD: $27.1 \pm 2.6$

Duration of infertility (y): group A letrozole: $4.2 \pm 1.7$, group B LOD: $4.2 \pm 1.7$

Country: Egypt

Group A: letrozole, $5 \mathrm{mg} /$ day given orally for 5 days during cycle days $3-7$ for up to 6 cycles
Group B: LOD, triple-puncture laparoscopy, monopolar diathermy, needle electrode set at $40 \mathrm{~W}$
pressed against border of ovary for $4 \mathrm{sec}$ to achieve penetration depths of 7 - $8 \mathrm{~mm}$, punctured at $4-6$
points

$\begin{array}{ll}\text { Outcomes } & \text { Primary outcomes: ovulation rate } \\ & \begin{array}{l}\text { Secondary outcomes: endometrial thickness on the day of hCG injection, rates of clinical pregnancy, } \\ \text { spontaneous abortion, live birth and multiple pregnancies }\end{array}\end{array}$

Notes Ethical approval: yes, the study was approved by Mansoura University Hospital Research Ethics Committee.

Informed consent: yes, all participants gave informed consent before inclusion in the trial.

Source of funding: not stated

Conflicts of interest: quote:"Conflict of interest statement: We declare that we have no conflict of interest"

Authors contacted about information on OHSS

Power calculation: quote: "the sample size required to detect a $25 \%$ difference between the 2 groups with a power of $80 \%$ was estimated to be 68 patients per group."

\section{Risk of bias}

\begin{tabular}{lll}
\hline Bias & Authors' judgement & Support for judgement \\
\hline $\begin{array}{l}\text { Random sequence genera- } \\
\text { tion (selection bias) }\end{array}$ & Low risk & $\begin{array}{l}\text { Randomisation was performed using a computer-generated random numbers } \\
\text { table. }\end{array}$ \\
\hline $\begin{array}{l}\text { Allocation concealment } \\
\text { (selection bias) }\end{array}$ & Low risk & $\begin{array}{l}\text { Allocation concealment was achieved using serially-numbered opaque en- } \\
\text { velopes that were only opened once the interventions were assigned. }\end{array}$ \\
\hline $\begin{array}{l}\text { Blinding of participants } \\
\text { and personnel (perfor- } \\
\text { mance bias) }\end{array}$ & Unclear risk & Not mentioned \\
$\begin{array}{l}\text { All outcomes } \\
\begin{array}{l}\text { Blinding of outcome as- } \\
\text { sessment (detection bias) }\end{array}\end{array}$ & Unclear risk & Not mentioned \\
\end{tabular}


Abdellah 2011 (Continued)

All outcomes

$\begin{array}{ll}\begin{array}{l}\text { Incomplete outcome data } \\ \text { (attrition bias) }\end{array} & \text { Low risk }\end{array}$

All outcomes

\begin{tabular}{lll}
\hline $\begin{array}{l}\text { Selective reporting (re- } \\
\text { porting bias) }\end{array}$ & Low risk & All expected outcomes reported \\
\hline Other bias & Low risk & None \\
\hline
\end{tabular}

\section{Abu Hashim 2010a}

\begin{tabular}{ll}
\hline Methods & Randomised controlled clinical trial \\
& Duration and location of the trial: quote: "The study comprised of 260 women with CC-resistant PCOS \\
among those attending the Outpatient Clinic in Mansoura University Hospitals, and a private practice \\
setting in the period from August 2006 to March 2009."
\end{tabular}

Participants

Inclusion criteria: infertile women with CC resistance and PCOS based on the Rotterdam criteria 2003. Patent fallopian tubes proved by hysterosalpingography and normal semen analysis for their partners according to the modified criteria of WHO.

Exclusion criteria: other causes of infertility, age over 40 years, BMI > 35, contraindication to general anaesthetic, previous history of LOD and women who had received metformin, gonadotropin, oral contraceptives or other hormonal drugs during the preceding 6 months. Women who intended to start a diet or a specific programme of physical activity were also excluded.

Number of centres: 2, outpatient clinic in Mansoura University hospitals and a private practice setting

Number of women randomised: 260, 128 in the letrozole group and 132 in the LOD group

Number of women analysed: 128 in the letrozole group and 132 in the LOD group

Number of withdrawals/exclusions/loss to follow-up and reasons: none

Age (y): group A letrozole: $27.3 \pm 2.6$, group B LOD: $26.4 \pm 2.4$

BMI ( $\left.\mathbf{k g} / \mathbf{m}^{2}\right)$ : group A letrozole: $26.4 \pm 3.3$, group B LOD: $26.6 \pm 3.6$

Duration of infertility $(\mathbf{y})$ : group A letrozole: $4.3 \pm 1.11$, group B LOD: $4.5 \pm 1.24$

Country: Egypt

Interventions

Group A: letrozole, $2.5 \mathrm{mg} /$ day orally given for 5 days starting from day 3 of the cycle

Group B: LOD, laparoscopy was performed using 3-puncture technique. Each ovary was cauterised at 4 points, each for $4 \mathrm{~s}$ at $40 \mathrm{~W}$ for a depth of $4 \mathrm{~mm}$ with a mixed current, using a monopolar electrosurgical needle.

Outcomes Primary outcome: ovulation rate

Secondary outcomes: midcycle endometrial thickness $(\mathrm{mm})$, biochemical pregnancy/cycle, clinical pregnancy/participant, biochemical miscarriage/cycle, clinical miscarriage/participant and live birth rates

Notes

Ethical approval: yes, the study was approved by Mansoura University Hospital Research Ethics Committee.

Informed consent: yes, all participants gave informed consent before inclusion in the trial. 
Abu Hashim 2010a (Continued)

Source of funding: not stated

Conflicts of interest: quote:"Conflict of interest statement: We declare that we have no conflict of interest"

Power calculation: quote: "Sample size was calculated based on the fact that with an expected rate of ovulation of $70 \%$ in the LOD group we needed 244 women to show an absolute increase of $15 \%$ in ovulation rate in the letrozole group, with a power of $80 \%$ at confidence interval of $95 \%$ using a two tailed chi-square test with a $5 \%$ significance level (type alfa error)."

We had contact with Prof. Abu Hashim, and all questions were answered in detail.

\section{Risk of bias}

\begin{tabular}{|c|c|c|}
\hline Bias & Authors' judgement & Support for judgement \\
\hline $\begin{array}{l}\text { Random sequence genera- } \\
\text { tion (selection bias) }\end{array}$ & Low risk & $\begin{array}{l}\text { Women were randomised according to a computer-generated random-numer- } \\
\text { ic table prepared by an independent statistician. }\end{array}$ \\
\hline $\begin{array}{l}\text { Allocation concealment } \\
\text { (selection bias) }\end{array}$ & Low risk & $\begin{array}{l}\text { Concealment of treatment allocation was done by using sealed opaque en- } \\
\text { velopes that were given to a third party (nurse) who assigned participants to } \\
\text { study arms. }\end{array}$ \\
\hline $\begin{array}{l}\text { Blinding of participants } \\
\text { and personnel (perfor- } \\
\text { mance bias) } \\
\text { All outcomes }\end{array}$ & High risk & $\begin{array}{l}\text { Quote: "Once allocated, the treatment was revealed to both the investigator } \\
\text { and the patient." }\end{array}$ \\
\hline $\begin{array}{l}\text { Blinding of outcome as- } \\
\text { sessment (detection bias) } \\
\text { All outcomes }\end{array}$ & High risk & $\begin{array}{l}\text { Quote: "Once allocated, the treatment was revealed to both the investigator } \\
\text { and the patient." }\end{array}$ \\
\hline $\begin{array}{l}\text { Incomplete outcome data } \\
\text { (attrition bias) } \\
\text { All outcomes }\end{array}$ & Low risk & No dropouts reported \\
\hline $\begin{array}{l}\text { Selective reporting (re- } \\
\text { porting bias) }\end{array}$ & Low risk & All expected outcomes reported \\
\hline Other bias & Low risk & None \\
\hline
\end{tabular}

Abu Hashim 2010b

Methods Randomised controlled clinical trial

Duration and location of the trial: quote: "The study comprised of 260 women with CC-resistant PCOS among those attending the Outpatient Clinic in Mansoura University Hospitals, and a private practice setting in the period from August 2006 to March 2009.“

Participants

Inclusion criteria: infertile women with PCOS based on the Rotterdam 2003 criteria. Additionally, diagnosed as CC-resistant, patent fallopian tubes proved by hysterosalpingography and normal semen analysis for their partners according to the modified criteria of WHO 1999

Exclusion criteria: none stated

Number of centres: 2, Outpatient clinic in Mansoura University hospitals and a private practice setting 
Abu Hashim 2010b (Continued)

Number of women randomised: 250, 123 in the letrozole group and 127 in the CC + metformin (met) group

Number of women analysed: 123 in the letrozole group and 127 in the $\mathrm{CC}+$ met group

Number of withdrawals/exclusions/loss to follow-up and reasons: 0

Age (y): group A letrozole: $28.3 \pm 2.7$, group B CC + met: $26.2 \pm 2.2$

BMI ( $\left.\mathbf{k g} / \mathbf{m}^{2}\right)$ : group A letrozole: $29.1 \pm 3.2$, group B CC + met: $30.1 \pm 2.3$

Duration of infertility $(\mathbf{y})$ : not stated

Country: Egypt

Interventions

Group A: letrozole $2.5 \mathrm{mg} /$ day for 5 days from cycle days 3 to 7

Group B: metformin $\mathrm{HCl}, 500 \mathrm{mg}$ thrice daily for 6 - 8 weeks, followed by $150 \mathrm{mg}$ of CC orally given for 5 days starting on day 3 of menstruation

Participants continued treatment for 3 successive cycles using the same protocol.

Outcomes

Primary outcomes: ovulation rate, number of growing and mature follicles, serum oestrogen, serum progesterone and endometrial thickness

Secondary outcomes: pregnancy and miscarriage rates, multiple pregnancies and cases of OHSS

Notes

Ethical approval: yes, the study was approved by the local research ethics committee.

Informed consent: yes, all participants gave informed consent before inclusion in the trial.

Source of funding: not stated

Conflicts of interest: quote: "All authors have nothing to disclose"

Power calculation: quote: "the sample size was based on the fact that for an expected rate of ovulation of $70 \%$ in the combined metformin-CC group we needed 244 women to show an absolute increase of $15 \%$ in ovulation rate in the letrozole group, with a power of $80 \%$ at confidence interval of $95 \%$ using a two-tailed $x^{2}$ test with a $5 \%$ significance level."

We had contact with Prof. Abu Hashim, and all questions were answered in detail.

\section{Risk of bias}

\begin{tabular}{lll}
\hline Bias & Authors' judgement & Support for judgement \\
\hline $\begin{array}{l}\text { Random sequence genera- } \\
\text { tion (selection bias) }\end{array}$ & Low risk & Computer-generated random table \\
\hline $\begin{array}{l}\text { Allocation concealment } \\
\text { (selection bias) }\end{array}$ & Low risk & $\begin{array}{l}\text { Quote: "Dark, sealed envelopes containing the intervention and taken from a } \\
\text { computer-generated random numeric table were prepared by a third party (in- } \\
\text { dependent statistician) not involved in the allocation process." }\end{array}$ \\
\hline $\begin{array}{l}\text { Blinding of participants } \\
\begin{array}{l}\text { and personnel (perfor- } \\
\text { mance bias) }\end{array}\end{array}$ & High risk & $\begin{array}{l}\text { Quote: "patients were not blinded because of the difference in shape, colour } \\
\text { and size of letrozole, CC and metformin tablets" (Email with Prof. Abu Hashim) }\end{array}$ \\
\hline $\begin{array}{l}\text { Blinding of outcome as- } \\
\text { sessment (detection bias) } \\
\begin{array}{ll}\text { All outcomes } \\
\hline\end{array}\end{array}$ & High risk & $\begin{array}{l}\text { It is not plausible that outcome assessors were blinded if participants were } \\
\text { not. }\end{array}$ \\
\hline
\end{tabular}


Abu Hashim 2010b (Continued)

Incomplete outcome data Low risk No dropouts reported
(attrition bias)

All outcomes

\begin{tabular}{lll}
\hline $\begin{array}{l}\text { Selective reporting (re- } \\
\text { porting bias) }\end{array}$ & Low risk & All expected outcomes reported \\
\hline Other bias & Low risk & None \\
\hline
\end{tabular}

Al-Omari 2004

Methods Randomised double blind clinical trial

Duration and location of the trial: not stated

Participants

Inclusion criteria: non-fertile clomiphene-resistant women with PCOS

Exclusion criteria: tubal, peritoneal and uterine causes of infertility were excluded by laparoscopic hysterosalpingogram or by ultrasonography. Specific endocrine abnormalities and male-factor causes for infertility were also excluded. Participants had to end clomiphene treatment at least 2 months before enrolment.

Number of centres: quote: "The study was done in the Baghdad teaching hospital/ Medical city which is a tertiary ref. hospital affiliated with Baghdad Med college/ University of Baghdad." (Email)

Number of women randomised: 22 in the letrozole group and 18 in the anastrozole group

Number of women analysed: 22 in the letrozole group and 18 in the anastrozole group

Number of withdrawals/exclusions/loss to follow-up and reasons: 0

Age (y): group A letrozole: $28.4 \pm 5.18$, group B anastrozole: $25.56 \pm 6.26$

BMI $\left(\mathbf{k g} / \mathbf{m}^{2}\right)$ : group A letrozole: $29.95 \pm 3.73$, group B anastrozole: $27.90 \pm 5.29$

Duration of infertility $(\mathbf{y})$ : group A letrozole: $3.95 \pm 2.70$, group B anastrozole: $4.50 \pm 3.61$

Country: Iraq

Interventions Group A: letrozole $2.5 \mathrm{mg} /$ day orally given for 5 days during cycle days 3 - 7

Group B: anastrozole $1 \mathrm{mg} /$ day orally given for 5 days during cycle days 3 - 7

Treatment was continued for 3 months. When ovulation or pregnancy did not occur, the same treatment protocol was used with the doubling of the first dose for a maximum of 2 treatment cycles.

Outcomes

Primary outcomes: ovulation rate/cycle, endometrial thickness $(\mathrm{mm})$ measured on day of hCG administration

Secondary outcomes: multiple pregnancy rate, pregnancy rate/cycle, E2 (pmol/l), progesterone (nmol/l), LH (U/l), number and size of follicles, pulsatility index, day of hCG administration

Notes

Ethical approval: quote: "Ethical approval was obtained from the Iraqi Board for medical specialization/ Scientific committee" (email contact)

Informed consent: quote: "written consent was obtained from all patients" (email contact)

Source of funding: quote: "The study was partially funded by the Iraqi Board for medical specialization as well as the Drug Scientific Office of the Iraqi Ministry of Health." 
Al-Omari 2004 (Continued)

Power calculation: not reported

We had email contact with Dr. Al-Omari, but there was no further information available about the outcomes.

\begin{tabular}{|c|c|c|}
\hline \multicolumn{3}{|l|}{ Risk of bias } \\
\hline Bias & Authors' judgement & Support for judgement \\
\hline $\begin{array}{l}\text { Random sequence genera- } \\
\text { tion (selection bias) }\end{array}$ & Low risk & $\begin{array}{l}\text { Quote: "Actually, we just put all envelopes in a box, mixing them then the pa- } \\
\text { tient herself selected one." (email with Dr. Al-Omari) }\end{array}$ \\
\hline $\begin{array}{l}\text { Allocation concealment } \\
\text { (selection bias) }\end{array}$ & Unclear risk & $\begin{array}{l}\text { Quote: "My associate informed me that for randomisation we distributed } \\
\text { blank envelops containing the medications at our Gyn.clinic on twice weekly } \\
\text { basis." (email with Dr. Al-Omari) }\end{array}$ \\
\hline $\begin{array}{l}\text { Blinding of participants } \\
\text { and personnel (perfor- } \\
\text { mance bias) } \\
\text { All outcomes }\end{array}$ & High risk & Participants were not blinded \\
\hline $\begin{array}{l}\text { Blinding of outcome as- } \\
\text { sessment (detection bias) } \\
\text { All outcomes }\end{array}$ & High risk & It is not plausible that outcome assessors were blinded if participants were not \\
\hline $\begin{array}{l}\text { Incomplete outcome data } \\
\text { (attrition bias) } \\
\text { All outcomes }\end{array}$ & Low risk & No dropouts reported \\
\hline $\begin{array}{l}\text { Selective reporting (re- } \\
\text { porting bias) }\end{array}$ & Low risk & All expected outcomes reported \\
\hline Other bias & Low risk & None \\
\hline
\end{tabular}

Amer 2017

$\begin{array}{ll}\text { Methods } & \text { Randomised double-blind controlled clinical trial } \\ & \text { Duration and location of the trial: quote: "This study was conducted at the Fertility Unit, Derby } \\ & \text { Teaching Hospitals NHS Foundation Trust between April } 2007 \text { and June 2014." }\end{array}$

Participants

Inclusion criteria: quote: "eligible participants were women aged 18 - 39 years with $\mathrm{BMI} \leq 35 \mathrm{~kg} / \mathrm{m} 2$, anovulatory infertility, and a diagnosis of PCOS based on Rotterdam consensus (two of three criteria: oligo-/anovulation, hyperandrogaenemia and sonographic appearance of polycystic ovaries) (Rotterdam ESHRE/ASRM-sponsored PCOS consensus workshop group, 2004). Diagnosis of oligo-/anovulation was based on a menstrual pattern of oligo-/amenorrhoea (cycle > 35 days) and/or a low mid-luteal serum progesterone concentration. Hyperandrogenaemia was diagnosed either clinically (acne/hirsutism) or biochemically (testosterone $\geq 2.5 \mathrm{nmol} / \mathrm{l}$ or free androgen index [FAl] $\geq 5$ ). Ultrasound criteria included $\geq 12$ follicles $(2-9 \mathrm{~mm}$ ) and/or an ovarian volume of $>10 \mathrm{ml}$ (Jonard et al., 2003). All participants had proven patency of at least one fallopian tube and normal semen analysis of their male partners (WHO, 1999)."

Exclusion criteria: quote: "We excluded patients who have received OI within 6 months and those with uncontrolled thyroid disease or hyperprolactinaemia. Patients with marked hyperandrogaenemia were screened for adult onset congenital adrenal hyperplasia (by measuring serum 17- $\alpha$-hydroxyl-progesterone concentration) and Cushing syndrome (by measuring urinary free cortisol)."

Number of women randomised: 159 women were randomised in total; 79 to CC, 80 to letrozole 
Number of women analysed: all women randomised were also analysed in the ITT analysis.

Number of withdrawals/exclusions/loss to follow-up and reasons: 3 women in the CC group discontinued treatment due to failing to attend; also 3 women discontinued treatment in the letrozole arm ( 1 due to social reasons, 1 failed to attend, 1 withdrew consent).

Number of centres: this was a single centre, 2-arm double-blind RCT.

Age (y): letrozole: 28.3 (4.4) vs CC: 28.1 (4.2)

BMI (kg/m²): letrozole: 27.5 (23.4 - 32.2) vs CC: 27.7 (23.0 - 31.0)

Duration of infertility $(y): 1.5(1.0-2.0)$ for both groups

Country: United Kingdom

Group A: letrozole was prescribed (by the senior investigator, SA) orally daily for 5 days starting on Days $2-4$ of a menstrual period or a progestogen-induced bleed (medroxy-progesterone acetate 10 $\mathrm{mg}$ twice daily for 5 days). The starting dose was 1 tablet/day (letrozole $2.5 \mathrm{mg}$ ) and if ovulation was not achieved, the dose would be doubled in the second cycle.

Group B: CC was prescribed daily for 5 days starting on days 2 - 4 of a menstrual period or a progestogen-induced bleed (medroxy-progesterone acetate $10 \mathrm{mg}$ twice daily for 5 days). The starting dose was 1 tablet/day $(50 \mathrm{mg}$ ) and if ovulation was not achieved, the dose would be doubled in the second cycle. Participants who failed to ovulate on the maximum dose (2 tablets) or to conceive after 6 ovulatory cycles were crossed over to the other drug (after a 6-week wash-out period) following the same procedures as with the first drug.

Outcomes

Primary outcomes: clinical pregnancy (diagnosed by ultrasonographic visualisation of a gestational sac) rate per participant on primary treatment (before the cross-over).

Secondary outcomes: secondary outcomes included ovulation, live birth, pregnancy by ovulating participant, pregnancy by strata, mono-ovulation, endometrial development (thickness and grades), pregnancy outcome and pregnancy complications. Other outcomes included pregnancy and live birth rates on secondary and overall (primary and secondary) treatments.

Notes

Ethical approval: the trial was approved by West Midlands Research Ethics Committee (Reference: 07/ MRE07/5) and by the Medicines and Healthcare Products Regulatory Agency (MHRA).

Informed consent: all participants gave written informed consent and the trial was monitored by the sponsor.

Source of funding: it was sponsored by the University of Nottingham.

Power calculation: quote: "to detect a clinically significant difference of $20 \%$ between the previously reported pregnancy rate of $\mathrm{CC}(\sim 35 \%)$ and letrozole with a two-sided $5 \%$ significance level and power of $80 \%$, a sample size of 212 participants (106 per arm) was required (Dickey and Holtkamp, 1996;Kousta et al., 1997; Imani et al., 2002)."

\section{Risk of bias}

\begin{tabular}{lll}
\hline Bias & Authors' judgement & Support for judgement \\
\hline $\begin{array}{l}\text { Random sequence genera- } \\
\text { tion (selection bias) }\end{array}$ & Low risk & $\begin{array}{l}\text { Quote: "An independent pharmacist randomly allocated participants to letro- } \\
\text { zole or CC, in } 1: 1 \text { ratio according to a randomisation list created by the trial } \\
\text { statistician using NQuery Advisor v6.0 software. Randomization was stratified } \\
\left.\text { by patients' BMI (non-obese }<30 \mathrm{~kg} / \mathrm{m}^{2} \text { and obese } 30-35 \mathrm{~kg} / \mathrm{m}^{2}\right) \mathrm{using} \text { mixed } \\
\text { block sizes." }\end{array}$ \\
\hline $\begin{array}{l}\text { Allocation concealment } \\
\text { (selection bias) }\end{array}$ & Low risk & $\begin{array}{l}\text { Quote: "An independent pharmacist randomly allocated participants to letro- } \\
\text { zole or CC, in } 1: 1 \text { ratio." }\end{array}$ \\
\hline
\end{tabular}


Amer 2017 (Continued)

$\begin{array}{ll}\text { Blinding of participants } & \text { Low risk } \\ \text { and personnel (perfor- } & \text { Quote: "Investigators, patients, outcome assessors and the statistician were } \\ \text { blinded to the allocation of participants." }\end{array}$
mance bias)

All outcomes

\begin{tabular}{|c|c|c|}
\hline $\begin{array}{l}\text { Blinding of outcome as- } \\
\text { sessment (detection bias) }\end{array}$ & Low risk & $\begin{array}{l}\text { Quote: "Investigators, patients, outcome assessors and the statistician were } \\
\text { blinded to the allocation of participants." }\end{array}$ \\
\hline
\end{tabular}

All outcomes

Incomplete outcome data Low risk

(attrition bias)

Quote: "Intention-to-treat (ITT) analysis included all randomised subjects,

All outcomes regardless of whether or not they received the study drug. Per protocol (PP) analysis included all randomised subjects who received the study drug and were not lost to follow-up. Participants who were lost to follow-up were assumed neither to be pregnant nor to have given LB in the ITT analysis."

\begin{tabular}{lll}
\hline $\begin{array}{l}\text { Selective reporting (re- } \\
\text { porting bias) }\end{array}$ & Low risk & All expected outcomes reported \\
\hline Other bias & Low risk & None \\
\hline
\end{tabular}

Atay 2006

\begin{tabular}{ll}
\hline Methods & Randomised controlled clinical trial \\
& Duration and location of the trial: not stated \\
\hline Participants & $\begin{array}{l}\text { Inclusion criteria: women with primary infertility and PCOS with no other known cause of infertility } \\
\text { were enrolled into the study. All participants had a history of oligo- or amenorrhoea and ovaries with at } \\
\text { least } 10 \text { subcapsular cysts } 2 \text { - } 10 \text { mm in diameter and hyperechogenic stroma. }\end{array}$
\end{tabular}

Exclusion criteria: none declared

Number of centres: setting unknown, tried to contact authors via email

Number of women randomised: 51 in the letrozole group and 55 in the CC group

Number of women analysed: 51 in the letrozole group and 55 in the CC group

Number of withdrawals/exclusions/loss to follow-up and reasons: 0

Age (y): group A letrozole: $27.1 \pm 0.9$, group B CC: $26.2 \pm 1.1$

BMI (kg/m²): group A letrozole: $26.1 \pm 1.9$, group B CC: $25.8 \pm 1.8$

Duration of infertility (y): group A letrozole: $2.2 \pm 0.7$, group B CC: $2.4 \pm 0.9$

Country: Turkey

Interventions Group A: letrozole, $2.5 \mathrm{mg} /$ day orally given for 5 days starting on cycle day 3

Group B: clomiphene citrate, $100 \mathrm{mg} /$ day orally given for 5 days starting on cycle day 3

Outcomes

Outcomes: number of mature follicles, endometrial thickness (mm), day of hCG administration, ovulation rate, pregnancy rate, multiple pregnancies

Notes

Ethical approval: yes, the study protocol was approved by the institutional ethics committee

Informed consent: yes, informed consent was obtained from all study participants 
Conflicts of interest: quote:"Conflicts of interest: No conflicts of interest were declared in relation to this article"

\section{Power calculation: not stated}

We contacted Dr. V Atay via email about the study setting, about how randomisation and allocation were done, blinding and if data are available on OHSS, miscarriage rate and live birth rate, but no response.

\section{Risk of bias}

\begin{tabular}{lll}
\hline Bias & Authors' judgement & Support for judgement \\
\hline $\begin{array}{l}\text { Random sequence genera- } \\
\text { tion (selection bias) }\end{array}$ & Unclear risk & Unclear how it was done \\
\hline $\begin{array}{l}\text { Allocation concealment } \\
\text { (selection bias) }\end{array}$ & Unclear risk & Unclear how it was done \\
\hline
\end{tabular}

Blinding of participants Unclear risk Not reported

and personnel (perfor-

mance bias)

All outcomes

Blinding of outcome as- $\quad$ Unclear risk $\quad$ Not reported
sessment (detection bias)
All outcomes

Incomplete outcome data Low risk No dropouts reported
(attrition bias)
All outcomes

All outcomes

Selective reporting (re- Unclear risk $\quad$ Protocol of the study was not available
porting bias)

Other bias Low risk None

Badawy 2008

Methods Randomised controlled trial

Duration and location of the trial: quote: "The study comprised of 220 women (574 cycles) with CCresistant PCOS among those attending the Fertility Outpatient Clinic in Mansoura University Hospitals, Mansoura University, Egypt, and a private practice setting in the period from May 2005 to January 2007."

Participants

Inclusion criteria: diagnosis of PCOS based on the revised 2003 consensus on diagnostic criteria and long-term health risks related to PCOS. All women were previously treated with $100 \mathrm{mg}$ of CC daily for 5 days each cycle, for 2 - 3 cycles with persistent anovulation or ovulate with very thin endometrium $<5$ $\mathrm{mm}$ at the time of $\mathrm{hCG}$ administration. They had patent fallopian tubes proved by hysterosalpingography and normal semen analysis for their partners according to the modified criteria of WHO.

Exclusion criteria: no exclusion criteria stated

Number of centres: 2, outpatient clinic in Mansoura University Hospitals and a private practice setting 
Number of women randomised: 111 in the letrozole group and 109 in the anastrozole group

Number of women analysed: 111 in the letrozole group and 109 in the anastrozole group

Number of withdrawals/exclusions/loss to follow-up and reasons: 0

Age (y): group A letrozole: $28.2 \pm 2.8$, group B anastrozole: $26.3 \pm 2.5$

BMI $\left(\mathbf{k g} / \mathbf{m}^{2}\right)$ : group A letrozole: $29.1 \pm 3.1$, group B anastrozole: $30.1 \pm 2.1$

Duration of infertility $(y)$ : not stated

Country: Egypt

Group B: anastrozole $1 \mathrm{mg} /$ day orally given for 5 days during cycle days 3 - 7

Treatment was continued for 3 months. $(\mathrm{ng} / \mathrm{mL})$, and endometrial thickness $(\mathrm{mm})$.

Secondary Outcomes: pregnancy rate, miscarriage rate, multiple pregnancy rate, ovarian hyperstimulation syndrome rate

Power calculation: not stated

\section{Risk of bias}

\begin{tabular}{|c|c|c|}
\hline Bias & Authors' judgement & Support for judgement \\
\hline $\begin{array}{l}\text { Random sequence genera- } \\
\text { tion (selection bias) }\end{array}$ & Low risk & $\begin{array}{l}\text { Participants were randomly allocated using a computer-generated random ta- } \\
\text { ble into } 2 \text { treatment groups }\end{array}$ \\
\hline $\begin{array}{l}\text { Allocation concealment } \\
\text { (selection bias) }\end{array}$ & Unclear risk & Not reported \\
\hline $\begin{array}{l}\text { Blinding of participants } \\
\text { and personnel (perfor- } \\
\text { mance bias) } \\
\text { All outcomes }\end{array}$ & Unclear risk & Not reported \\
\hline $\begin{array}{l}\text { Blinding of outcome as- } \\
\text { sessment (detection bias) } \\
\text { All outcomes }\end{array}$ & Unclear risk & Not reported \\
\hline $\begin{array}{l}\text { Incomplete outcome data } \\
\text { (attrition bias) } \\
\text { All outcomes }\end{array}$ & Low risk & No dropouts reported \\
\hline $\begin{array}{l}\text { Selective reporting (re- } \\
\text { porting bias) }\end{array}$ & Low risk & All expected outcomes reported \\
\hline Other bias & Low risk & None \\
\hline
\end{tabular}




Methods Randomised controlled study

Duration and location of the trial: quote: "The study comprised 438 women (1063 cycles) with PCOS among those attending the Fertility Outpatient Clinic in Mansoura University Hospitals, Mansoura University, Egypt, and private practices in the period from January 2004 and September 2006."

Participants

Inclusion criteria: infertile women with clomiphene-resistant PCOS, diagnosis of PCOS based on the 2003 Rotterdam criteria. Normal serum PRI, TSH and 17OH-P.

Exclusion criteria: infertility caused by fallopian tube problems, infertility problems caused by male partner

Number of centres: 2, outpatient clinic in Mansoura University Hospitals and a private practice setting

Number of women randomised: 110 in the short letrozole group and 108 in the long letrozole group

Number of women analysed: 110 in the short letrozole group and 108 in the long letrozole group

Number of withdrawals/exclusions/loss to follow-up and reasons: 0

Age (y): group A short letrozole: $25.1 \pm 3.2$, group B long letrozole: $25.3 \pm 3.0$

BMI $\left(\mathbf{k g} / \mathbf{m}^{2}\right)$ : group A short letrozole: $33.9 \pm 3.1$, group B long letrozole: $34.2 \pm 2.6$

Duration of infertility $(y)$ : not stated

Country: Egypt

Interventions

Group A: letrozole orally given, $5 \mathrm{mg} /$ day for 5 days, from cycle days 3 - 7

Group B: letrozole orally given, $2.5 \mathrm{mg} /$ day for 10 days, from cycle days 3 - 12

Outcomes

Primary Outcomes: number of growing and mature follicles, serum E2 $(\mathrm{pg} / \mathrm{mL})$, serum progesterone $(\mathrm{ng} / \mathrm{mL})$, and endometrial thickness $(\mathrm{mm})$

Secondary Outcomes: pregnancy rate, miscarriage rate, multiple pregnancies, OHSS

Notes Ethical approval: yes, the study was approved by the hospital ethics research committee.

Informed consent: yes, all participants gave informed consent before inclusion in the trial

Source of funding: not stated

Conflicts of interest: quote:"All authors have nothing to disclose"

Power calculation: quote: "Sample size calculation, using StatCalc 3.02 computer package 8Acastat software, Leesburg, VA), showed that each arm should contain at least 103 patients to have $80 \%$ power of the study at $95 \%$ confidence interval $(\mathrm{Cl}) . "$

We contacted the authors, but information on live birth was not collected.

\section{Risk of bias}

\begin{tabular}{lll}
\hline Bias & Authors' judgement & Support for judgement \\
\hline $\begin{array}{l}\text { Random sequence genera- } \\
\text { tion (selection bias) }\end{array}$ & Low risk & $\begin{array}{l}\text { Quote: "Patients were randomly allocated into two treatment groups using a } \\
\text { computer-generated random table: short letrozole group and long letrozole } \\
\text { group." }\end{array}$ \\
\hline
\end{tabular}


Badawy 2009a (Continued)

$\begin{aligned} & \text { Allocation concealment } \\ & \text { (selection bias) }\end{aligned}$
Unclear risk $\quad$ Not stated

Blinding of participants Unclear risk Not stated
and personnel (perfor-
mance bias)
All outcomes

\begin{tabular}{lll}
\hline $\begin{array}{l}\text { Blinding of outcome as- } \\
\text { sessment (detection bias) } \\
\text { All outcomes }\end{array}$ & Unclear risk & Not stated \\
\hline $\begin{array}{l}\text { Incomplete outcome data } \\
\begin{array}{l}\text { (attrition bias) } \\
\text { All outcomes }\end{array}\end{array}$ & Low risk & No dropouts reported \\
\hline $\begin{array}{l}\text { Selective reporting (re- } \\
\text { porting bias) }\end{array}$ & Low risk & All stated outcomes were reported \\
\hline Other bias & Low risk & None \\
\hline
\end{tabular}

\section{Badawy 2009b}

Methods
Prospective randomised trial
Duration and location of the trial: quote: "The study comprised 218 women (444 cycles) with
clomiphene-resistant PCOS among those attending the gynecology outpatient clinic in Mansoura Uni-
versity Hospitals, Egypt, and a private practice setting in the period from December 2005 to December
2007.“

\section{Participants}

Inclusion criteria: diagnosis of PCOS based on the 2003 Rotterdam criteria. All women had patent fallopian tubes proved by hysterosalpingography and their partners had normal semen analysis parameters according to the modified criteria of the WHO. All participants had normal serum prolactin, TSH and $17-\mathrm{OH}$ progesterone.

Exclusion criteria: not stated

Number of centres: multiple, University teaching hospital and private practices

Number of women randomised: 218 in the letrozole group and 220 in the CC group

Number of women analysed: 218 in the letrozole group and 220 in the CC group

Number of withdrawals/exclusions/loss to follow-up and reasons: 0

Age (y): group A letrozole: $27.1 \pm 3.2$, Group B clomiphene citrate: $29.3 \pm 2.9$

BMI $\left(\mathbf{k g} / \mathbf{m}^{2}\right)$ : group A letrozole: $28.1 \pm 3.2$, group B CC: $27.1 \pm 3.1$

Duration of infertility $(\mathbf{y})$ : not reported

Country: Egypt

Interventions

Group A: letrozole orally given $5 \mathrm{mg}$ /day for 5 days from cycle days 3 - 7

Group B: clomiphene citrate orally given $100 \mathrm{mg} /$ day for 5 days from cycle days 3 - 7 
Secondary Outcomes: ovulation rate, ovarian hyperstimulation rate, pregnancy rate, miscarriage rate, multiple pregnancy rate

Notes

Ethical approval: yes, the study was approved by the hospital research ethics committee.

Informed consent: yes, all participants gave informed consent before inclusion in the trial

Source of funding: the study was self-funded

Power calculation: not stated

Authors were contacted via email and gave all information, but they did not measure the live birth.

\section{Risk of bias}

\begin{tabular}{lll}
\hline Bias & Authors' judgement & Support for judgement \\
\hline $\begin{array}{l}\text { Random sequence genera- } \\
\text { tion (selection bias) }\end{array}$ & Low risk & $\begin{array}{l}\text { Participants were randomly allocated using a computer-generated random ta- } \\
\text { ble into 2 groups }\end{array}$ \\
\hline $\begin{array}{l}\text { Allocation concealment } \\
\text { (selection bias) }\end{array}$ & Low risk & $\begin{array}{l}\text { Quote: "Allocation concealment was done by sequentially numbered opaque } \\
\text { sealed envelopes opened by the chief nurse" (by email contact with authors) }\end{array}$ \\
\hline $\begin{array}{l}\text { Blinding of participants } \\
\text { and personnel (perfor- } \\
\text { mance bias) } \\
\text { All outcomes }\end{array}$ & High risk & Not blinded, email with Prof. Badawy \\
\hline
\end{tabular}

Blinding of outcome as-

High risk

It is not plausible that outcome assessors were blinded if participants were not sessment (detection bias)

All outcomes

\begin{tabular}{lll}
$\begin{array}{l}\text { Incomplete outcome data } \\
\text { (attrition bias) } \\
\text { All outcomes }\end{array}$ & Low risk & No dropouts reported \\
\hline $\begin{array}{l}\text { Selective reporting (re- } \\
\text { porting bias) }\end{array}$ & Low risk & All expected outcomes were reported, Live birth was not measured \\
\hline Other bias & Low risk & None
\end{tabular}

Bayar 2006

Methods Randomised controlled study

Duration and location of the trial: quote: "During the study period of 2004 through 2005, 80 patients with PCOS who attended the outpatient clinics of the Infertility and Reproductive Medicine Unit of the Zonguldak Karaelmas University Hospital (Zonguldak, Turkey) participated in this study.“

\section{Participants}

Inclusion criteria: women with anovulatory PCOS diagnosed by using 2003 Rotterdam criteria

Exclusion criteria: tubal, peritoneal and uterine cause of infertility. Male-factor infertility. Specific endocrine abnormalities (Cushings disease/syndrome, hypothyroidism, hyperthyroidism, prolactinoma)

Number of centres: 1, outpatient clinics of the Infertility and Reproductive Medicine Unit of the Zonguldak Karaelmas University Hospital (Zonguldak, Turkey)

Number of women randomised: 80,40 in group A letrozole and 40 in group B CC 
Number of women analysed: 38 in group A letrozole and 36 in group B CC

Number of withdrawals/exclusions/loss to follow-up and reasons: 6 lost to follow-up, no reasons given

Age (y): group A letrozole: $32.2 \pm 3.9$, group B CC: $30.6 \pm 4.0$

BMI $\left(\mathbf{k g} / \mathbf{m}^{2}\right):$ not stated

Duration of infertility (y): group A letrozole: 5 (1 - 10), group B CC: $3(3-11)$

Country: Turkey

$\begin{array}{ll}\text { Interventions } & \text { Group A: letrozole, } 5 \mathrm{mg} / \text { day orally given for } 5 \text { days during cycle days } 3-7 \\ & \text { Group B: clomiphene citrate, } 100 \mathrm{mg} / \text { day orally given for } 5 \text { days during cycle days } 3-7\end{array}$

\section{Outcomes}

Outcomes: ovulation rate by cycle, pregnancy rate by cycle, delivery rate by cycle, miscarriage rate, multiple pregnancy rate, endometrial thickness on the day of $\mathrm{hCG}(\mathrm{mm}), \mathrm{N}$ of follicles sized $>15 \mathrm{~mm}$ in diameter on the day of hCG, E2 level on the day of hCG (pg/mL), E2 per follicle sized > $15 \mathrm{~mm}$ in diameter on the day of hCG $(\mathrm{pg} / \mathrm{mL})$

Notes Ethical approval: yes, the study was approved by the institutional ethics committee of Karelmal university.

\section{Informed consent: not stated}

Source of funding: no funding source or conflicts of interest stated

Power calculation: Sample-size determination was based on the difference between the median number of follicles sized > $15 \mathrm{~mm}$ and E2 concentration on hCG day. A sample size of 60 participants ( 30 in each group) was targeted to be able to detect a difference of at least one follicle or of $200 \mathrm{pmol} / \mathrm{L}$ between the 2 groups, with alfa (type I error) set at 0.05 and $80 \%$ power.

We contacted Dr. Bayar by email for additional information, but he did not respond.

\section{Risk of bias}

\begin{tabular}{lll}
\hline Bias & Authors' judgement & Support for judgement \\
\hline $\begin{array}{l}\text { Random sequence genera- } \\
\text { tion (selection bias) }\end{array}$ & Low risk & Simple randomisation performed by a computer \\
\hline $\begin{array}{l}\text { Allocation concealment } \\
\text { (selection bias) }\end{array}$ & Unclear risk & $\begin{array}{l}\text { Allocation concealment was achieved by using central consultation for treat- } \\
\text { ment of eligible participants. }\end{array}$ \\
\hline $\begin{array}{l}\text { Blinding of participants } \\
\text { and personnel (perfor- } \\
\text { mance bias) }\end{array}$ & Unclear risk & $\begin{array}{l}\text { Stated as double-blind but it is not clear who was actually blinded and how } \\
\text { this was achieved }\end{array}$ \\
\hline $\begin{array}{l}\text { Blinding outcomes outcome as- } \\
\text { sessment (detection bias) } \\
\text { All outcomes }\end{array}$ & Unclear risk & $\begin{array}{l}\text { Stated as double-blind but it is not clear who was actually blinded and how } \\
\text { this was achieved }\end{array}$ \\
\hline $\begin{array}{l}\text { Incomplete outcome data } \\
\text { (attrition bias) } \\
\text { All outcomes }\end{array}$ & Low risk & 6 participants lost to follow-up, 4 and 2 respectively \\
\hline $\begin{array}{l}\text { Selective reporting (re- } \\
\text { porting bias) }\end{array}$ & Low risk & All expected outcomes reported \\
\hline \hline
\end{tabular}


Bayar 2006 (Continued)
Other bias
Low risk
None

Begum 2009

Methods Randomised non-blinded controlled trial

Duration and location of the trial: quote: "The study was conducted in a private infertility care setting as a randomized controlled trial between August 2004 and December 2005."

Participants Inclusion criteria: infertile women with PCOS diagnosed by the Rotterdam criteria 2003 who failed to ovulate by taking $100 \mathrm{mg}$ of CC/day for 5 days in 2 consecutive cycles

Exclusion criteria: women with hyperprolactinaemia, thyroid disorder, male-factor infertility, known or suspicious tubal factor infertility (endometriosis and pelvic inflammatory disease), and unexplained infertility were excluded from the study.

Number of centres: 1 , private infertility care setting

Number of women randomised: 32 in each group

Number of women analysed: 32 in each group

Number of withdrawals/exclusions/loss to follow-up and reasons: 0

Age (y): group A letrozole: $25.5 \pm 4.0$, group B clomiphene citrate: $26.1 \pm 3.6$

BMI ( $\left.\mathbf{k g} / \mathbf{m}^{2}\right)$ : group A letrozole: $22.7 \pm 2.8$, group B clomiphene citrate: $23.6 \pm 3.2$

Duration of infertility (y): group A letrozole: $2.7 \pm 1.1$, group B clomiphene citrate: $2.6 \pm 1.1$

Country: India

Interventions

Group A: letrozole, $7.5 \mathrm{mg} /$ day orally given for 5 days from cycle days 3 - 7

Group B: clomiphene citrate, $150 \mathrm{mg} /$ day orally given for 5 days from cycle days 3 - 7

Outcomes

Primary Outcomes: ovulation and pregnancy rate

Secondary Outcomes: follicular development by day $16(\mathrm{~mm})$, serum E2 on day of hCG $(\mathrm{pg} / \mathrm{mL})$, endometrial development by day $16(\mathrm{~mm})$, serum progesterone on day $21(\mathrm{ng} / \mathrm{mL})$, multiple pregnancies, OHSS cases. Live birth rate was provided by email contact.

Notes Ethical approval: yes, the study protocol was approved by the institutional review board (IRB) of Dhaka medical college.

Informed consent: yes, participants were counselled and informed consent was obtained before recruitment.

Source of funding: the study was self-funded.

Power calculation: a study population of 57 women was calculated, considering an average of $60 \%$ of PCOS women are associated with insulin resistance, allowing an alfa value of 0.05 .

Authors were contacted by email, and additional information was provided.

\section{Risk of bias}

Bias Authors' judgement Support for judgement


Begum 2009 (Continued)

Random sequence genera- Low risk Randomisation was done by lottery method. They put the name of letrozole tion (selection bias) and $\mathrm{CC}$ in a sealed opaque envelope. By calculating sample size they made 64 pieces of paper, 32 for letrozole and 32 for CC.

\section{Allocation concealment Unclear risk} (selection bias)

Quote: "All unleveled envelop were put together and the patients drew one piece of envelop from them. Then we opened the envelop to see the name of the drug." (by email contact with Prof. Rashida)

Blinding of participants High risk Quote: "There was no blinding" (by email contact with Prof. Rashida)

and personnel (perfor-

mance bias)

All outcomes

\begin{tabular}{lll}
\hline $\begin{array}{l}\text { Blinding of outcome as- } \\
\text { sessment (detection bias) } \\
\text { All outcomes }\end{array}$ & High risk & Quote: "There was no blinding" (email with Prof. Rashida) \\
\hline $\begin{array}{l}\text { Incomplete outcome data } \\
\begin{array}{l}\text { (attrition bias) } \\
\text { All outcomes }\end{array}\end{array}$ & Low risk & No dropouts \\
\hline $\begin{array}{l}\text { Selective reporting (re- } \\
\text { porting bias) }\end{array}$ & Low risk & All outcomes reported \\
\hline Other bias & Low risk & None
\end{tabular}

\section{Chen 2016}

Methods Randomised controlled study

Duration and location of the trial: quote: "All patients were admitted in our hospital between January 2013 and January 2015, who were not pregnant without contraception for over one year." tic criteria of the 2003 Rotterdam Conference, i.e. at least two of the following three were met: 1) ovulation abnormality (sporadic ovulation or no ovulation) occurred after continuous monitoring for two or more natural cycles; 2 ) the results of B ultrasound showed polycystic ovary; 3 ) patients had hyperandrogenism or showed clinical manifestations of androgen excess. Through salpingography or hydrotubation under transvaginal B ultrasound and other examinations, all cases were confirmed to have tubal patency on at least one side. The semen of male was normal."

Exclusion criteria: quote:"Those with androgen excess caused by other diseases such as adrenal hyperplasia Cushing's syndrome and androgen-secreting tumours were excluded. Exclusion criteria: 1) Infertility patients caused by non-PCOS ovulatory disorder or other factors; 2) patients with history of ovarian surgery or complication with endometriosis or pelvic adhesion; 3) patients complicated with liver, kidney or thyroid dysfunction; 4) patients who did not receive treatment after enrolment according to the established regimen or gave up in the midst of treatment."

Number of women randomised: 156 patients, 52 in each group

Number of women analysed: 156 patients, 52 in each group

Number of withdrawals/exclusions/loss to follow-up and reasons: none reported

Number of centres: single-centre trial

Age (y): letrozole group $26.4 \pm 4.2$; CC group $27.1 \pm 4.7$; letrozole + HMG group $27.7 \pm 5.2$ years 
Chen 2016 (Continued)

BMI $\left(\mathbf{k g} / \mathbf{m}^{2}\right)$ : letrozole group $22.4 \pm 4.5$; CC group $23.4 \pm 1.5$; letrozole + HMG group $22.6 \pm 2.6$ years

Duration of infertility (y): letrozole group $3.4 \pm 1.1$; CC group $3.2 \pm 0.7$; letrozole + HMG group $3.3 \pm 1.3$ years

Country: China

Interventions

Group A (letrozole): the participants orally took 2.5 - $5.0 \mathrm{mg} / \mathrm{d}-1 \mathrm{LE}$ (trade name: Fu Rui, Jiangsu Hengrui Medicine Co., Ltd.) on the 3rd - 5th days of menstrual cycle for 5 consecutive days.

Group B (CC group): the participants were orally administered with 50 - $100 \mathrm{mg} / \mathrm{d}-1 \mathrm{CC}$ (trade name: Fertilan, Codal Synto Pharmaceutical Co., Ltd.) on the 3rd - 5th days of menstrual cycle for 5 consecutive days.

Group C (letrozole + HMG group): the participants orally took $2.5-5.0 \mathrm{mg} / \mathrm{d}-1 \mathrm{LE}$ on the $3 \mathrm{rd}$ - 5 th days of menstrual cycle for 5 consecutive days. Starting from the day of oral administration of CC, 75 IU HMG (trade name: Lebaode, Livzon Group Livzon Pharmaceutical Co. Ltd.) was intramuscularly injected every other day for 5 consecutive days.

Outcomes

Primary outcomes: clinical pregnancy, defined as a fetal heart beat visible via transvaginal ultrasound on 30th day after ovulation

Secondary outcomes: OHSS, miscarriage, multiple pregnancy

Notes

Ethical approval: this study has been approved by the ethics committee of our hospital.

Informed consent: written consent has been obtained from all patients.

Source of funding: quote: "None"

Power calculation: no power calculation was reported.

\section{Risk of bias}

\begin{tabular}{|c|c|c|}
\hline Bias & Authors' judgement & Support for judgement \\
\hline $\begin{array}{l}\text { Random sequence genera- } \\
\text { tion (selection bias) }\end{array}$ & Unclear risk & $\begin{array}{l}\text { Quote: " the patients were randomly divided into an LE group, a CC group and } \\
\text { an LE + HMG group" }\end{array}$ \\
\hline $\begin{array}{l}\text { Allocation concealment } \\
\text { (selection bias) }\end{array}$ & Unclear risk & Not reported \\
\hline $\begin{array}{l}\text { Blinding of participants } \\
\text { and personnel (perfor- } \\
\text { mance bias) } \\
\text { All outcomes }\end{array}$ & Unclear risk & Not reported \\
\hline $\begin{array}{l}\text { Blinding of outcome as- } \\
\text { sessment (detection bias) } \\
\text { All outcomes }\end{array}$ & Unclear risk & Not reported \\
\hline $\begin{array}{l}\text { Incomplete outcome data } \\
\text { (attrition bias) } \\
\text { All outcomes }\end{array}$ & Low risk & All participants randomised were also analysed. \\
\hline $\begin{array}{l}\text { Selective reporting (re- } \\
\text { porting bias) }\end{array}$ & Low risk & No study protocol was found, but all outcomes reported were also analysed. \\
\hline Other bias & Low risk & None \\
\hline
\end{tabular}


Davar 2011

Single-blind randomised clinical trial
Duration and location of the trial: quote: "In this single blind randomized trial, 148 ovarian cycles
were studied in 100 clomiphene- resistance patients with PCOS who were chosen among 250 PCOS pa-
tients attending the Research and Clinical Center for Infertility, Shahid Sadoughi University of Medical
Sciences, Yazd, Iran during the years 2007-2008."

Participants Inclusion criteria: women who received $150 \mathrm{mg}$ CC daily for 3 cycles and failed to become pregnant, and were diagnosed with anovulatory PCOS based on Rotterdam 2003.

Exclusion criteria: quote: "We excluded patients with liver and kidney dysfunction, cardiovascular disease, diabetics, and those who use metformin or drugs affecting insulin secretion and clomiphene citrate in recent 2 cycles."

Number of centres: 1, research and clinical centre for infertility, Shahid Sadoughi University of Medical Sciences, Yazd

Number of women randomised: 100 women, 50 in group A met-letrozole, 50 in group B met-CC

Number of women analysed: 48 in group A met-letrozole, 50 in group B met-CC

Number of withdrawals/exclusions/loss to follow-up and reasons: 2, experienced side effects with metformin before letrozole was started

Age (y): group A metformin-letrozole: $28.5 \pm 3.1$, group B metformin-clomiphene citrate: $29.6 \pm 3.5$

BMI $\left(\mathbf{k g} / \mathbf{m}^{2}\right)$ : group A met-letrozole: $29.0 \pm 3.8$, group B met-CC: $29.2 \pm 2.9$

Duration of infertility (y): group A met-letrozole: 3.8 , group B met-CC: 3.8

Country: Iran

Interventions

Group A: metformin $1500 \mathrm{mg}$ daily for 6 - 8 weeks, followed by $5 \mathrm{mg}$ letrozole daily orally given for 5 days during cycle days 3 - 7 if pregnancy did not occur

Group B: metformin $1500 \mathrm{mg}$ daily for 6 - 8 weeks, followed by $100 \mathrm{mg}$ CC daily orally given for 5 days during cycle days 3 - 7 if pregnancy did not occur

Outcomes $\quad E 2(\mathrm{pg} / \mathrm{mL})$ on day of $\mathrm{hCG}$ administration, number of follicles $>18 \mathrm{~mm}$ in diameter, endometrial thickness on day of hCG administration $(\mathrm{mm})$, clinical pregnancy rate, miscarriage rate

Notes

SEthical approval: yes, the study was approved by ethical board of Shahid Sagoughi University of Medical Sciences, Yazd.

Informed consent: no, at least nothing written about it - authors contacted

Source of funding: quote: "the study was fully supported and funded by Shahid Sadoughi University of Medical Sciences, Yazd, Iran”

Power calculation: quote: "In this study, 50 cases were needed in each group so as to gain a significant difference of $22 \%$ in pregnancy rate at a significant level of $5 \%$ and a power of $80 \% "$

We contacted Dr Davar by email to get additional information, but we did not get a response.

\section{Risk of bias}

\begin{tabular}{lll}
\hline Bias & Authors' judgement & Support for judgement \\
\hline $\begin{array}{l}\text { Random sequence genera- } \\
\text { tion (selection bias) }\end{array}$ & Low risk & Randomisation was done using a random-numbers table \\
\hline \hline
\end{tabular}


Davar 2011 (Continued)

\begin{tabular}{|c|c|c|}
\hline $\begin{array}{l}\text { Allocation concealment } \\
\text { (selection bias) }\end{array}$ & Unclear risk & Not stated \\
\hline $\begin{array}{l}\text { Blinding of participants } \\
\text { and personnel (perfor- } \\
\text { mance bias) } \\
\text { All outcomes }\end{array}$ & Unclear risk & Not stated who was blinded in this single-blinded trial \\
\hline $\begin{array}{l}\text { Blinding of outcome as- } \\
\text { sessment (detection bias) } \\
\text { All outcomes }\end{array}$ & Unclear risk & Not stated who was blinded in this single-blinded trial \\
\hline $\begin{array}{l}\text { Incomplete outcome data } \\
\text { (attrition bias) } \\
\text { All outcomes }\end{array}$ & Low risk & $\begin{array}{l}2 \text { participants lost to follow-up due to side effects experienced with metformin } \\
\text { before letrozole was started. }\end{array}$ \\
\hline $\begin{array}{l}\text { Selective reporting (re- } \\
\text { porting bias) }\end{array}$ & Low risk & All outcomes reported stated in the protocol \\
\hline Other bias & Low risk & None \\
\hline
\end{tabular}

Dehbashi 2009

Methods
Duration and location of the trial: quote: "During the period of February 2004 through November
2006, 100 patients with PCOS who attended the outpatient infertility clinics at Shiraz University of Med-
ical Sciences participated in the present study."

Participants Inclusion criteria: infertility for at least 1 year, diagnosis of PCOS by the Rotterdam criteria 2003, having patent tubes on hysterosalpingogram, and normal semen analysis of the husband

Exclusion criteria: participants must not have received any other medication for ovulation induction before enrolment into the study.

Number of centres: 1 , outpatient infertility clinics at Shiraz University of Medical Sciences

Number of women randomised: 100 women, 50 in each group

Number of women analysed: 100 women, 50 in each group

Number of withdrawals/exclusions/loss to follow-up and reasons: 0

Age (y): group A letrozole: $23.6 \pm 2.9$, group B CC: $24.3 \pm 3.4$

BMI $\left(\mathbf{k g} / \mathbf{m}^{2}\right)$ : group A letrozole: $27.5 \pm 4.6$, group B CC: $27.1 \pm 3.6$

Duration of infertility $(\mathbf{y})$ : group A letrozole: $2.0 \pm 1.3$, group B CC: $2.3 \pm 1.9$

Country: Iran

Interventions Group A: letrozole, $5 \mathrm{mg} /$ day orally given for 5 days during cycle days 3 - 7

Group B: clomiphene citrate, $100 \mathrm{mg} /$ day orally given for 5 days during cycle days 3 - 7

\section{Outcomes}

Total number of follicles with diameter $\geq 14 \mathrm{~mm}$, endometrial thickness on the day of hCG injection, pregnancy rate, miscarriage rate, multiple pregnancy rate, live birth rate 
Dehbashi 2009 (Continued) Notes
Ethical approval: yes, quote: "The study was approved by the Institutional Ethics Committee of the University."

Informed consent: yes, quote: "An informed written consent was obtained from each patient"

Source of funding: not stated

Conflicts of interest: quote: "Conflicts of interest: None declared"

Power calculation: not stated

Authors contacted about randomisation, allocation, and information about OHSS

\section{Risk of bias}

\begin{tabular}{|c|c|c|}
\hline Bias & Authors' judgement & Support for judgement \\
\hline $\begin{array}{l}\text { Random sequence genera- } \\
\text { tion (selection bias) }\end{array}$ & Unclear risk & Not stated how it was done \\
\hline $\begin{array}{l}\text { Allocation concealment } \\
\text { (selection bias) }\end{array}$ & Unclear risk & Not stated \\
\hline $\begin{array}{l}\text { Blinding of participants } \\
\text { and personnel (perfor- } \\
\text { mance bias) } \\
\text { All outcomes }\end{array}$ & Low risk & $\begin{array}{l}\text { Only the pharmacist knew the name of the medication that had been taken by } \\
\text { the participants. }\end{array}$ \\
\hline $\begin{array}{l}\text { Blinding of outcome as- } \\
\text { sessment (detection bias) } \\
\text { All outcomes }\end{array}$ & Low risk & $\begin{array}{l}\text { Only the pharmacist knew the name of the medication that had been taken by } \\
\text { the participants. }\end{array}$ \\
\hline $\begin{array}{l}\text { Incomplete outcome data } \\
\text { (attrition bias) } \\
\text { All outcomes }\end{array}$ & Low risk & No participants excluded or lost to follow-up \\
\hline $\begin{array}{l}\text { Selective reporting (re- } \\
\text { porting bias) }\end{array}$ & Low risk & All expected outcomes reported \\
\hline Other bias & Low risk & None \\
\hline
\end{tabular}

\section{El-Gharib 2015}

\begin{tabular}{ll}
\hline Methods & Randomised controlled trial \\
& Duration and location of the trial: quote: "This prospective intervention study was performed during \\
the period from January 2010 till August 2012 at the outpatient clinic of Tanta University Hospital."
\end{tabular}

Participants

Inclusion criteria: the most important inclusion criteria were fulfilment of at least 2 of Rotterdam criteria of PCOS, negative history of medical problems that can affect fertility such as diabetes mellitus, thyroid dysfunction, hyperprolactinaemia, congenital adrenal hyperplasia, normal hysterosalpingography and BMI between 20 and 30 .

Exclusion criteria: history of medical problems which affect fertility, history of recent hormonal therapy, having pelvic infections and/or having abnormal laboratory findings other than PCOS findings. Women whose husbands had defective semen were also excluded.

Number of women randomised: 60 participants, 30 in each group 
Number of women analysed: 60 participants analysed

Number of withdrawals/exclusions/loss to follow-up and reasons: no participants were lost to follow-up.

Number of centres: 1 , single-centre trial

Age (y): letrozole $26.2 \pm 0.9$; tamoxifen $26.9 \pm 1.1$

BMI $\left(\mathbf{k g} / \mathbf{m}^{2}\right)$ : letrozole $27.7 \pm 4.1$; tamoxifen $28.4 \pm 3.8$

Duration of infertility $(\mathbf{y})$ : letrozole $3.2 \pm 2.7$; tamoxifen $3.0 \pm 2.1$

Country: Egypt

Interventions

Group A: letrozole (Femara; Novartis) $2.5 \mathrm{mg}$ /day given from day 5 - 9 of the menstrual cycle, for 3 successive cycles

Group B: TMX 20 mg/day given from day 5 - 9 of the menstrual cycle, for 3 successive cycles

\begin{tabular}{|c|c|c|}
\hline Outcomes & \multicolumn{2}{|c|}{ Pregnancy rate, follicular growth, endometrial thickness, cumulative ovulation } \\
\hline \multirow[t]{4}{*}{ Notes } & \multicolumn{2}{|c|}{$\begin{array}{l}\text { Ethical approval: the study was approved by the institutional ethics committee of Tanta Faculty of } \\
\text { Medicine. }\end{array}$} \\
\hline & \multicolumn{2}{|c|}{$\begin{array}{l}\text { Informed consent: all women subjected to history taking, physical examination, counselling and sign- } \\
\text { ing a written consent }\end{array}$} \\
\hline & \multicolumn{2}{|c|}{ Source of funding: not reported } \\
\hline & \multicolumn{2}{|c|}{ Power calculation: not reported } \\
\hline \multicolumn{3}{|l|}{ Risk of bias } \\
\hline Bias & Authors' judgement & Support for judgement \\
\hline $\begin{array}{l}\text { Random sequence genera- } \\
\text { tion (selection bias) }\end{array}$ & Unclear risk & $\begin{array}{l}\text { Methods of randomisation were not sufficiently described: quote: "arranged at } \\
\text { random, by sealed envelopes" }\end{array}$ \\
\hline $\begin{array}{l}\text { Allocation concealment } \\
\text { (selection bias) }\end{array}$ & Unclear risk & Not reported \\
\hline $\begin{array}{l}\text { Blinding of participants } \\
\text { and personnel (perfor- } \\
\text { mance bias) } \\
\text { All outcomes }\end{array}$ & Unclear risk & Not reported \\
\hline
\end{tabular}

Blinding of outcome as- Unclear risk Not reported
sessment (detection bias)

All outcomes

Incomplete outcome data Low risk
(attrition bias)

All outcomes

\begin{tabular}{lll}
\hline $\begin{array}{l}\text { Selective reporting (re- } \\
\text { porting bias) }\end{array}$ & Low risk & All expected outcomes reported \\
\hline Other bias & Low risk & None \\
\hline
\end{tabular}




Methods Randomised double-blind controlled trial

Duration and location of the trial: quote: "A prospective double-blind randomized controlled trial was conducted at the Teaching University Hospital of Cairo University, Cairo, Egypt, between August 1, 2013, and December 31, 2014.“

Participants

Inclusion criteria: quote: "eligible women were younger than 40 years, had primary or secondary infertility associated with PCOS, and had not ovulated in response to three cycles of $150 \mathrm{mg}$ clomiphene citrate every day for 5 days from day 3 of the menstrual cycle. PCOS diagnoses were based on the revised 2003 Rotterdam consensus criteria. The presence of at least two of the following characteristics was considered diagnostic of PCOS: oligo ovulation or anovulation; hyperandrogenism; and polycystic ovaries detected using vaginal ultrasonography."

Exclusion criteria: quote: "exclusion criteria were other factors of infertility, diabetes mellitus, hypertension, liver or kidney malfunction, heart disease, urinary symptoms, persistent hyperprolactinaemia, thyroid dysfunction, gonadotropin induction, and previous ovarian drilling. Male factor infertility was defined as a sperm count of less than $15 \times 10^{\wedge} 6 / \mathrm{mL}$, a total motility of less than $40 \%$, or normal morphology of less than $4 \%$. Tubal factor infertility was confirmed by hysterosalpingography."

Number of women randomised: 100 women were randomised.

Number of women analysed: 100 women were analysed, 50 in each group

Number of withdrawals/exclusions/loss to follow-up and reasons: none

Number of centres: single centre

Age (y): CC $26.6 \pm 2.9$; letrozole $25.8 \pm 3.6$

BMI $\left(\mathbf{k g} / \mathbf{m}^{2}\right):$ CC $26.6 \pm 2.7$; letrozole $26.5 \pm 2.8$

Duration of infertility (y): CC $3.1 \pm 1.4$; letrozole $2.7 \pm 1.6$

Country: Egypt

Interventions

Group A: (control group) received $100 \mathrm{mg}$ clomiphene citrate, given as $2 \times 50 \mathrm{mg}$ tablets daily for 5 days from the third day of the menstrual cycle.

Group B: $5 \mathrm{mg}$ letrozole, given as $2 \times 2.5 \mathrm{mg}$ tablets daily for 5 days from the third day of the menstrual cycle.

Participants in both groups also received metformin and pioglitazone, which was taken daily as 1 tablet containing $850 \mathrm{mg}$ metformin and $15 \mathrm{mg}$ pioglitazone, for 10 days starting from the first day of the menstrual cycle.

Outcomes

Primary outcome measure: cumulative ovulation rate (proportion of cycles in which ovulation occurred in the whole follow-up period).

Other outcome measures: number of follicles $\geq 18 \mathrm{~mm}$ in size, endometrial thickness and serum estradiol levels on the day of hCG administration, serum progesterone level on day 21, and rate of clinical pregnancy (at least 1 intrauterine gestational sac detected)

Ethical approval: approved by the research ethics committee of the teaching University Hospital of Cairo University

Informed consent: all participants signed a written informed consent form.

Source of funding: Cairo University

Power calculation: Previous data indicated that the ovulation rate in group A would be $62 \%$. If the ovulation rate for the letrozole, metformin, and pioglitazone (experimental) group was $87 \%$ (previous unpublished data from the study unit), a total of 47 women would have to be recruited to each group 
El-Khayat 2016 (Continued)

to ensure a sufficiently powered study. Assuming an attrition of $10 \%$, the total number of patients to be recruited was 50 per group. Intention-to-treat analyses were planned.

\begin{tabular}{|c|c|c|}
\hline \multicolumn{3}{|l|}{ Risk of bias } \\
\hline Bias & Authors' judgement & Support for judgement \\
\hline $\begin{array}{l}\text { Random sequence genera- } \\
\text { tion (selection bias) }\end{array}$ & Low risk & $\begin{array}{l}\text { Quote: "Enrolled women were randomly allocated using computer-generated } \\
\text { random number tables (block size four)" }\end{array}$ \\
\hline $\begin{array}{l}\text { Allocation concealment } \\
\text { (selection bias) }\end{array}$ & Low risk & $\begin{array}{l}\text { Quote: "Opaque sealed envelopes containing group allocations were prepared } \\
\text { at a separate location every } 24 \text { hours. These envelopes were sent to an as- } \\
\text { signed nurse, who opened them before commencing ovulation induction" }\end{array}$ \\
\hline $\begin{array}{l}\text { Blinding of participants } \\
\text { and personnel (perfor- } \\
\text { mance bias) } \\
\text { All outcomes }\end{array}$ & Low risk & $\begin{array}{l}\text { Quote: "Participants, the staff who conducted follow-up, and data analysts } \\
\text { were masked to the allocation to avoid bias" }\end{array}$ \\
\hline $\begin{array}{l}\text { Blinding of outcome as- } \\
\text { sessment (detection bias) } \\
\text { All outcomes }\end{array}$ & Low risk & $\begin{array}{l}\text { Quote: "Participants, the staff who conducted follow-up, and data analysts } \\
\text { were masked to the allocation to avoid bias" }\end{array}$ \\
\hline $\begin{array}{l}\text { Incomplete outcome data } \\
\text { (attrition bias) } \\
\text { All outcomes }\end{array}$ & Low risk & No participants were lost to follow-up \\
\hline $\begin{array}{l}\text { Selective reporting (re- } \\
\text { porting bias) }\end{array}$ & Low risk & All expected outcomes were reported \\
\hline Other bias & Low risk & None \\
\hline
\end{tabular}

\section{Elgafor 2013}

Methods Randomised controlled trial

Duration and location of the trial: not stated

Inclusion criteria: clomiphene citrate-resistant women with infertility due to PCOS, diagnosed according to the Rotterdam 2003 criteria. Clomiphene citrate resistance was defined as failure to achieve adequate follicular maturation after 3 consecutive induction cycles with CC at $150 \mathrm{mg} /$ day for 5 days.

Exclusion criteria: exclusion criteria include women with other causes of infertility such as male factor or tubal factor, those with endocrine disorders such as thyroid dysfunction and hyperprolactinaemia, women who received hormonal treatment or ovulation induction drugs 3 months before the study

Number of centres: 1, Zagazig University Hospital, Egypt

Number of women randomised: 146 women, 73 in each group

Number of women analysed: 146 women, 73 in each group

Number of withdrawals/exclusions/loss to follow-up and reasons: 0

Age (y): group A metformin + letrozole: $24.7 \pm 1.8$, group B LOD: $25.1 \pm 2.1$

BMI $\left(\mathbf{k g} / \mathbf{m}^{2}\right)$ : group A metformin + letrozole: $31.5 \pm 3.3$, group B LOD: $32.4 \pm 4.4$

Duration of infertility (y): group A metformin + letrozole: $3.4 \pm 0.9$, group B LOD: $3.9 \pm 1.1$ 
Elgafor 2013 (Continued)

\section{Country: Egypt}

Interventions Group A: metformin 850 to $1700 \mathrm{mg}$ daily for 6 - 8 weeks, followed by 5 mg letrozole daily orally given for 5 days during cycle days 3 - 7 if pregnancy did not occur

Group B: LOD, laparoscopy was performed using 3-puncture technique.

Outcomes Cycle regularity, ovulation rate, clinical pregnancy rate, miscarriage rate

Notes $\quad$ Ethical approval: yes, quote: "Ethics Committee of Zagazig University approved the study"

Informed consent: yes, quote: "written informed consent was obtained from each patient at the start of the study"

Source of funding: not stated

Conflicts of interest: quote: "conflicts of interest: none"

Power calculation: not stated

\begin{tabular}{|c|c|c|}
\hline \multicolumn{3}{|l|}{ Risk of bias } \\
\hline Bias & Authors' judgement & Support for judgement \\
\hline $\begin{array}{l}\text { Random sequence genera- } \\
\text { tion (selection bias) }\end{array}$ & Low risk & $\begin{array}{l}\text { Quote: "The participant women were randomised according to a comput- } \\
\text { er-generated random numeric table." }\end{array}$ \\
\hline $\begin{array}{l}\text { Allocation concealment } \\
\text { (selection bias) }\end{array}$ & Low risk & $\begin{array}{l}\text { The random allocation sequence was concealed in sealed dark envelopes, } \\
\text { then participants assigned randomly into group } 1(n=73) \text { received metformin } \\
\text { plus letrozole, and group } 2(n=73) \text { underwent LOD. }\end{array}$ \\
\hline $\begin{array}{l}\text { Blinding of participants } \\
\text { and personnel (perfor- } \\
\text { mance bias) } \\
\text { All outcomes }\end{array}$ & Unclear risk & Not stated \\
\hline $\begin{array}{l}\text { Blinding of outcome as- } \\
\text { sessment (detection bias) } \\
\text { All outcomes }\end{array}$ & Unclear risk & Not stated \\
\hline $\begin{array}{l}\text { Incomplete outcome data } \\
\text { (attrition bias) } \\
\text { All outcomes }\end{array}$ & Low risk & No dropouts reported \\
\hline $\begin{array}{l}\text { Selective reporting (re- } \\
\text { porting bias) }\end{array}$ & Low risk & All expected outcomes reported \\
\hline Other bias & Low risk & None \\
\hline
\end{tabular}

Foroozanfard 2011

$\begin{array}{ll}\text { Methods } & \text { Randomised controlled clinical trial } \\ & \text { Duration and location of the trial: quote: "This clinical trial was performed on } 120 \text { infertile women } \\ & \text { with PCOS who attended in the outpatient infertility clinic in Kashan, Iran during 2008." }\end{array}$


Foroozanfard 2011 (Continued)

Participants

Inclusion criteria: quote: "Our inclusion criteria were age 20-35 years, infertility for at least one year and resistance to Clomiphene (at least 3 cycles Clomiphene usage, $150 \mathrm{mg} /$ day with no ovulatory response)"

Exclusion criteria: exclusion criteria were BMI > 27, endocrine disorders such as hypothyroidism, hyperprolactinaemia, infertility due to male factors, uterine factors and adhesive diseases due to pelvic surgery.

Number of centres: 1 , outpatient infertility clinic in Kashan

Number of women randomised: 60 in each group

Number of women analysed: 60 in each group

Number of withdrawals/exclusions/loss to follow-up and reasons: 0

Age (y): group A letrozole + hMG: $25.8 \pm 3.8$, group B CC + hMG: $25.3 \pm 4.1$

BMI $\left(\mathbf{k g} / \mathbf{m}^{2}\right)$ : group A letrozole + hMG: $24.1 \pm 2.3$, group B CC + hMG: $24.9 \pm 2.0$

Duration of infertility (y): group A letrozole + hMG: $2.8 \pm 2.3$, group B CC + hMG: $2.6 \pm 2.1$

Country: Iran

Group A: letrozole, $5 \mathrm{mg}$ /day orally given for 5 days from cycle days $3-7+150 \mathrm{IU}$ hMG intramuscularly during cycle days 5 - 8

Group B: clomiphene citrate, $100 \mathrm{mg} /$ day orally given for 5 days from cycle days $3-7+150$ IU hMG intramuscularly during cycle days 5 - 8

Outcomes

Live birth rate, OHSS rate, pregnancy rate, miscarriage rate, multiple birth rate, number of dominant follicles, endometrial thickness $(\mathrm{mm})$, ectopic pregnancies

Notes

Ethical approval: Yes, quote: "approval was obtained from the Institute Research Board to perform this study."

Informed consent: Yes, quote: "All patients were informed about possible side effects ad also off label use of letrozole for the purpose of inducing ovulation and written consent were obtained for all participants."

Source of funding: Yes, quote: "Authors acknowledge the research deputy of Kashan University of Medical Sciences for providing the financial support."

Power calculation: Not stated

Authors contacted by email, all information provided

\section{Risk of bias}

\begin{tabular}{lll}
\hline Bias & Authors' judgement & Support for judgement \\
\hline $\begin{array}{l}\text { Random sequence genera- } \\
\text { tion (selection bias) }\end{array}$ & Low risk & Simple randomisation was performed by a computer \\
\hline $\begin{array}{l}\text { Allocation concealment } \\
\text { (selection bias) }\end{array}$ & Low risk & By sequentially-numbered opaque sealed envelopes (email with authors) \\
\hline $\begin{array}{l}\text { Blinding of participants } \\
\text { and personnel (perfor- } \\
\text { mance bias) }\end{array}$ & Low risk & $\begin{array}{l}\text { Quote: "Before commence of the study all patients were informed of the study } \\
\text { and were told about this issue that it is possible to be enrolled in letrozole or } \\
\text { clomiphene group but none of them knew which group she allocated to and } \\
\text { the researcher was blinded also to patients' treatment approach." (email con- } \\
\text { tact with authors) }\end{array}$
\end{tabular}


Foroozanfard 2011 (Continued)

Blinding of outcome as-
sessment (detection bias)

All outcomes

\begin{tabular}{lll}
\hline $\begin{array}{l}\text { Incomplete outcome data } \\
\text { (attrition bias) } \\
\text { All outcomes }\end{array}$ & Low risk & No dropouts reported \\
\hline $\begin{array}{l}\text { Selective reporting (re- } \\
\text { porting bias) }\end{array}$ & Low risk & All expected outcomes reported \\
\hline Other bias & Low risk & None
\end{tabular}

Ganesh 2009

Methods Randomised controlled trial

Duration and location of the trial: not stated

Participants Inclusion criteria: 1387 women with PCOS diagnosed by the Rotterdam criteria who had previously failed to conceive or ovulate with CC treatment and undergoing IUI. Specific inclusion criteria for the study were normal TSH and prolactin levels and normozoospermic male partners as per WHO guidelines.

Exclusion criteria: women with pre-existing ovarian cyst on day 3 and previous history of ovarian drilling were excluded.

Number of centres: 1 , a tertiary infertility care unit, Institute of Reproductive Medicine, Kolkata, India

Number of women randomised: 1378

Number of women analysed: 1378

Number of withdrawals/exclusions/loss to follow-up and reasons: 0

Age (y): group A letrozole: $30.3 \pm 4.9$, group B CC: $30.4 \pm 5.2$, group C rFSH: $30.8 \pm 4.6$

BMI ( $\left(\mathbf{g g} / \mathbf{m}^{2}\right.$ ): group A letrozole: $24.5 \pm 3.8$, group B CC: $24.8 \pm 4.1$, group C rFSH: $24.1 \pm 3.4$

Duration of infertility (y): Not reported

Country: India

Group B: clomiphene citrate, $100 \mathrm{mg} /$ day orally given for 5 days from cycle days $3-7+75$ or $100 \mathrm{IU}$ rFSH during cycle days 3 and 8.

Group C: rFSH 75IU/100IU from day 2 until the day of hCG administration

\begin{tabular}{ll}
\hline Outcomes & Primary outcome measures: ovulation rate, cancellation rate, miscarriage rate and pregnancy rate \\
& Secondary outcomes: OHSS rate and multiple pregnancy rate.
\end{tabular}
Secondary outcomes: OHSS rate and multiple pregnancy rate.

Notes

Ethical approval: yes, approval was obtained from the institutional Research Ethics Board.

Informed consent: yes, quote: "Written informed consent was taken from all women included in this study."

Source of funding: quote: "This study was not funded by any funding agency." 
Authors contacted by email, all information provided

\section{Risk of bias}

Bias Authors' judgement Support for judgement

Random sequence genera- Low risk tion (selection bias)

Quote: "The subjects recruited for the study were randomly and blindly assigned to one of the treatment protocols. The procedure was carried out by requesting the patient to pick up randomly an opaque, sealed envelope. Each envelope contained a piece of paper with one of the three protocols written on it. Many such sealed envelopes were prepared and placed randomly. Once the patient picked the envelope, the seal was opened in front of the patient and the coordinator, the content showed and the protocol allocated." (Information by email from the author)

\begin{tabular}{|c|c|c|}
\hline $\begin{array}{l}\text { Allocation concealment } \\
\text { (selection bias) }\end{array}$ & Low risk & $\begin{array}{l}\text { Quote: "the allocation was done using sealed envelopes where the person allo- } \\
\text { cating was blinded to the type of protocol received by the patients." }\end{array}$ \\
\hline
\end{tabular}

$\begin{array}{lll}\begin{array}{l}\text { Blinding of participants } \\ \text { and personnel (perfor- }\end{array} & \text { High risk } & \begin{array}{l}\text { Quote: "Only researcher was blinded and the patient aware of the protocol fol- } \\ \text { lowed since the route of administration was different in all the three groups." }\end{array}\end{array}$

mance bias)

All outcomes

Blinding of outcome as- Low risk sessment (detection bias) Quote: "Only researcher was blinded and the patient aware of the protocol followed since the route of administration was different in all the three groups."

All outcomes

Incomplete outcome data Low risk No dropouts reported
(attrition bias)

(attrition bias)

All outcomes

Selective reporting (re- Low risk All expected outcomes reported
porting bias)

Other bias Low risk None

Ghahiri 2016

Methods Randomised controlled clinical trial

Duration of the trial: quote: "This was a randomized prospective clinical trial, including consecutive women with primary or secondary infertility due to PCOS from Jan 2009 to Sept 2011."

Participants

Inclusion criteria: the major criteria for diagnosis of PCOS were oligo- and/or anovulation, clinical or biochemical signs of hyperandrogenism, and polycystic ovaries, in accord with the revised 2003 Rotterdam criteria of PCOS. Thyroid function, prolactin level, and husband's sperm analysis were checked for normal values.

Exclusion criteria: women with other causes of infertility, infertility $<1$ year, and those who got previous treatment(s) for infertility were not included in the study.

Number of women randomised: 103; 51 to group A (CC), 52 to group B (letrozole)

Number of women analysed: 50 participants in group A, 51 in group B 
Number of withdrawals/exclusions/loss to follow-up and reasons: 2 participants, 1 from each group lost to follow-up due to no show

Number of centres: single-centre study

Age (y): no mean age reported for the treatment groups

BMI $\left(\mathbf{k g} / \mathbf{m}^{2}\right)$ : group A $27.1 \pm 4.9$; group B $28.2 \pm 5.2$

Duration of infertility $(\mathbf{y})$ : no means reported

Country: Iran

Interventions

Group A: clomiphene citrate $100 \mathrm{mg}$ for 5 days starting from day 3 of their menstrual cycle

Group B: 5 mg letrozole for 5 days from day 3 of their menstrual cycle

Both groups were advised to have intercourse on days 11,13 , and 15 of their menstrual cycles.

\begin{tabular}{|c|c|}
\hline Outcomes & Pregnancy rate, miscarriage rate, multiple pregnancies, ectopic pregnancies, OHSS rate \\
\hline \multirow[t]{4}{*}{ Notes } & Ethical approval: the protocol was approved by the ethical investigation committee of the institution \\
\hline & $\begin{array}{l}\text { Informed consent: informed consent was obtained from all the participants after full informative ses- } \\
\text { sion. }\end{array}$ \\
\hline & Source of funding: not reported \\
\hline & $\begin{array}{l}\text { Power calculation: quote: "based on our statistical data, the fair needed number for performing this } \\
\text { study was } 50 \text { per group (the sample size was calculated by considering } z, p \text {, and } d \text { as } 1.96,0.15 \text {, and } 0.1 \text {, } \\
\text { respectively)." }\end{array}$ \\
\hline
\end{tabular}

Risk of bias

\begin{tabular}{|c|c|c|}
\hline Bias & Authors' judgement & Support for judgement \\
\hline $\begin{array}{l}\text { Random sequence genera- } \\
\text { tion (selection bias) }\end{array}$ & Unclear risk & $\begin{array}{l}\text { All candidates were randomised based on envelope method into either } \\
\text { clomiphene citrate group (group } A, n=51 \text { ) or letrozole group (group } B, n=50 \text { ) }\end{array}$ \\
\hline $\begin{array}{l}\text { Allocation concealment } \\
\text { (selection bias) }\end{array}$ & Unclear risk & Not reported \\
\hline $\begin{array}{l}\text { Blinding of participants } \\
\text { and personnel (perfor- } \\
\text { mance bias) } \\
\text { All outcomes }\end{array}$ & Unclear risk & Not reported \\
\hline $\begin{array}{l}\text { Blinding of outcome as- } \\
\text { sessment (detection bias) } \\
\text { All outcomes }\end{array}$ & Unclear risk & Not reported \\
\hline $\begin{array}{l}\text { Incomplete outcome data } \\
\text { (attrition bias) } \\
\text { All outcomes }\end{array}$ & Low risk & 2 of 103 participants were lost to follow-up \\
\hline $\begin{array}{l}\text { Selective reporting (re- } \\
\text { porting bias) }\end{array}$ & Low risk & All expected outcomes were reported \\
\hline Other bias & Low risk & None \\
\hline
\end{tabular}




Methods Randomised controlled clinical trial

Duration and location of the trial: quote: "The study was performed from March to November 2010 at the Mashhad IVF center, a university based infertility center."

Inclusion criteria: based on Rotterdam criteria, 70 women with PCOS were enrolled in this randomised clinical trial. The diagnosis of PCOS was made when 2 of the following 3 criteria existed: oligomenorrhoea or amenorrhoea, clinical hyperandrogenism, and polycystic ovaries on ultrasonography. The inclusion criteria were as follows: i. Previous diagnosis of PCOS according to Rotterdam criteria, ii. Age between 20 and 30 years, iii. No previous history of ovarian surgery, and iv. lack of ovulation with CC in at least 3 previous cycles (lack of follicle $\geq 18 \mathrm{~mm}$ on ultrasound scan). The woman's age, her partner's age, duration of infertility, type of infertility (primary and secondary), history of previous intrauterine insemination (IUI) cycles, pattern of ovary (PCO and non-PCO), pattern of menstruation (regular, oligomenorrhoea and amenorrhoea), BMI and basal LH/FSH ratio were recorded for each participant.

Exclusion criteria: the exclusion criteria were as follows: i. No other infertility factors, ii. Exposure to cytotoxic drugs and iii. Pelvic radiation therapy.

Number of women randomised: 70

Number of women analysed: 69

Number of withdrawals/exclusions/loss to follow-up and reasons: 1 patient discontinued treatment in group $B$

Number of centres: single-centre study

Age (y): group A: $25.3 \pm 4.4$, group B: $25.6 \pm 3.5$

BMI $\left(\mathbf{k g} / \mathbf{m}^{2}\right)$ : group A: $27.0 \pm 3.8$, group B: $26.4 \pm 4.8$

Duration of infertility $(\mathbf{y})$ : number of previous treatment cycles $(\mathrm{CC})$ : group A: $1.1 \pm 0.4$, group B: $1.3 \pm$ 0.5

Country: Mashhad, Iran

Group B: group B $(n=35)$ receiving the same amount on cycle days 5 - 9.

\begin{tabular}{|c|c|c|}
\hline Outcomes & \multicolumn{2}{|c|}{ The cycle characteristics, the ovulation and pregnancy rate } \\
\hline \multirow[t]{4}{*}{ Notes } & \multicolumn{2}{|c|}{$\begin{array}{l}\text { Ethical approval: this study was approved by Ethical Committee of Mashhad University of Medical } \\
\text { Sciences. }\end{array}$} \\
\hline & \multicolumn{2}{|c|}{ Informed consent: a written informed consent was taken from all women participating in this study. } \\
\hline & \multicolumn{2}{|c|}{ Source of funding: not reported } \\
\hline & \multicolumn{2}{|c|}{ Power calculation: not reported } \\
\hline \multicolumn{3}{|l|}{ Risk of bias } \\
\hline Bias & Authors' judgement & Support for judgement \\
\hline $\begin{array}{l}\text { Random sequence genera- } \\
\text { tion (selection bias) }\end{array}$ & Unclear risk & Not reported \\
\hline
\end{tabular}


Ghomian 2015 (Continued)

\begin{tabular}{lll}
$\begin{array}{l}\text { Allocation concealment } \\
\text { (selection bias) }\end{array}$ & Unclear risk & Not reported \\
\hline $\begin{array}{l}\text { Blinding of participants } \\
\text { and personnel (perfor- } \\
\text { mance bias) }\end{array}$ & Unclear risk & Not reported \\
All outcomes & &
\end{tabular}

\begin{tabular}{lll}
\hline $\begin{array}{l}\text { Blinding of outcome as- } \\
\text { sessment (detection bias) } \\
\text { All outcomes }\end{array}$ & Unclear risk & Not reported \\
\hline $\begin{array}{l}\text { Incomplete outcome data } \\
\begin{array}{l}\text { (attrition bias) } \\
\text { All outcomes }\end{array}\end{array}$ & Low risk & 1 participant was excluded from analysis due to discontinuation of treatment. \\
\hline $\begin{array}{l}\text { Selective reporting (re- } \\
\text { porting bias) }\end{array}$ & Low risk & All expected outcomes were reported. \\
\hline Other bias & Low risk & None \\
\hline
\end{tabular}

Hassan 2017

Methods Randomised controlled clinical trial

Duration and location of the trial: quote: "This was a balanced, randomized (allocation ratio 1:1), parallel group study conducted in Cairo and Beni-Suef University Hospitals from May 2013 to January 2015."

Participants

Inclusion criteria: women included in the study had CC-resistant PCOS, and were aged $20-40$ years. PCOS was diagnosed according to the Rotterdam 2003 criteria. CC resistance was defined as failure of ovulation despite receiving $150 \mathrm{mg}$ of CC for 5 days during successive menstrual cycles for 3 months.

Exclusion criteria: other causes of infertility, BMI> $35 \mathrm{~kg} / \mathrm{m}^{2}$, hyperprolactinaemia, allergy to $\mathrm{FSH}$, and previous use of FSH or letrozole therapies.

Number of women randomised: 140,70 to each group

Number of women analysed: 140, 70 in each group

Number of withdrawals/exclusions/loss to follow-up and reasons: 3 women in the letrozole group and 2 women in the uFSH group were lost to follow-up; intention-to-treat analysis was adopted in which these participants were considered anovulatory in the 3 cycles.

Number of centres: 2-centre trial

Age (y): letrozole group $28.7 \pm 6.2$, uFSH group $30.0 \pm 5.6$

BMI ( $\left.\mathbf{k g} / \mathbf{m}^{2}\right)$ : letrozole group $27.6 \pm 4.1$, uFSH group $27.2 \pm 3.8$

Duration of infertility $(\mathbf{y})$ : letrozole group $87.0 \pm 2.1$, uFSH group $5.2 \pm 2.2$

Country: Cairo University and Beni-Suef University Hospitals, Egypt

Interventions

Group A: quote: "group 1 received letrozole (Femara VR, Novartis, Basel, Switzerland) $2.5 \mathrm{mg}$ twice daily for five days starting from the third day of menstruation or progesterone withdrawal bleeding."

Group B: quote: "group 2 received uFSH (Fostimon VR IBSA, Geneva, Switzerland). To minimize the risk of multiple pregnancy and OHSS, we used a low-dose FSH setup regimen. The starting daily dose of 
Hassan 2017 (Continued)

UFSH was 75 IU for seven days starting from the third day of menstruation or progesterone withdrawal bleeding. If the follicular diameter did not exceed $9 \mathrm{~mm}$, the daily dose was increased by $37.5 \mathrm{IU}$ every seven days. The cycle was cancelled if no follicles exceeded $9 \mathrm{~mm}$ by four weeks after starting FSH."

Cumulative clinical pregnancy, defined as the presence of an intrauterine gestational sac 5 weeks after
timed intercourse
Secondary outcomes were ovulation, miscarriage and possible drug side effects, i.e. OHSS, headache,
dizziness, hot flushes, nausea, vomiting or constipation

Notes

Ethical approval: the study was approved by the research ethics committees of both institutions.

Informed consent: written informed consent was obtained

Source of funding: quote: "The study was self-funded"

Power calculation: quote: "The required sample size was estimated using PS Power and Sample Size Calculations software, version 3.0.11 for Microsoft Windows. We needed to study 64 women receiving letrozole and 64 women receiving $\mathrm{uFSH}$ for three cycles to be able to reject the null hypothesis that the pregnancy rates for letrozole and uFSH in CC-resistant women were equal, with a probability (power) of 0.9."

\section{Risk of bias}

\begin{tabular}{|c|c|c|}
\hline Bias & Authors' judgement & Support for judgement \\
\hline $\begin{array}{l}\text { Random sequence genera- } \\
\text { tion (selection bias) }\end{array}$ & Low risk & $\begin{array}{l}\text { An independent individual generated the allocation sequence using comput- } \\
\text { er-generated random numbers }\end{array}$ \\
\hline $\begin{array}{l}\text { Allocation concealment } \\
\text { (selection bias) }\end{array}$ & Low risk & $\begin{array}{l}\text { Allocation was concealed using sequentially-numbered opaque sealed en- } \\
\text { velopes }\end{array}$ \\
\hline $\begin{array}{l}\text { Blinding of participants } \\
\text { and personnel (perfor- } \\
\text { mance bias) } \\
\text { All outcomes }\end{array}$ & Unclear risk & Not reported \\
\hline $\begin{array}{l}\text { Blinding of outcome as- } \\
\text { sessment (detection bias) } \\
\text { All outcomes }\end{array}$ & Unclear risk & Not reported \\
\hline $\begin{array}{l}\text { Incomplete outcome data } \\
\text { (attrition bias) } \\
\text { All outcomes }\end{array}$ & Low risk & All participants randomised were also analysed \\
\hline $\begin{array}{l}\text { Selective reporting (re- } \\
\text { porting bias) }\end{array}$ & Low risk & All expected outcomes were reported \\
\hline Other bias & Low risk & None \\
\hline
\end{tabular}

Hendawy 2011

Methods Randomised controlled clinical trial

Duration and location of the trial: not stated

Participants

Inclusion criteria: quote: "infertile patients (defined as one year of unprotected coitus without conception in patients who have never conceived before) with PCOS, aged younger than 35 years, and at- 
tending the infertility out- patient clinic at Ain Shams University Hospital and/or a local private outpatient setting. Diagnosis of PCOS was based on the Rotterdam criteria (2003 ESHRE/ ASRM consensus), whereby patients diagnosed with PCOS require the presence of two of three criteria, i.e., oligomenorrhoea and/or anovulation, clinical and/ or biochemical signs of hyperandrogenism, and/or polycystic ovaries on ultrasound. All patients had a history of failed induction of ovulation with appropriately timed intercourse at least 4-6 times."

Exclusion criteria: women with infertility due to uterine and tubal pathologies or male factor

Number of women randomised: 60 women with primary infertility

Number of women analysed: 54 women were analysed, 28 in group 1 (letrozole) and 26 in group 2 (clomiphene citrate)

Number of withdrawals/exclusions/loss to follow-up and reasons: during folliculometry, 2 participants in Group 1 and 4 participants in Group 2 showed no follicular response and were excluded from the study.

Number of centres: 2-centre trial

Age (y): group 1 included 30 women aged $21-34$ (mean \pm SD, $27.2 \pm 5.18$ ) years, group 2 included 30 women aged $20-33$

BMI ( $\left.\mathbf{k g} / \mathbf{m}^{2}\right)$ : group 1 included 30 women with a BMI of $24-31(26.2 \pm 1.8)$. Group 2 included 30 women with a BMI of $23-32(29.1 \pm 2.3)$

Duration of infertility (y): mean duration of infertility not reported

Country: Egypt

Group A: group 1 included 30 women who were given letrozole (Femara ${ }^{\circledR}$, Novartis, Basel, Switzerland) orally at a dose of $2.5 \mathrm{mg}$ once daily on days $3-7$ of the menstrual cycle.

Group B: group 2 included 30 women who were given clomiphene citrate (Clomid ${ }^{\circledR}$, Sano Aventis, France) $50 \mathrm{mg}$ orally twice daily on days $3-7$ of the menstrual cycle.

Outcomes Pregnancy rate, multiple pregnancy rate, number of follicles on hCG administration day, endometrial thickness

Notes

Ethical approval: the study was approved by the medical ethics committee of Ain Shams University Hospital.

Informed consent: Informed consent was obtained from all participants

Source of funding: not reported

Power calculation: none reported

\section{Risk of bias}

\begin{tabular}{lll}
\hline Bias & Authors' judgement & Support for judgement \\
\hline $\begin{array}{l}\text { Random sequence genera- } \\
\text { tion (selection bias) }\end{array}$ & Low risk & Participants were randomised using a computer-generated programme \\
\hline $\begin{array}{l}\text { Allocation concealment } \\
\text { (selection bias) }\end{array}$ & Unclear risk & Not reported \\
\hline $\begin{array}{l}\text { Blinding of participants } \\
\text { and personnel (perfor- } \\
\text { mance bias) }\end{array}$ & Unclear risk & double-blind randomised, but not reported how blinding was achieved \\
All outcomes & \\
\hline
\end{tabular}


Hendawy 2011 (Continued)

Blinding of outcome as- Unclear risk double-blind randomised, but not reported how blinding was achieved sessment (detection bias)

All outcomes

Incomplete outcome data Low risk $\quad 6 / 60$ participants were lost to follow-up
(attrition bias)
All outcomes

\begin{tabular}{lll}
\hline $\begin{array}{l}\text { Selective reporting (re- } \\
\text { porting bias) }\end{array}$ & Unclear risk & No study protocol was found \\
\hline Other bias & Unclear risk & None \\
\hline
\end{tabular}

Ibrahim 2017

Methods Randomised controlled trial

Duration of the trial: quote: "The study was conducted during the period from 1st August 2015 to 30 th March 2016."

Participants

Inclusion criteria: quote: "age > 20 and $<35$ years old, patients were diagnosed to have PCOS criteria of diagnosis of PCO. Normal HSG and their partners had normal semen analysis according to WHO criteria (WHO, 2010) and CC-resistant. If patients fail to respond to $150 \mathrm{mg} /$ day for 5 days for 3 consecutive cycles, they are considered as CC-resistant."

Exclusion criteria: quote: "Age less than 20 yr or more than $35 \mathrm{yr}$, non-PCOS, and those Patients with poor ovarian reserve i.e. hyperprolactinaemia, hypo and hyperthyroidism, diabetic patients and Cushing's syndrome were excluded, non-classical congenital adrenal hyperplasia, current or previous (within the last 6 months) use of oral contraceptives, glucocorticoids, antiandrogens, antidiabetic or antiobesity drugs, or other hormonal drugs, any subject was affected by either neoplastic, metabolic, hepatic, or cardiovascular disorder or other concurrent medical illness (i.e. diabetes, renal disease, or malabsorptive disorders) were excluded, pelvic diseases, previous pelvic surgery, suspected peritoneal factor infertility, tubal infertility and male factor infertility were excluded with a hysterosalpingogram and with semen analysis, respectively."

Number of women randomised: 80 women, 40 within each group

Number of women analysed: 80 women, 40 within each group

Number of withdrawals/exclusions/loss to follow-up and reasons: none

Number of centres: single-centre trial

Age (y): LOD group $28.8 \pm 3.1$ vs let group $29.7 \pm 3.7$

BMI $\left(\mathbf{k g} / \mathbf{m}^{2}\right)$ : LOD group $29.1 \pm 1.6$, letrozole group $29.2 \pm 1.7$

Duration of infertility $(\mathbf{y})$ : no mean \pm SD reported

Country: Egypt

Group A: quote: "In group A, laparoscopy was performed under intravenous general anaesthesia with the patient in a supine position. A $5 \mathrm{~mm}$ incision was made in the navel, through which a long sheath punctured into the abdominal cavity, and the inflatable pneumoperitoneum was placed. Another two 5-mm incisions were made on the right and left lower abdomen and the surgical instruments were inserted into the abdominal cavity. The patient was adjusted into a position with the head high up, the pelvic organs were exposed and a comprehensive exploration of the pelvic organs was made, focusing on the structure and position of the adjacent organs of the bilateral ovaries. Once immobilized, each ovary was cauterized at 4-6 points, using a monopolar electrosurgical needle, according to the size 
of each ovary. Following cauterization, a bilateral tubal hydrotubation with methylene blue was performed. During the procedure. The pelvis was irrigated using physiological saline. Ringer's solution plus dexamethasone was added into the abdominal cavity to avoid adhesion. The total duration of the procedure, as well as any intra-operative or post-operative complications, was noted."

Group B: quote: "In group B, 2.5 mg twice daily LE oral tablets were administered on the 3rd day of menses and then every day for 5 days.

Treatment was repeated for up to six cycles if the patient failed to ovulate, the patients were followed-up for 6 months after the treatment in both groups."

Outcomes Pregnancy rate, abortion rate, ovulation, regular cycles, ovarian volume, antral follicle count (AFC)

Notes

Ethical approval: This study was approved by Minia University Ethical Committee

Informed consent: quote: "Informed consent was obtained from all participating women after the nature and purpose of the study had been explained to them and were fully understood"

Source of funding: quote: "We have not received any funding from any corporate body or pharmaceutical company. "

Power calculation: none reported

\section{Risk of bias}

\begin{tabular}{lll}
\hline Bias & Authors' judgement & Support for judgement \\
\hline $\begin{array}{l}\text { Random sequence genera- } \\
\text { tion (selection bias) }\end{array}$ & Low risk & $\begin{array}{l}\text { Quote: "Randomization was achieved via the use of a randomisation num- } \\
\text { ber allocated prior to dosing, once eligibility had been determined, and a ran- } \\
\text { domisation schedule was produced by an interactive voice response system } \\
\text { vendor." }\end{array}$ \\
\hline $\begin{array}{l}\text { Allocation concealment } \\
\text { (selection bias) }\end{array}$ & Unclear risk & Not reported \\
\hline $\begin{array}{l}\text { Blinding of participants } \\
\text { and personnel (perfor- } \\
\text { mance bias) }\end{array}$ & High risk & Participants were not blinded \\
All outcomes &
\end{tabular}

\begin{tabular}{|c|c|c|}
\hline $\begin{array}{l}\text { Blinding of outcome as- } \\
\text { sessment (detection bias) } \\
\text { All outcomes }\end{array}$ & Low risk & $\begin{array}{l}\text { Quote: "Once the patients had been allocated to one of the two groups, the } \\
\text { treatment was revealed to the investigator; however, the doctor responsible } \\
\text { for performing the transvaginal ultrasound follow up assessment was blinded } \\
\text { to the treatment groups." }\end{array}$ \\
\hline
\end{tabular}

Incomplete outcome data Low risk All women randomised were also analysed.
(attrition bias)

All outcomes

\begin{tabular}{lll}
\hline $\begin{array}{l}\text { Selective reporting (re- } \\
\text { porting bias) }\end{array}$ & Unclear risk & We found no reporting of outcomes in a study protocol or Methods section \\
\hline Other bias & Low risk & None \\
\hline
\end{tabular}

Kamath 2010

Methods Randomised double-blind placebo-controlled trial


Duration and location of the trial: quote: "This trial was conducted in a university teaching hospital between 2007 and 2009.“

\section{Participants}

Inclusion criteria: women with PCOS and clomiphene resistance who were being treated with ovulation induction. Additionally, women had to have a normal hormone profile and a male partner with normal semen parameters by WHO criteria. Normal hormone profile was defined as a FSH level of $<12$ $\mathrm{IU} / \mathrm{L}$, serum prolactin level of $<25 \mathrm{ng} / \mathrm{mL}$, and a thyroid-stimulating hormone (TSH) value between 0.3 and $4.5 \mu \mathrm{IU} / \mathrm{mL}$.

Exclusion criteria: women with other endocrine disorders such as Cushing syndrome, and congenital adrenal hyperplasia

Number of centres: 1 , Reproductive Medicine Unit, Christian Medical College, Vellore, Tamil Nadu, India

Number of women randomised: 18 in each group

Number of women analysed: 17 in each group

Number of withdrawals/exclusions/loss to follow-up and reasons: 2 lost to follow-up before treatment started

Age (y): group A letrozole: $25.6 \pm 3.6$, group B placebo: $25.7 \pm 3.7$

BMI $\left(\mathbf{k g} / \mathbf{m}^{2}\right)$ : group A letrozole: $26.1 \pm 3.7$, group B placebo: $24.7 \pm 4.2$

Duration of infertility (y): group A letrozole: $5.2 \pm 3.2$, group B placebo: $3.6 \pm 2.2$

Country: India

Interventions Group A: letrozole, orally given $2.5 \mathrm{mg} /$ day for 5 days from cycle days 2 - 6

Group B: placebo, also given for 5 days from cycle days 2 - 6

Outcomes

Primary Outcome: ovulation rate

Secondary Outcomes: live birth rate, OHSS rate, pregnancy rate, miscarriage rate, multiple pregnancy rate, endometrial thickness $(\mathrm{mm})$, day 21 serum progesterone $(\mathrm{nmol} / \mathrm{L})$, number of participants with mature follicle (\%)

Notes

Ethical approval: yes, the protocol of the study was approved by the institutional review board

Informed consent: yes, written informed consent was obtained from each participant

Source of funding: not stated

Conflicts of interest: quote: "The Authors have nothing to disclose"

Power calculation: quote: "Our literature pointed to a $75 \%$ ovulation rate when $2.5 \mathrm{mg}$ of letrozole was used in women with PCOS who had clomiphene resistance. We hypothesized an ovulation rate of $60 \&$ with letrozole and $10 \%$ with placebo. On this basis, a sample size of 17 women in each arm ( $80 \%$ and alpha .05 for a two-sided test) was calculated."

Contacted authors about OHSS rate and how randomisation and allocation concealment were done in detail. All information provided

\begin{tabular}{lll}
\hline Bias & Authors' judgement & Support for judgement \\
\hline $\begin{array}{l}\text { Random sequence genera- } \\
\text { tion (selection bias) }\end{array}$ & Low risk & $\begin{array}{l}\text { Randomly distributed using a computer-generated randomisation sequence in } \\
\text { blocks of 6, into 2 groups. }\end{array}$ \\
\hline
\end{tabular}


Kamath 2010 (Continued)

$\begin{array}{ll}\begin{array}{l}\text { Allocation concealment } \\ \text { (selection bias) }\end{array} & \text { Low risk }\end{array} \quad \begin{aligned} & \text { Allocation concealment was done by using consecutively-numbered sealed } \\ & \text { opaque envelopes containing the treatment packets. }\end{aligned}$

Blinding of participants Low risk

The randomisation code was maintained by the pharmacy department, which and personnel (perforrevealed the group assignments at the end of the trial.

mance bias)

All outcomes

Blinding of outcome as-
sessment (detection bias) $\quad$ Low risk code was revealed after the statistical analysis had been performed.

(detection bias)

All outcomes

$\begin{array}{ll}\begin{array}{l}\text { Incomplete outcome data } \\ \text { (attrition bias) }\end{array} & \begin{array}{l}1 \text { women in each group was lost to follow-up, after randomisation and before } \\ \text { treatment started. }\end{array} \\ \text { All outcomes } & \end{array}$

\begin{tabular}{lll}
\hline $\begin{array}{l}\text { Selective reporting (re- } \\
\text { porting bias) }\end{array}$ & Low risk & All outcomes reported \\
\hline Other bias & Low risk & None \\
\hline
\end{tabular}

Kar 2012

\begin{tabular}{ll}
\hline Methods & Randomised controlled trial \\
& $\begin{array}{l}\text { Duration of the trial: quote "The prospective randomized trial was conducted between July } 2010 \text { and } \\
\text { July } 2011 . "\end{array}$
\end{tabular}

Participants

Inclusion criteria: quote: "PCOS was diagnosed according to Rotterdam criteria. All women were treatment-naive i.e. had not undergone any significant treatment for infertility/ovulation induction earlier."

Exclusion criteria: quote: "Patients with hyperprolactinaemia, thyroid disorder, male factor, suspected tubal factor, endometriosis, unexplained infertility were not included in the study."

Number of centres: quote: "This study was conducted at a private hospital with a large gynaecological practice."

Number of women randomised: 103 women, 52 in the letrozole group and 51 in the CC group.

Number of women analysed: 103 women, 52 in the letrozole group and 51 in the CC group.

Number of withdrawals/exclusions/loss to follow-up and reasons: 0

Age (y): group A letrozole: $26.3 \pm 2.4$, group B CC: $26.3 \pm 2.5$

BMI $\left(\mathbf{k g} / \mathbf{m}^{\mathbf{2}}\right)$ : group A letrozole: $25.9 \pm 3.6$, group B placebo: $26.0 \pm 3.3$

Duration of infertility $(\mathbf{y})$ : group A letrozole: $3.1 \pm 1.9$, group B CC: $3.1 \pm 2.2$

Country: India

Interventions Group A: letrozole, $5 \mathrm{mg} /$ day orally given for 5 days from cycle days 2 - 6

Group B: clomiphene citrate, $100 \mathrm{mg} /$ day orally given for 5 days from cycle days 2 - 6

Outcomes

Primary outcomes: ovulation rate, endometrial thickness, mono vs. multi-follicular rate, and days to ovulation.

Secondary outcomes: pregnancy and miscarriage rate 
Kar 2012 (Continued)

Notes

Ethical approval: yes, quote: "Study protocol was approved by the institutional ethics committee."

Informed consent: not stated.

Source of funding: quote: "Nil"

Power calculation: not reported

\section{Risk of bias}

\begin{tabular}{lll}
\hline Bias & Authors' judgement & Support for judgement \\
\hline $\begin{array}{l}\text { Random sequence genera- } \\
\text { tion (selection bias) }\end{array}$ & Unclear risk & Quote: "Patients were randomised by lottery" \\
\hline $\begin{array}{l}\text { Allocation concealment } \\
\text { (selection bias) }\end{array}$ & Unclear risk & Not stated \\
\hline $\begin{array}{l}\text { Blinding of participants } \\
\text { and personnel (perfor- } \\
\text { mance bias) } \\
\text { All outcomes }\end{array}$ & Unclear risk & Not stated \\
\hline
\end{tabular}

Blinding of outcome as- Unclear risk Not stated

sessment (detection bias)

All outcomes

\begin{tabular}{lll}
\hline $\begin{array}{l}\text { Incomplete outcome data } \\
\text { (attrition bias) } \\
\text { All outcomes }\end{array}$ & Low risk & No dropouts reported \\
\hline $\begin{array}{l}\text { Selective reporting (re- } \\
\text { porting bias) }\end{array}$ & Low risk & All expected outcomes were reported \\
\hline Other bias & Low risk & None \\
\hline
\end{tabular}

Legro 2014

Methods Randomised double-blind multicentre trial

Duration of the trial: quote: "Enrollment began in February 2009 and was completed in January 2012."

Participants Inclusion criteria: women with PCOS defined by the Rotterdam criteria and at least 1 patent fallopian tube and normal uterine cavity, and a male partner with sperm concentration of $>14$ million $/ \mathrm{mL}$

Exclusion criteria: quote: "We will exclude subjects with medical conditions that represent contraindications to CC,letrozole and/or pregnancy or who are unable to comply with the study procedures."

Number of centres: multicentre trial

Number of women randomised: 750,374 in the letrozole group and 376 in the CC group

Number of women analysed: 750,374 in the letrozole group and 376 in the CC group

Number of withdrawals/exclusions/loss to follow-up and reasons: 0

Age (y): group A letrozole: $29 \pm 5$, group B CC: $28 \pm 4$

BMI (kg/m²): group A letrozole: $35 \pm 10$, group B CC: $35 \pm 9$ 
Legro 2014 (Continued)

Duration of infertility (y): not reported

Country: USA

Group A: letrozole, orally given $2.5 \mathrm{mg} /$ day for 5 days during cycle days 3 - 7

Group B: clomiphene citrate, orally given $100 \mathrm{mg} /$ day for 5 days during cycle days 3 - 7

Outcomes Live birth, ovulation rate, clinical pregnancy rate, miscarriage rate, multiple pregnancy rate

Notes $\quad$ Ethical approval: quote:"The institutional review board at each centre approved the protocol, and all participants (women and their male partners) gave written informed consent."

Informed consent: quote: "The institutional review board at each centre approved the protocol, and all participants (women and their male partners) gave written informed consent."

Source of funding: quote: "The study is funded through a cooperative agreement by the Eunice Kennedy ShriverNational Institutes of Child Health and Human Development (NICHD)"

Power calculation: a sample size of 300 subjects in each arm of the randomisation yields $81 \%$ statistical power to prospectively demonstrate a 0.10 absolute difference in live birth proportions between treatment arms ( 0.20 for $\mathrm{CC}$ and 0.30 for letrozole) using the Pearson's $\mathrm{Chi}^{2}$ test with a 2 -sided significance level of 0.05

\section{Risk of bias}

\begin{tabular}{|c|c|c|}
\hline Bias & Authors' judgement & Support for judgement \\
\hline $\begin{array}{l}\text { Random sequence genera- } \\
\text { tion (selection bias) }\end{array}$ & Low risk & $\begin{array}{l}\text { Quote: "Almac statisticians will generate the randomisation scheme for the } \\
\text { study." }\end{array}$ \\
\hline $\begin{array}{l}\text { Allocation concealment } \\
\text { (selection bias) }\end{array}$ & Low risk & Third-party allocation \\
\hline $\begin{array}{l}\text { Blinding of participants } \\
\text { and personnel (perfor- } \\
\text { mance bias) } \\
\text { All outcomes }\end{array}$ & Low risk & $\begin{array}{l}\text { Quote: "In order to maintain the double-blind, CC and letrozole will be over } \\
\text { encapsulated and packaged in identically appearing numbered study kits (us- } \\
\text { ing AlmacClinical Services, Durham NC) which will then be directly shipped to } \\
\text { each clinical site." }\end{array}$ \\
\hline $\begin{array}{l}\text { Blinding of outcome as- } \\
\text { sessment (detection bias) } \\
\text { All outcomes }\end{array}$ & Low risk & $\begin{array}{l}\text { Quote: "In order to maintain the double-blind, CC and letrozole will be over } \\
\text { encapsulated and packaged in identically appearing numbered study kits (us- } \\
\text { ing AlmacClinical Services, Durham NC) which will then be directly shipped to } \\
\text { each clinical site. The randomisation scheme (including block size) will be dis- } \\
\text { closed to the DCC data manager, but not to any RMN investigators or staff, in- } \\
\text { cluding the Protocol Lead Investigator." }\end{array}$ \\
\hline $\begin{array}{l}\text { Incomplete outcome data } \\
\text { (attrition bias) } \\
\text { All outcomes }\end{array}$ & Low risk & No dropouts were reported \\
\hline $\begin{array}{l}\text { Selective reporting (re- } \\
\text { porting bias) }\end{array}$ & Low risk & All expected outcomes were reported \\
\hline Other bias & Low risk & None \\
\hline
\end{tabular}

Liu 2015

Methods Randomised controlled clinical trial


Liu 2015 (Continued)

Duration and location of the trial: not stated

Participants

Inclusion criteria: quote: "the women were diagnosed with PCOS based on the Revised 2003 Consensus Diagnostic Criteria for PCOS. Clomiphene resistance, i.e. failure to ovulate following $100 \mathrm{mg}$ CC for 5 days for at least three cycles; patent fallopian tubes, confirmed by hysterosalpingography or hysteroscopic diagnosis; normal semen analysis parameters of the patients' spouses according to the modified criteria of the World Health Organization (14); normal serum prolactin, thyroid stimulating hormone and $17-\mathrm{OH}$ progesterone; no systemic disease; no gonadotropin or other hormonal drug treatment during the preceding 3 months; normal blood count and blood chemistry, including glut amic-pyruvic transaminase, glutamic-oxaloacetic transaminase, urea nitrogen, creatinine, glucose and urine analysis. The semen of the patients' spouses was tested to strengthen the comparability between the two groups. During the period of treatment, all patients were requested to follow a normal diet and rest regime and to avoid intense physical activities in any form and mental stress and fatigue."

Exclusion criteria: infertility induced by reasons other than PCOS; uterine cavity lesions or ovarian cyst; > 40 years old; $\mathrm{BMI}>26 \mathrm{~kg} / \mathrm{m}^{2}$; contraindications to general anaesthesia; history of pelvic surgery; other endocrine diseases; or a history of liver or kidney disease

Number of women randomised: 141 women were randomly assigned, 71 to group A (letrozole) and 70 to group B (LOD)

Number of women analysed: all women randomised were also analysed

Number of withdrawals/exclusions/loss to follow-up and reasons: none

Number of centres: single-centre trial

Age (y): letrozole group $29.5 \pm 3.3$, LOD group $28.1 \pm 3.6$

BMI $\left(\mathbf{k g} / \mathbf{m}^{2}\right)$ : letrozole group $22.5 \pm 1.5$, LOD group $22.4 \pm 2.1$

Duration of infertility $(\mathbf{y})$ : letrozole group $3.4 \pm 0.4$, LOD group $3.2 \pm 0.7$

Country: China

Interventions

Group A: quote: "In group A, 2.5 mg LE oral tablets (Adooq Bioscience, Nanjing, China) were administered on the fifth day of menses and then every day for 5 days. Treatment was repeated for up to six cycles if the patient failed to conceive."

Group B: quote: "In group B, laparoscopy was performed under intravenous general anaesthesia (Diprivan; AstraZeneca S.p.A., Rome, Italy) with the patient in a supine position. A $5-\mathrm{mm}$ incision was made in the navel, through which a long sheath punctured into the abdominal cavity, and the inflatable pneumoperitoneum (Guangxi University, Yuannan, China) was placed. Another two 5-mm incisions were made on the right and left lower abdomen and the surgical instruments were inserted into the abdominal cavity. The patient was adjusted into a position with the head high up, the pelvic organs were exposed and a comprehensive exploration of the pelvic organs was made, focusing on the structure and position of the adjacent organs of the bilateral ovaries. Once immobilized, each ovary was cauterized at $4-6$ points, each for $4 \mathrm{sec}$ at $40 \mathrm{~W}$, at a depth of $7-8 \mathrm{~mm}$ and a diameter of $3-5 \mathrm{~mm}$, using a monopolar electrosurgical needle (Kirgen Co., Shanghai, China), according to the size of each ovary. Following cauterization, a bilateral tubal hydrotubation with methylene blue was performed. During the procedure, small pieces of the ovaries were obtained for pathological analysis. The pelvis was irrigated using physiological saline. Ringer's solution (ZiQi Bioscience, Shanghai, China) plus dexamethasone was added into the abdominal cavity to avoid adhesion. The total duration of the procedure, as well as any intra-operative or post-operative complications, was noted. The patients were fol lowed-up for 6 months after the procedure."

Outcomes Live birth rate, OHSS, clinical pregnancy was defined by a fetal heart beat monitored by ultrasound at 6 weeks of gestation.

Biochemical pregnancy was considered when $\mathrm{hCG}$ was $>2.5 \mathrm{mlU} / \mathrm{ml}$ in the absence of menstruation. 
Liu 2015 (Continued)

Ovulation rate, endometrial thickness in $\mathrm{mm}$, synchronous cycles, mean follicular diameter, spontaneous abortion rate, multiple pregnancy rate

Notes

Ethical approval: this study was approved by Tongji Hospital Research Ethics Committee (Shanghai, China)

Informed consent: all participants provided informed consent prior to inclusion in the trial.

Source of funding: the present study was supported by the Shanghai Natural Science Foundation (grant no. 12ZR1434200).

Power calculation: none reported

\section{Risk of bias}

\begin{tabular}{|c|c|c|}
\hline Bias & Authors' judgement & Support for judgement \\
\hline $\begin{array}{l}\text { Random sequence genera- } \\
\text { tion (selection bias) }\end{array}$ & Unclear risk & $\begin{array}{l}\text { Quote: "The women were randomly allocated into the either the letrozole or } \\
\text { LOD group (groups A and B, respectively)." }\end{array}$ \\
\hline $\begin{array}{l}\text { Allocation concealment } \\
\text { (selection bias) }\end{array}$ & Unclear risk & Not reported \\
\hline $\begin{array}{l}\text { Blinding of participants } \\
\text { and personnel (perfor- } \\
\text { mance bias) } \\
\text { All outcomes }\end{array}$ & Unclear risk & $\begin{array}{l}\text { Quote: "Once the patients had been allocated to one of the two groups, the } \\
\text { treatment was revealed to the investigator; however, the doctor responsi- } \\
\text { ble for performing the transvaginal ultrasound follow-up assessment was } \\
\text { blinded to the treatment groups." }\end{array}$ \\
\hline $\begin{array}{l}\text { Blinding of outcome as- } \\
\text { sessment (detection bias) } \\
\text { All outcomes }\end{array}$ & Low risk & $\begin{array}{l}\text { Quote: "Once the patients had been allocated to one of the two groups, the } \\
\text { treatment was revealed to the investigator; however, the doctor responsi- } \\
\text { ble for performing the transvaginal ultrasound fol low-up assessment was } \\
\text { blinded to the treatment groups." }\end{array}$ \\
\hline $\begin{array}{l}\text { Incomplete outcome data } \\
\text { (attrition bias) } \\
\text { All outcomes }\end{array}$ & Low risk & All women randomised were also analysed \\
\hline $\begin{array}{l}\text { Selective reporting (re- } \\
\text { porting bias) }\end{array}$ & Unclear risk & All expected outcomes were reported \\
\hline Other bias & Unclear risk & None \\
\hline
\end{tabular}

Liu 2017

Methods Randomised controlled clinical trial

Duration and location of the trial: quote: "PCOS patients attending the outpatient department of the hospital between April 2012 and March 2014, who had a desire for childbearing and fulfilled the Rotterdam diagnostic criteria as well, were recruited for this study."

Participants

Inclusion criteria: quote: "PCOS patients attending the outpatient department of the hospital between April 2012 and March 2014, who had a desire for childbearing and fulfilled the Rotterdam diagnostic criteria as well, were recruited for this study. The inclusion criteria for this study were as follows: (1) patency of at least one side of the fallopian tube and (2) normal spouse's sperm."

Exclusion criteria: quote:"The exclusion criteria were as follows: (1) patients with gynaecologic tumours or genital tract malformations, (2) patients with severe systemic disease or acute and chron- 
Liu 2017 (Continued)

ic urogenital tract infections, (3) patients with other endocrine diseases such as thyroid disease and adrenal disease, (4) body mass index (BMI)>30, and (5) age over 35 years or below 20 years."

Number of women randomised: 268 women

Number of women analysed: Unknown if all 268 or only 240 were analysed

Number of withdrawals/exclusions/loss to follow-up and reasons: 28 women left the study; 13 in the CC groups, 15 in the LE groups; 5 in the CC + met and 7 in the LE + met group left the study due to complications; 3 participants were excluded (no reasons reported), the rest were lost to follow-up

Number of centres: single-centre trial

Age (y): group A (CC) $26.8 \pm 3.1$; group B (CC + met) $27.2 \pm 2.8$; group C (letrozole) $27.0 \pm 3.0$; group D (letrozole + met) $27.2 \pm 3.3$

BMI (kg/m²): group A (CC) 21.1 (19.9, 22.8); Group B (CC + met) $21.4(19.8,23.6)$; group C (letrozole) 20.8 (19.1, 22.3); group D (letrozole + met) $21.6(19.2,23.6)$

Duration of infertility (y): group $A(C C) 1(0,2)$; group $B(C C+$ met $) 1(0,3)$; group C (let) $1(0,2)$; group D (let + met) $1(0,3)$

Country: China

Interventions

Group A: the oral administration of CC was started in the group CC or CC + met from day 3 to day 5 of the menstrual cycle at a daily dose of $50 \mathrm{mg}$ for 5 days; and the daily dose gradually increased to 100 $\mathrm{mg}$ or $150 \mathrm{mg}$ at maximum in the next cycle if the undeveloped follicle $(<16 \mathrm{~mm})$ was present in the previous cycle.

Group B: The oral administration of letrozole started in the group letrozole or letrozole + met from day 3 to day 5 of the menstrual cycle at a daily dose of $5 \mathrm{mg}$ for 5 days.

Additional met $(1000-1500 \mathrm{mg} / \mathrm{d})$ was orally administered to participants in the groups CC + met and letrozole + met.

Outcomes Ovulation rate, pregnancy rate, live birth rate, miscarriage rate, premature delivery, OHSS, multiple pregnancy rate

Notes

Ethical approval: the study was approved by the ethics committee of the West China Second University Hospital, Sichuan University, China (approval No. Medical Research 2012 No. 004), and the study was registered in the Chinese Clinical Trial Registry Center (registration No. ChiCTR-TRC-11001821).

Informed consent: informed consent was obtained from each participant.

Source of funding: self-supported by West China Women's and Children's Hospital S.C.U

Power calculation: ovulation rate as the main indicator, the sample size was calculated by introducing maximal and minimal ovulation rate retrieved in literatures into the formula

\section{Risk of bias}

\begin{tabular}{lll}
\hline Bias & Authors' judgement & Support for judgement \\
\hline $\begin{array}{l}\text { Random sequence genera- } \\
\text { tion (selection bias) }\end{array}$ & Low risk & Randomisation with computer-generated blocks \\
\hline $\begin{array}{l}\text { Allocation concealment } \\
\text { (selection bias) }\end{array}$ & Unclear risk & Not reported \\
\hline $\begin{array}{l}\text { Blinding of participants } \\
\text { and personnel (perfor- } \\
\text { mance bias) }\end{array}$ & High risk & Not blinded \\
\hline
\end{tabular}


Liu 2017 (Continued)

All outcomes

\begin{tabular}{lll}
$\begin{array}{l}\text { Blinding of outcome as- } \\
\text { sessment (detection bias) } \\
\text { All outcomes }\end{array}$ & High risk & Not blinded \\
\hline $\begin{array}{l}\text { Incomplete outcome data } \\
\begin{array}{l}\text { (attrition bias) } \\
\text { All outcomes }\end{array}\end{array}$ & High risk & 28 of 268 women left the study $(>10 \%)$ \\
\hline
\end{tabular}

\begin{tabular}{lll}
\hline $\begin{array}{l}\text { Selective reporting (re- } \\
\text { porting bias) }\end{array}$ & Low risk & All outcomes expected were reported \\
\hline Other bias & Low risk & None \\
\hline
\end{tabular}

Moussa 2016

\begin{tabular}{ll}
\hline Methods & Randomised controlled clinical trial \\
& Duration and location of the trial: quote: "Three hundred and thirty seven infertile women with \\
anovulatory (PCOS) were recruited from the outpatient clinics of both 6th October and Bab Elshaaria \\
University Hospitals from August 2014 and January 2015."
\end{tabular}

Inclusion criteria: infertile women with anovulatory (PCOS), age between 20 and 35 years, BMI be-
tween 18 and $30 \mathrm{~kg} / \mathrm{m}^{2}$, normal uterus and patent tubes by hysterosalpingography, normal semen
analysis and normal serum prolactin

Exclusion criteria: women with endocrinal disturbance, active liver disease, local disease as hydro- or pyosalpinx, and history of previous ovarian surgery

Number of women randomised: 150 women

Number of women analysed: 150 women were analysed, 50 within each group

Number of withdrawals/exclusions/loss to follow-up and reasons: none

Number of centres: 2-centre trial

Age (y): group A: $27.5 \pm 4.1$, group B: $27.2 \pm 3.9$, group C: $27.5 \pm 4.1$

BMI (kg/m²): group A: $26.9 \pm 1.7$, group B: $26.8 \pm 1.7$, group C: $26.7 \pm 1.5$

Duration of infertility $(\mathbf{y})$ : group A: $1.9 \pm 0.7$, group B: $1.9 \pm 0.7$, and group C: $2.2 \pm 0.7$

Country: Egypt

Each of the 3 groups received 2 tablets for 5 days starting from day 3 - day 7 of the cycle
Group A: $100 \mathrm{mg}(50 \mathrm{mg} /$ tablet $)$ clomiphene citrate
Group B: $5 \mathrm{mg}(2.5 \mathrm{mg} /$ tablet $)$ letrozole
Group C: $40 \mathrm{mg}(20 \mathrm{mg} /$ tablet $)$ tamoxifen

Outcomes

Primary outcomes: endometrial thickness and endometrial blood flow (PI and RI)

Secondary outcomes: development and number of follicles, and the pregnancy rate

Ethical approval: the study was approved by the ethical committee of Al Azhar University. 
Moussa 2016 (Continued)

Informed consent: not reported

Source of funding: authors declare that they have neither conflict of interest nor received financial support.

Power calculation: not reported

\begin{tabular}{|c|c|c|}
\hline \multicolumn{3}{|l|}{ Risk of bias } \\
\hline Bias & Authors' judgement & Support for judgement \\
\hline $\begin{array}{l}\text { Random sequence genera- } \\
\text { tion (selection bias) }\end{array}$ & Low risk & $\begin{array}{l}\text { Quote: "The patients were prospectively randomised into three groups each } \\
\text { containing fifty patients by computer" }\end{array}$ \\
\hline $\begin{array}{l}\text { Allocation concealment } \\
\text { (selection bias) }\end{array}$ & Unclear risk & Not reported \\
\hline $\begin{array}{l}\text { Blinding of participants } \\
\text { and personnel (perfor- } \\
\text { mance bias) } \\
\text { All outcomes }\end{array}$ & Unclear risk & Not reported \\
\hline $\begin{array}{l}\text { Blinding of outcome as- } \\
\text { sessment (detection bias) } \\
\text { All outcomes }\end{array}$ & Unclear risk & Not reported \\
\hline $\begin{array}{l}\text { Incomplete outcome data } \\
\text { (attrition bias) } \\
\text { All outcomes }\end{array}$ & Low risk & All participants randomised were also analysed \\
\hline $\begin{array}{l}\text { Selective reporting (re- } \\
\text { porting bias) }\end{array}$ & Unclear risk & We found no study protocol \\
\hline Other bias & Low risk & None \\
\hline
\end{tabular}

Nazik 2012

Methods A partly-randomised controlled clinical trial.

Duration and location of the trial: not stated

Participants Inclusion criteria: infertile women with PCOS, diagnosis based on the 2003 Rotterdam criteria

Exclusion criteria: women with ovarian or adnexal surgery, hypothyroidism, hyperprolactinaemia, bilateral tubal occlusion diagnosed with hysterosalpingography and unexplained infertility, and those with follicles greater than $10 \mathrm{~mm}$

Number of centres: 1, infertility polyclinic of Atatürk University Medical Faculty Erzurum

Number of women randomised: 31 in group A, 33 in group B

Number of women analysed: 31 in group A, 33 in group B

Number of withdrawals/exclusions/loss to follow-up and reasons: 0

Age (y): group A letrozole: $25.6 \pm 4.5$, group B CC: $27.8 \pm 6.2$

BMI $\left(\mathbf{k g} / \mathbf{m}^{2}\right)$ : group A letrozole: $24.7 \pm 3.6$, group B CC: $24.9 \pm 4.8$ 
Nazik 2012 (Continued)

Duration of infertility $(\mathbf{y})$ : group A letrozole: $3.4 \pm 3.0$, group B CC: $4.4 \pm 3.6$

Country: Turkey

Interventions

Group A: letrozole, orally given $2.5 \mathrm{mg} /$ day for 5 days during cycle days 3 - 7

Group B: clomiphene citrate, orally given $100 \mathrm{mg} /$ day for 5 days during cycle days 3 - 7

Outcomes

Primary Outcomes: ovulation rate and pregnancy rate

Secondary Outcomes: ovarian hyperstimulation syndrome rate, miscarriage rate, multiple pregnancy rate, number of follicles on day of hCG ( $\geq 17 \mathrm{~mm}), \mathrm{E} 2(\mathrm{pg} / \mathrm{mL})$ on hCG day, endometrial thickness (mm), other side effects

Notes

Ethical approval: yes, quote: "Ethical approval was obtained from the institutional review board of Atatürk University Medical Faculty in order to conduct this study."

Informed consent: quote: "Instead of written consent verbal approval was obtained from the patients prior to study begin and treatment" - correspondence with Dr. Hakan Nazik

Source of funding: quote: "This study was done by researchers without any funding"

Power calculation: not stated

All questions were answered by Dr. Hakan Nazik

\section{Risk of bias}

\begin{tabular}{lll}
\hline Bias & Authors' judgement & Support for judgement \\
\hline $\begin{array}{l}\text { Random sequence genera- } \\
\text { tion (selection bias) }\end{array}$ & Low risk & $\begin{array}{l}\text { Quote: "The patients were randomly allocated using a computer random list } \\
\text { into first and second groups" }\end{array}$ \\
\hline $\begin{array}{l}\text { Allocation concealment } \\
\text { (selection bias) }\end{array}$ & Unclear risk & $\begin{array}{l}\text { Quote: "The patients were randomly allocated using a computer random list } \\
\text { into first and second groups" }\end{array}$ \\
\hline $\begin{array}{l}\text { Blinding of participants } \\
\text { and personnel (perfor- } \\
\text { mance bias) } \\
\begin{array}{l}\text { All outcomes } \\
\text { ing }\end{array}\end{array}$ & High risk & Quote: "There was no blinding in our study" (email with Dr. Hakan Nazik) \\
\hline
\end{tabular}

\begin{tabular}{|c|c|c|}
\hline Blinding of outcome as- & High risk & Quote: "There was no blinding in our study" (email with Dr. Hakan Nazik) \\
\hline
\end{tabular}
sessment (detection bias)

All outcomes

\begin{tabular}{lll}
$\begin{array}{l}\text { Incomplete outcome data } \\
\text { (attrition bias) } \\
\text { All outcomes }\end{array}$ & Low risk & No dropouts reported \\
\hline $\begin{array}{l}\text { Selective reporting (re- } \\
\text { porting bias) }\end{array}$ & Low risk & All expected outcomes reported \\
\hline Other bias & High risk & $\begin{array}{l}\text { Participants in Group 2 letrozole were significantly younger and had a signifi- } \\
\text { cantly shorter duration of infertility. }\end{array}$
\end{tabular}

Ramezanzadeh 2011

Methods Randomised controlled trial


Ramezanzadeh 2011 (Continued)

Duration and location of the trial: quote: "The study was conducted in the infertility clinic of a tertiary referral centre (Vali-E-asr Hospital-Tehran University of Medical Sciences) as a randomized controlled trial, between March 2009 and February 2010.“

Participants

Inclusion criteria: women with PCOS with infertility who underwent ovulation induction and timed intercourse for the first time. PCOS was diagnosed by the Rotterdam 2003 criteria. Participants were $<35$ years old with at least 1 year of infertility with no other infertility factor.

Exclusion criteria: ovarian cysts on cycle day 3 found by transvaginal ultrasound examination.

Number of centres: 1 , an infertility clinic of a tertiary referral centre

Number of women randomised: 80; group A letrozole $5 \mathrm{mg}$ : 40, group B letrozole $7.5 \mathrm{mg}: 40$

Number of women analysed: group A letrozole $5 \mathrm{mg}$ : 30, group B letrozole $7.5 \mathrm{mg}: 37$

Number of withdrawals/exclusions/loss to follow-up and reasons: 4 excluded in group $A$ due to a cyst before treatment, 6 lost to follow-up in group A and 3 lost to follow-up in group B

Age (y): group A letrozole $5 \mathrm{mg}: 28.3 \pm 5.0$, group B letrozole $7.5 \mathrm{mg}: 28.2 \pm 4.5$

BMI (kg/m²): group A letrozole $5 \mathrm{mg}: 25.9 \pm 4.2$, group B letrozole $7.5 \mathrm{mg}: 26.7 \pm 3.6$

Duration of infertility (y): group A letrozole $5 \mathrm{mg}: 3.6 \pm 2.3$, group B letrozole $7.5 \mathrm{mg}: 4.7 \pm 3.2$

Country: Iran

Interventions $\quad$ Group A: letrozole orally given, $5 \mathrm{mg} /$ day for 5 days from cycle days 3 - 7

Group B: letrozole orally given, $7.5 \mathrm{mg} /$ day for 5 days from cycle days 3 - 7

Outcomes

Number and size of follicles and endometrial thickness on days $12-14$, the number of days to reach mature follicle, day 7 testosterone level, day 21 progesterone level, ovulation rate, pregnancy rate, miscarriage rate, multiple pregnancy rate, ovarian hyperstimulation syndrome rate

Notes

Ethical approval: yes, the hospital research ethics board approved the study.

Informed consent: all participants gave informed consent before inclusion in trial.

Source of funding: not stated

Conflicts of interest: quote: "Conflict of interest: All of the authors do not have any conflict of interest"

Power calculation: quote: "Using PASS software and based on two previous studies, a sample size of 30 subjects in each group would provide $80 \%$ power to detect a significant difference in the number of mature follicles and duration of stimulation between two groups with a significant level of $0.05 . "$

\section{Risk of bias}

\begin{tabular}{lll}
\hline Bias & Authors' judgement & Support for judgement \\
\hline $\begin{array}{l}\text { Random sequence genera- } \\
\text { tion (selection bias) }\end{array}$ & Low risk & $\begin{array}{l}\text { Participants were randomly allocated using computer-generated random ta- } \\
\text { ble into 2 letrozole treatment groups. }\end{array}$ \\
\hline $\begin{array}{l}\text { Allocation concealment } \\
\text { (selection bias) }\end{array}$ & Unclear risk & Not stated \\
\hline $\begin{array}{l}\text { Blinding of participants } \\
\text { and personnel (perfor- } \\
\text { mance bias) } \\
\text { All outcomes }\end{array}$ & Unclear risk & Not stated \\
\hline
\end{tabular}


Ramezanzadeh 2011 (Continued)
Blinding of outcome as-
Unclear risk
Not stated sessment (detection bias)

All outcomes

\begin{tabular}{|c|c|c|}
\hline $\begin{array}{l}\text { Incomplete outcome data } \\
\text { (attrition bias) } \\
\text { All outcomes }\end{array}$ & High risk & $\begin{array}{l}4 \text { participants excluded due to ovarian cyst on day } 3 \text { sonography. } 9 \text { partici- } \\
\text { pants lost to follow-up, } 6 \text { from group A and } 3 \text { from group B, without reasons } \\
\text { given }\end{array}$ \\
\hline $\begin{array}{l}\text { Selective reporting (re- } \\
\text { porting bias) }\end{array}$ & Low risk & All outcomes reported. \\
\hline
\end{tabular}

\section{Ray 2012}

Methods Comparative randomised phase III open-labelled trial

Duration and location of the trial: quote: "A comparative, prospective, phase III, open labelled trial study was conducted in the Eden Hospital, Medical College Kolkata between January 2008 and December 2009."

Participants

Inclusion criteria: infertile women aged 20 - 35 with PCOS diagnosis based on the Rotterdam criteria 2003

Exclusion criteria: women with hyperprolactinaemia, thyroid disorder, male-factor infertility, known or suspicious tubal-factor infertility (endometriosis and pelvic inflammatory disease). Also women with a history of liver and kidney failure, cardiovascular diseases, diabetes, or women who consumed metformin or drugs affecting insulin secretion or CC in the previous 2 months

Number of centres: 1 , Eden Hopsital, Mecial College Kolkata

Number of women randomised: 147; group A letrozole: 69, group B CC: 78

Number of women analysed: group A letrozole: 69, group B CC: 78

Number of withdrawals/exclusions/loss to follow-up and reasons: 0

Age (y): group A letrozole: 28 (19 - 35), group B CC: 29 (20 - 35)

BMI ( $\left.\mathbf{k g} / \mathbf{m}^{2}\right)$ : group A letrozole: 28.8 (23.2 - 34.6), group B CC: 28.5 (24.2 - 33.6$)$

Duration of infertility (y): group A letrozole: 2.2, group B CC: 2.4 (SD or range not given)

Country: India

Interventions Group A: letrozole, $2.5 \mathrm{mg}$ /day given orally for 5 days from cycle day 3 - 7

Group B: clomiphene citrate, $100 \mathrm{mg} /$ day given orally for 5 days from cycle day 3 - 7

Outcomes

Primary Outcomes: ovulation rate, average follicular diameter on day 16 , number of mature follicles produced by cycle, mean estradiol level on the day of hCG administration, mean endometrial thickness, pregnancy rate

Secondary Outcomes: miscarriage rate, live birth rate

Notes

Ethical approval: yes, the study protocol was approved by the ethical committee of Medical College Kolkata

Informed consent: yes, participants were counselled and informed consent was obtained before recruitment 
Source of funding: quote: "Conflict of interest: the authors hereby declare that they have not received any financial support for this study and there is no conflict of interest."

Power calculation: not stated

We contacted Dr. Ray by email about randomisation, allocation, blinding, MPR and OHSS, but he did not respond.

\section{Risk of bias}

\begin{tabular}{|c|c|c|}
\hline Bias & Authors' judgement & Support for judgement \\
\hline $\begin{array}{l}\text { Random sequence genera- } \\
\text { tion (selection bias) }\end{array}$ & Unclear risk & Unclear how randomisation was done \\
\hline $\begin{array}{l}\text { Allocation concealment } \\
\text { (selection bias) }\end{array}$ & Unclear risk & Unclear how allocation was done \\
\hline $\begin{array}{l}\text { Blinding of participants } \\
\text { and personnel (perfor- } \\
\text { mance bias) } \\
\text { All outcomes }\end{array}$ & Unclear risk & Not reported if anyone was blinded \\
\hline $\begin{array}{l}\text { Blinding of outcome as- } \\
\text { sessment (detection bias) } \\
\text { All outcomes }\end{array}$ & Unclear risk & Not reported if anyone was blinded \\
\hline $\begin{array}{l}\text { Incomplete outcome data } \\
\text { (attrition bias) } \\
\text { All outcomes }\end{array}$ & Unclear risk & $\begin{array}{l}\text { No participants stated as lost, but } 147 \text { participants is an odd number to start } \\
\text { with, and so are the groups of } 69 \text { and } 78 \text { respectively; authors contacted for } \\
\text { protocol }\end{array}$ \\
\hline $\begin{array}{l}\text { Selective reporting (re- } \\
\text { porting bias) }\end{array}$ & Unclear risk & All expected outcomes were reported, but contacted authors for protocol \\
\hline Other bias & Low risk & None \\
\hline
\end{tabular}

Roy 2012

Methods Randomised clinical trial

Duration and location of the trial: quote: "This prospective randomized controlled trial was performed at a tertiary care hospital from January 2005 to January 2010."

Participants

Inclusion criteria: women aged 20 - 35 years having infertility for $>1$ year, $\mathrm{BMI}<28$, and with anovulatory PCOS based on the Rotterdam 2003 criteria

Exclusion criteria: quote: "in all patients, a comprehensive infertility work-up was done. This included a tubal patency test, pelvic ultrasonography, husband semen analysis, and serum hormone measurements (FSH, LH, prolactin, estradiol, progesterone, and testosterone) on the 2 nd to 5 th day of the cycle. Patients having abnormality in any of these tests, which may be responsible for reproductive failure, were excluded from the study."

Number of centres: 1 , a tertiary care hospital in India

Number of women randomised: 212 women; group A let: 104, group B CC: 108

Number of women analysed: letrozole group: 98, clomiphene group: 106

Number of withdrawals/exclusions/loss to follow-up and reasons: 8 lost to follow-up 
Age (y): group A letrozole: $26.1 \pm 1.8$, group B CC: $26.5 \pm 1.3$

BMI ( $\left.\mathbf{k g} / \mathbf{m}^{2}\right)$ : group A letrozole: $25.8 \pm 2.1$, group B CC: $25.4 \pm 1.6$

Duration of infertility $(\mathbf{y})$ : group A letrozole: $6.4 \pm 3$.8, group B CC: $5.8 \pm 3.1$

Country: India

Interventions

Group A: letrozole, orally given in doses of $2.5 \mathrm{mg} /$ day and $5 \mathrm{mg} /$ day for 5 days during cycle days 3 - 7

Group B: clomiphene citrate, orally given in doses of $50 \mathrm{mg} /$ day and $100 \mathrm{mg} /$ day for 5 days during cycle days $3-7$

Treatment was continued for 3 months.

Outcomes The mean number of follicles, endometrial thickness, ovulatory cycle rate, conception rate, pregnancy
outcome, miscarriage rate, multiple pregnancies and OHSS rate

Notes Ethical approval: yes, the necessary ethical approval was taken from Institutional Review Board to conduct this study.

Informed consent: yes, the participants were counselled, and informed consent was taken before randomisation.

Source of funding: quote: "Source of support: Nil, Conflict of interest: None declared."

Power calculation: quote: "On basis of previous studies, to achieve a statistically valid comparison of pregnancy rates in the two groups, with a type I error of 0.05 and a power of $80 \%$, a sample size of at least 40 women in each arm was required."

We contacted Dr. Roy by email to get additional information, but he did not respond.

\section{Risk of bias}

\begin{tabular}{lll}
\hline Bias & Authors' judgement & Support for judgement \\
\hline $\begin{array}{l}\text { Random sequence genera- } \\
\text { tion (selection bias) }\end{array}$ & Low risk & $\begin{array}{l}\text { Online software was used to generate a random number table (www.random- } \\
\text { ization.com). }\end{array}$ \\
\hline $\begin{array}{l}\text { Allocation concealment } \\
\text { (selection bias) }\end{array}$ & Unclear risk & $\begin{array}{l}\text { Quote: "Randomisation codes (A, B) were packed into sealed opaque en- } \\
\text { velopes by an individual not involved in enrolment, treatment and follow-up } \\
\text { of subjects to ensure concealment of allocation. One resident had the respon- } \\
\text { sibility for dispensing the trial drugs to the patient based on the unique ran- } \\
\text { domisation code. At the end of allocation, the resident provided us with a ran- } \\
\text { domisation list." }\end{array}$ \\
\hline
\end{tabular}

Blinding of participants $\quad$ Unclear risk $\quad$ Not stated
and personnel (perfor-
mance bias)

\begin{tabular}{lll}
\hline $\begin{array}{l}\text { Blinding of outcome as- } \\
\text { sessment (detection bias) } \\
\text { All outcomes }\end{array}$ & Unclear risk & Not stated \\
\hline $\begin{array}{l}\text { Incomplete outcome data } \\
\text { (attrition bias) }\end{array}$ & Low risk & 8 losses to follow-up of 112 participants \\
All outcomes & \\
\hline
\end{tabular}

Selective reporting (re- Low risk $\quad$ All expected outcomes reported
porting bias)


Roy 2012 (Continued)
Other bias
Low risk
None

Selim 2012

\begin{tabular}{ll} 
Methods & Randomised controlled trial \\
& Duration and location of the trial: not stated \\
\hline Participants & $\begin{array}{l}\text { Inclusion criteria: diagnosis of PCOS based on Rotterdam criteria provided that anovulation is } 1 \text { of the } \\
2 \text { required criteria }\end{array}$ \\
& Exclusion criteria: quote: "exclusion criteria included hyperprolactinaemia, congenital adrenal hyper- \\
plasia, thyroid disease, other causes of amenorrhoea such as premature ovarian failure, and clinical- \\
ly suspected Cushing's syndrome or androgen-secreting neoplasm. Exclusion criteria also included all \\
women who had received metformin or ovarian drilling in the previous 6 months. Other causes of infer- \\
tility were excluded by documentation of a normal uterine cavity and at least one patent fallopian tube, \\
and each woman's current partner had a semen concentration of at least $2 \cdot 107 / \mathrm{mL} . "$
\end{tabular}

Number of centres: not reported

Number of women randomised: 220; group A letrozole: 110, group B CC: 110

Number of women analysed: group A letrozole: 102, group B CC: 99

Number of withdrawals/exclusions/loss to follow-up and reasons: quote: "In the letrozole group, eight women were excluded because of missed follow-up visits (three women), treatment suspension (two women), and homogenous not triple-line endometrial pattern (three women). In the CC group, 11 women were excluded because of missed follow-up visits (four women), treatment suspension (two women), and homogenous not triple-line endometrial pattern (five women)."

Age (y): group A letrozole: $26.0 \pm 2.7$, group B CC: $25.1 \pm 3.1$

BMI ( $\left.\mathbf{k g} / \mathbf{m}^{2}\right)$ : group A letrozole: $24.4 \pm 4.3$, group B CC: $23.8 \pm 3.7$

Duration of infertility (y): group A letrozole: $2.9 \pm 0.6$, group B CC: $2.6 \pm 0.7$

Country: Saudi Arabia

Interventions

Group A: 110 participants treated with $5 \mathrm{mg} /$ day of letrozole (Femara; Novartis, Switzerland) in 2 divided doses from cycle day $3-7$

Group B: 110 participants treated with 100 mg/day of CC (Clomid; Sanofi Aventis, France) in 2 divided doses from cycle day 3 - 7

Outcomes quote: "The mean number of follicles, endometrial thickness, the Doppler study of endometrial and sub endometrial vasculatures, ovulation rate, and pregnancy rate were compared in both groups."

Notes Ethical approval: quote: "approval was obtained from the Institutional Review Board of Jeddah Clinic Hospital, Jeddah, Saudi Arabia."

Informed consent: yes, quote: "all participants gave verbal and written informed consent."

Source of funding: not stated

Conflicts of interest: quote: "No competing financial interests exist."

Power calculation: not stated 
Selim 2012 (Continued)

\begin{tabular}{|c|c|c|}
\hline Bias & Authors' judgement & Support for judgement \\
\hline $\begin{array}{l}\text { Random sequence genera- } \\
\text { tion (selection bias) }\end{array}$ & Low risk & $\begin{array}{l}\text { Participants were randomly allocated to the letrozole group or CC group by } \\
\text { means of a series of blind envelopes numbered from } 1 \text { to } 220 \text {. }\end{array}$ \\
\hline $\begin{array}{l}\text { Allocation concealment } \\
\text { (selection bias) }\end{array}$ & Low risk & $\begin{array}{l}\text { Each participant was invited to choose an envelope and was placed by the } \\
\text { clinic secretary in either the letrozole group or the CC group. }\end{array}$ \\
\hline $\begin{array}{l}\text { Blinding of participants } \\
\text { and personnel (perfor- } \\
\text { mance bias) } \\
\text { All outcomes }\end{array}$ & High risk & Quote: "The patients were not blinded about the treating drug in either group." \\
\hline $\begin{array}{l}\text { Blinding of outcome as- } \\
\text { sessment (detection bias) } \\
\text { All outcomes }\end{array}$ & Low risk & $\begin{array}{l}\text { To remove any inter-observational bias, ultrasound on all participants was } \\
\text { demonstrated by a single observer (MF Selim) who was blinded to the treating } \\
\text { drug. }\end{array}$ \\
\hline $\begin{array}{l}\text { Incomplete outcome data } \\
\text { (attrition bias) } \\
\text { All outcomes }\end{array}$ & Low risk & All dropouts were reported, reasons given. \\
\hline $\begin{array}{l}\text { Selective reporting (re- } \\
\text { porting bias) }\end{array}$ & Low risk & All expected outcomes were reported. \\
\hline Other bias & Low risk & None \\
\hline
\end{tabular}

Seyedoshohadaei 2016

Methods Randomised controlled clinical trial

Duration and location of the trial: quote: "This double blind clinical trial study was conducted on 100 PCOS infertile women who have not responded to initial treatment, referring to the Infertility Center of Sanandaj Besat Hospital from June 2014 to December 2015.“

\section{Participants}

Inclusion criteria: PCOS infertile women who have not responded to initial treatment. PCOS was confirmed by Rotterdam criteria (menstrual disturbances: oligomenorrhoea or amenorrhoea, clinical or biochemical hyperandrogenism and sonographic findings of polycystic ovaries). Women with 2 of the 3 PCOS criteria were included in the study.

Exclusion criteria: women with hyperprolactinaemia, thyroid problems and anatomical problem in uterus cavity and fallopian tubes confirmed by hysterosalpangiography, sonohysterography or laparoscopy were excluded from the study.

Number of women randomised: 100 women, 50 to each group

Number of women analysed: 100 women, 50 in each group

Number of withdrawals/exclusions/loss to follow-up and reasons: none

Number of centres: single centre

Age (y): group A (CC + EV) $30.3 \pm 3.1$; group B (letrozole) $29.6 \pm 5.1$

BMI $\left(\mathbf{k g} / \mathbf{m}^{2}\right)$ : not reported

Duration of infertility (y): group A (CC + EV) $3.4 \pm 2.8$; group B (letrozole) $3.9 \pm 2.4$

Country: Iran 
Seyedoshohadaei 2016 (Continued)

Interventions

Group A: 100 mg clomiphene citrate (Iran Hormone Pharmaceutical Company) from day 3 - day 7 of menstruation and $4 \mathrm{mg}$ estradiol valerate (Aburaihan Pharmacy Company) after the 8th day of menstruation until 14th day

Group B: 5 mg letrozole (Iran Hormone Pharmaceutical Company) from day 3 - 7 of menstruation with placebo from 8 th - 14th day of menstruation

\begin{tabular}{|c|c|}
\hline Outcomes & Pregnancy rate, outcome of pregnancy, live birth, miscarriage rate, endometrial thickness \\
\hline \multirow[t]{4}{*}{ Notes } & $\begin{array}{l}\text { Ethical approval: quote: "This study was approved by the Ethics Committee of Kurdistan University } \\
\text { of Medical Sciences and has been registered in the Iranian Registry of Clinical Trials with registration } \\
\text { number IRCT2015052612789N11." }\end{array}$ \\
\hline & Informed consent: quote: "Written consent was taken before the intervention." \\
\hline & $\begin{array}{l}\text { Source of funding: quote: "Authors would like to thank Vice Chancellor for Research of Kurdistan Uni- } \\
\text { versity of Medical Sciences to support the study financially. " }\end{array}$ \\
\hline & $\begin{array}{l}\text { Power calculation: quote: "The sample size was calculated based on previous studies. Considering the } \\
\text { mean of endometrial thickness, } 5 \% \text { type I error and } 20 \% \text { type II error, } 45 \text { patients were required in each } \\
\text { group. To compensate for possible loss and increase the power of the study, } 50 \text { patients were studied in } \\
\text { each group." }\end{array}$ \\
\hline
\end{tabular}

\section{Risk of bias}

\begin{tabular}{|c|c|c|}
\hline Bias & Authors' judgement & Support for judgement \\
\hline $\begin{array}{l}\text { Random sequence genera- } \\
\text { tion (selection bias) }\end{array}$ & Low risk & Women were block-randomised and divided in 2 groups \\
\hline $\begin{array}{l}\text { Allocation concealment } \\
\text { (selection bias) }\end{array}$ & Unclear risk & Not reported \\
\hline $\begin{array}{l}\text { Blinding of participants } \\
\text { and personnel (perfor- } \\
\text { mance bias) } \\
\text { All outcomes }\end{array}$ & Unclear risk & $\begin{array}{l}\text { Quote: "To blind the study, transvaginal sonography was performed by a fel- } \\
\text { low of infertility, the medication was prescribed by a gynaecologist and the pa- } \\
\text { tients in group B received placebo." }\end{array}$ \\
\hline $\begin{array}{l}\text { Blinding of outcome as- } \\
\text { sessment (detection bias) } \\
\text { All outcomes }\end{array}$ & Unclear risk & $\begin{array}{l}\text { Quote: "To blind the study, transvaginal sonography was performed by a fel- } \\
\text { low of infertility, the medication was prescribed by a gynaecologist and the pa- } \\
\text { tients in group B received placebo." }\end{array}$ \\
\hline $\begin{array}{l}\text { Incomplete outcome data } \\
\text { (attrition bias) } \\
\text { All outcomes }\end{array}$ & Low risk & All women randomised were also analysed \\
\hline $\begin{array}{l}\text { Selective reporting (re- } \\
\text { porting bias) }\end{array}$ & Unclear risk & No study protocol was found \\
\hline Other bias & Low risk & None \\
\hline
\end{tabular}

\section{Sh-El-Arab Elsedeek 2011}

Methods Randomised controlled double-blind trial

Duration and location of the trial: not stated 
Sh-El-Arab Elsedeek 2011 (Continued) $\begin{array}{ll}\text { Participants } & \text { Inclusion criteria: diagnosis of PCOS based on Rotterdam criteria provided that anovulation is } 1 \text { of the } \\ 2 \text { required criteria }\end{array}$

Exclusion criteria: exclusion criteria were BMI > 35, presence of other causes of infertility, $>5$ years infertility duration and known poor response to either drugs in previous cycles. Cases found to have baseline ovarian cysts or endometrial pathology were also excluded.

Number of centres: 1 , an infertility unit of a university hospital

Number of women randomised: 124; group A letrozole: 62, group B CC: 62

Number of women analysed: group A letrozole: 59, group B CC: 57

Number of withdrawals/exclusions/loss to follow-up and reasons: 3 in the letrozole and 5 in the CC group were reported as lost to follow-up, but no further explanation given

Age (y): group A letrozole: $25.0 \pm 3.1$, group B CC: $25.0 \pm 3.6$

BMI (kg/m²): group A letrozole: $27.7 \pm 3.5$, group B CC: $29.2 \pm 3.5$

Duration of infertility (y): Not reported

Country: India

\begin{tabular}{ll} 
Interventions & Group A: letrozole, $5 \mathrm{mg} /$ day orally given for 5 days, cycle days not given \\
& Group B: clomiphene citrate, $100 \mathrm{mg} /$ day orally given for 5 days, cycle days not given \\
\hline Outcomes & $\begin{array}{l}\text { Pregnancy rate, ovulation rate, endometrial thickness }(\mathrm{mm}), \text { mid-luteal progesterone level }(\mathrm{ng} / \mathrm{mL}), \\
\text { number of follicles } \geq 12 \mathrm{~mm}\end{array}$
\end{tabular}

Notes

Ethical approval: yes, institutional review board (IRB) approval was obtained for the study.

Informed consent: yes, informed consent was taken from all included cases

Source of funding: not reported, also no conflicts of interest given.

Power calculation: not stated

We contacted Dr. Sheik-el-Arab Elsedeek by email about allocation concealment, blinding of outcome assessors, information on live birth, miscarriage rate, OHSS, multiple pregnancies and funding/COI, but he did not respond.

\section{Risk of bias}

\begin{tabular}{lll}
\hline Bias & Authors' judgement & Support for judgement \\
\hline $\begin{array}{l}\text { Random sequence genera- } \\
\text { tion (selection bias) }\end{array}$ & Low risk & $\begin{array}{l}\text { Quote: "Patients were randomised using computer generated tables to under- } \\
\text { go one cycle of CC or let induction." }\end{array}$ \\
\hline $\begin{array}{l}\text { Allocation concealment } \\
\text { (selection bias) }\end{array}$ & Unclear risk & Not stated \\
\hline $\begin{array}{l}\text { Blinding of participants } \\
\begin{array}{l}\text { and personnel (perfor- } \\
\text { mance bias) }\end{array}\end{array}$ & Unclear risk & Not stated if personnel were blinded and how the participants were blinded \\
$\begin{array}{l}\text { All outcomes } \\
\begin{array}{l}\text { Blinding of outcome as- } \\
\text { sessment (detection bias) } \\
\text { All outcomes }\end{array}\end{array}$ & Unclear risk & $\begin{array}{l}\text { Quote: "Both patients and sonographers were blinded to this allocation." - Un- } \\
\text { clear if the other outcome assessors were blinded }\end{array}$ \\
\hline
\end{tabular}


Sh-El-Arab Elsedeek 2011 (Continued)
Incomplete outcome data Low risk
8 participants lost to follow-up, reasons unknown
(attrition bias)
risk
8 participants lost to follow-up, reasons unknown

All outcomes

\begin{tabular}{lll}
$\begin{array}{l}\text { Selective reporting (re- } \\
\text { porting bias) }\end{array}$ & Unclear risk & Only pregnancy was reported; we contacted the authors to get study protocol. \\
\hline Other bias & Low risk & None
\end{tabular}

Sharief 2015

Methods Randomised controlled clinical trial

Duration and location of the trial: quote: "The prospective clinical trial was conducted at Basrah Maternity and Child Hospital, Basrah, Iraq, between January 2012 and April 2013, and comprised women with PCOS and primary infertility."

Participants

Inclusion criteria: quote: "Women with PCOS and primary infertility. The subjects were selected from among those who were attending the infertility centre with primary infertility, which was defined as inability of a couple to obtain pregnancy after 1-2 years of unprotected intercourse. All subjects were diagnosed as having anovulation due to PCOS. PCOS was diagnosed when the ultrasonographic (USG) findings of the ovaries were $>10$ follicles $2-8 \mathrm{~mm}$ in diameter scattered either around or through an echodense thickened central stroma. In addition, there had to be one or more of the following: oligomenorrhoea, positive progesterone, withdrawal bleeding, hirsutism/acne, obesity, and Luteinizing hormone/Follicle-stimulating hormone (LH/FSH) ratio $>2$ or raised circulating androgen, normal thyroid stimulating hormone (TSH). Those included were aged between 18 and 36 years, period of infertility was more than 2 years, serum prolactin level was normal, serum FSH $<12 \mathrm{u} / \mathrm{L}$, normal thyroid function, and hirsutism, which was diagnosed when the Ferriman and Gallwey score was $>8.9$ Besides, the male partners had to have a normal seminal analysis by World Health Organisation (WHO) criterion."

Exclusion criteria: all women having had patent tubes by either hysterosalpingogram or laparoscopy, history of pelvic surgery with tubal blockage were excluded from the study.

Number of women randomised: not stated how many participants were randomised

Number of women analysed: 75 women were analysed, 40 in group A, 35 in group B

Number of withdrawals/exclusions/loss to follow-up and reasons: not stated

Number of centres: single centre

Age (y): group A $25.3 \pm 2.1$ years, group B $26.1 \pm 1.3$ years

BMI $\left(\mathbf{k g} / \mathbf{m}^{2}\right)$ : group A $27.8 \pm 1.7$, group B $28.1 \pm 1.9$

Duration of infertility (y): group A $2.3 \pm 0.4$, group B $2.4 \pm 0.6$

Country: Iraq

Interventions

Group A: clomiphene citrate for 6 months with a dose between $100-200$ mg for 5 days beginning on day 3 of the menstrual cycle

Group B: letrozole 2.5 - $5 \mathrm{mg}$ daily for 5 days starting from the 3rd day of a spontaneous or progesterone-induced menstrual bleeding

\section{Outcomes}

Pregnancy rate, multiple pregnancies, follicular development, $\mathrm{N}$ of follicles, serum E2 on day of HCG, endometrial thickness, ovulation rate 
Sharief 2015 (Continued)

Notes
Ethical approval: approval was obtained from the ethical committee of the College of Medicine, University of Basrah, Iraq.

Informed consent: not reported if informed consent was obtained

Source of funding: not reported

Power calculation: not reported

\section{Risk of bias}

\begin{tabular}{|c|c|c|}
\hline Bias & Authors' judgement & Support for judgement \\
\hline $\begin{array}{l}\text { Random sequence genera- } \\
\text { tion (selection bias) }\end{array}$ & Unclear risk & Quote: "The patients were randomised into two groups." \\
\hline $\begin{array}{l}\text { Allocation concealment } \\
\text { (selection bias) }\end{array}$ & Unclear risk & Not reported \\
\hline $\begin{array}{l}\text { Blinding of participants } \\
\text { and personnel (perfor- } \\
\text { mance bias) } \\
\text { All outcomes }\end{array}$ & Unclear risk & Not reported \\
\hline $\begin{array}{l}\text { Blinding of outcome as- } \\
\text { sessment (detection bias) } \\
\text { All outcomes }\end{array}$ & Unclear risk & Not reported \\
\hline $\begin{array}{l}\text { Incomplete outcome data } \\
\text { (attrition bias) } \\
\text { All outcomes }\end{array}$ & Unclear risk & Not reported how many women were randomised in first instance \\
\hline $\begin{array}{l}\text { Selective reporting (re- } \\
\text { porting bias) }\end{array}$ & Unclear risk & No study protocol was found \\
\hline Other bias & Low risk & None \\
\hline
\end{tabular}

\section{Sohrabvand 2006}

\begin{tabular}{ll}
\hline Methods & Single-blinded randomised clinical trial \\
& Duration and location of the trial: quote: "In this single-blind randomized clinical trial, 120 ovarian \\
cycles were studied in 60 clomiphene-resistant patients with PCOS, who were chosen among 115 PCOS \\
patients attending the infertility clinic of Vali-e-Asr Hospital (Tehran, Iran) during the years 2003-2004."
\end{tabular}

Participants

Inclusion criteria: women with PCOS who had failed to become pregnant after 3 courses of $150 \mathrm{mg}$ clomiphene citrate (considered as clomiphene-resistant), whereas the values of hormonal tests were normal. Tests: thyroid function, prolactin level, hysterosalpingography and husband's sperm analysis

Exclusion criteria: women with a history of liver and kidney failure, cardiovascular disease, diabetes (based on criteria set by the American Diabetic Association) or women who consumed metformin or drugs affecting insulin secretion or clomiphene citrate in the previous 2 months

Number of centres: 1 , infertility clinic of Vali-e-Asr Hospital, Tehran

Number of women randomised: 60; group A met-letrozole: 30 , group B met-CC: 30

Number of women analysed: group A met-letrozole: 29 , group B met-CC: 30 
Number of withdrawals/exclusions/loss to follow-up and reasons: 1 because she got pregnant after met treatment before letrozole was started

Age (y): group A met-letrozole: $28.2 \pm 3.1$, group B met-CC: $29.6 \pm 3.5$

BMI $\left(\mathbf{k g} / \mathbf{m}^{2}\right)$ : group A met-letrozole: $30.0 \pm 4.8$, group B met-CC: $30.2 \pm 3.9$

Duration of infertility (y): group A met-letrozole: 3.8 , group B met-CC: 3.8

Country: Iran

Interventions

Group A: metformin $500 \mathrm{mg}$ x 3/d for 6 - 8 weeks. If pregnancy did not occur, $2.5 \mathrm{mg}$ letrozole from cycle days 3 - 7 was given orally.

Group B: metformin $500 \mathrm{mg}$ x 3/d for 6 - 8 weeks. If pregnancy did not occur, $100 \mathrm{mg}$ CC from cycle days 3 - 7 was given orally.

Treatment was continued for 2 cycles.

Outcomes Endometrial thickness on day of hCG administration $(\mathrm{cm}), \mathrm{N}$ of follicles $>18$ mm in diameter, Mean total estradiol level on day of hCG administration (pM/L), mean estradiol level by mature follicle (pM/l), regular menses after metformin, adverse effects of metformin, live birth rate, pregnancy rate, miscarriage rate

Notes

Ethical approval: yes, consent from the deputy of research and the medical ethics committee of Tehran University of Medical Sciences

Informed consent: not obtained because quote: "it was the routine treatment protocol and it was just put in the frame of a structured study" (email with Dr Farnaz Sohrabvand)

Source of funding: quote: "No funding was necessary" (email with Dr Farnaz Sohrabvand)

Power calculation: not stated

Authors were contacted about live birth, multiple pregnancies, OHSS per woman randomised, informed consent, funding. No data available on live birth, multiple pregnancies and OHSS. Information retrieved about informed consent and funding (email with Dr Farnaz Sohrabvand)

\section{Risk of bias}

\begin{tabular}{lll}
\hline Bias & Authors' judgement & Support for judgement \\
\hline $\begin{array}{l}\text { Random sequence genera- } \\
\text { tion (selection bias) }\end{array}$ & Low risk & $\begin{array}{l}\text { Quote: "A series of blind envelopes numbered from 1 to } 60 \text { had been prepared. } \\
\text { Each patient was invited to pull out an envelope and was placed by the clinic } \\
\text { secretary in either the metformin-letrozole group (number 1-30) or in the met- } \\
\text { formin-CC group (31-60)." }\end{array}$ \\
\hline $\begin{array}{l}\text { Allocation concealment } \\
\text { (selection bias) }\end{array}$ & Unclear risk & $\begin{array}{l}\text { Quote: "A series of blind envelopes numbered from 1 to 60 had been prepared. } \\
\text { Each patient was invited to pull out an envelope and was placed by the clinic } \\
\text { secretary in either the metformin-letrozole group (number 1-30) or in the met- } \\
\text { formin-CC group (31-60)." }\end{array}$ \\
\hline
\end{tabular}

Blinding of participants High risk Participants were not blinded.
and personnel (perfor-
mance bias)
All outcomes

Blinding of outcome as-

High risk

It is not plausible that outcome assessors were blinded if participants were not sessment (detection bias)

All outcomes 
Sohrabvand 2006 (Continued)

Incomplete outcome data Low risk One participant was excluded due to pregnancy after start of metformin treat(attrition bias) ment

All outcomes

Selective reporting (re- Low risk All outcomes were reported

porting bias)

Other bias Low risk None

Wu 2016

Methods Randomised clinical trial

Duration of the trial: quote: "The trial was started on October 2009. Owing to the expiration of the study drug (berberine and matching placebo), the data safety and monitoring board decided to stop enrollment in November 2013“

Participants

Inclusion criteria: quote: "Chinese women with PCOS attempting to get pregnant were eligible if they fulfilled the following criteria: 1 ) age $20-40$ years; 2 ) diagnosis of PCOS according to two of the three Rotterdam 2003 criteria, including oligo-ovulation or anovulation, clinical and/or biochemical signs of hyperandrogenism, and/or polycystic ovaries; 3 ) at least one open fallopian tube and normal uterine cavity documented by hysterosalpingography, sonohysterography, or diagnostic laparoscopy within the past 3 years; 4) a male partner with sperm concentration of 15 million $/ \mathrm{mL}$ and motility of $40 \%$ in at least one ejaculate; and 5) at least 1 year of infertility."

Exclusion criteria: quote: "Subjects were excluded if they used hormonal drugs or other medications, including Chinese herbal prescriptions, in the past 3 months; had known severe organ dysfunction or mental illness; were pregnant, post-miscarriage, postpartum, or breastfeeding within the past 6 weeks; or had congenital adrenal hyperplasia, clinically suspected Cushing syndrome, or an androgen-secreting neoplasm."

\section{Number of women randomised: 644 women}

Number of women analysed: 644 women were analysed, 215 in group A, 214 in group B, 215 in group C.

Number of withdrawals/exclusions/loss to follow-up and reasons: $16 / 215(7.4 \%)$ in the letrozole group, $25 / 214(11.7 \%)$ in the berberine group, and $15 / 215(7.0 \%)$ in the combination group $(P=0.16)$. Reasons for withdrawal were similar among the 3 groups $(P=0.16$ for the 3 groups; $P=0.19$ for lost to follow-up; $\mathrm{P}=0.88$ for dropout; $\mathrm{P}=1.0$ for protocol violations; and $\mathrm{P}=0.33$ for adverse events).

Number of centres: multicentre trial, 19 hospitals

Age (y): group A $27.8 \pm 3.6$; group B $27.8 \pm 3.7$; group C $27.8 \pm 3.6$

BMI $\left(\mathbf{k g} / \mathbf{m}^{2}\right)$ : group A $24.8 \pm 4.5$; group B $24.5 \pm 4.1$; group C $25.1 \pm 5.0$

Duration of infertility (months): group A $32.7 \pm 24$.0; group B $28.5 \pm 21.6$; group C $29.8 \pm 21.3$

Country: China

Interventions

Group A: $2.5 \mathrm{mg}$ ( 1 tablet) of letrozole on days $3-7$ of the first 3 treatment cycles. This dose was increased to $5 \mathrm{mg}$ letrozole ( 2 tablets) or 2 tablets of letrozole placebo on days $3-7$ of the last 3 treatment cycles if not pregnant

Group B: berberine was administered orally at a daily dose of $1.5 \mathrm{~g}$ for 6 months.

Group C: letrozole and berberine were administered in the same doses as reported above. 
Wu 2016 (Continued)

Outcomes Cumulative live births, ovulation rate, conception rate, clinical pregnancy rate, multiple pregnancy rate, abortion rate, pregnancy complications, adverse events from study medications

Notes

Ethical approval: the Institutional Review Boards at participating hospitals approved the protocol.

Informed consent: every participant gave written informed consent.

Source of funding: supported by National Public Welfare Projects for Chinese Medicine (200807021) of China, National Key Discipline of Chinese Medicine in Gynecolog, 2009-14, Heilongjiang Province Foundation for Outstanding Youths (JC200804), Intervention for Polycystic Ovary Syndrome Based on Traditional Chinese Medicine Theory-"TianGui Shi Xu" (2011TD006), and National Clinical Research Base in Chinese Medicine, 2009-14, at First Affiliated Hospital, Heilongjiang University of Chinese Medicine. The funding sources had no involvement in the study design, the collection, analysis, and interpretation of data, the writing of the report, or in the decision to submit the article for publication.

Power calculation: the sample size calculation was based on anticipated live birth rate.

\section{Risk of bias}

Bias Authors' judgement Support for judgement

Random sequence genera- Low risk tion (selection bias)
Quote: "The randomisation was performed through a web-based computer program (http://210.76.97.192:8080/cjbyj) operated by an independent data coordinating centre, the Institute of Basic Clinical Medicine of the China Academy of Chinese Medical Sciences. The randomisation was stratified by the participating sites."

\begin{tabular}{|c|c|c|}
\hline $\begin{array}{l}\text { Allocation concealment } \\
\text { (selection bias) }\end{array}$ & Low risk & Randomisation was operated by an independent data co-ordinating centre \\
\hline $\begin{array}{l}\text { Blinding of participants } \\
\text { and personnel (perfor- } \\
\text { mance bias) } \\
\text { All outcomes }\end{array}$ & Low risk & $\begin{array}{l}\text { Participants, investigators, physicians taking care of the participants, labora- } \\
\text { tory technicians, and data analysers were blinded to the assignments. }\end{array}$ \\
\hline $\begin{array}{l}\text { Blinding of outcome as- } \\
\text { sessment (detection bias) } \\
\text { All outcomes }\end{array}$ & Low risk & $\begin{array}{l}\text { Participants, investigators, physicians taking care of the participants, labora- } \\
\text { tory technicians, and data analysers were blinded to the assignments. }\end{array}$ \\
\hline $\begin{array}{l}\text { Incomplete outcome data } \\
\text { (attrition bias) } \\
\text { All outcomes }\end{array}$ & Low risk & $\begin{array}{l}7 \%-12 \% \text { were lost to follow-up, had protocol violations or adverse events. ITT } \\
\text { analysis was performed. }\end{array}$ \\
\hline $\begin{array}{l}\text { Selective reporting (re- } \\
\text { porting bias) }\end{array}$ & Low risk & $\begin{array}{l}\text { None, study protocol was published prior to participant enrolment in the } \\
\text { study }\end{array}$ \\
\hline Other bias & Low risk & None \\
\hline
\end{tabular}

\begin{tabular}{ll}
\hline Methods & Randomised controlled clinical trial \\
& $\begin{array}{l}\text { Duration of the trial: quote: "They underwent intra uterine insemination (IUI) between August } 2011 \\
\text { and December } 2012 . "\end{array}$ \\
\hline Participants & $\begin{array}{l}\text { Inclusion criteria: quote: "patients with CC-resistant PCOS. According to Rotterdam criteria, patients } \\
\text { with at least } 2 \text { out of } 3 \text { of below criteria were included as a PCOS: 1- Chronic anovulation, 2- Clinical }\end{array}$
\end{tabular}


Zarei 2015 (Continued)

and/or biochemical evidence of hyperandrogenism and 3- polycystic appearance of ovaries in Transvaginal Ultrasound (TVS) Moreover, infertility was defined as failure to conceive despite having unprotected and frequent intercourse for at least 1 year. CC-resistance was considered as absence of ultrasound evidence regarding ovarian response consumption of $150 \mathrm{mg}$ of $\mathrm{CC}$ between the 5 th and the 9 th day of menstruation cycle for three consecutive cycles. All participants had a documented normal blood test, renal function test, liver function test, hysterosalpingography (HSG) and negative pregnancy test before the study. The partners should have at least two semen analyses. According to WHO, a normal semen analysis should have these properties: Sperm concentration $\geq 15$ million $/ \mathrm{ml}$, total sperm count $\geq 39$ million, mobility rate $>40 \%$, progressive motility $\geq 32 \%$ and normal morphology $\geq 4 \%$."

Exclusion criteria: women with breast cancer, renal and liver diseases, autoimmune problems and endocrinological problems such as diabetes, hyperprolactinaemia, thyroid diseases, Cushing's syndrome and smokers were excluded from the study.

Number of women randomised: 140 women

Number of women analysed: 131 women were analysed, 67 patients in control group and 64 cases in letrozole group.

Number of withdrawals/exclusions/loss to follow-up and reasons: quote: "during this study, we eliminated 6 patients from the control group, 4 fell out of the study and 2 were finally diagnosed for OHSS. Three patients were also eliminated from the letrozole group; one fell out of the study protocol and 2 due to OHSS."

Number of centres: single-centre trial

Age (y): aged 18 - 35: control group: $27.7 \pm 1.8$, letrozole group: $27.9 \pm 1.9$

BMI ( $\left.\mathbf{k g} / \mathbf{m}^{2}\right)$ : control group: $25.6 \pm 3.2$, letrozole group: $25.1 \pm 4.4$

Duration of infertility (y): control group: $5.4 \pm 1.9$, letrozole group: $5.0 \pm 3.0$

Country: Shiraz, Iran Greece) intramuscularly, from the 3rd day through the day of HCG injection

Group B: letrozole group additionally received $5 \mathrm{mg}$ /day letrozole (Razak Drug Laboratory, Tehran, Iran) since the 8th day of cycle up to the day of HCG injection.

$\begin{array}{ll}\text { Outcomes } & \begin{array}{l}\text { Premature LH surge, pregnancy rate, abortion rate, ongoing pregnancy rate, } \mathrm{N} \text { of follicles }>18 \mathrm{~mm} \text {, en- } \\ \text { dometrial thickness }(\mathrm{mm})\end{array}\end{array}$

$\begin{array}{ll}\text { Notes } & \text { Ethical approval: not reported } \\ \text { Informed consent: not reported } \\ \text { Source of funding: not reported. } \\ \text { Power calculation: not reported }\end{array}$

\section{Risk of bias}

Bias Authors' judgement Support for judgement

$\begin{array}{ll}\begin{array}{l}\text { Random sequence genera- } \\ \text { tion (selection bias) }\end{array} & \text { Unclear risk } \\ \text { vided into two groups of control ( } n=70) \text { and letrozole }(n=70) . "\end{array}$

Allocation concealment $\quad$ Unclear risk $\quad$ Not reported
(selection bias)

(selection bias) 
Zarei 2015 (Continued)

Blinding of participants Unclear risk Not reported
and personnel (perfor-
mance bias)
All outcomes

\begin{tabular}{|c|c|c|}
\hline $\begin{array}{l}\text { Blinding of outcome as- } \\
\text { sessment (detection bias) } \\
\text { All outcomes }\end{array}$ & Unclear risk & Not reported \\
\hline
\end{tabular}

Incomplete outcome data Low risk (attrition bias)

All outcomes
Quote: "During this study, we eliminated 6 patients from the control group, 4 fell out of the study and 2 were finally diagnosed for OHSS. Three patients were also eliminated from the letrozole group; one fell out of the study protocol and 2 due to OHSS. Thus, 67 patients (age ranges 18-39 years) remained in control group and 64 cases (age ranges 21-37 years) remained in letrozole group."

\begin{tabular}{|c|c|c|}
\hline $\begin{array}{l}\text { Selective reporting (re- } \\
\text { porting bias) }\end{array}$ & Unclear risk & $\begin{array}{l}\text { Unclear; Quote: "This trial was registered in Islamic Republic Clinical Trials } \\
\text { Database (IRCT2014010615102N2)." } \\
\text { We were unable to find the protocol, because the given trial registry number } \\
\text { leads to a study protocol for pain medication after rhinoplastic surgery. }\end{array}$ \\
\hline Other bias & High risk & $\begin{array}{l}\text { Methods not very well described, Clinical trial registration number leads to } \\
\text { wrong trial. }\end{array}$ \\
\hline
\end{tabular}

\section{Zeinalzadeh 2010}

\begin{tabular}{ll}
\hline Methods & Randomised controlled trial \\
& $\begin{array}{l}\text { Duration and location of the trial: quote: "This clinical trial was performed on } 107 \text { infertile patients } \\
\text { with PCOS who were referred to Fatemeh Zahra Infertility Center, Babol, Iran, in } 2006 \text { and } 2007 . “\end{array}$
\end{tabular}

$\begin{array}{ll}\text { Participants } & \text { Inclusion criteria: women with primary infertility, documented PCOS, age }<35 \text { years, }<5 \text { years infertil- } \\ & \text { ity and BMI between } 19 \text { and } 26 . \text { PCOS was defined on the basis of ultrasonography findings, oligomen- } \\ & \text { orrhoea and an increased luteinising hormone }(\mathrm{LH}) / \text { follicle-stimulating hormone (FSH) ratio }(>3) \text {. }\end{array}$

Exclusion criteria: moderate or severe case of OHSS during trial, infertility resulting from male factors, tubular factors and endometriosis.

Number of centres: 1 , Fatemeh Zahra Infertility Center, Babol

Number of women randomised: 107; group A letrozole: 50, group B CC: 57

Number of women analysed: 107; group A letrozole: 50, group B CC: 57

Number of withdrawals/exclusions/loss to follow-up and reasons: 0

Age (y): group A letrozole: $23.8 \pm 3.6$, group B CC: $23.1 \pm 3.6$

BMI $\left(\mathbf{k g} / \mathbf{m}^{2}\right)$ : not reported

Duration of infertility $(\mathbf{y})$ : group A letrozole: $2.4 \pm 1$, group B CC: $2.6 \pm 1.2$

Country: Iran

Interventions

Group A: 5 mg letrozole from cycle days 3 - 7 was given orally.

Group B: 100 mg CC from cycle days 3 - 7 was given orally. 
Zeinalzadeh 2010 (Continued)

Outcomes

Ovulation rate, pregnancy rate, number of follicles $>17 \mathrm{~mm}$, OHSS rate, multiple pregnancy rate, endometrial thickness.

Notes

Ethical approval: yes, "The study protocol was approved by the ethics committee of Babol Medical University."

Informed consent: yes, "All the patients signed a written consent form as to be enrolled in the study"

Source of funding: no, but "Financial disclosure: The authors have no connection to any companies or products mentioned in this article"

Power calculation: not stated

We contacted authors for additional information, but they did not respond.

\section{Risk of bias}

\begin{tabular}{|c|c|c|}
\hline Bias & Authors' judgement & Support for judgement \\
\hline $\begin{array}{l}\text { Random sequence genera- } \\
\text { tion (selection bias) }\end{array}$ & Unclear risk & $\begin{array}{l}\text { Quote: "The participants were assigned to two groups using systematic ran- } \\
\text { domisation method" }\end{array}$ \\
\hline $\begin{array}{l}\text { Allocation concealment } \\
\text { (selection bias) }\end{array}$ & Unclear risk & Not stated \\
\hline $\begin{array}{l}\text { Blinding of participants } \\
\text { and personnel (perfor- } \\
\text { mance bias) } \\
\text { All outcomes }\end{array}$ & Unclear risk & Not stated \\
\hline $\begin{array}{l}\text { Blinding of outcome as- } \\
\text { sessment (detection bias) } \\
\text { All outcomes }\end{array}$ & Unclear risk & Not stated \\
\hline $\begin{array}{l}\text { Incomplete outcome data } \\
\text { (attrition bias) } \\
\text { All outcomes }\end{array}$ & Low risk & No dropouts reported \\
\hline $\begin{array}{l}\text { Selective reporting (re- } \\
\text { porting bias) }\end{array}$ & Low risk & All expected outcomes were reported \\
\hline Other bias & Low risk & None \\
\hline
\end{tabular}

BMI: body mass index; CC: clomiphene citrate; FSH: follicle-stimulating hormone; hCG: human chorionic gonadotropin; hMG: human menopausal gonadotropin; LH: luteinising hormone; LOD: laparoscopic ovarian drilling; OHSS: ovarian hyperstimulation syndrome; PCOS: polycystic ovary syndrome; s: seconds; SD: standard deviation; TSH: thyroid-stimulating hormone; W: watts; y: year

Characteristics of excluded studies [ordered by study ID]

\begin{tabular}{ll}
\hline Study & Reason for exclusion \\
\hline Akbari 2012 & No PCOS \\
\hline Al-Hussaini 2014 & $\begin{array}{l}\text { Only short conference abstract; we did not find a published study article. We were unable to re- } \\
\text { trieve any information from study authors. }\end{array}$ \\
\hline Al-Shaikh 2017 & Not a RCT \\
\hline \hline
\end{tabular}




\begin{tabular}{|c|c|}
\hline Study & Reason for exclusion \\
\hline Angel 2014 & RCT, but not about women with PCOS \\
\hline Anwary 2012 & Not a RCT \\
\hline Azargoon 2012 & Not a RCT \\
\hline Azmoodeh 2015 & No PCOS \\
\hline Badawy $2009 c$ & Not a RCT \\
\hline Baruah 2009 & $\begin{array}{l}\text { Quasi-randomised trial (quote: "Based on attendance order, patients with odd numbers were given } \\
\text { letrozole and those with even numbers were given } C C \text { ") }\end{array}$ \\
\hline El Bigawy 2008 & Quasi-randomised trial \\
\hline Foroozanfard 2013 & Not randomised for clomiphene or letrozole \\
\hline Khanna 2013 & Not a RCT, no PCOS \\
\hline Li 2016 & Not randomised for letrozole \\
\hline Mittal 2004 & Not a RCT \\
\hline Nahid 2012 & Suspected quasi-randomisation based on attendance order \\
\hline NCT00610077 & $\begin{array}{l}\text { No published data found, last updated on clinicaltrials.gov in 2008. No response from study au- } \\
\text { thors. }\end{array}$ \\
\hline NCT01315912 & Not a RCT \\
\hline NCT01431352 & $\begin{array}{l}\text { For the } 2018 \text { update, there was no update on clinicaltrials.gov. No study data available, and no re- } \\
\text { sponse from authors. }\end{array}$ \\
\hline NCT01577017 & No study results found, unable to obtain more information from study authors \\
\hline \multirow[t]{2}{*}{ NCT01679574 } & $\begin{array}{l}\text { Study should be finished. We contacted authors by email found through Google because no con- } \\
\text { tact information was written in the study protocol: abd_ellah98@yahoo.com. }\end{array}$ \\
\hline & $\begin{array}{l}\text { For the } 2018 \text { update, there was no update on clinicaltrials.gov and still no response from the au- } \\
\text { thor. }\end{array}$ \\
\hline NCT01793038 & $\begin{array}{l}\text { Unable to obtain information from study authors. No study data found, no update on clinicaltrial- } \\
\text { s.gov. }\end{array}$ \\
\hline Ozdemir 2013 & RCT, but not about women with PCOS \\
\hline Pakrashi 2014 & Not randomised for letrozole \\
\hline Palihawadana 2015 & Women with PCOS were excluded from the study \\
\hline Pourali 2017 & Women with PCOS were excluded from the study \\
\hline Sarvi 2010 & Not randomised for letrozole \\
\hline Sharma 2010 & $\begin{array}{l}\text { Only conference abstract available, full article could not be found. Contact address of authors un- } \\
\text { known }\end{array}$ \\
\hline
\end{tabular}




\begin{tabular}{ll}
\hline Study & Reason for exclusion \\
\hline Xi 2015 & Not a RCT \\
\hline Yang 2008 & $\begin{array}{l}\text { Not a RCT (Quote: "the allocation depended on the patients' choice" - translated by Prof Taixiang } \\
\text { Wu) }\end{array}$ \\
\hline Yun 2015 & Not a RCT \\
\hline
\end{tabular}

Characteristics of studies awaiting assessment [ordered by study ID]

\begin{tabular}{ll}
\hline Mygen $\mathbf{2 0 0 7}$ & Randomised clinical study \\
\hline Participants & 15 infertile women with polycystic ovarian syndrome \\
\hline Interventions & Women were randomised into 3 treatment groups: \\
& $\begin{array}{l}\text { In group } 1 \text {, continuous metformin was used at the dose of } 850 \mathrm{mg} / \text { tid } / \text { day for } 6 \text { months; after- } \\
\text { wards, daily } 2.5 \text { mg letrozole between } 3 \text { and } 7 \text { days of the menstrual cycle was added to the met- } \\
\text { formin therapy. } \\
\text { Group } 2 \text { participants received only daily } 2.5 \text { mg letrozole between days } 3 \text { and } 7 \text { of the menstrual cy- } \\
\text { cle. } \\
\text { Group } 3 \text { participants received daily } 100 \text { mg clomiphene citrate only between days } 3 \text { and } 7 \text { of the } \\
\text { menstrual cycle. }\end{array}$ \\
\hline Outcomes & Unclear \\
\hline Notes & The article was written in Turkish, and we were not able to have it translated properly.
\end{tabular}

Lorzadeh 2011

\begin{tabular}{ll}
\hline Methods & Randomised clinical trial \\
\hline Participants & 100 infertile women with PCOS referred to Asali Hospital and private clinic in 2008 \\
\hline Interventions & $\begin{array}{l}\text { The women were randomised into } 2 \text { groups of } 50 \text { that were treated with } 5 \mathrm{mg} \text { letrozole or } 100 \mathrm{mg} \\
\text { clomiphene citrate from day } 3 \text { to } 7 \text { of the menstrual cycle. }\end{array}$ \\
\hline Outcomes & Outcomes: Pregnancy rate \\
\hline Notes & The article was written in Persian, but we were not able to have it translated properly. \\
\hline
\end{tabular}

\section{NCT02551367}

\begin{tabular}{ll}
\hline Methods & Randomised controlled trial \\
\hline Participants & $\begin{array}{l}110 \text { infertile women diagnosed as polycystic ovary syndrome (PCOS) aged } 20 \text { - } 35 \text { distributed ran- } \\
\text { domly }\end{array}$
\end{tabular}


NCT02551367 (Continued)

Interventions
55 women will receive letrozole $2.5 \mathrm{mg}$ twice daily orally from the $2 \mathrm{nd}$ to the 6 th day of the cycle for 3 successive cycles.

55 women will receive clomiphene citrate $50 \mathrm{mg}$ twice daily orally from the 2 nd to the 6 th day of the cycle for 3 successive cycles.
Outcomes
1. Rate of ovulation assessed by number of mature follicles produced per cycle.
2. Serum progesterone level on day 21 (assessed up to 24 weeks).
3. Mean endometrial thickness ( assessed up to 24 weeks).
4. Chemical pregnancy (assessed up to 24 weeks).
5. Ongoing pregnancy (assessed up to 24 weeks).

Notes

We found no study data, although trial completed since 2016 on clinicaltrials.gov

\section{Safdarian 2012}

\begin{tabular}{ll}
\hline Methods & Double-blind randomised clinical trial \\
\hline Participants & $\begin{array}{l}59 \text { infertile women who had the inclusion criteria for PCOS were evaluated in the Infertility Clinic of } \\
\text { Shariati Hospital in Tehran, Iran in } 2010-2011 .\end{array}$ \\
\hline Interventions & The participants were assigned to 2 letrozole and 1 letrozole-plus-HMG groups. \\
\hline Outcomes & Reported no outcomes of interest to our review \\
\hline Notes & The article was written in Persian, but we were not able to have it translated properly. \\
\hline
\end{tabular}

\section{Shirin 2009}

\begin{tabular}{ll}
\hline Methods & $\begin{array}{l}\text { Randomised clinical trial, "Quote: The cases were assigned to two groups through simple random } \\
\text { sampling" }\end{array}$ \\
\hline Participants & $\begin{array}{l}100 \text { infertile, 20 - 35-year-old women with PCOS attending Vali-e-Asr Infertility Clinic from April 2003 } \\
\text { to April } 2007\end{array}$ \\
\hline Interventions & Group A received clomiphene citrate plus HMG, Group B received letrozole plus HMG \\
\hline Outcomes & Outcomes: pregnancy, miscarriage and multiple pregnancy rates \\
\hline Notes & The article was written in Persian, but we were not able to have it translated properly. \\
\hline
\end{tabular}

\section{Characteristics of ongoing studies [ordered by study ID]}

\section{NCT03009838}

\section{Trial name or title}

Methods

Letrozole versus laparoscopic ovarian drilling in polycystic ovary syndrome

Participants

Randomised, open-label, clinical trial

Inclusion criteria: 
NCT03009838 (Continued)

- History of at least 1 year of infertility, either primary or secondary

- BMI: 25 - 35

- Normal fallopian tubes

- Normal semen analysis of the husband

- Women who will agree to participate in the study

Exclusion criteria:

- $\mathrm{BMI}>35$

- Contraindication to general anaesthesia

- Previous laparoscopic drilling

- Presence of other causes of infertility

- Women who had received metformin, gonadotropin, oral contraceptives or other hormonal drugs during the preceding 6 months

- Women who intended to start a diet programme

- Women who refuse to participate in the study

\begin{tabular}{ll}
\hline Interventions & Group A: letrozole $2.5 \mathrm{mg}$ \\
& Group B: laparoscopic ovarian drilling \\
\hline Outcomes & Ovulation rate \\
\hline Starting date & January 2017 \\
\hline Contact information & Responsible party: Ahmed Mohamed Abbas, Assiut University \\
\hline Notes & Estimated primary completion date: December 2018 \\
\hline
\end{tabular}

\section{DATA AND ANALYSES}

\section{Comparison 1. Letrozole compared to placebo}

\begin{tabular}{lllll}
\hline Outcome or subgroup title & No. of studies & $\begin{array}{l}\text { No. of partici- } \\
\text { pants }\end{array}$ & Statistical method & Effect size \\
\hline $\begin{array}{llll}1 \text { Live birth rate } \\
\text { 2 Ovarian hyperstimulation } \\
\text { syndrome rate }\end{array}$ & 1 & 36 & Odds Ratio (M-H, Fixed, 95\% Cl) & $3.17[0.12,83.17]$ \\
\hline $\begin{array}{l}3 \text { Clinical pregnancy rate } \\
\text { 4 Miscarriage rate by woman } \\
\text { randomised }\end{array}$ & 2 & 167 & $\begin{array}{l}\text { Risk Difference (M-H, Fixed, 95\% } \\
\text { Cl) }\end{array}$ & $0.00[-0.05,0.05]$ \\
\hline $\begin{array}{l}5 \text { Miscarriage rate by pregnan- } \\
\text { cies }\end{array}$ & 1 & 167 & Odds Ratio (M-H, Fixed, 95\% Cl) & $2.88[1.08,7.66]$ \\
\hline \begin{tabular}{l}
6 Multiple pregnancy rate \\
\hline
\end{tabular} & 1 & 167 & Odds Ratio (M-H, Fixed, 95\% Cl) & $1.60[0.26,9.89]$ \\
\hline
\end{tabular}


Analysis 1.1. Comparison 1 Letrozole compared to placebo, Outcome 1 Live birth rate.

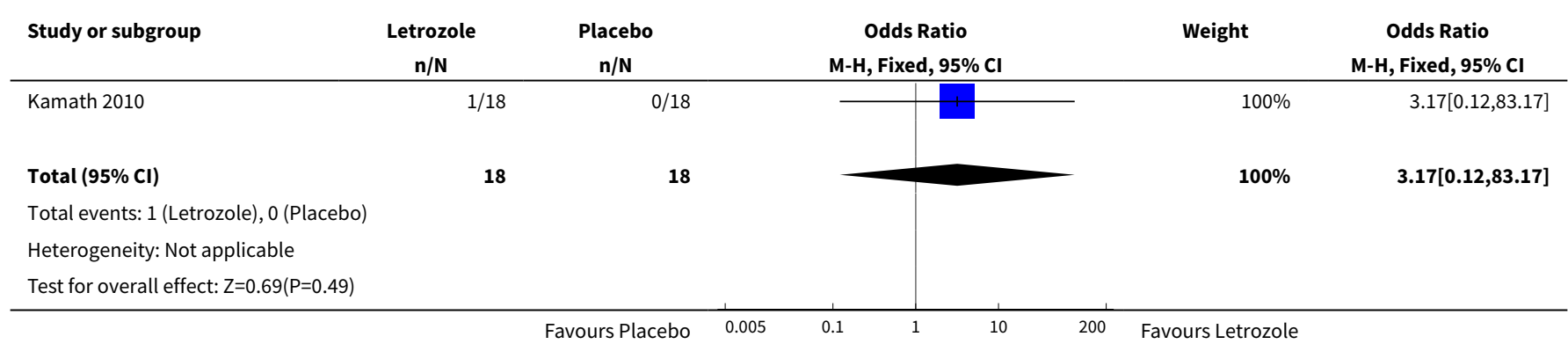

Analysis 1.2. Comparison 1 Letrozole compared to placebo, Outcome 2 Ovarian hyperstimulation syndrome rate.

\begin{tabular}{|c|c|c|c|c|c|}
\hline Study or subgroup & $\begin{array}{c}\text { Letrozole } \\
\mathrm{n} / \mathrm{N}\end{array}$ & $\begin{array}{c}\text { Placebo } \\
\mathbf{n} / \mathbf{N}\end{array}$ & $\begin{array}{c}\text { Risk Difference } \\
\text { M-H, Fixed, 95\% Cl }\end{array}$ & Weight & $\begin{array}{c}\text { Risk Difference } \\
\text { M-H, Fixed, 95\% Cl }\end{array}$ \\
\hline Kamath 2010 & $0 / 18$ & $0 / 18$ & - & $21.57 \%$ & $0[-0.1,0.1]$ \\
\hline Zarei 2015 & $2 / 64$ & $2 / 67$ & & $78.43 \%$ & $0[-0.06,0.06]$ \\
\hline Total $(95 \% \mathrm{Cl})$ & 82 & 85 & & $100 \%$ & $0[-0.05,0.05]$ \\
\hline \multicolumn{6}{|c|}{ Total events: 2 (Letrozole), 2 (Placebo) } \\
\hline Test for overall effect & & & & & \\
\hline
\end{tabular}

Analysis 1.3. Comparison 1 Letrozole compared to placebo, Outcome 3 Clinical pregnancy rate.

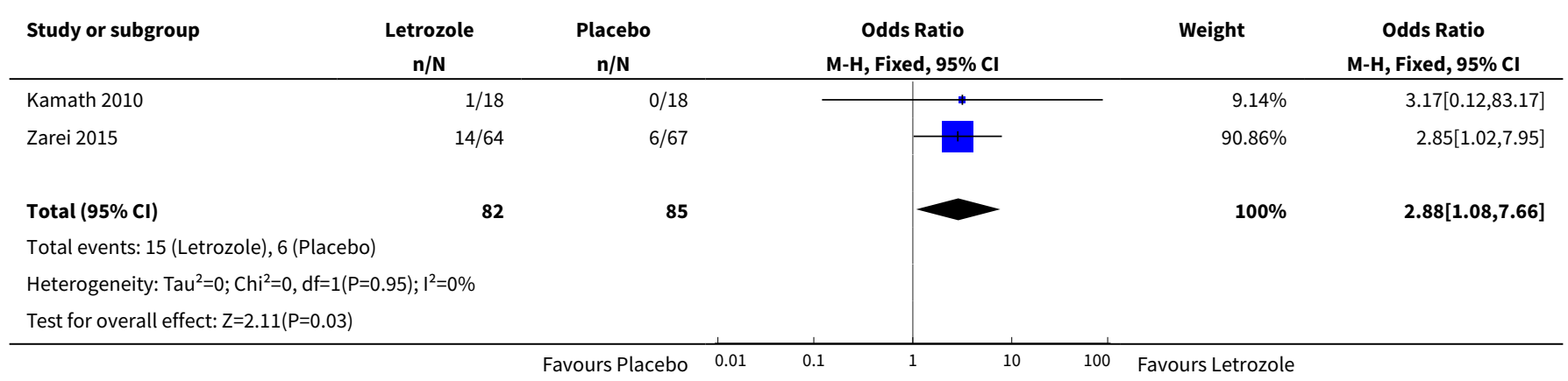

Analysis 1.4. Comparison 1 Letrozole compared to placebo, Outcome 4 Miscarriage rate by woman randomised.

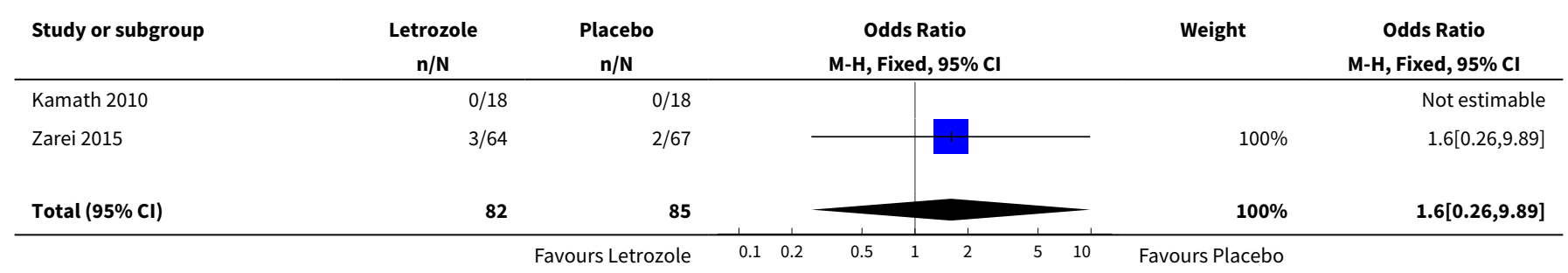




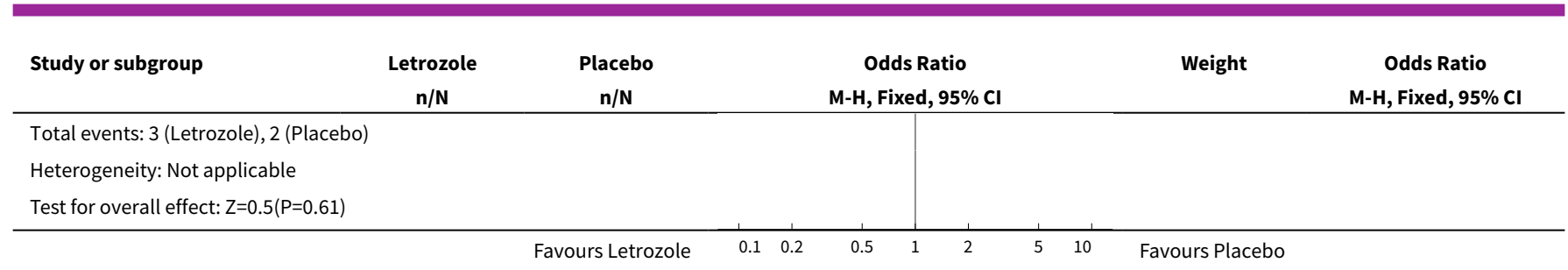

Analysis 1.5. Comparison 1 Letrozole compared to placebo, Outcome 5 Miscarriage rate by pregnancies.

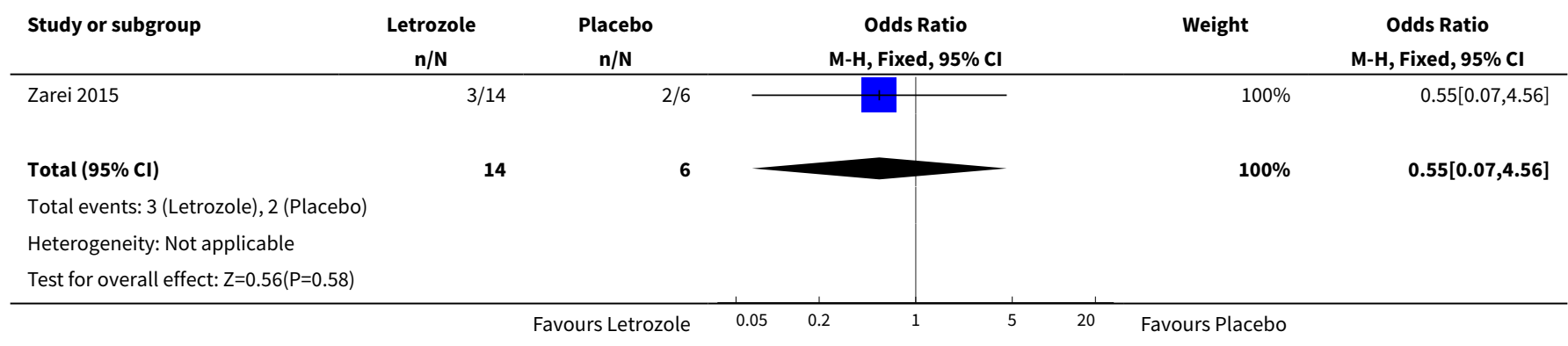

Analysis 1.6. Comparison 1 Letrozole compared to placebo, Outcome 6 Multiple pregnancy rate.

\begin{tabular}{|c|c|c|c|c|c|c|}
\hline \multirow{2}{*}{$\begin{array}{l}\text { Study or subgroup } \\
\text { Kamath } 2010\end{array}$} & $\begin{array}{c}\text { Letrozole } \\
\mathrm{n} / \mathrm{N}\end{array}$ & $\begin{array}{c}\text { Placebo } \\
\mathrm{n} / \mathrm{N}\end{array}$ & \multicolumn{3}{|c|}{$\begin{array}{c}\text { Odds Ratio } \\
\text { M-H, Fixed, } 95 \% \text { CI }\end{array}$} & \multirow{2}{*}{$\begin{array}{c}\text { Odds Ratio } \\
\text { M-H, Fixed, } \mathbf{9 5 \%} \mathbf{~ C l} \\
\text { Not estimable }\end{array}$} \\
\hline & $0 / 18$ & $0 / 18$ & & & & \\
\hline
\end{tabular}

Comparison 2. Letrozole compared to selective estrogen receptor modulators with or without adjuncts, followed by timed intercourse

\begin{tabular}{|c|c|c|c|c|}
\hline Outcome or subgroup title & No. of studies & $\begin{array}{l}\text { No. of partici- } \\
\text { pants }\end{array}$ & Statistical method & Effect size \\
\hline 1 Live birth rate & 13 & 2954 & $\begin{array}{l}\text { Odds Ratio (M-H, Fixed, 95\% } \\
\text { Cl) }\end{array}$ & $1.68[1.42,1.99]$ \\
\hline 1.1 Als versus clomiphene citrate & 8 & 1646 & $\begin{array}{l}\text { Odds Ratio (M-H, Fixed, 95\% } \\
\text { Cl) }\end{array}$ & $1.79[1.42,2.25]$ \\
\hline $\begin{array}{l}1.2 \mathrm{Al} \text { versus clomiphene + met- } \\
\text { formin }\end{array}$ & 1 & 250 & $\begin{array}{l}\text { Odds Ratio (M-H, Fixed, 95\% } \\
\text { Cl) }\end{array}$ & $1.05[0.60,1.81]$ \\
\hline $\begin{array}{l}\text { 1.3 Aromatase inhibitor }+ \text { met- } \\
\text { formin compared to clomiphene }+ \\
\text { metformin }\end{array}$ & 2 & 194 & $\begin{array}{l}\text { Odds Ratio (M-H, Fixed, 95\% } \\
\text { Cl) }\end{array}$ & $1.70[0.89,3.23]$ \\
\hline $\begin{array}{l}\text { 1.4 Aromatase inhibitor + FSH } \\
\text { compared to clomiphene + FSH }\end{array}$ & 1 & 120 & $\begin{array}{l}\text { Odds Ratio (M-H, Fixed, 95\% } \\
\mathrm{Cl})\end{array}$ & $1.18[0.53,2.61]$ \\
\hline
\end{tabular}




\begin{tabular}{|c|c|c|c|c|}
\hline Outcome or subgroup title & No. of studies & $\begin{array}{l}\text { No. of partici- } \\
\text { pants }\end{array}$ & Statistical method & Effect size \\
\hline $\begin{array}{l}\text { 1.5 Als versus clomiphene + estra- } \\
\text { diol valerate }\end{array}$ & 1 & 100 & $\begin{array}{l}\text { Odds Ratio (M-H, Fixed, 95\% } \\
\text { Cl) }\end{array}$ & $1.48[0.54,4.06]$ \\
\hline $\begin{array}{l}\text { 1.6 Als +/- berberine versus berber- } \\
\text { ine }\end{array}$ & 1 & 644 & $\begin{array}{l}\text { Odds Ratio (M-H, Fixed, 95\% } \\
\mathrm{Cl})\end{array}$ & $1.94[1.33,2.84]$ \\
\hline 2 Live birth rate by BMI & 11 & 2774 & $\begin{array}{l}\text { Odds Ratio (M-H, Fixed, 95\% } \\
\text { Cl) }\end{array}$ & $1.69[1.42,2.02]$ \\
\hline $2.1 \mathrm{BMI}>25$ & 7 & 1678 & $\begin{array}{l}\text { Odds Ratio (M-H, Fixed, 95\% } \\
\text { Cl) }\end{array}$ & $1.67[1.34,2.09]$ \\
\hline $2.2 \mathrm{BMI}<25$ & 4 & 1096 & $\begin{array}{l}\text { Odds Ratio (M-H, Fixed, 95\% } \\
\text { Cl) }\end{array}$ & $1.73[1.31,2.28]$ \\
\hline $\begin{array}{l}3 \text { Live birth rate by first- or sec- } \\
\text { ond-line treatment }\end{array}$ & 13 & & $\begin{array}{l}\text { Odds Ratio (M-H, Fixed, 95\% } \\
\text { Cl) }\end{array}$ & Subtotals only \\
\hline $\begin{array}{l}\text { 3.1 No previous ovulation induc- } \\
\text { tion }\end{array}$ & 4 & 1089 & $\begin{array}{l}\text { Odds Ratio (M-H, Fixed, 95\% } \\
\text { Cl) }\end{array}$ & $1.61[1.22,2.14]$ \\
\hline 3.2 CC-resistant women & 4 & 344 & $\begin{array}{l}\text { Odds Ratio (M-H, Fixed, 95\% } \\
\text { Cl) }\end{array}$ & $1.78[1.08,2.93]$ \\
\hline 3.3 Unclear or mixed study cohort & 5 & 1521 & $\begin{array}{l}\text { Odds Ratio (M-H, Fixed, 95\% } \\
\text { Cl) }\end{array}$ & $1.71[1.35,2.16]$ \\
\hline $\begin{array}{l}4 \text { Impact of allocation bias for live } \\
\text { birth rate }\end{array}$ & 13 & & $\begin{array}{l}\text { Odds Ratio (M-H, Fixed, 95\% } \\
\text { Cl) }\end{array}$ & Subtotals only \\
\hline 4.1 Unclear risk of allocation & 8 & 1031 & $\begin{array}{l}\text { Odds Ratio (M-H, Fixed, 95\% } \\
\text { Cl) }\end{array}$ & $1.90[1.42,2.54]$ \\
\hline 4.2 Low risk of allocation & 5 & 1923 & $\begin{array}{l}\text { Odds Ratio (M-H, Fixed, 95\% } \\
\text { Cl) }\end{array}$ & $1.58[1.29,1.95]$ \\
\hline $\begin{array}{l}5 \text { Impact of detection bias for live } \\
\text { birth rate }\end{array}$ & 13 & 2954 & $\begin{array}{l}\text { Odds Ratio (M-H, Fixed, 95\% } \\
\text { Cl) }\end{array}$ & $1.68[1.42,1.99]$ \\
\hline 5.1 High risk of detection & 1 & 64 & $\begin{array}{l}\text { Odds Ratio (M-H, Fixed, 95\% } \\
\text { Cl) }\end{array}$ & $2.6[0.83,8.13]$ \\
\hline 5.2 Low risk of detection & 7 & 2083 & $\begin{array}{l}\text { Odds Ratio (M-H, Fixed, 95\% } \\
\text { Cl) }\end{array}$ & $1.63[1.33,1.99]$ \\
\hline 5.3 Unclear risk of detection & 5 & 807 & $\begin{array}{l}\text { Odds Ratio (M-H, Fixed, 95\% } \\
\mathrm{Cl})\end{array}$ & $1.76[1.27,2.44]$ \\
\hline $\begin{array}{l}6 \text { Impact of attrition bias for live } \\
\text { birth rate }\end{array}$ & 13 & & $\begin{array}{l}\text { Odds Ratio (M-H, Fixed, 95\% } \\
\text { Cl) }\end{array}$ & Subtotals only \\
\hline 6.1 Unclear risk of attrition & 1 & 147 & $\begin{array}{l}\text { Odds Ratio (M-H, Fixed, 95\% } \\
\mathrm{Cl} \text { ) }\end{array}$ & $2.04[0.93,4.50]$ \\
\hline
\end{tabular}




\begin{tabular}{|c|c|c|c|c|}
\hline Outcome or subgroup title & No. of studies & $\begin{array}{l}\text { No. of partici- } \\
\text { pants }\end{array}$ & Statistical method & Effect size \\
\hline 6.2 Low risk of attrition & 11 & 2539 & $\begin{array}{l}\text { Odds Ratio (M-H, Fixed, 95\% } \\
\mathrm{Cl})\end{array}$ & $1.69[1.41,2.03]$ \\
\hline 6.3 High risk of attrition & 1 & 268 & $\begin{array}{l}\text { Odds Ratio (M-H, Fixed, 95\% } \\
\mathrm{Cl})\end{array}$ & $1.46[0.85,2.50]$ \\
\hline $\begin{array}{l}7 \text { Ovarian hyperstimulation syn- } \\
\text { drome rate }\end{array}$ & 12 & 2536 & $\begin{array}{l}\text { Risk Difference (M-H, Fixed, } \\
95 \% \mathrm{Cl})\end{array}$ & $-0.00[-0.01,0.00]$ \\
\hline 7.1 Als versus clomiphene citrate & 9 & 2010 & $\begin{array}{l}\text { Risk Difference (M-H, Fixed, } \\
95 \% \mathrm{Cl})\end{array}$ & $-0.00[-0.01,0.00]$ \\
\hline $\begin{array}{l}7.2 \mathrm{Al} \text { versus clomiphene + met- } \\
\text { formin }\end{array}$ & 1 & 250 & $\begin{array}{l}\text { Risk Difference }(\mathrm{M}-\mathrm{H} \text {, Fixed, } \\
95 \% \mathrm{Cl})\end{array}$ & $0.0[-0.02,0.02]$ \\
\hline $\begin{array}{l}\text { 7.3 Aromatase inhibitor + hMG ver- } \\
\text { sus clomiphene + hMG }\end{array}$ & 2 & 276 & $\begin{array}{l}\text { Risk Difference (M-H, Fixed, } \\
95 \% \mathrm{Cl})\end{array}$ & $0.0[-0.04,0.04]$ \\
\hline $\begin{array}{l}8 \text { Ovarian hyperstimulation syn- } \\
\text { drome rate per BMI }\end{array}$ & 11 & & $\begin{array}{l}\text { Risk Difference (M-H, Fixed, } \\
95 \% \mathrm{Cl})\end{array}$ & Subtotals only \\
\hline $8.1 \mathrm{BMI}>25$ & 6 & 1851 & $\begin{array}{l}\text { Risk Difference (M-H, Fixed, } \\
95 \% \mathrm{Cl})\end{array}$ & $-0.00[-0.01,0.00]$ \\
\hline $8.2 \mathrm{BMI}<25$ & 5 & 605 & $\begin{array}{l}\text { Risk Difference (M-H, Fixed, } \\
95 \% \mathrm{Cl})\end{array}$ & $0.0[-0.02,0.02]$ \\
\hline 9 Clinical pregnancy rate & 25 & 4629 & $\begin{array}{l}\text { Odds Ratio (M-H, Fixed, 95\% } \\
\mathrm{Cl})\end{array}$ & $1.56[1.37,1.78]$ \\
\hline 9.1 Als versus clomiphene citrate & 17 & 2930 & $\begin{array}{l}\text { Odds Ratio (M-H, Fixed, 95\% } \\
\mathrm{Cl})\end{array}$ & $1.50[1.28,1.76]$ \\
\hline $\begin{array}{l}9.2 \mathrm{Al} \text { versus clomiphene + met- } \\
\text { formin }\end{array}$ & 1 & 250 & $\begin{array}{l}\text { Odds Ratio (M-H, Fixed, 95\% } \\
\mathrm{Cl})\end{array}$ & $1.01[0.60,1.71]$ \\
\hline $\begin{array}{l}9.3 \text { Aromatase inhibitor + met- } \\
\text { formin versus clomiphene + met- } \\
\text { formin }\end{array}$ & 3 & 294 & $\begin{array}{l}\text { Odds Ratio (M-H, Fixed, 95\% } \\
\mathrm{CI})\end{array}$ & $1.86[1.05,3.29]$ \\
\hline $\begin{array}{l}\text { 9.4 Aromatase inhibitor + hMG ver- } \\
\text { sus clomiphene + hMG }\end{array}$ & 2 & 276 & $\begin{array}{l}\text { Odds Ratio (M-H, Fixed, 95\% } \\
\mathrm{Cl})\end{array}$ & $1.37[0.82,2.27]$ \\
\hline 9.5 Als versus tamoxifen & 2 & 135 & $\begin{array}{l}\text { Odds Ratio (M-H, Fixed, 95\% } \\
\text { Cl) }\end{array}$ & $1.58[0.64,3.90]$ \\
\hline $\begin{array}{l}\text { 9.6 Als versus clomiphene + estra- } \\
\text { diol valerate }\end{array}$ & 1 & 100 & $\begin{array}{l}\text { Odds Ratio (M-H, Fixed, 95\% } \\
\mathrm{Cl})\end{array}$ & $2.47[0.94,6.46]$ \\
\hline $\begin{array}{l}9.7 \text { Als } \pm \text { berberine versus berber- } \\
\text { ine }\end{array}$ & 1 & 644 & $\begin{array}{l}\text { Odds Ratio (M-H, Fixed, 95\% } \\
\mathrm{Cl})\end{array}$ & $2.15[1.48,3.13]$ \\
\hline $\begin{array}{l}10 \text { Impact of allocation bias for } \\
\text { clinical pregnancy rate }\end{array}$ & 23 & & $\begin{array}{l}\text { Odds Ratio (M-H, Fixed, 95\% } \\
\mathrm{Cl})\end{array}$ & Subtotals only \\
\hline
\end{tabular}




\begin{tabular}{|c|c|c|c|c|}
\hline Outcome or subgroup title & No. of studies & $\begin{array}{l}\text { No. of partici- } \\
\text { pants }\end{array}$ & Statistical method & Effect size \\
\hline 10.1 Unclear risk of allocation & 16 & 1907 & $\begin{array}{l}\text { Odds Ratio (M-H, Fixed, 95\% } \\
\mathrm{Cl})\end{array}$ & $1.77[1.43,2.18]$ \\
\hline 10.2 Low risk of allocation & 7 & 1912 & $\begin{array}{l}\text { Odds Ratio (M-H, Fixed, 95\% } \\
\mathrm{Cl} \text { ) }\end{array}$ & $1.36[1.12,1.65]$ \\
\hline $\begin{array}{l}11 \text { Miscarriage rate by woman ran- } \\
\text { domised }\end{array}$ & 18 & 3754 & $\begin{array}{l}\text { Odds Ratio (M-H, Fixed, 95\% } \\
\mathrm{Cl})\end{array}$ & $1.39[1.07,1.81]$ \\
\hline 11.1 Als versus clomiphene citrate & 11 & 2190 & $\begin{array}{l}\text { Odds Ratio (M-H, Fixed, 95\% } \\
\mathrm{Cl})\end{array}$ & $1.37[0.97,1.93]$ \\
\hline $\begin{array}{l}11.2 \mathrm{Al} \text { versus clomiphene + met- } \\
\text { formin }\end{array}$ & 1 & 250 & $\begin{array}{l}\text { Odds Ratio (M-H, Fixed, 95\% } \\
\mathrm{Cl} \text { ) }\end{array}$ & $1.03[0.25,4.23]$ \\
\hline $\begin{array}{l}\text { 11.3 Aromatase inhibitor + met- } \\
\text { formin versus clomiphene + met- } \\
\text { formin }\end{array}$ & 3 & 294 & $\begin{array}{l}\text { Odds Ratio (M-H, Fixed, 95\% } \\
\mathrm{Cl})\end{array}$ & $1.21[0.52,2.82]$ \\
\hline $\begin{array}{l}11.4 \text { Aromatase inhibitor + hMG } \\
\text { versus clomiphene }+\mathrm{hMG}\end{array}$ & 2 & 276 & $\begin{array}{l}\text { Odds Ratio (M-H, Fixed, 95\% } \\
\mathrm{Cl})\end{array}$ & $0.84[0.31,2.27]$ \\
\hline $\begin{array}{l}11.5 \text { Als versus clomiphene + estra- } \\
\text { diol valerate }\end{array}$ & 1 & 100 & $\begin{array}{l}\text { Odds Ratio (M-H, Fixed, 95\% } \\
\mathrm{Cl} \text { ) }\end{array}$ & $12.21[0.66,226.97]$ \\
\hline $\begin{array}{l}11.6 \text { Als +/- berberine versus } \\
\text { berberine }\end{array}$ & 1 & 644 & $\begin{array}{l}\text { Odds Ratio (M-H, Fixed, 95\% } \\
\mathrm{Cl} \text { ) }\end{array}$ & $1.63[0.87,3.04]$ \\
\hline 12 Miscarriage rate by pregnancies & 18 & 1210 & $\begin{array}{l}\text { Odds Ratio (M-H, Fixed, 95\% } \\
\mathrm{Cl})\end{array}$ & $0.94[0.70,1.26]$ \\
\hline 12.1 Als versus clomiphene citrate & 11 & 705 & $\begin{array}{l}\text { Odds Ratio (M-H, Fixed, 95\% } \\
\mathrm{Cl} \text { ) }\end{array}$ & $0.96[0.65,1.42]$ \\
\hline $\begin{array}{l}12.2 \mathrm{Al} \text { versus clomiphene + met- } \\
\text { formin }\end{array}$ & 1 & 85 & $\begin{array}{l}\text { Odds Ratio (M-H, Fixed, 95\% } \\
\mathrm{Cl})\end{array}$ & $1.03[0.24,4.40]$ \\
\hline $\begin{array}{l}\text { 12.3 Aromatase inhibitor + met- } \\
\text { formin versus clomiphene + met- } \\
\text { formin }\end{array}$ & 3 & 79 & $\begin{array}{l}\text { Odds Ratio (M-H, Fixed, 95\% } \\
\mathrm{Cl} \text { ) }\end{array}$ & $0.80[0.32,2.02]$ \\
\hline $\begin{array}{l}\text { 12.4 Aromatase inhibitor + hMG } \\
\text { versus clomiphene }+\mathrm{hMG}\end{array}$ & 2 & 104 & $\begin{array}{l}\text { Odds Ratio (M-H, Fixed, 95\% } \\
\mathrm{Cl} \text { ) }\end{array}$ & $0.67[0.23,1.96]$ \\
\hline $\begin{array}{l}12.5 \text { Als versus clomiphene + estra- } \\
\text { diol valerate }\end{array}$ & 1 & 24 & $\begin{array}{l}\text { Odds Ratio (M-H, Fixed, 95\% } \\
\mathrm{Cl})\end{array}$ & $8.13[0.39,167.90]$ \\
\hline $\begin{array}{l}12.6 \text { Als }+/ \text { - berberine versus } \\
\text { berberine }\end{array}$ & 1 & 213 & $\begin{array}{l}\text { Odds Ratio (M-H, Fixed, 95\% } \\
\mathrm{Cl} \text { ) }\end{array}$ & $0.88[0.43,1.80]$ \\
\hline 13 Multiple pregnancy rate & 17 & 3579 & $\begin{array}{l}\text { Odds Ratio (M-H, Fixed, 95\% } \\
\mathrm{Cl})\end{array}$ & $0.69[0.41,1.16]$ \\
\hline 13.1 Als versus clomiphene citrate & 13 & 2409 & $\begin{array}{l}\text { Odds Ratio (M-H, Fixed, 95\% } \\
\mathrm{Cl})\end{array}$ & $0.61[0.32,1.16]$ \\
\hline
\end{tabular}




\begin{tabular}{lllll}
\hline Outcome or subgroup title & No. of studies & $\begin{array}{l}\text { No. of partici- } \\
\text { pants }\end{array}$ & Statistical method & Effect size \\
\hline $\begin{array}{l}\text { 13.2 Al versus clomiphene + met- } \\
\text { formin }\end{array}$ & 1 & 250 & $\begin{array}{l}\text { Odds Ratio (M-H, Fixed, 95\% } \\
\text { Cl) }\end{array}$ & 0.14 [0.01, 2.82] \\
\hline $\begin{array}{l}\text { 13.3 Aromatase inhibitor + hMG } \\
\text { versus clomiphene + hMG }\end{array}$ & 2 & 276 & $\begin{array}{l}\text { Odds Ratio (M-H, Fixed, 95\% } \\
\text { Cl) }\end{array}$ & 0.94 [0.29, 3.05] \\
\hline $\begin{array}{l}\text { 13.4 Als +/- berberine versus } \\
\text { berberine }\end{array}$ & 1 & 644 & $\begin{array}{l}\text { Odds Ratio (M-H, Fixed, 95\% } \\
\text { Cl) }\end{array}$ & 4.53 [0.24, 84.46] \\
\hline
\end{tabular}

\section{Analysis 2.1. Comparison 2 Letrozole compared to selective estrogen receptor modulators with or without adjuncts, followed by timed intercourse, Outcome 1 Live birth rate.}

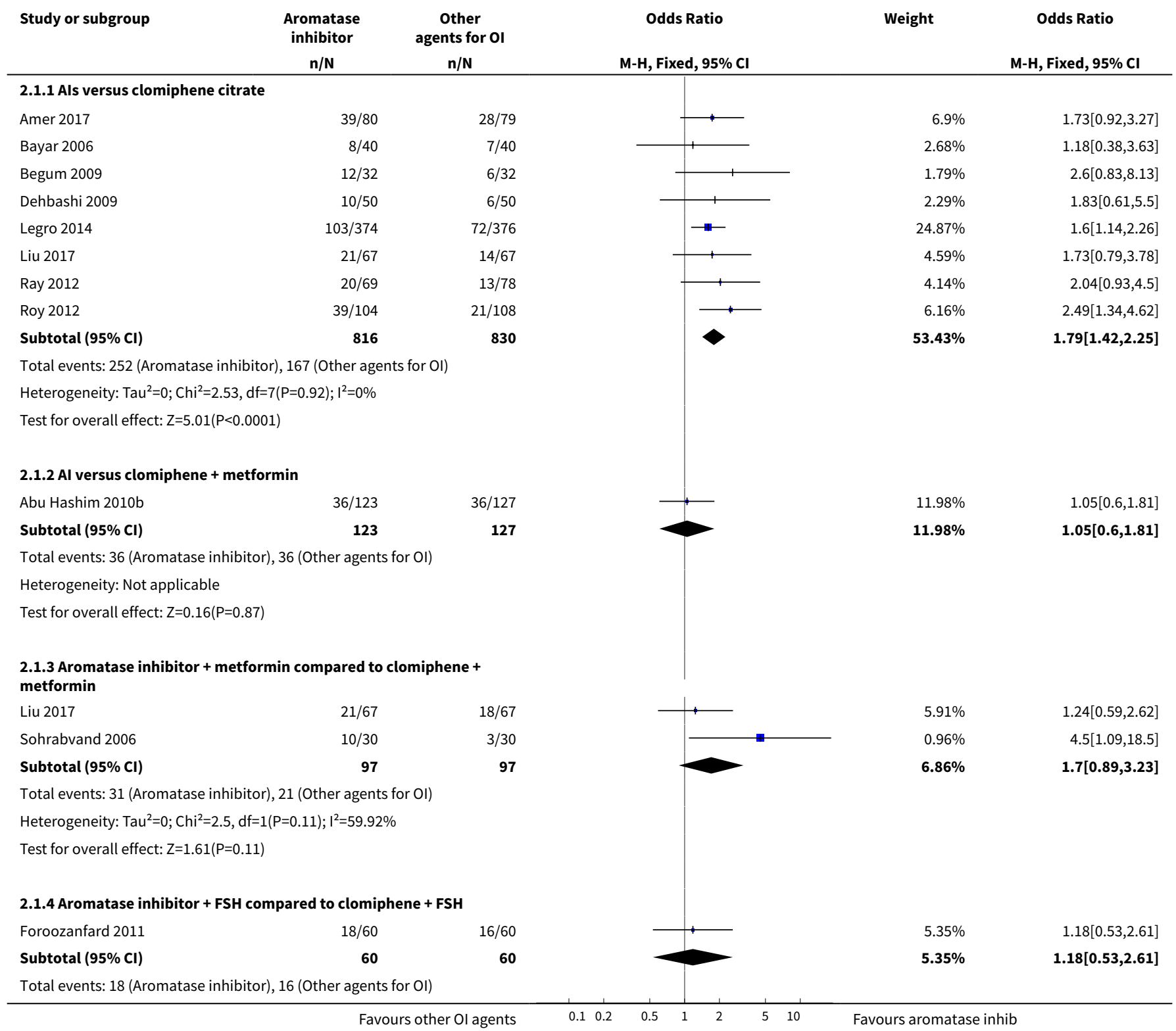




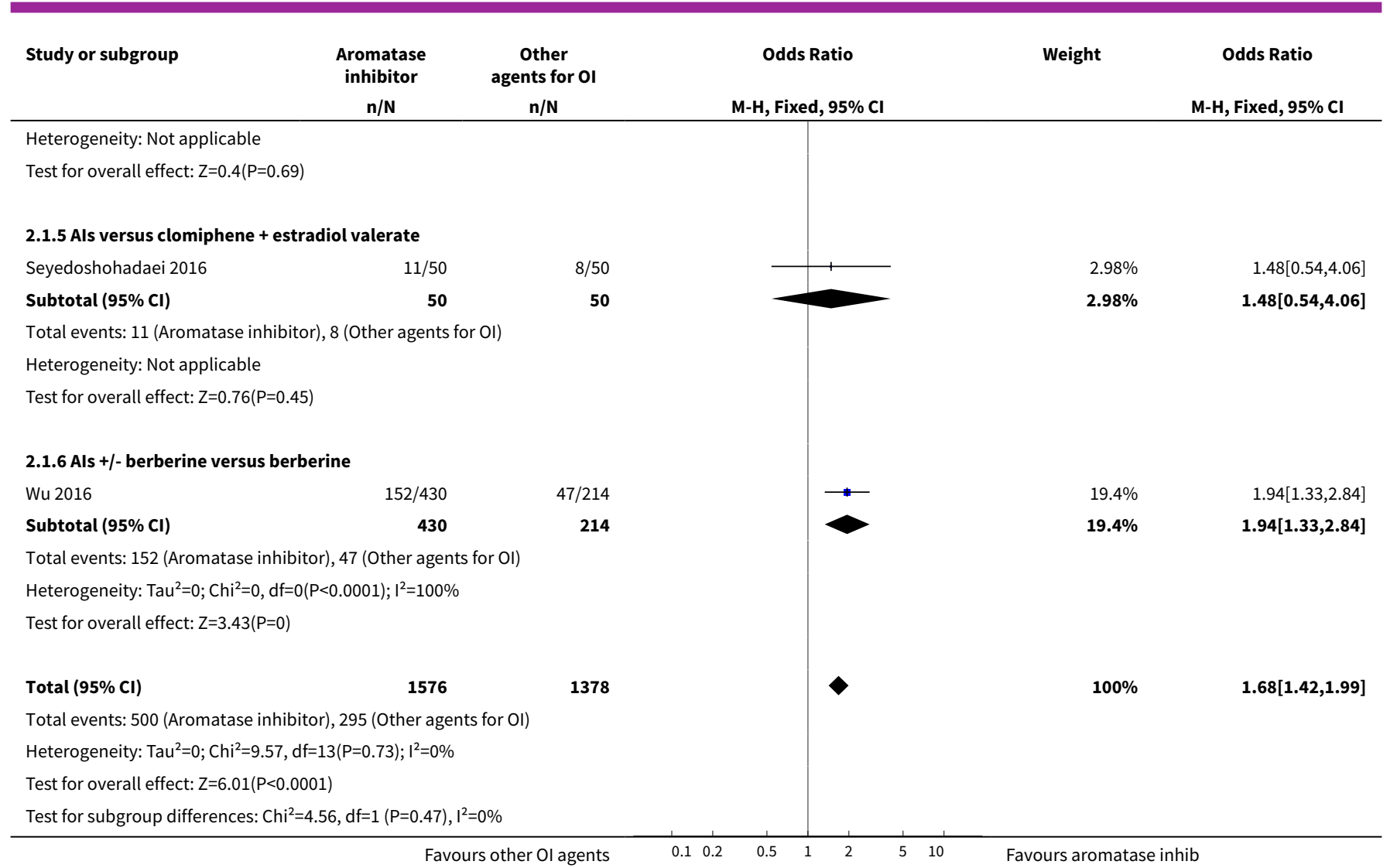

Analysis 2.2. Comparison 2 Letrozole compared to selective estrogen receptor modulators with or without adjuncts, followed by timed intercourse, Outcome 2 Live birth rate by BMI.

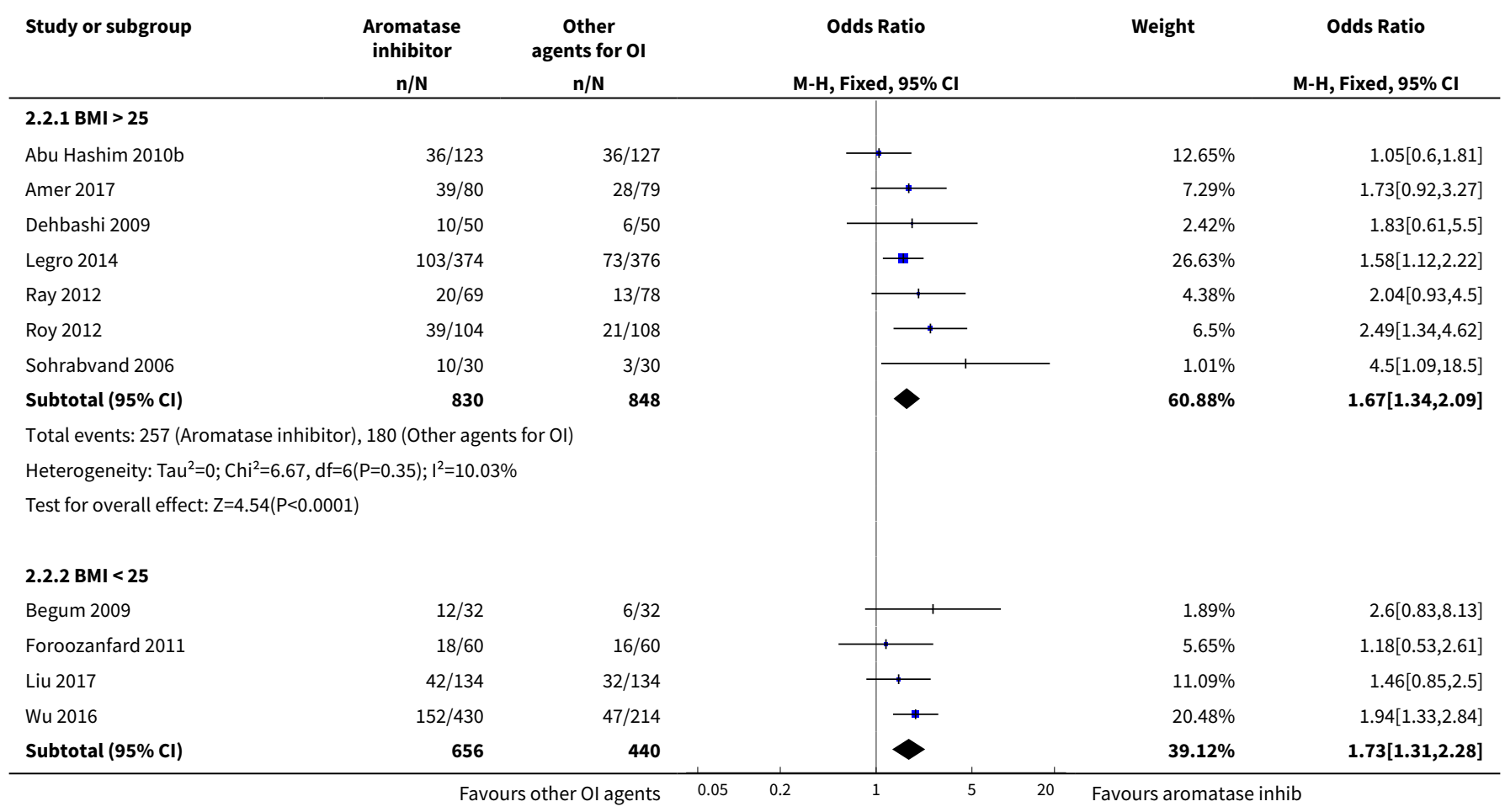




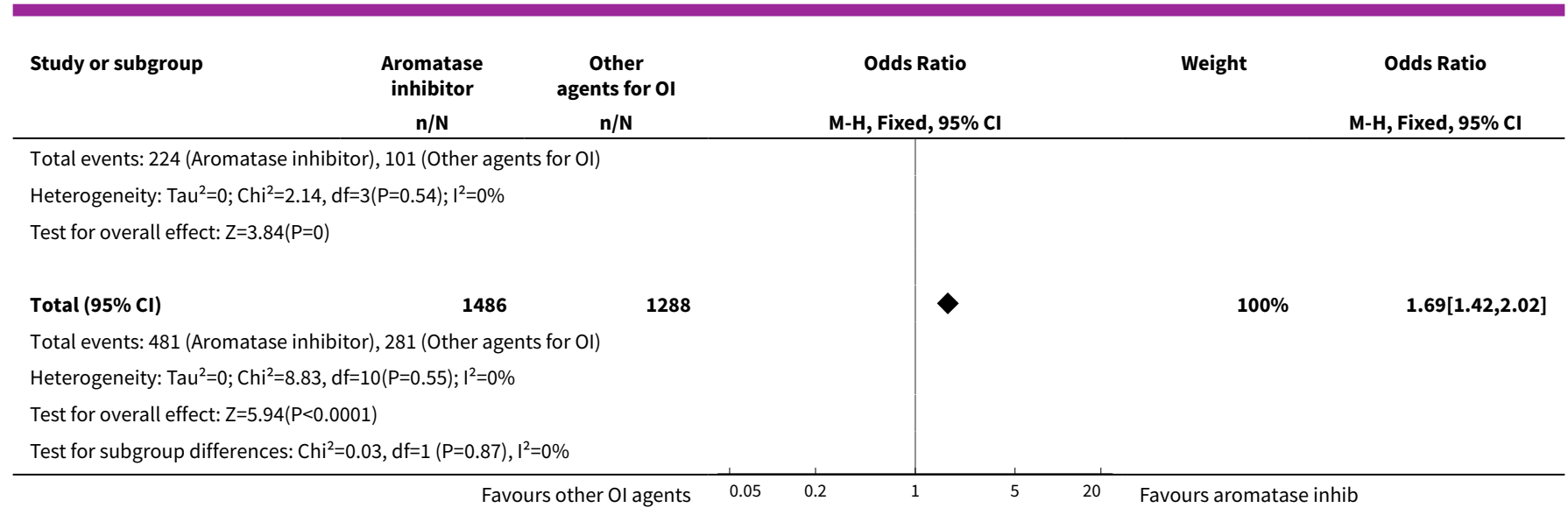

\section{Analysis 2.3. Comparison 2 Letrozole compared to selective estrogen receptor modulators with or without adjuncts, followed by timed intercourse, Outcome 3 Live birth rate by first- or second-line treatment.}

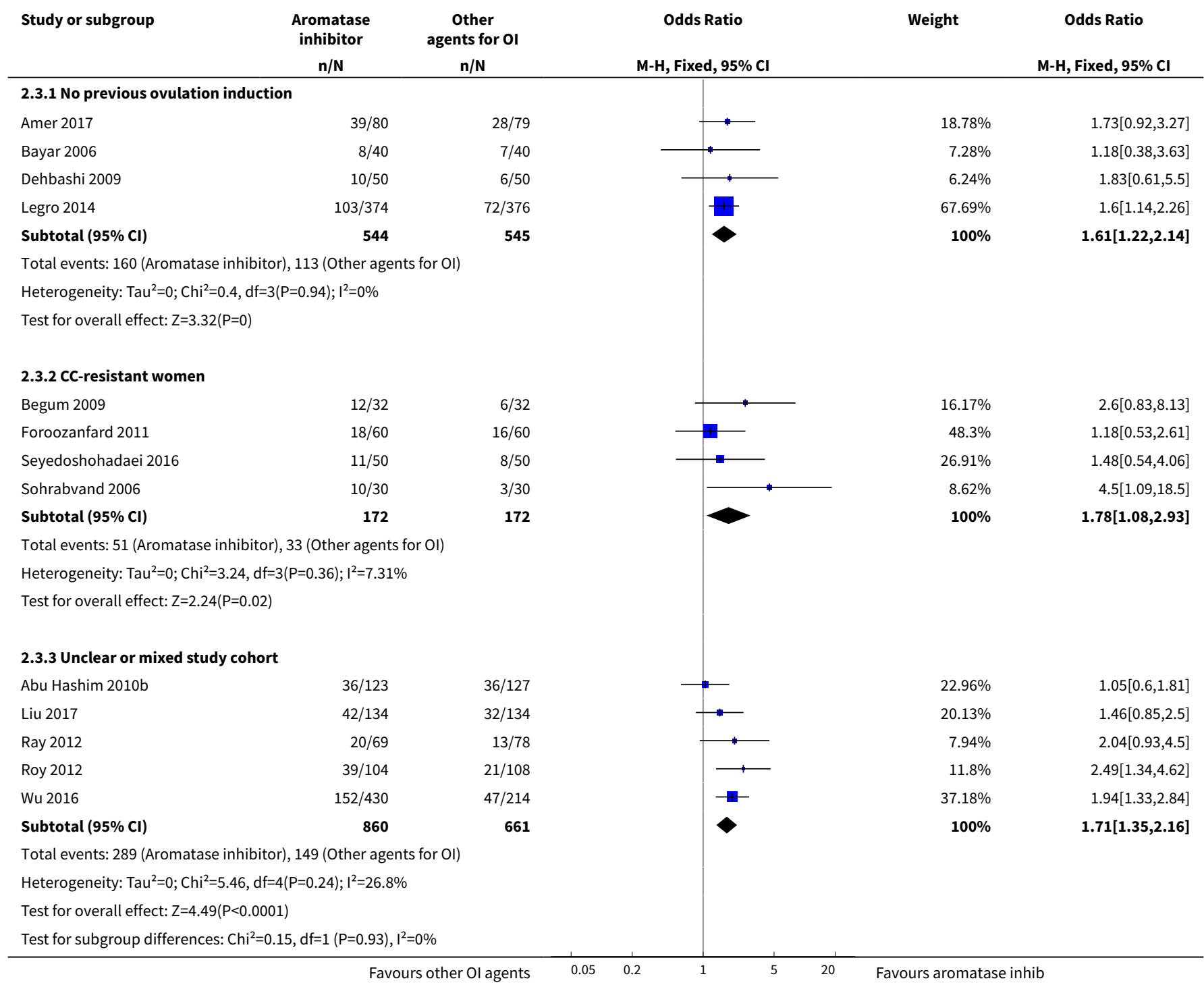


Analysis 2.4. Comparison 2 Letrozole compared to selective estrogen receptor modulators with or without adjuncts, followed by timed intercourse, Outcome 4 Impact of allocation bias for live birth rate.

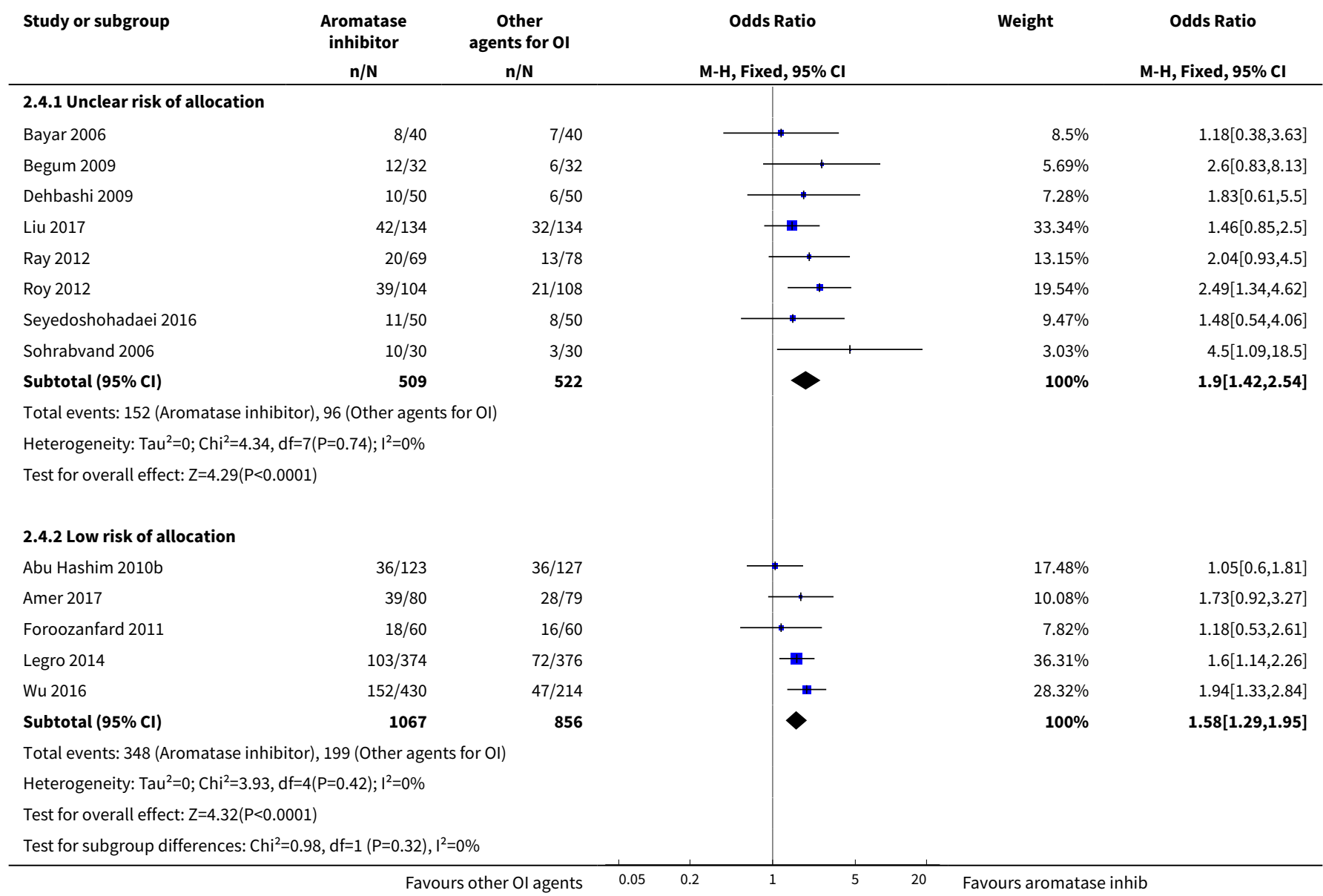

Analysis 2.5. Comparison 2 Letrozole compared to selective estrogen receptor modulators with or without adjuncts, followed by timed intercourse, Outcome 5 Impact of detection bias for live birth rate.

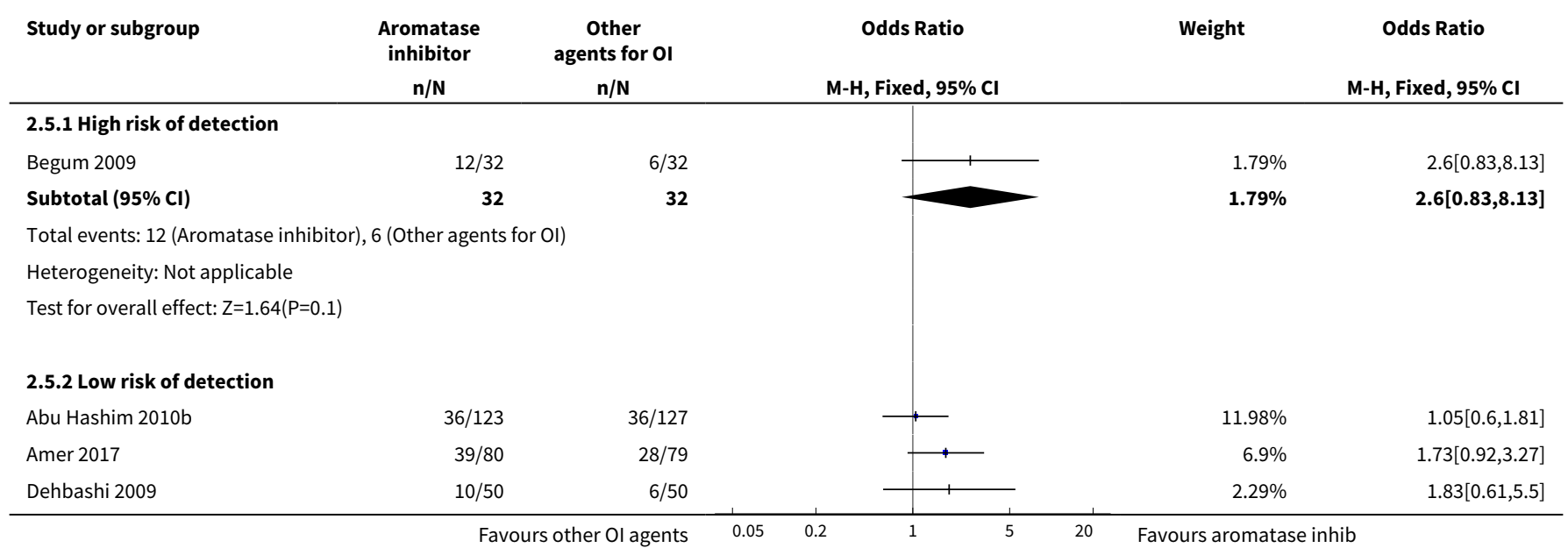




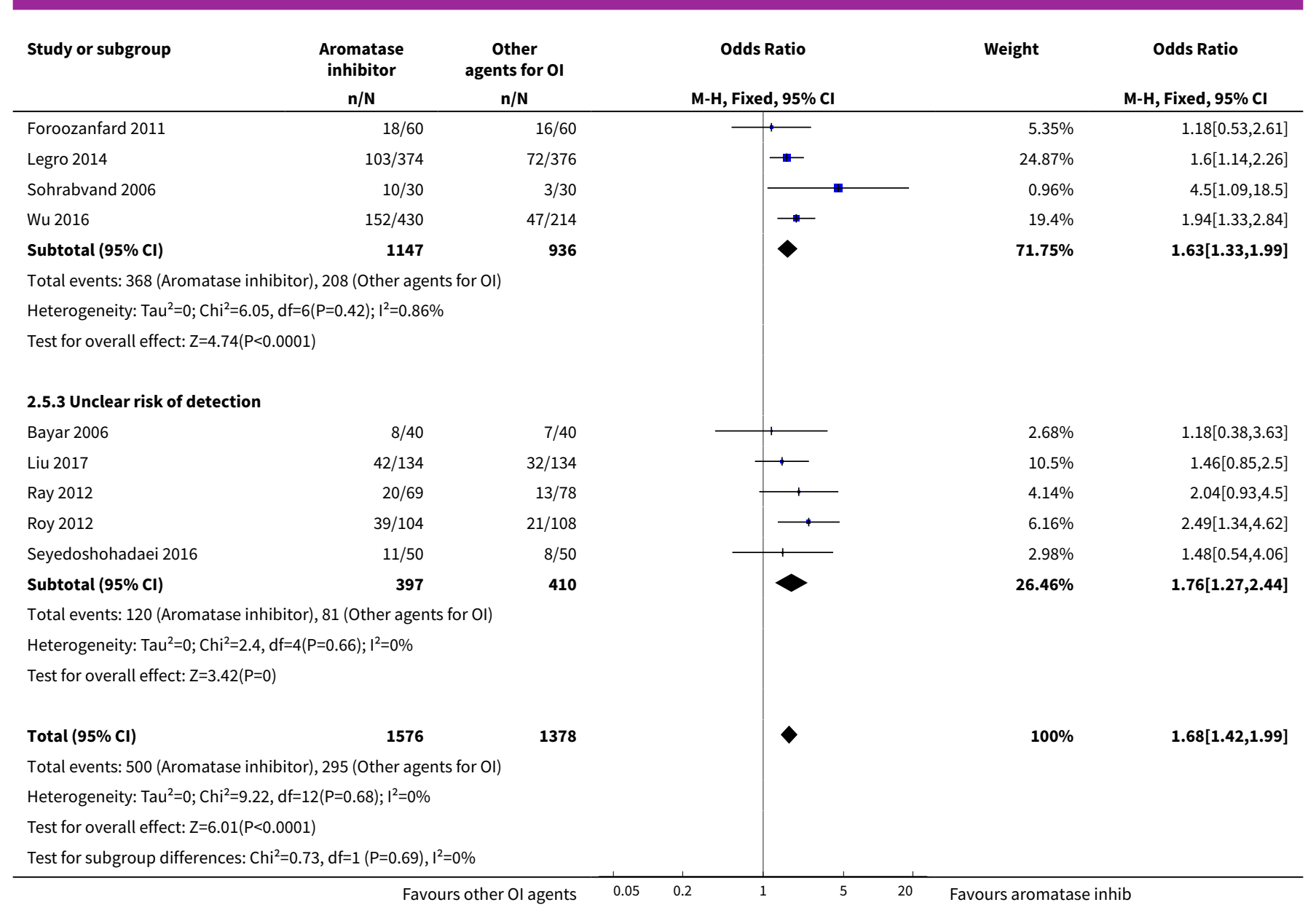

Analysis 2.6. Comparison 2 Letrozole compared to selective estrogen receptor modulators with or without adjuncts, followed by timed intercourse, Outcome 6 Impact of attrition bias for live birth rate.

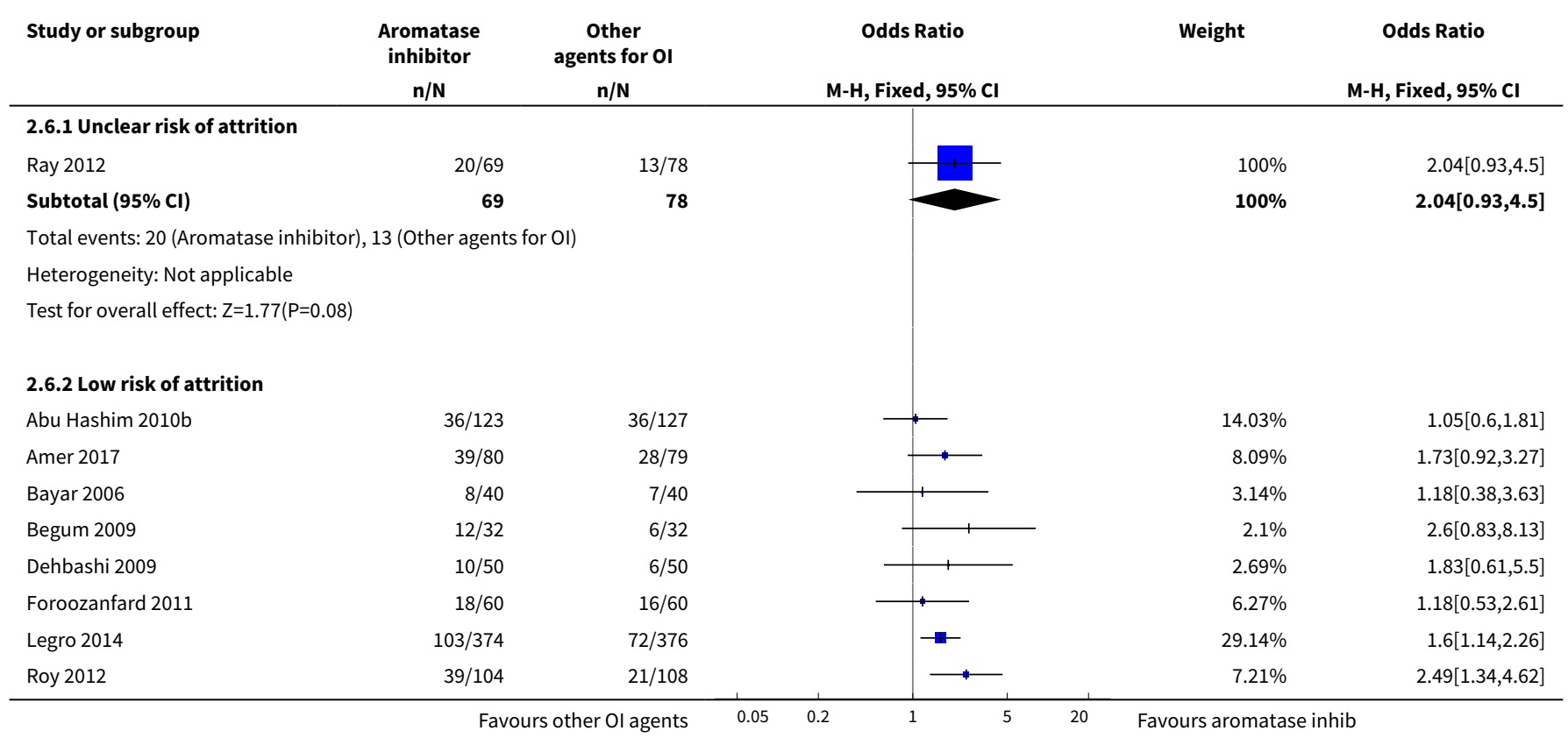




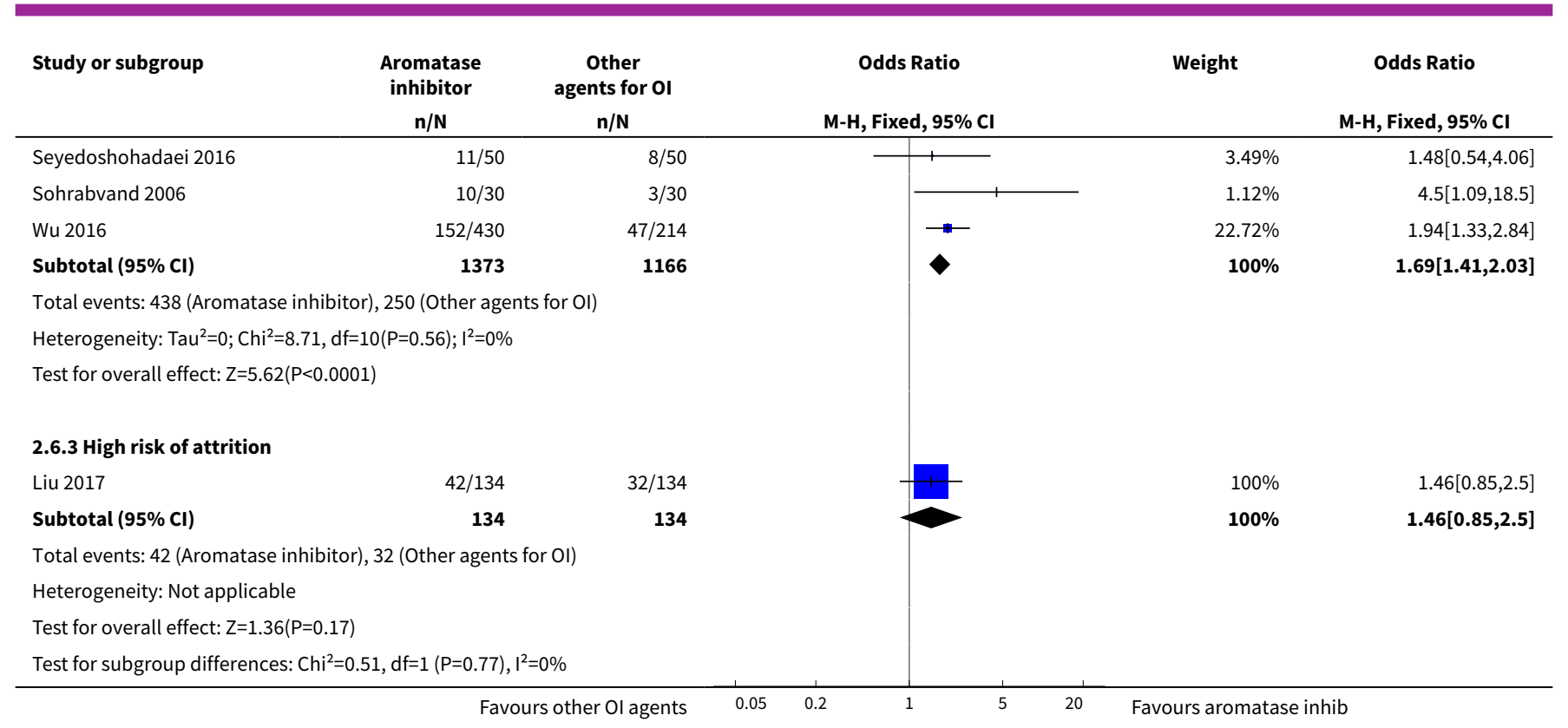

Analysis 2.7. Comparison 2 Letrozole compared to selective estrogen receptor modulators with or without adjuncts, followed by timed intercourse, Outcome 7 Ovarian hyperstimulation syndrome rate.

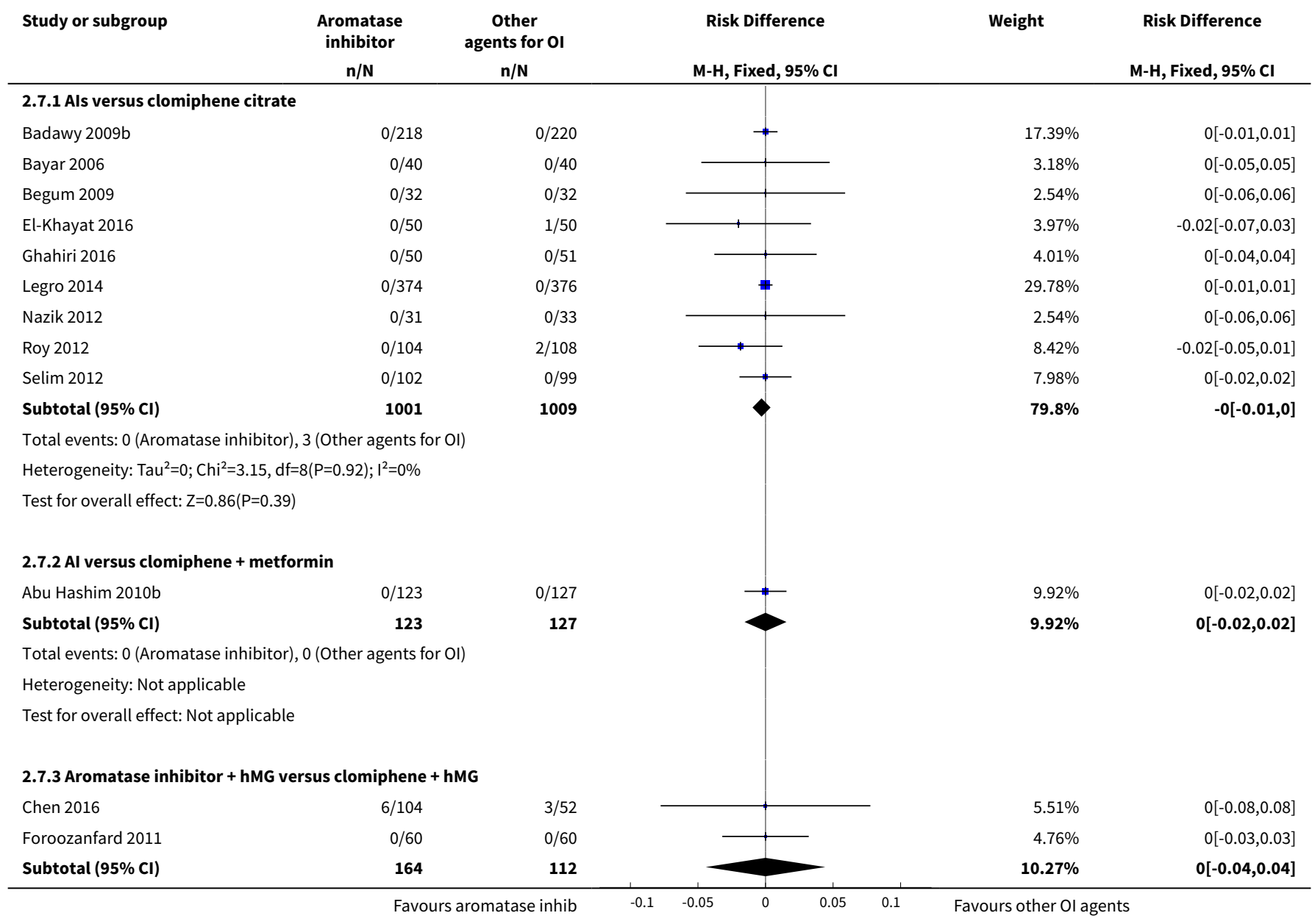




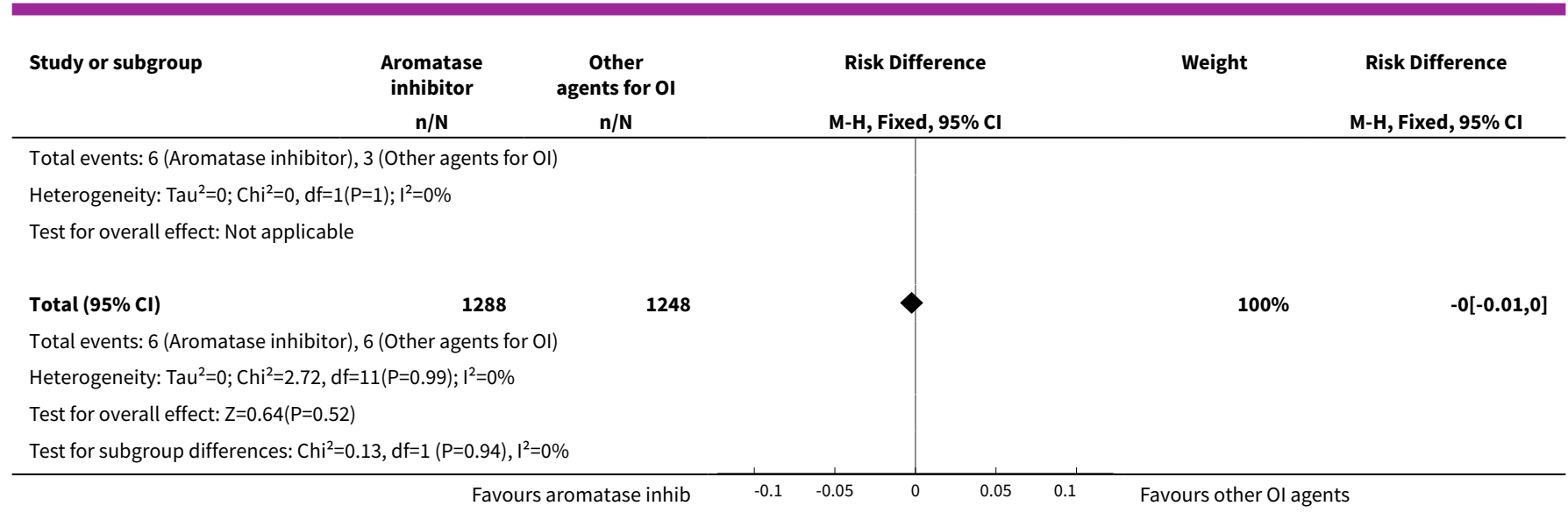

\section{Analysis 2.8. Comparison 2 Letrozole compared to selective estrogen receptor modulators with or without adjuncts, followed by timed intercourse, Outcome 8 Ovarian hyperstimulation syndrome rate per BMI.}

\begin{tabular}{|c|c|c|c|c|c|}
\hline \multirow[t]{2}{*}{ Study or subgroup } & $\begin{array}{l}\text { Aromatase } \\
\text { inhibitor }\end{array}$ & $\begin{array}{c}\text { Other } \\
\text { agents for OI }\end{array}$ & Risk Difference & Weight & Risk Difference \\
\hline & $n / N$ & $n / N$ & M-H, Fixed, 95\% Cl & & M-H, Fixed, $95 \% \mathrm{Cl}$ \\
\hline
\end{tabular}

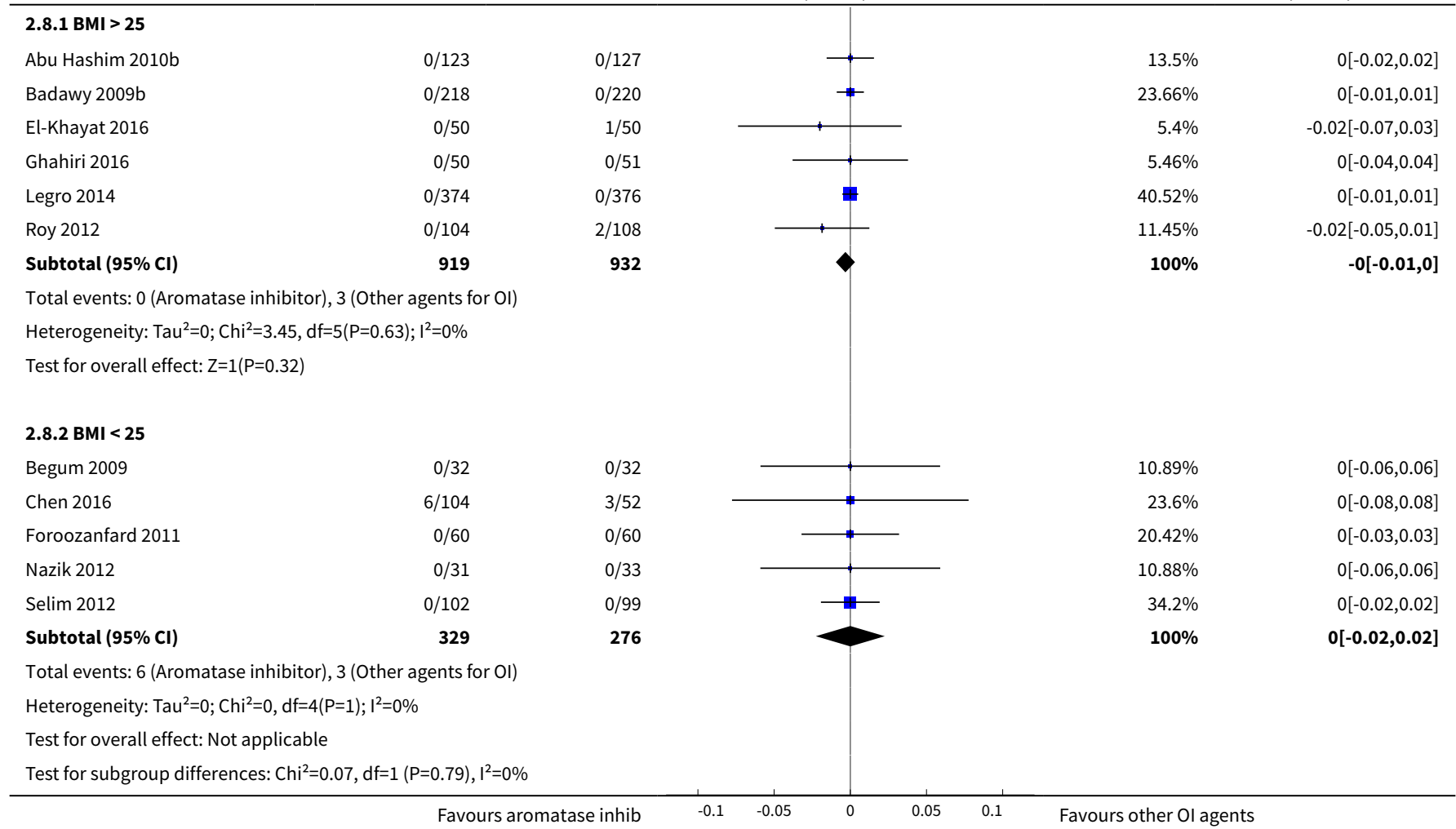


Analysis 2.9. Comparison 2 Letrozole compared to selective estrogen receptor modulators with or without adjuncts, followed by timed intercourse, Outcome 9 Clinical pregnancy rate.

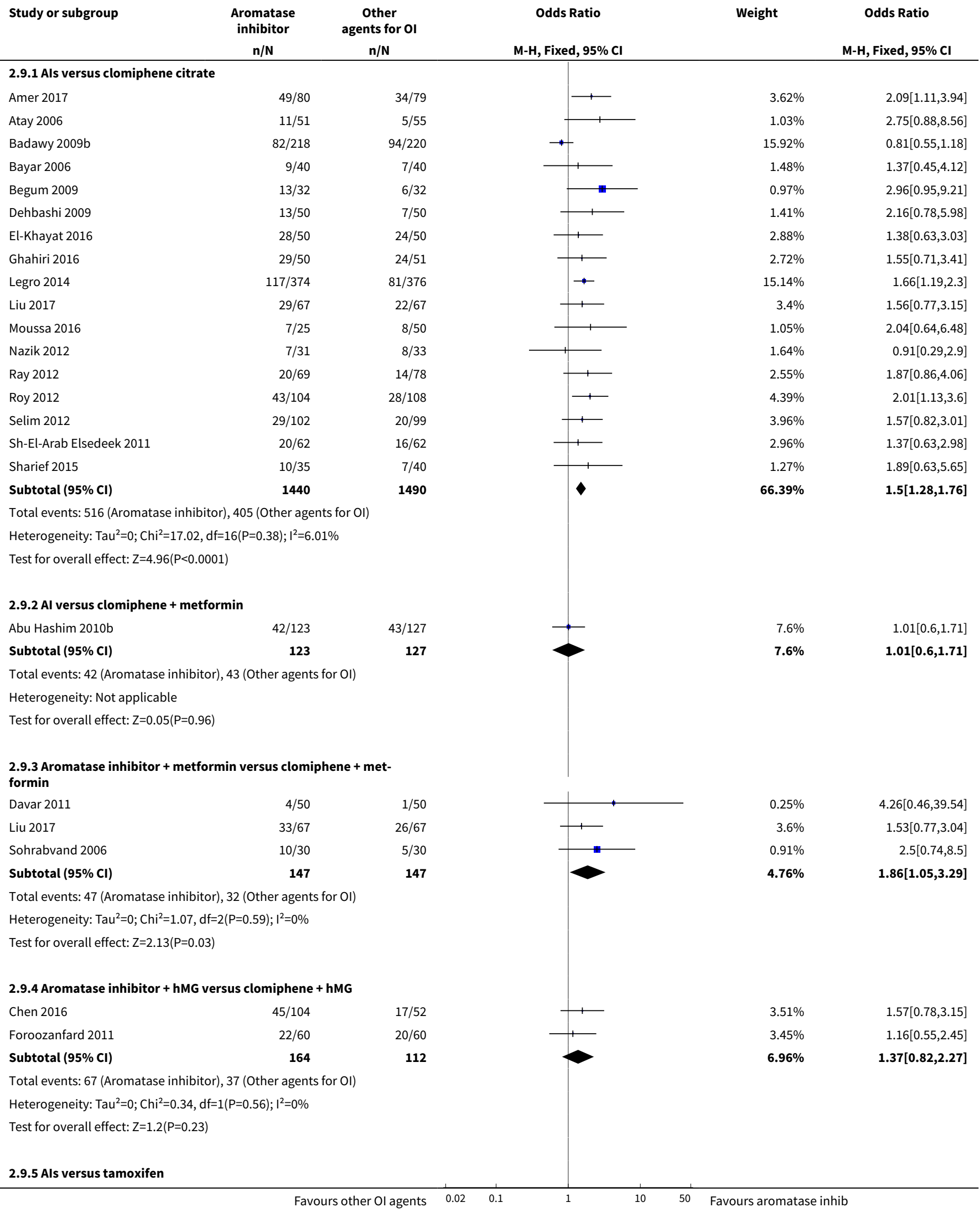




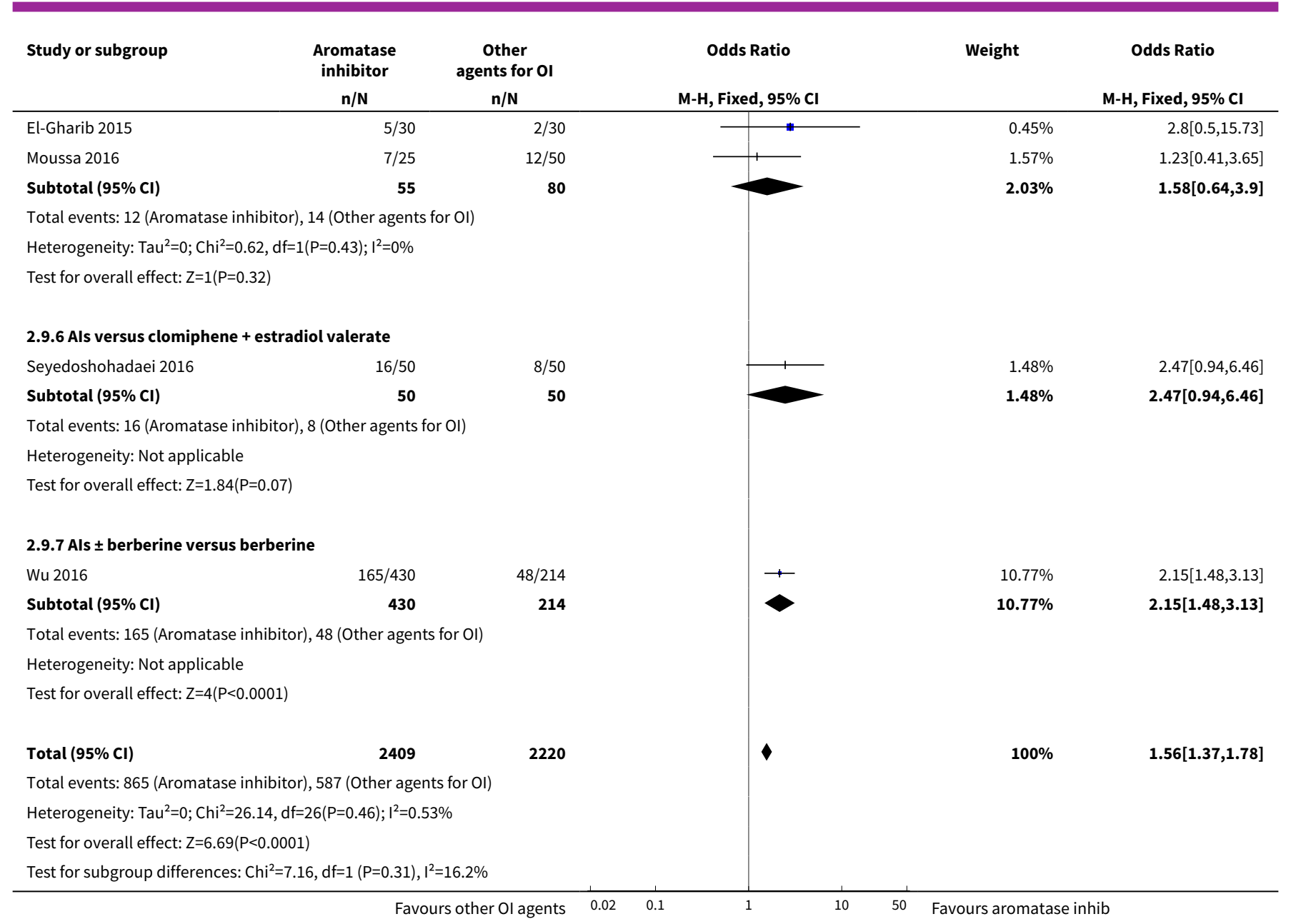

\section{Analysis 2.10. Comparison 2 Letrozole compared to selective estrogen receptor modulators with or without adjuncts, followed by timed intercourse, Outcome 10 Impact of allocation bias for clinical pregnancy rate.}

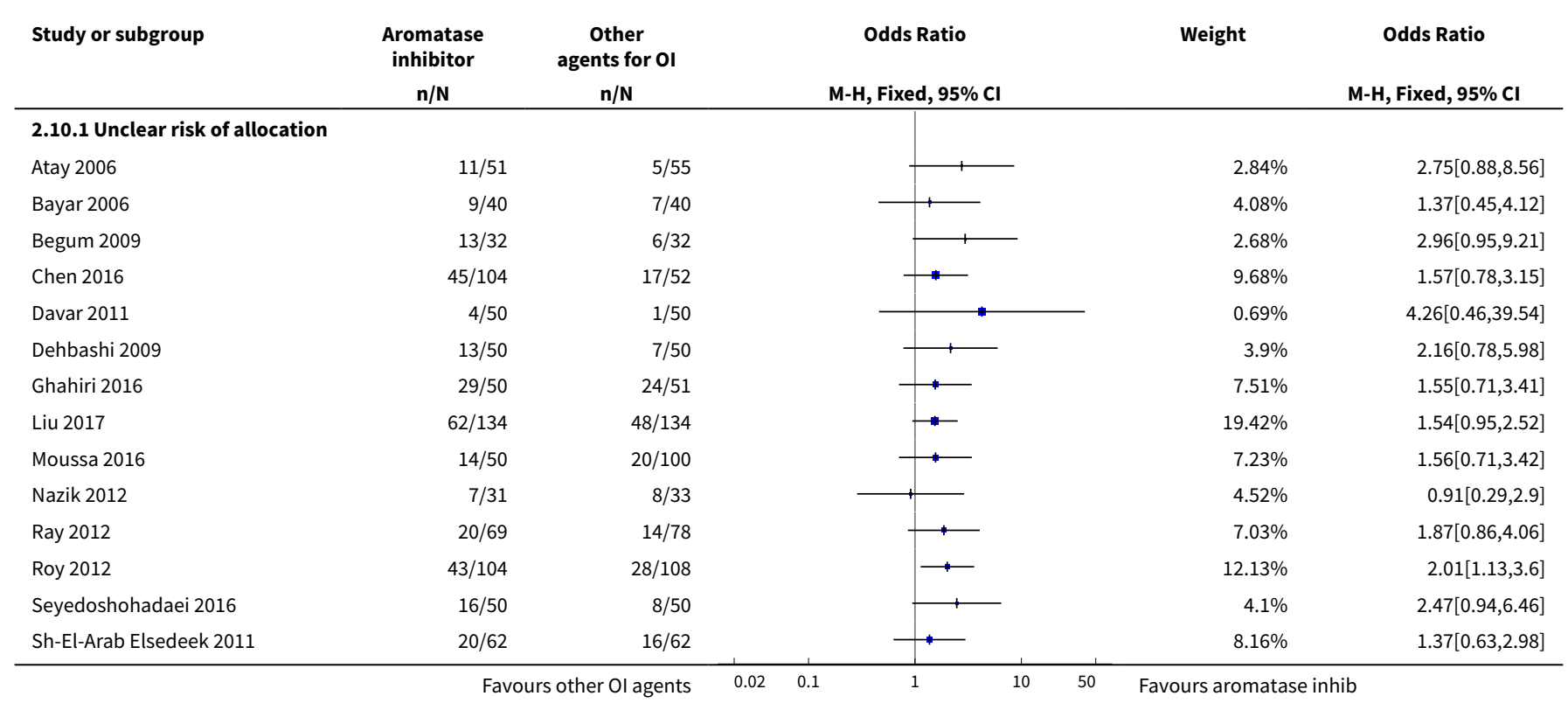




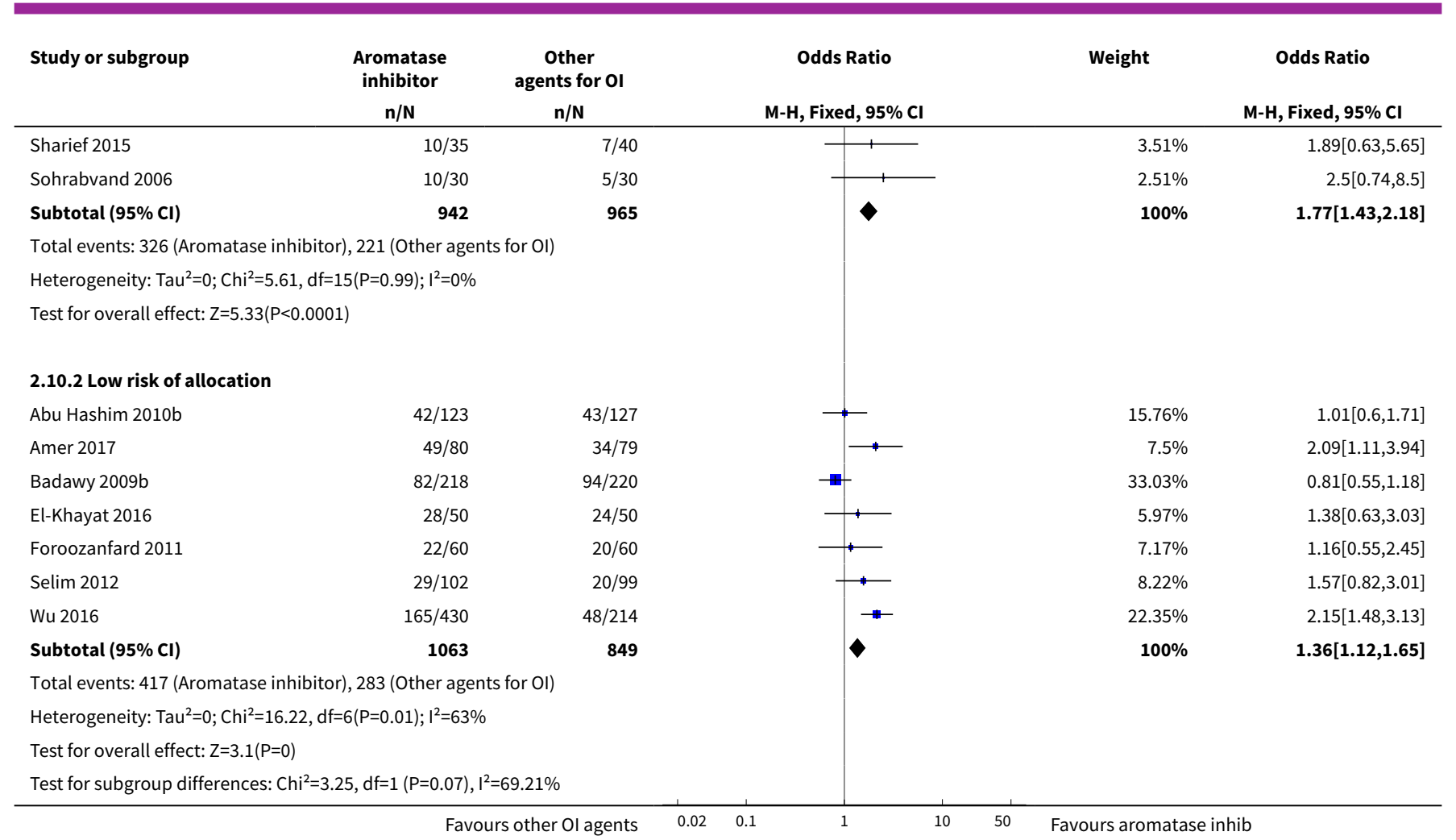

Analysis 2.11. Comparison 2 Letrozole compared to selective estrogen receptor modulators with or without adjuncts, followed by timed intercourse, Outcome 11 Miscarriage rate by woman randomised.

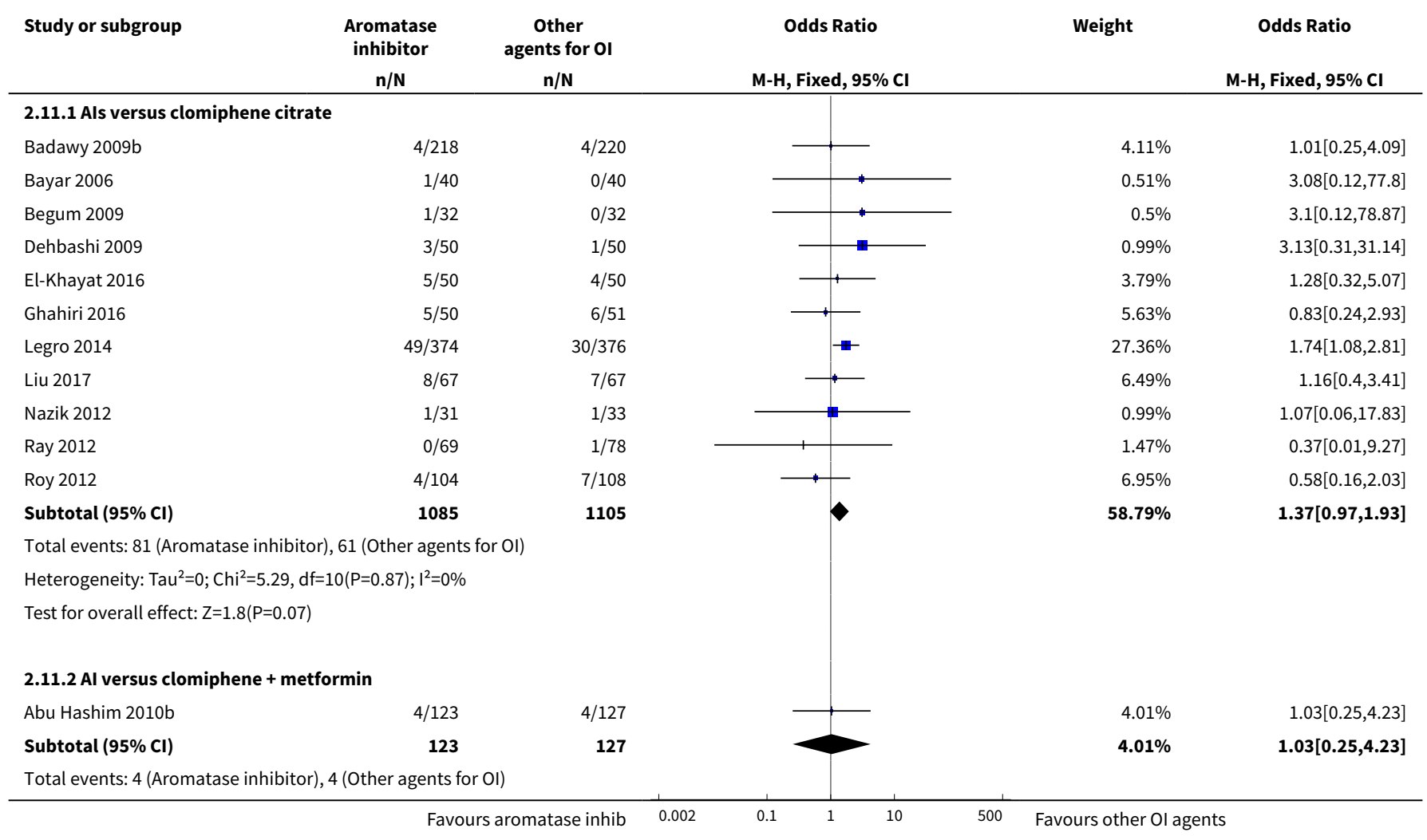




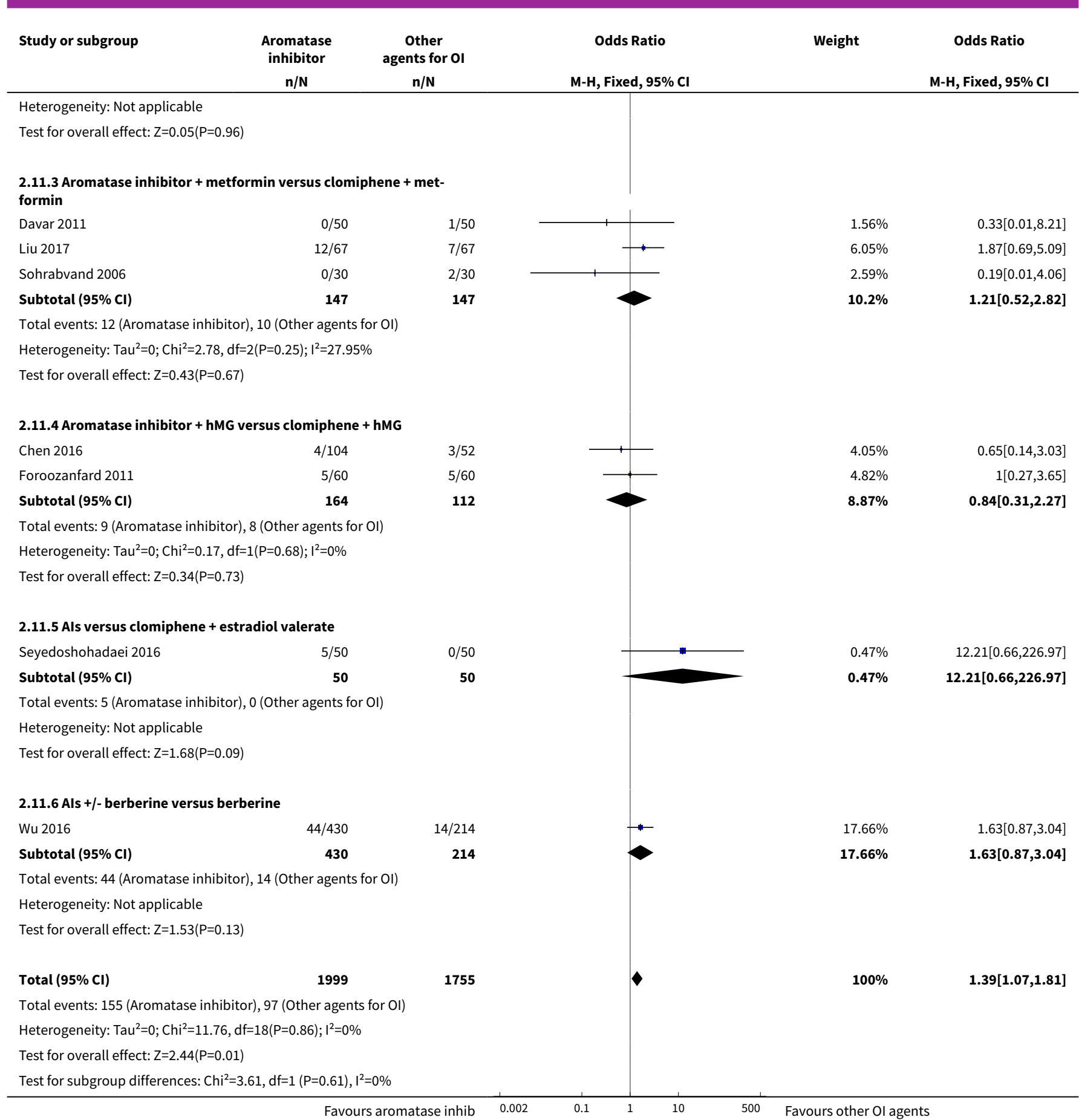

Analysis 2.12. Comparison 2 Letrozole compared to selective estrogen receptor modulators with or without adjuncts, followed by timed intercourse, Outcome 12 Miscarriage rate by pregnancies.

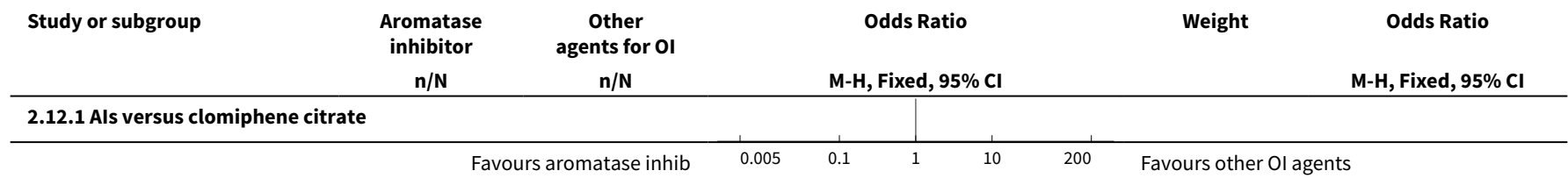




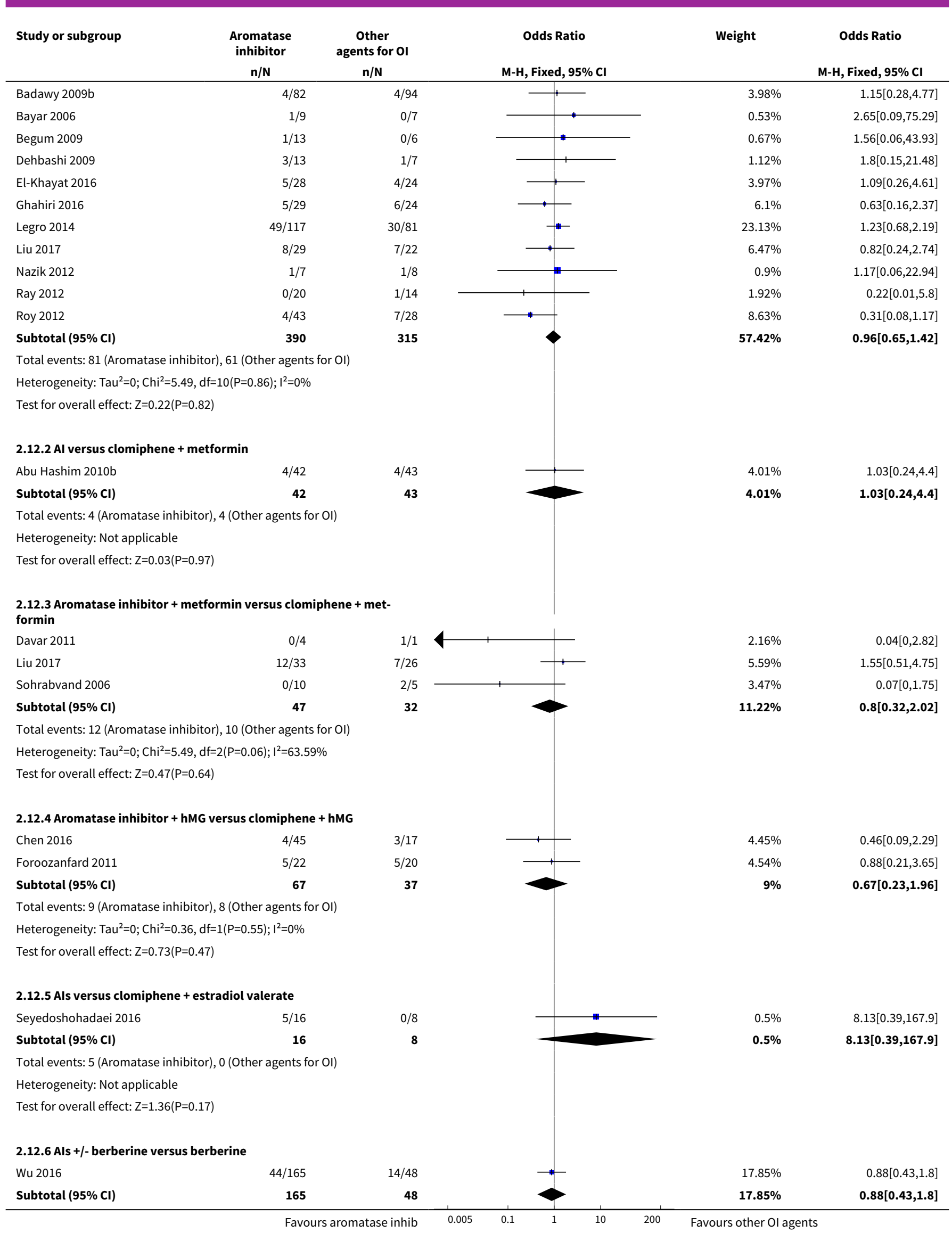




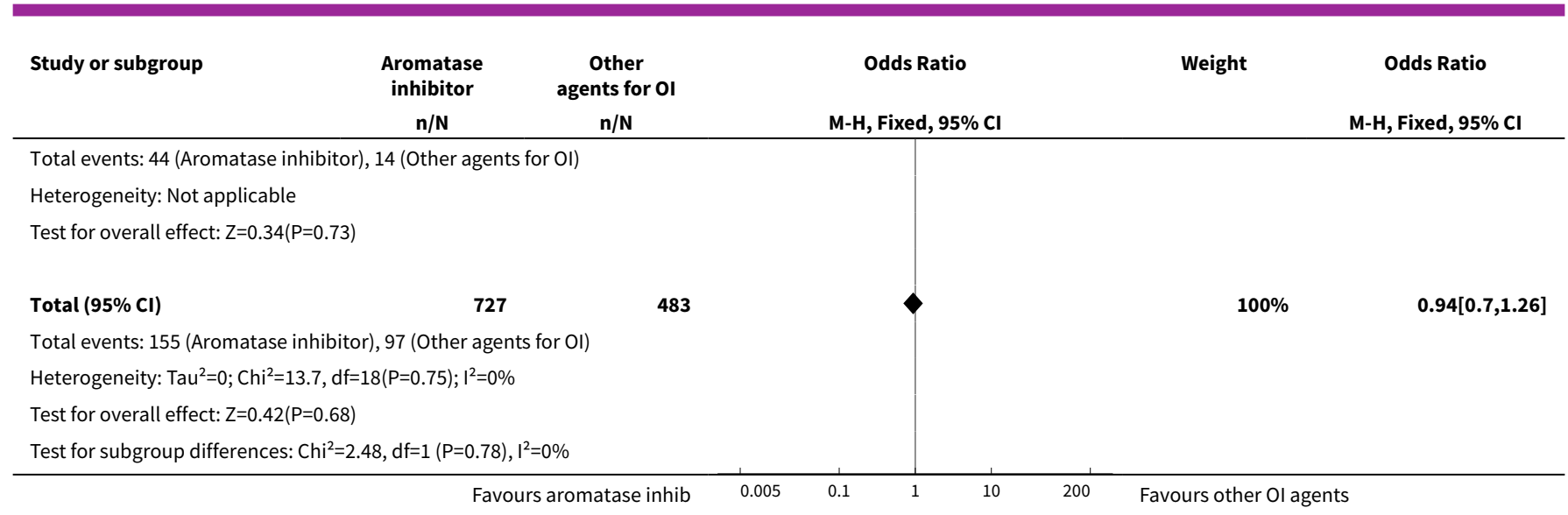

Analysis 2.13. Comparison 2 Letrozole compared to selective estrogen receptor modulators
with or without adjuncts, followed by timed intercourse, Outcome 13 Multiple pregnancy rate.

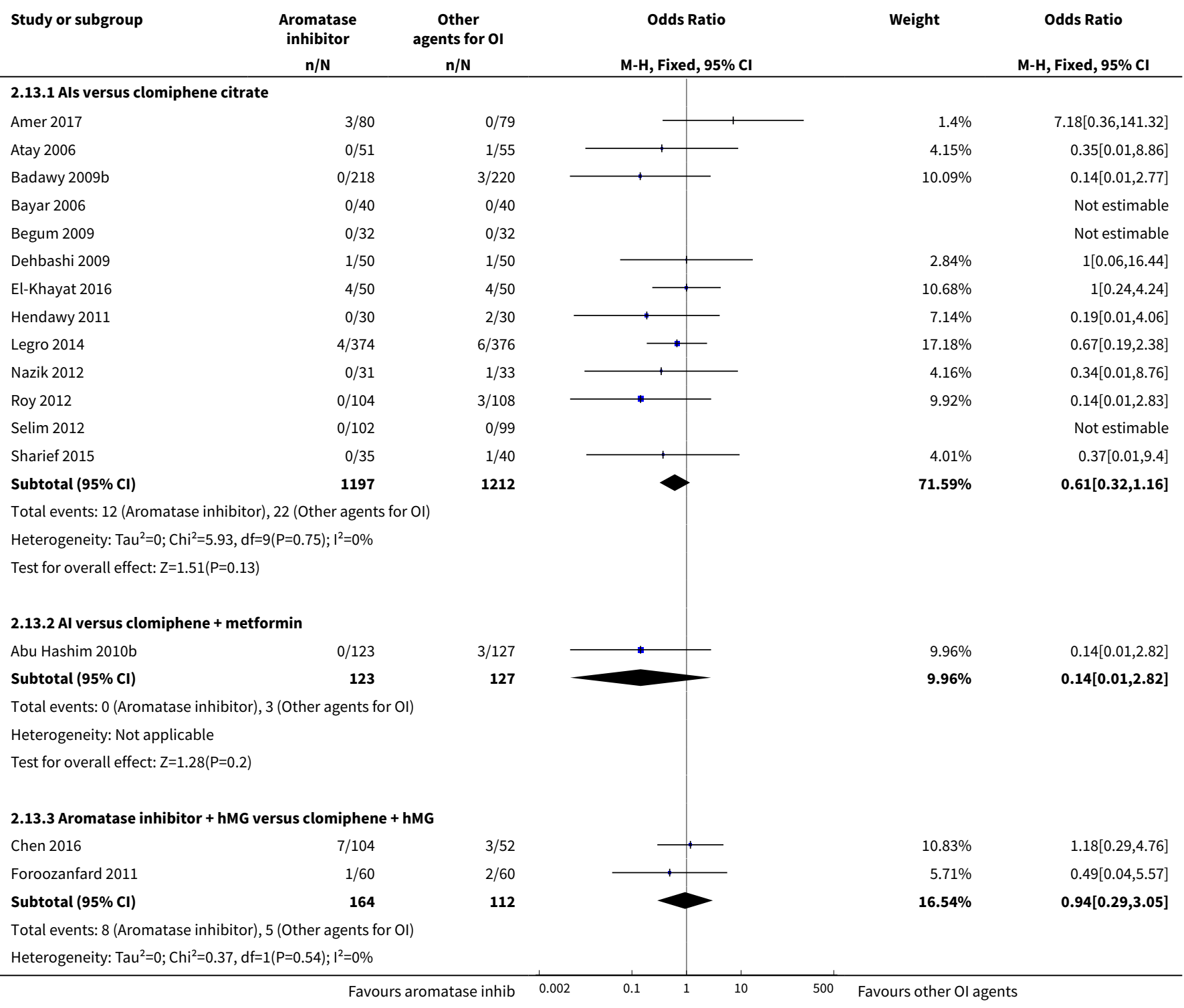




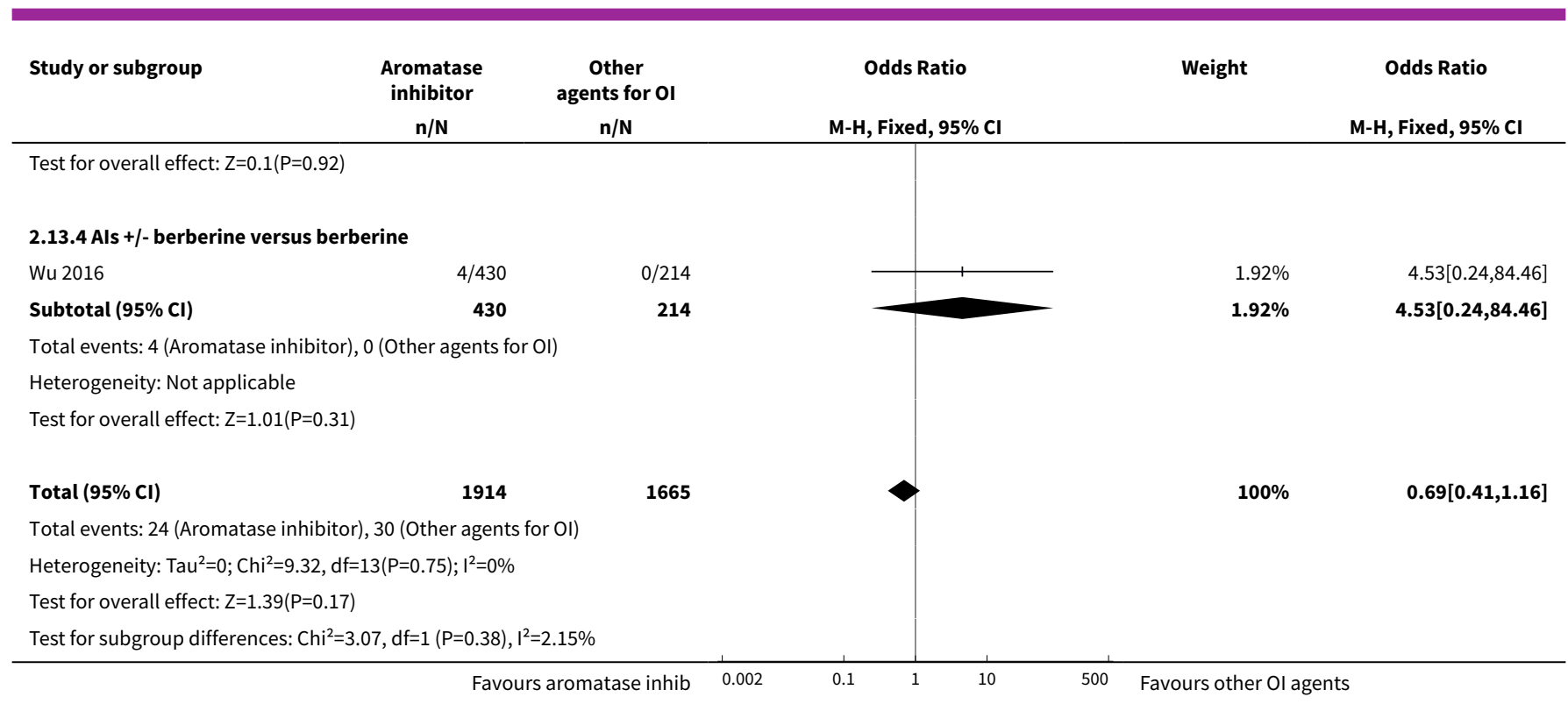

\section{Comparison 3. Letrozole compared to clomiphene citrate, followed by IUI}

\begin{tabular}{|c|c|c|c|c|}
\hline Outcome or subgroup title & No. of studies & $\begin{array}{l}\text { No. of partici- } \\
\text { pants }\end{array}$ & Statistical method & Effect size \\
\hline $\begin{array}{l}1 \text { Ovarian hyperstimulation syn- } \\
\text { drome rate }\end{array}$ & 2 & 1494 & $\begin{array}{l}\text { Risk Difference (M-H, Fixed, 95\% } \\
\mathrm{Cl} \text { ) }\end{array}$ & $-0.00[-0.01,0.00]$ \\
\hline $1.1 \mathrm{Al}$ versus Clomiphene & 1 & 107 & $\begin{array}{l}\text { Risk Difference (M-H, Fixed, 95\% } \\
\mathrm{Cl})\end{array}$ & $-0.02[-0.07,0.03]$ \\
\hline $\begin{array}{l}1.2 \mathrm{Al} \text { versus Clomiphene }+\mathrm{rFSH} \\
\text { and } \mathrm{rFSH} \text { only }\end{array}$ & 1 & 1387 & $\begin{array}{l}\text { Risk Difference (M-H, Fixed, 95\% } \\
\mathrm{Cl})\end{array}$ & $-0.00[-0.01,0.00]$ \\
\hline 2 Clinical pregnancy rate & 3 & 1597 & Odds Ratio (M-H, Fixed, 95\% CI) & $1.71[1.30,2.25]$ \\
\hline $2.1 \mathrm{Al}$ versus Clomiphene & 2 & 210 & Odds Ratio (M-H, Fixed, 95\% CI) & $2.09[0.97,4.53]$ \\
\hline $\begin{array}{l}2.2 \mathrm{Al} \text { versus Clomiphene }+\mathrm{rFSH} \\
\text { and rFSH only }\end{array}$ & 1 & 1387 & Odds Ratio (M-H, Fixed, 95\% CI) & $1.66[1.23,2.22]$ \\
\hline $\begin{array}{l}3 \text { Miscarriage rate by woman ran- } \\
\text { domised }\end{array}$ & 2 & 1490 & Odds Ratio (M-H, Fixed, 95\% Cl) & $1.22[0.62,2.40]$ \\
\hline 3.1 Al versus Clomiphene & 1 & 103 & Odds Ratio (M-H, Fixed, 95\% Cl) & $0.32[0.01,8.06]$ \\
\hline $\begin{array}{l}\text { 3.2 Al versus Clomiphene }+ \text { rFSH } \\
\text { and rFSH only }\end{array}$ & 1 & 1387 & Odds Ratio (M-H, Fixed, 95\% Cl) & $1.32[0.66,2.65]$ \\
\hline 4 Miscarriage rate by pregnancies & 2 & 260 & Odds Ratio (M-H, Fixed, 95\% CI) & $0.76[0.37,1.57]$ \\
\hline 4.1 Al versus Clomiphene & 1 & 15 & Odds Ratio (M-H, Fixed, 95\% Cl) & $0.10[0.00,3.09]$ \\
\hline $\begin{array}{l}4.2 \mathrm{Al} \text { versus Clomiphene }+\mathrm{rFSH} \\
\text { and } \mathrm{rFSH} \text { only }\end{array}$ & 1 & 245 & Odds Ratio (M-H, Fixed, 95\% Cl) & $0.85[0.40,1.79]$ \\
\hline
\end{tabular}




\begin{tabular}{lllll}
\hline Outcome or subgroup title & No. of studies & $\begin{array}{l}\text { No. of partici- } \\
\text { pants }\end{array}$ & Statistical method & Effect size \\
\hline 5 Multiple pregnancy rate & 3 & 1597 & Odds Ratio (M-H, Fixed, 95\% Cl) & $1.03[0.49,2.13]$ \\
\hline 5.1 Al versus Clomiphene & 2 & 210 & Odds Ratio (M-H, Fixed, 95\% Cl) & $3.48[0.14,87.49]$ \\
\hline $\begin{array}{l}\text { 5.2 Al versus Clomiphene +rFSH } \\
\text { and rFSH only }\end{array}$ & 1 & 1387 & Odds Ratio (M-H, Fixed, 95\% Cl) & $0.94[0.44,2.03]$ \\
\hline
\end{tabular}

Analysis 3.1. Comparison 3 Letrozole compared to clomiphene citrate, followed by IUI, Outcome 1 Ovarian hyperstimulation syndrome rate.

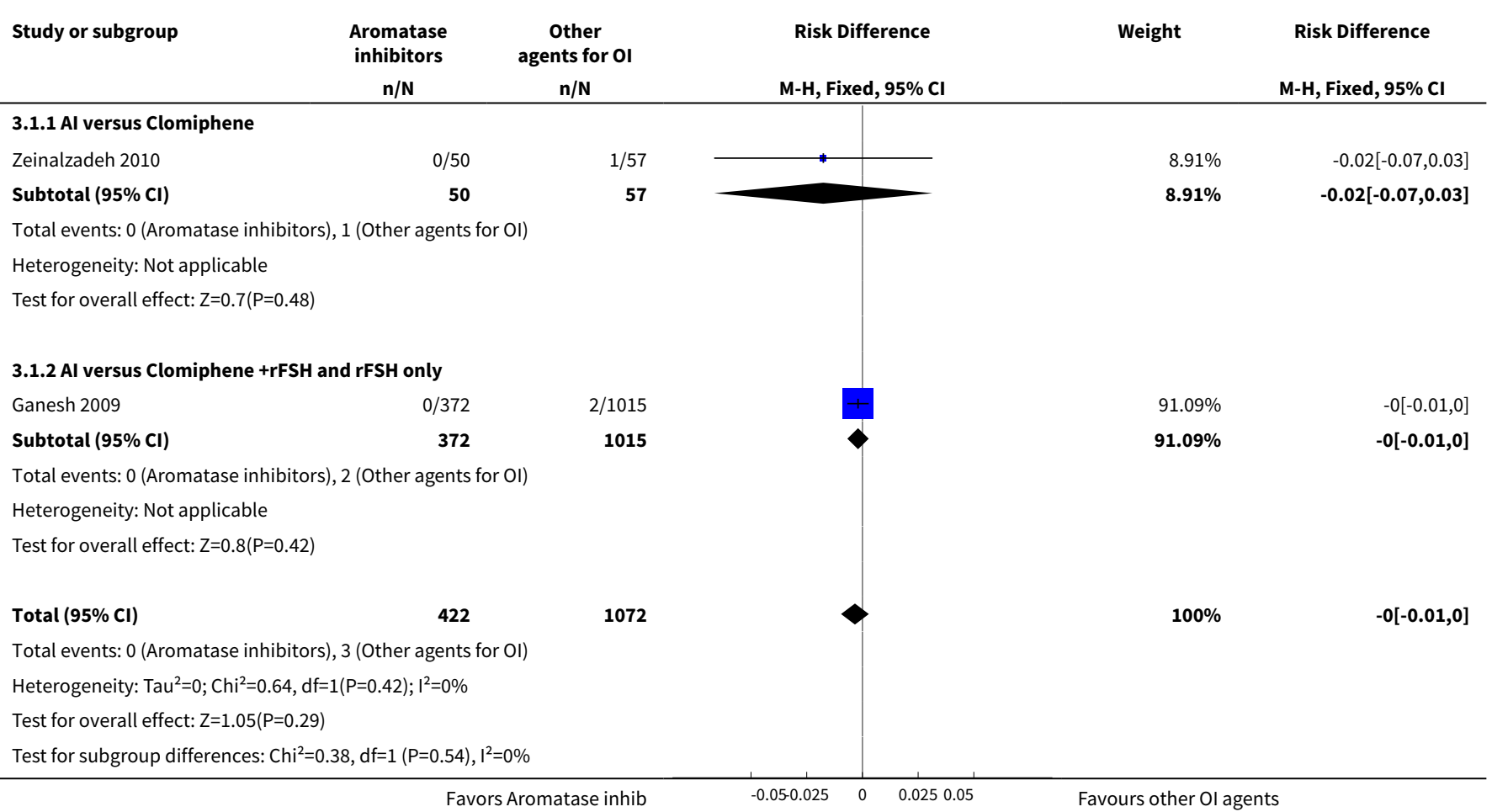

\section{Analysis 3.2. Comparison 3 Letrozole compared to clomiphene citrate, followed by IUI, Outcome 2 Clinical pregnancy rate.}

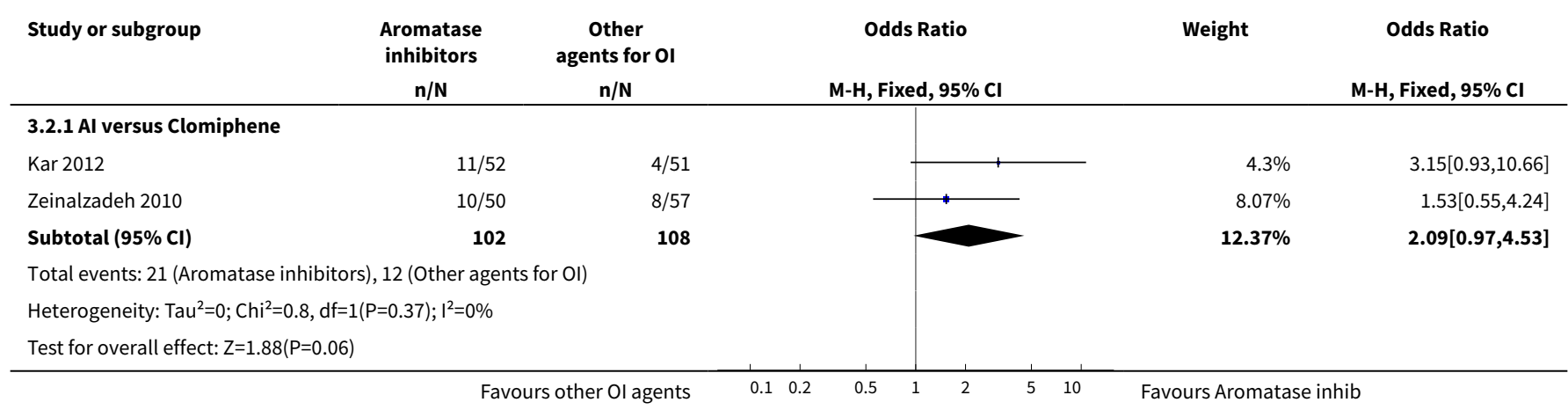




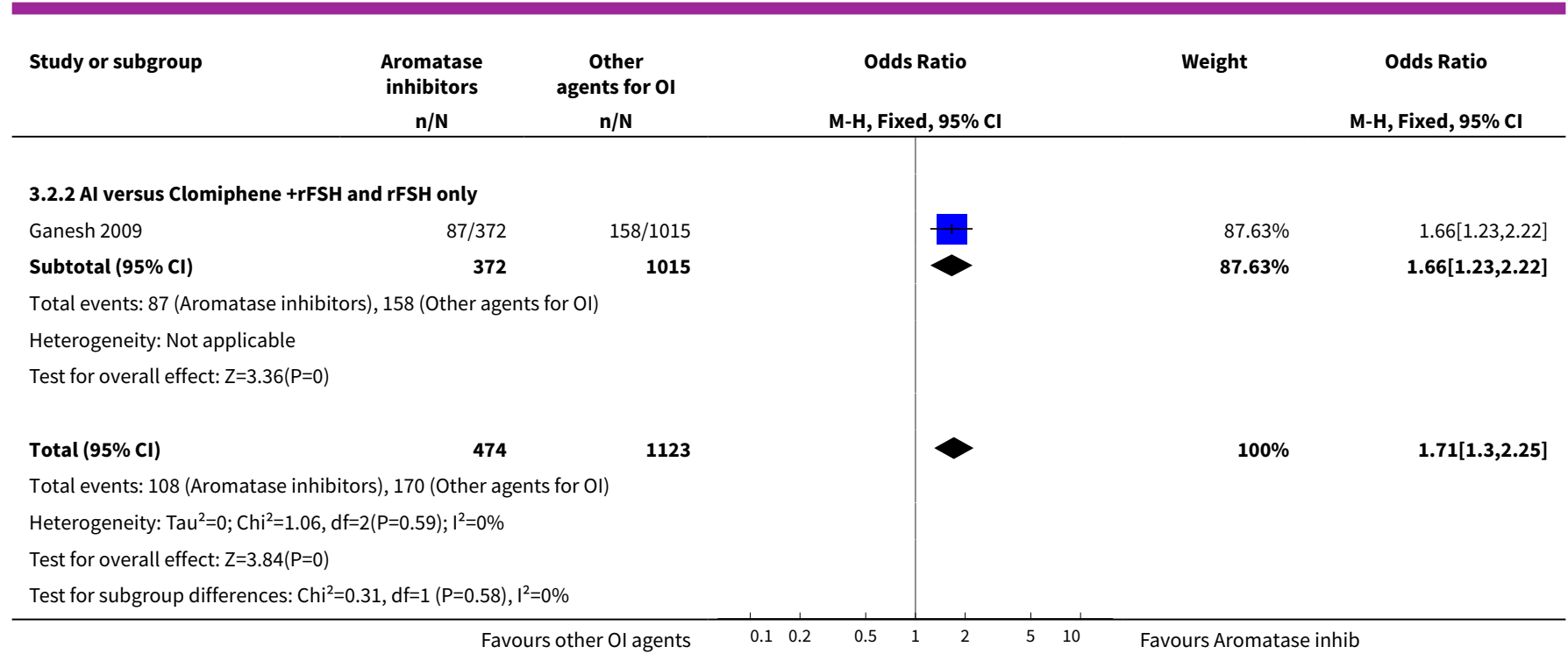

Analysis 3.3. Comparison 3 Letrozole compared to clomiphene citrate, followed by IUI, Outcome 3 Miscarriage rate by woman randomised.

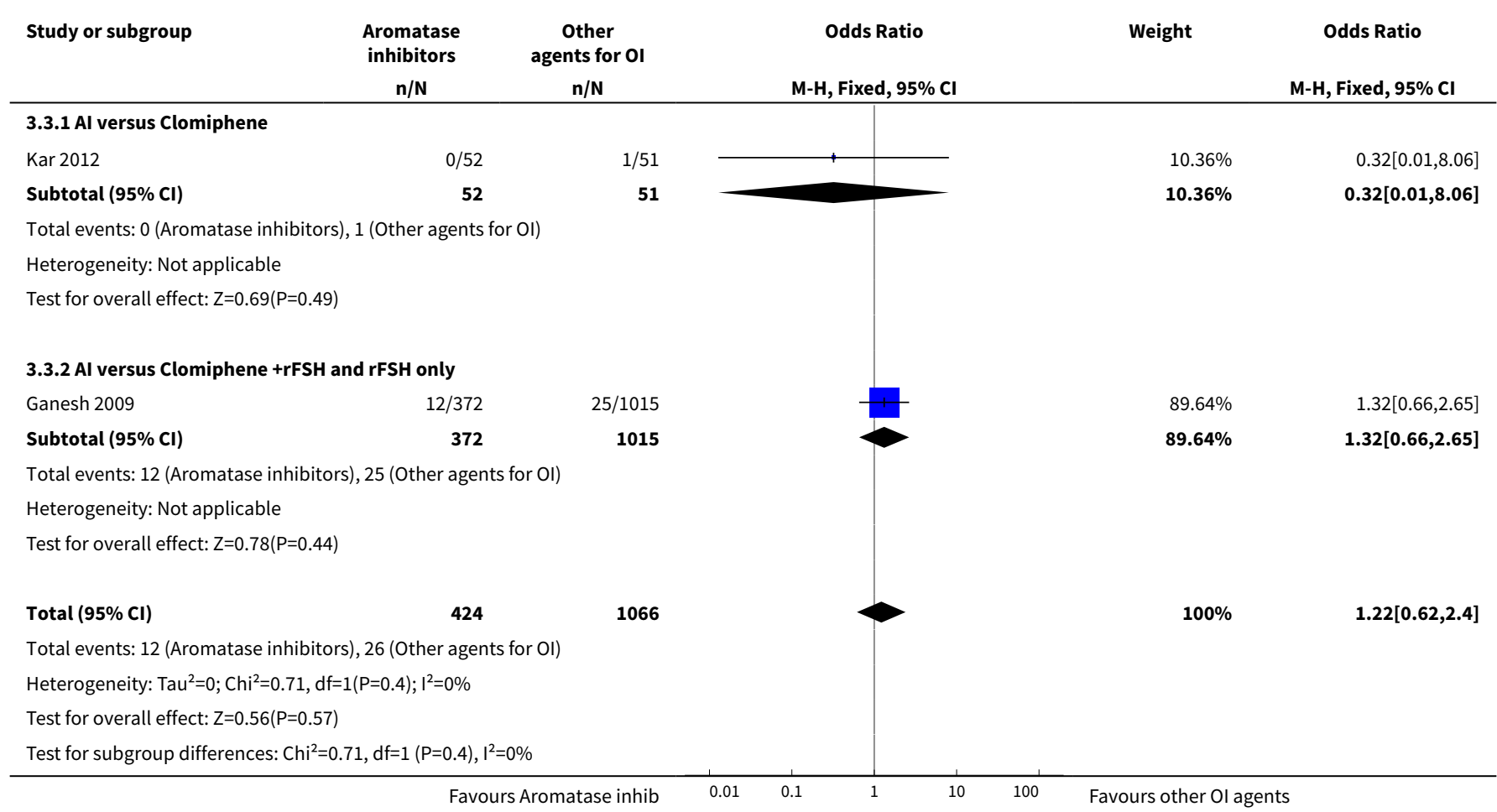


Analysis 3.4. Comparison 3 Letrozole compared to clomiphene citrate, followed by IUI, Outcome 4 Miscarriage rate by pregnancies.

\begin{tabular}{|c|c|c|c|c|c|}
\hline Study or subgroup & $\begin{array}{c}\text { Aromatase } \\
\text { inhibitors } \\
\mathrm{n} / \mathrm{N} \\
\end{array}$ & $\begin{array}{c}\text { Other } \\
\text { agents for OI } \\
n / N \\
\end{array}$ & M-H, Fixed, 95\% CI & Weight & $\begin{array}{c}\text { Odds Ratio } \\
\text { M-H, Fixed, } 95 \% \mathrm{Cl}\end{array}$ \\
\hline \multicolumn{6}{|c|}{ 3.4.1 Al versus Clomiphene } \\
\hline Kar 2012 & $0 / 11$ & $1 / 4$ & $\longrightarrow+$ & $11.71 \%$ & $0.1[0,3.09]$ \\
\hline Subtotal $(95 \% \mathrm{Cl})$ & 11 & 4 & & $11.71 \%$ & $0.1[0,3.09]$ \\
\hline \multicolumn{6}{|c|}{ Total events: 0 (Aromatase inhibitors), 1 (Other agents for OI) } \\
\hline \multicolumn{6}{|c|}{ Heterogeneity: Not applicable } \\
\hline \multicolumn{6}{|c|}{ Test for overall effect: $Z=1.31(P=0.19)$} \\
\hline \multicolumn{6}{|c|}{ 3.4.2 Al versus Clomiphene +rFSH and $\mathrm{rFSH}$ only } \\
\hline Ganesh 2009 & $12 / 87$ & $25 / 158$ & & $88.29 \%$ & $0.85[0.4,1.79]$ \\
\hline Subtotal $(95 \% \mathrm{Cl})$ & 87 & 158 & & $88.29 \%$ & $0.85[0.4,1.79]$ \\
\hline \multicolumn{6}{|c|}{ Total events: 12 (Aromatase inhibitors), 25 (Other agents for OI) } \\
\hline \multicolumn{6}{|c|}{ Test for overall effect: $Z=0.42(P=0.67)$} \\
\hline Total $(95 \% \mathrm{Cl})$ & 98 & 162 & & $100 \%$ & $0.76[0.37,1.57]$ \\
\hline \multicolumn{6}{|c|}{ Total events: 12 (Aromatase inhibitors), 26 (Other agents for OI) } \\
\hline \multicolumn{6}{|c|}{ Heterogeneity: $\operatorname{Tau}^{2}=0 ; \mathrm{Chi}^{2}=1.42, \mathrm{df}=1(\mathrm{P}=0.23) ; \mathrm{I}^{2}=29.69 \%$} \\
\hline \multicolumn{6}{|c|}{ Test for overall effect: $Z=0.73(P=0.46)$} \\
\hline Test for subgroup dif & $2, \mathrm{df}=1(P=0.23)$, & $29.64 \%$ & & & \\
\hline
\end{tabular}

\section{Analysis 3.5. Comparison 3 Letrozole compared to clomiphene citrate, followed by IUI, Outcome 5 Multiple pregnancy rate.}

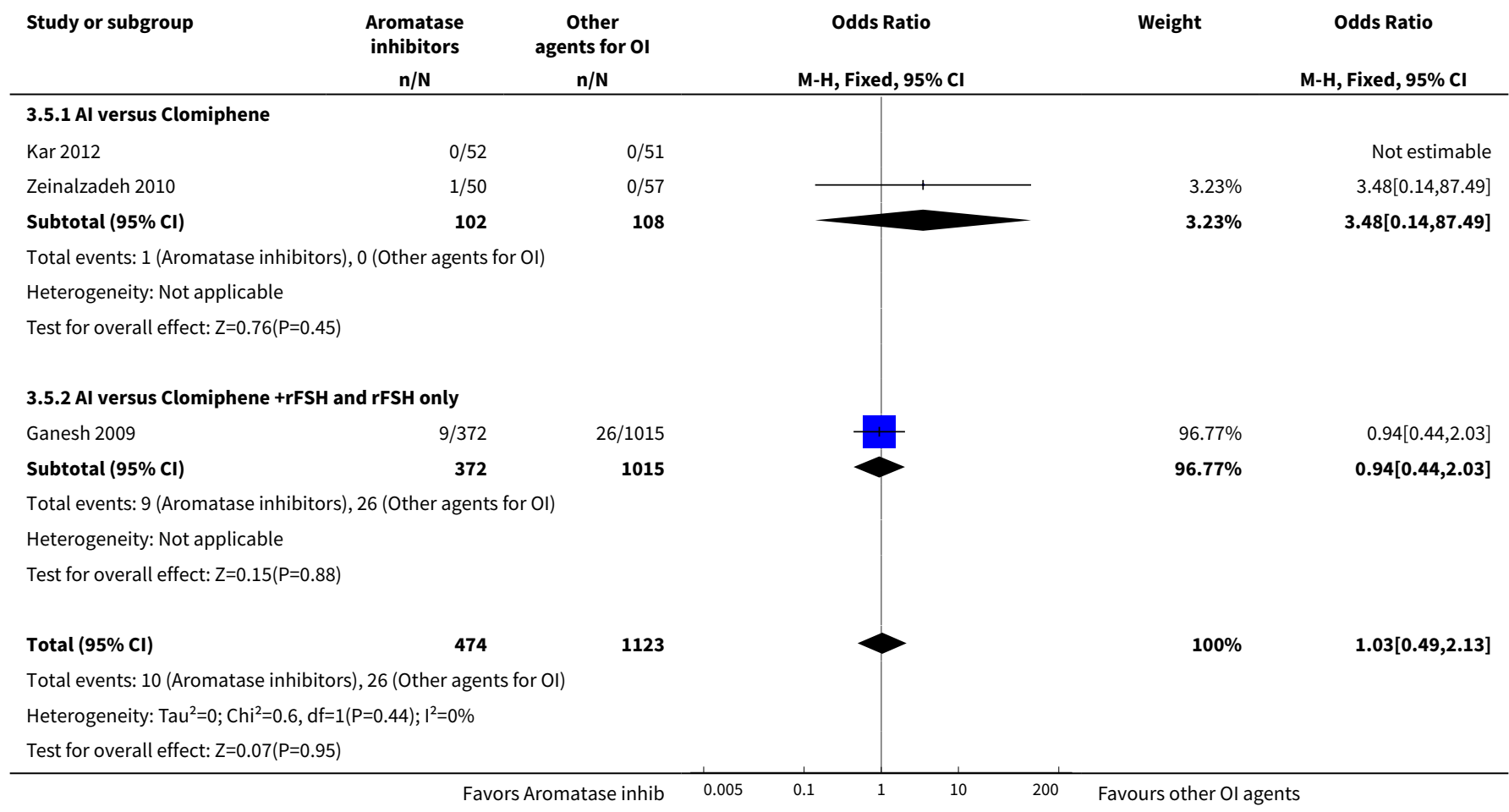




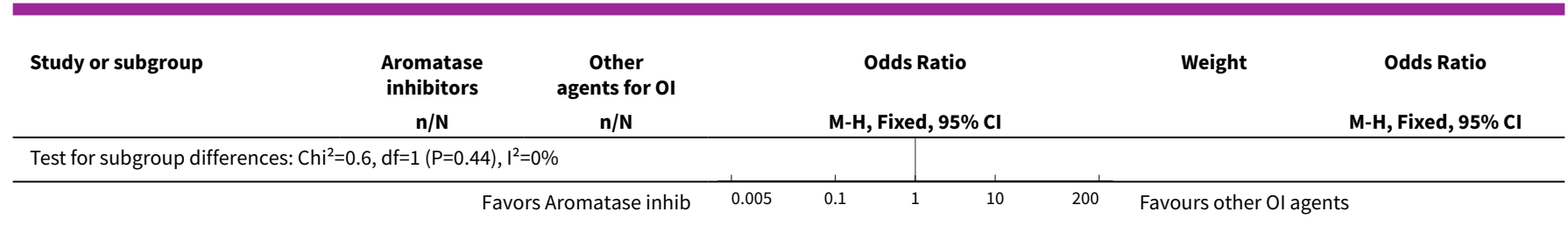

\section{Comparison 4. Letrozole compared to laparoscopic ovarian drilling}

\begin{tabular}{|c|c|c|c|c|}
\hline Outcome or subgroup title & No. of studies & $\begin{array}{l}\text { No. of partici- } \\
\text { pants }\end{array}$ & Statistical method & Effect size \\
\hline 1 Live birth rate & 3 & 548 & Odds Ratio (M-H, Fixed, 95\% Cl) & $1.38[0.95,2.02]$ \\
\hline $\begin{array}{l}2 \text { Ovarian hyperstimulation } \\
\text { syndrome rate }\end{array}$ & 1 & & $\begin{array}{l}\text { Risk Difference (M-H, Fixed, 95\% } \\
\mathrm{Cl})\end{array}$ & Totals not selected \\
\hline 3 Clinical pregnancy rate & 5 & 774 & Odds Ratio (M-H, Fixed, 95\% Cl) & $1.28[0.94,1.74]$ \\
\hline 3.1 Al versus LOD & 4 & 628 & Odds Ratio (M-H, Fixed, 95\% Cl) & $1.30[0.93,1.83]$ \\
\hline $\begin{array}{l}3.2 \mathrm{Al}+\text { metformin versus } \\
\text { LOD }\end{array}$ & 1 & 146 & Odds Ratio (M-H, Fixed, 95\% Cl) & $1.20[0.60,2.39]$ \\
\hline $\begin{array}{l}4 \text { Miscarriage rate by woman } \\
\text { randomised }\end{array}$ & 5 & 774 & Odds Ratio (M-H, Fixed, 95\% CI) & $0.81[0.38,1.70]$ \\
\hline 4.1 $\mathrm{Al}$ versus LOD & 4 & 628 & Odds Ratio (M-H, Fixed, 95\% Cl) & $0.69[0.29,1.63]$ \\
\hline $\begin{array}{l}4.2 \mathrm{Al}+\text { metformin versus } \\
\text { LOD }\end{array}$ & 1 & 146 & Odds Ratio (M-H, Fixed, 95\% Cl) & $1.35[0.29,6.27]$ \\
\hline $\begin{array}{l}5 \text { Miscarriage rate by preg- } \\
\text { nancies }\end{array}$ & 5 & 240 & Odds Ratio (M-H, Fixed, 95\% Cl) & $0.66[0.30,1.43]$ \\
\hline 5.1 Al versus LOD & 4 & 191 & Odds Ratio (M-H, Fixed, 95\% Cl) & $0.54[0.22,1.33]$ \\
\hline $\begin{array}{l}5.2 \mathrm{Al}+\text { metformin versus } \\
\text { LOD }\end{array}$ & 1 & 49 & Odds Ratio (M-H, Fixed, 95\% Cl) & $1.21[0.24,6.09]$ \\
\hline 6 Multiple pregnancy rate & 3 & 548 & Odds Ratio (M-H, Fixed, 95\% Cl) & $3.00[0.12,74.90]$ \\
\hline
\end{tabular}

Analysis 4.1. Comparison 4 Letrozole compared to laparoscopic ovarian drilling, Outcome 1 Live birth rate.

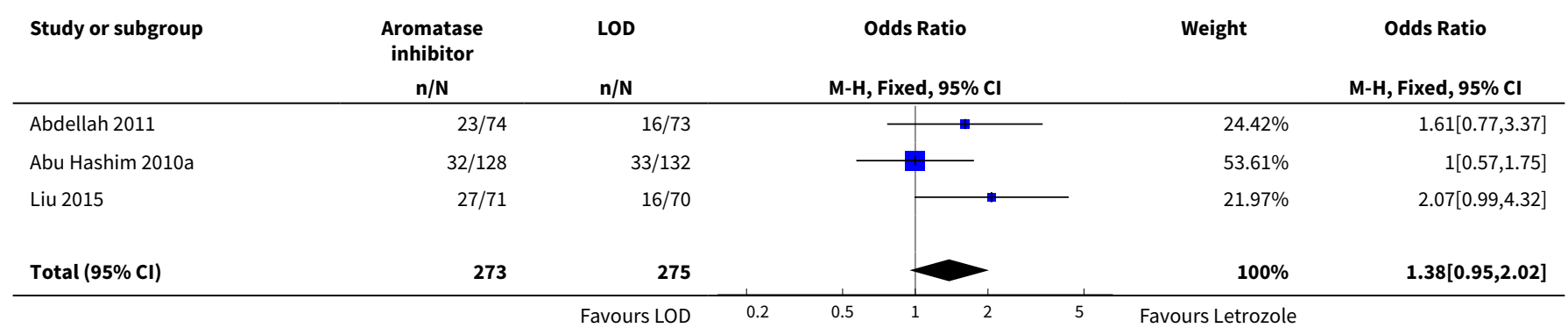




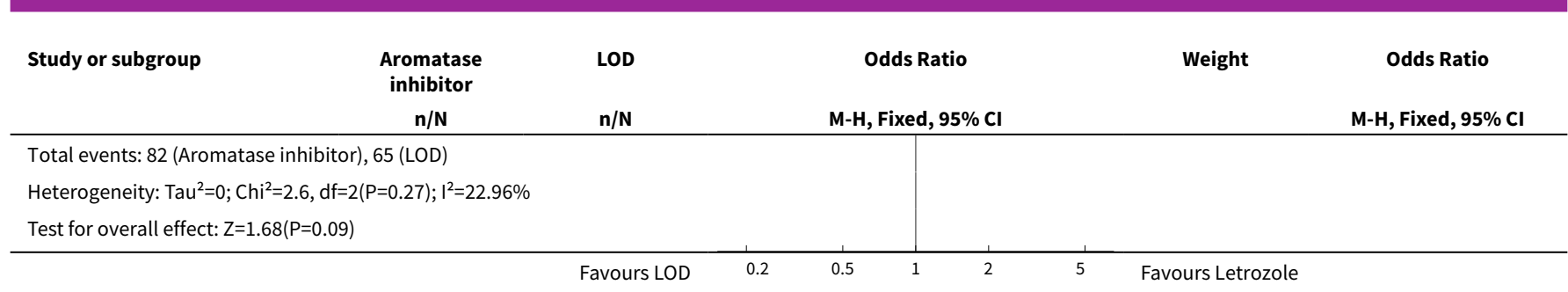

Analysis 4.2. Comparison 4 Letrozole compared to laparoscopic ovarian drilling, Outcome 2 Ovarian hyperstimulation syndrome rate.

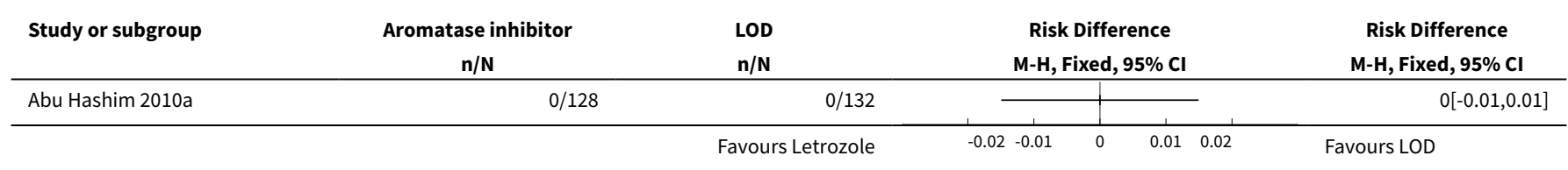

Analysis 4.3. Comparison 4 Letrozole compared to laparoscopic ovarian drilling, Outcome 3 Clinical pregnancy rate.

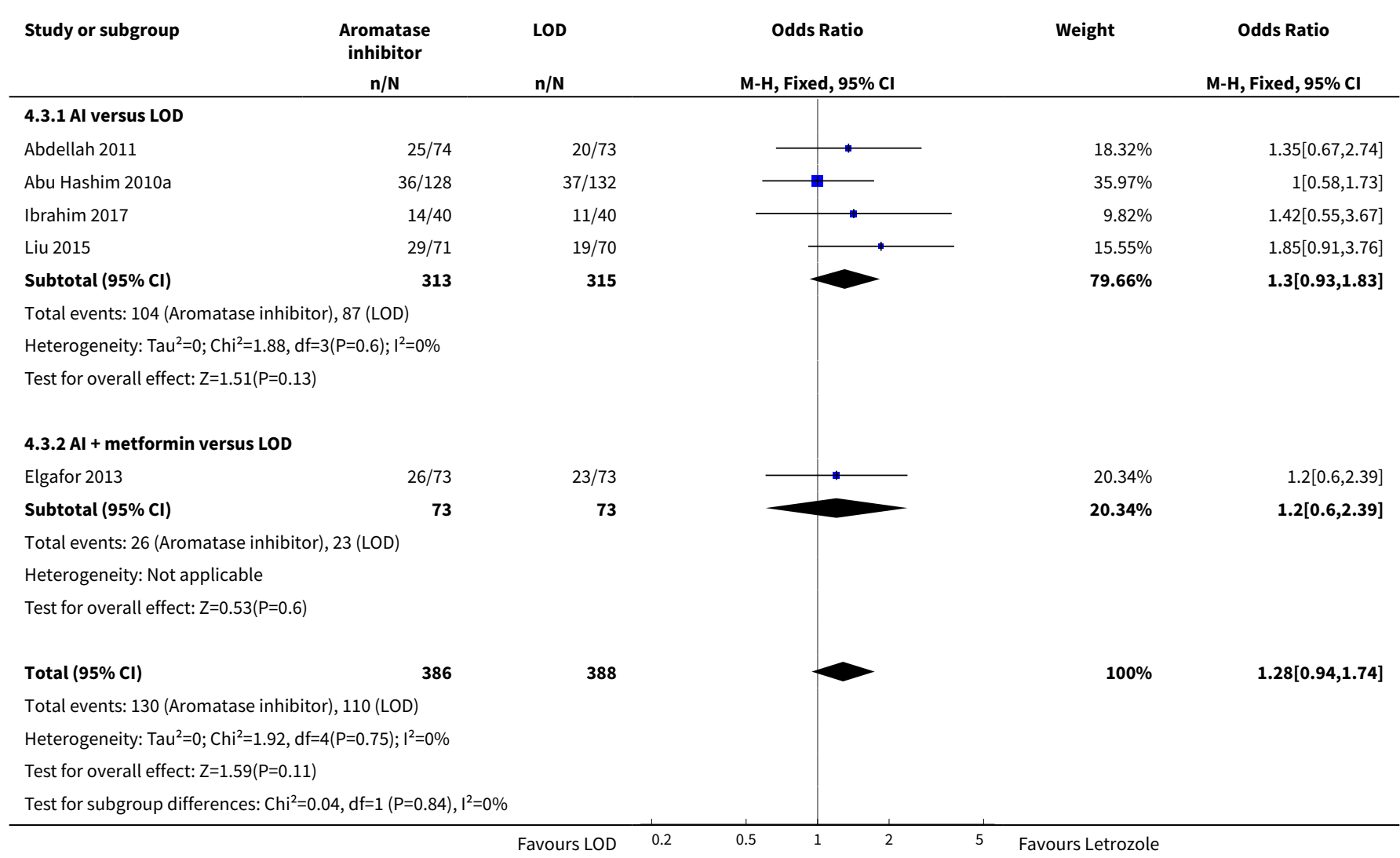


Analysis 4.4. Comparison 4 Letrozole compared to laparoscopic ovarian drilling, Outcome 4 Miscarriage rate by woman randomised.

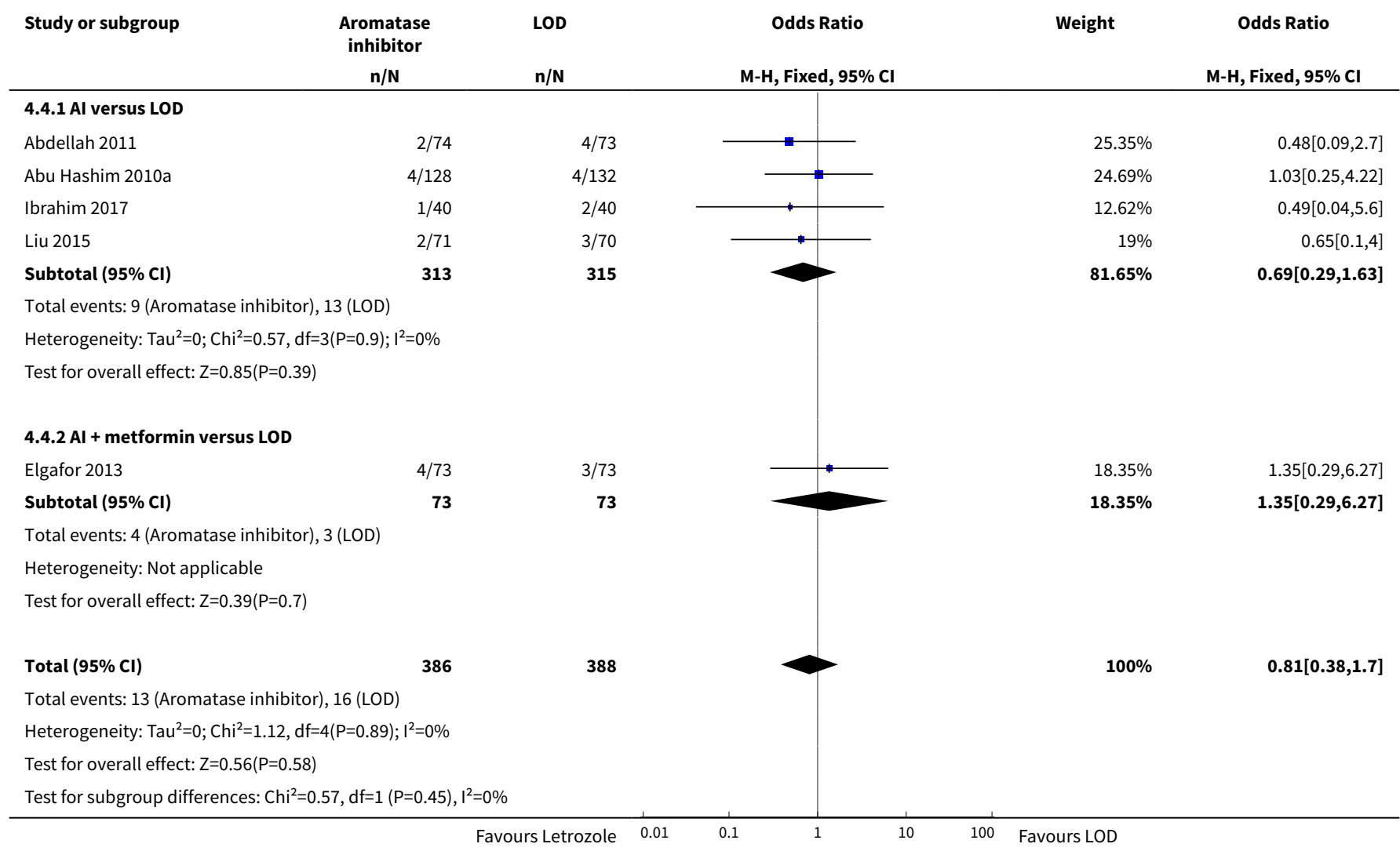

Analysis 4.5. Comparison 4 Letrozole compared to laparoscopic ovarian drilling, Outcome 5 Miscarriage rate by pregnancies.

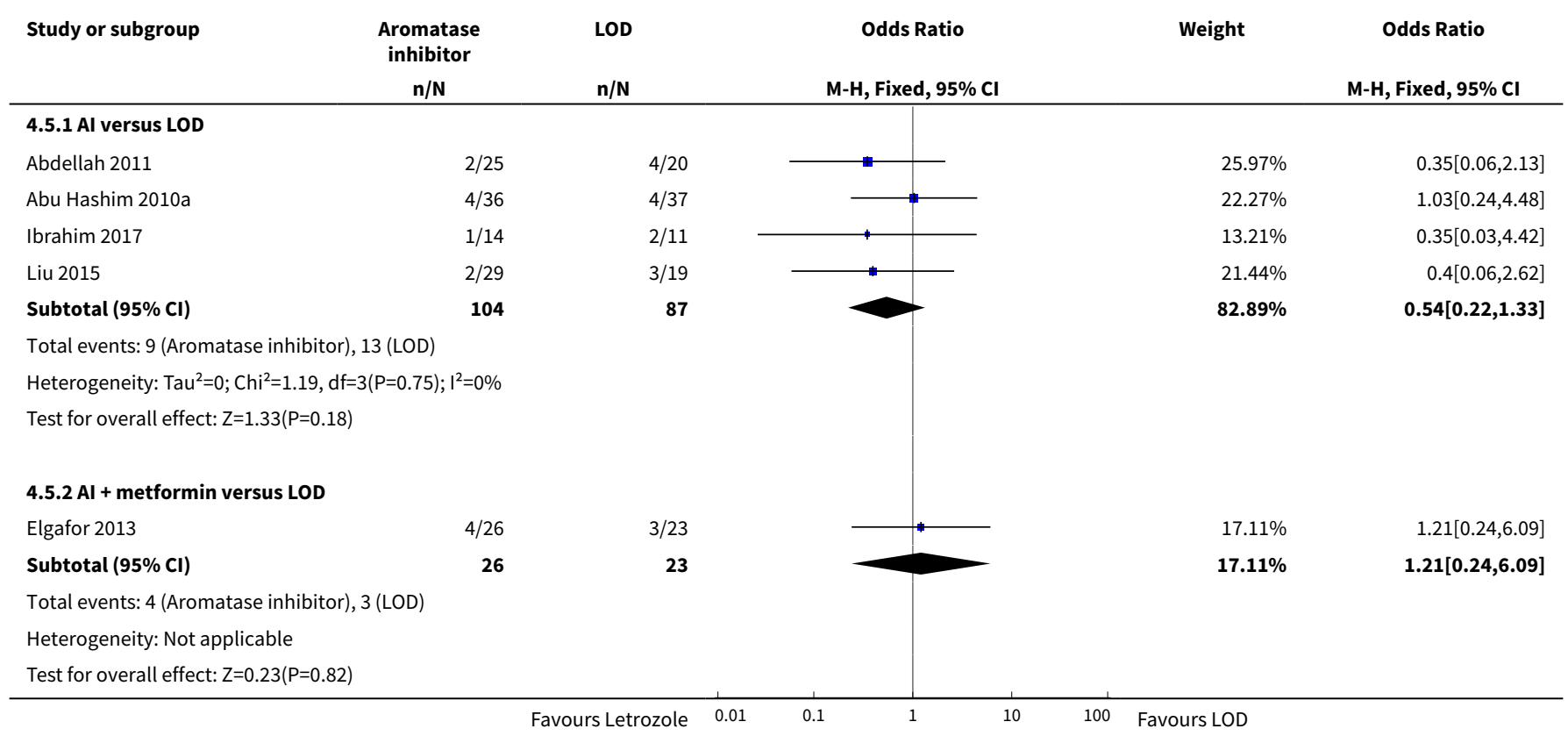




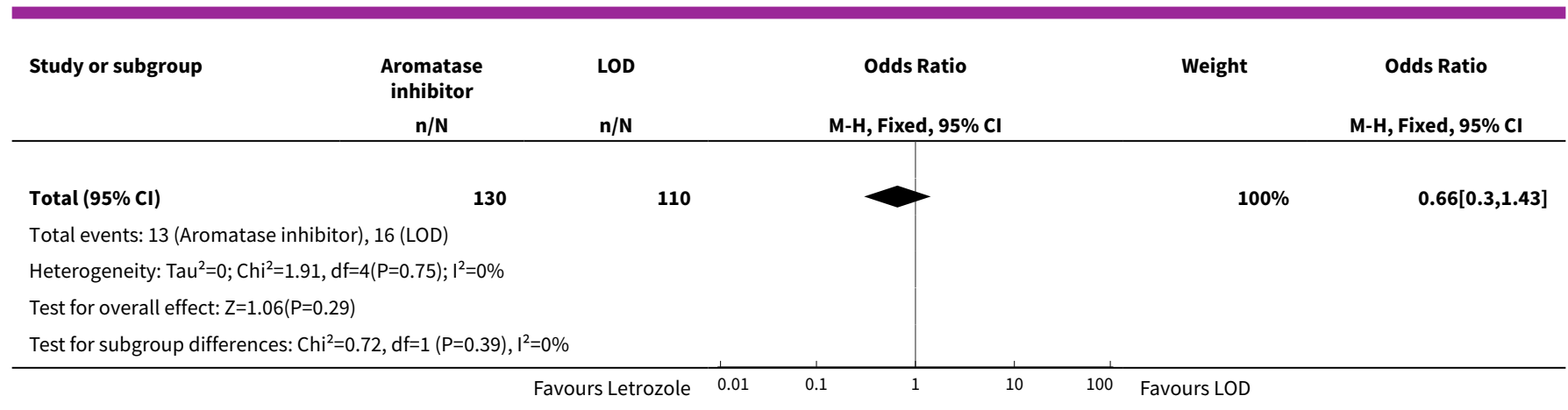

\section{Analysis 4.6. Comparison 4 Letrozole compared to laparoscopic} ovarian drilling, Outcome 6 Multiple pregnancy rate.

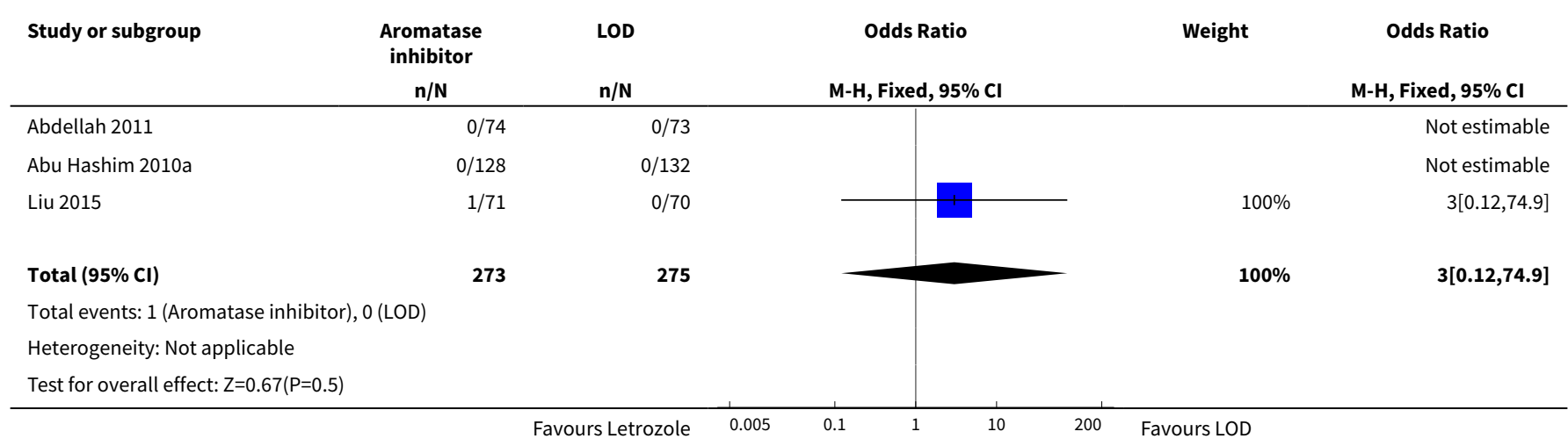

\section{Comparison 5. Letrozole compared to FSH}

\begin{tabular}{lllll}
\hline Outcome or subgroup title & No. of studies & $\begin{array}{l}\text { No. of partici- } \\
\text { pants }\end{array}$ & Statistical method & Effect size \\
\hline $\begin{array}{l}1 \text { Ovarian hyperstimulation syn- } \\
\text { drome rate }\end{array}$ & 1 & & $\begin{array}{l}\text { Risk Difference (M-H, Fixed, 95\% } \\
\text { Cl) }\end{array}$ & Totals not selected \\
\hline $\begin{array}{l}\text { 2 Clinical pregnancy rate } \\
\text { 3 Miscarriage rate by woman ran- } \\
\text { domised }\end{array}$ & 1 & 140 & Odds Ratio (M-H, Fixed, 95\% Cl) & $0.82[0.40,1.67]$ \\
\hline $\begin{array}{l}\text { Miscarriage rate by pregnancies } \\
\text { 5 Multiple pregnancy rate }\end{array}$ & 1 & Odds Ratio (M-H, Fixed, 95\% Cl) & Totals not selected \\
\hline
\end{tabular}


Analysis 5.1. Comparison 5 Letrozole compared to FSH, Outcome 1 Ovarian hyperstimulation syndrome rate.

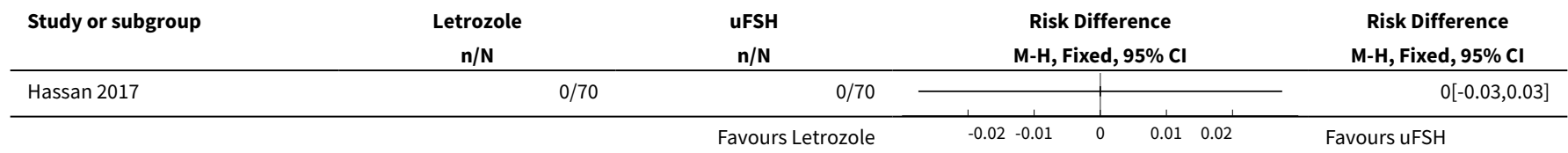

Analysis 5.2. Comparison 5 Letrozole compared to FSH, Outcome 2 Clinical pregnancy rate.

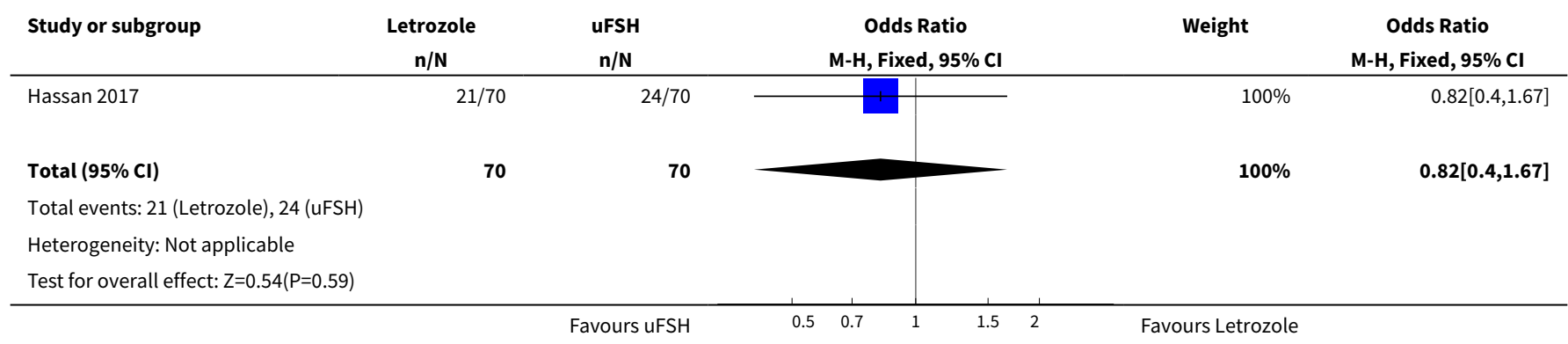

Analysis 5.3. Comparison 5 Letrozole compared to FSH, Outcome 3 Miscarriage rate by woman randomised.

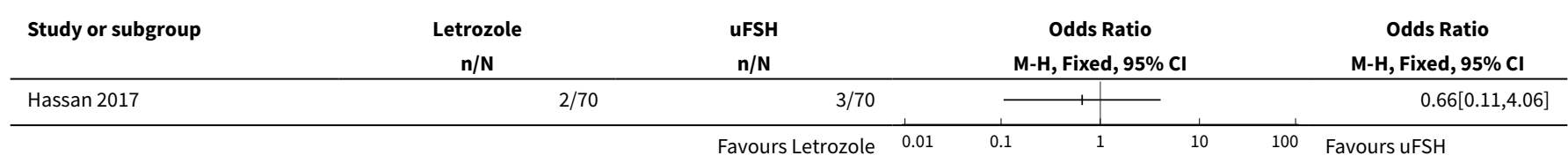

Analysis 5.4. Comparison 5 Letrozole compared to FSH, Outcome 4 Miscarriage rate by pregnancies.

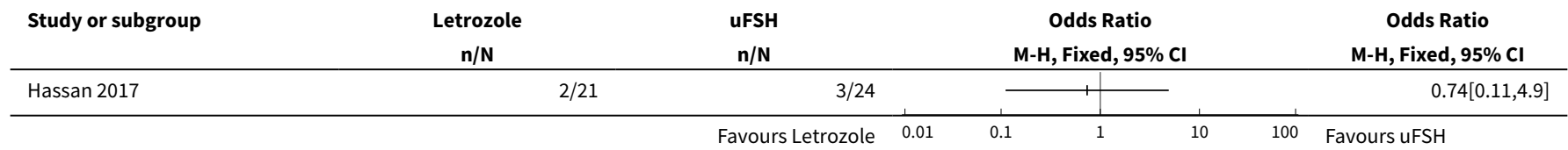

Analysis 5.5. Comparison 5 Letrozole compared to FSH, Outcome 5 Multiple pregnancy rate.

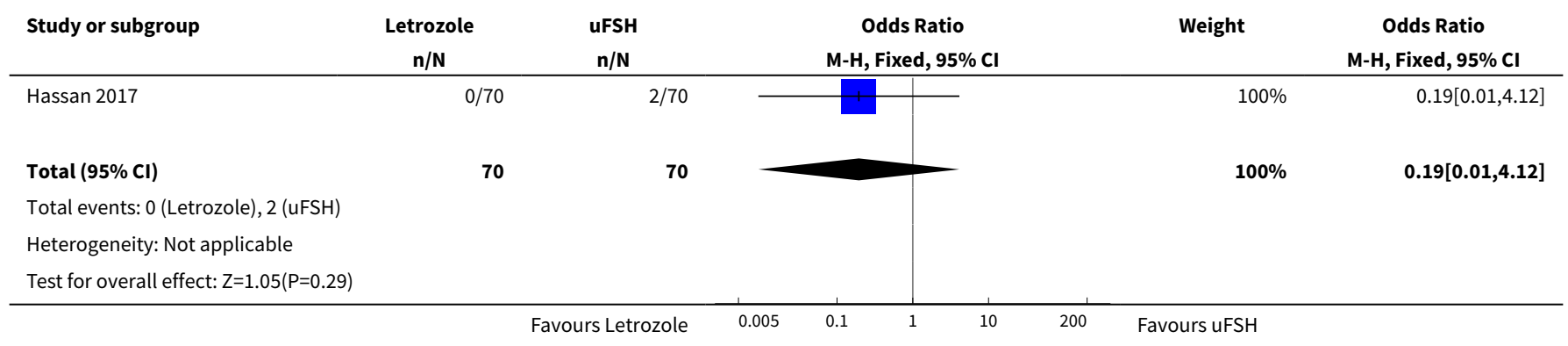


Comparison 6. Letrozole compared to anastrozole

\begin{tabular}{lllll}
\hline Outcome or subgroup title & No. of studies & $\begin{array}{l}\text { No. of partici- } \\
\text { pants }\end{array}$ & Statistical method & Effect size \\
\hline $\begin{array}{l}1 \text { Ovarian hyperstimulation syn- } \\
\text { drome rate }\end{array}$ & 1 & & $\begin{array}{l}\text { Risk Difference (M-H, Fixed, } \\
95 \% \text { Cl) }\end{array}$ & Totals not selected \\
\hline $\begin{array}{llll}\text { 2 Clinical pregnancy rate } \\
\text { 3 Miscarriage rate by woman ran- }\end{array}$ & 1 & 260 & $\begin{array}{l}\text { Odds Ratio (M-H, Fixed, 95\% } \\
\text { Cl) }\end{array}$ & $0.85[0.51,1.43]$ \\
\hline $\begin{array}{l}\text { domised } \\
\text { Miscarriage rate by pregnancies }\end{array}$ & 1 & $\begin{array}{l}\text { Odds Ratio (M-H, Fixed, 95\% } \\
\text { Cl) }\end{array}$ & Totals not selected \\
\hline 5 Multiple pregnancy rate & 2 & $\begin{array}{l}\text { Odds Ratio (M-H, Fixed, 95\% } \\
\text { Cl) }\end{array}$ & Totals not selected \\
\hline
\end{tabular}

Analysis 6.1. Comparison 6 Letrozole compared to anastrozole, Outcome 1 Ovarian hyperstimulation syndrome rate.

\begin{tabular}{|c|c|c|c|c|c|}
\hline Study or subgroup & $\begin{array}{c}\text { Letrozole } \\
\mathrm{n} / \mathrm{N}\end{array}$ & $\begin{array}{c}\text { Anastrozole } \\
\mathrm{n} / \mathrm{N} \\
\end{array}$ & $\begin{array}{r}\text { Risl } \\
\text { M-H, }\end{array}$ & $\begin{array}{l}\text { Difference } \\
\text { xed, } 95 \% \mathrm{Cl}\end{array}$ & $\begin{array}{c}\text { Risk Difference } \\
\text { M-H, Fixed, 95\% CI }\end{array}$ \\
\hline Badawy 2008 & $0 / 111$ & $0 / 109$ & 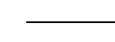 & + & $0[-0.02,0.02]$ \\
\hline
\end{tabular}

Analysis 6.2. Comparison 6 Letrozole compared to anastrozole, Outcome 2 Clinical pregnancy rate.

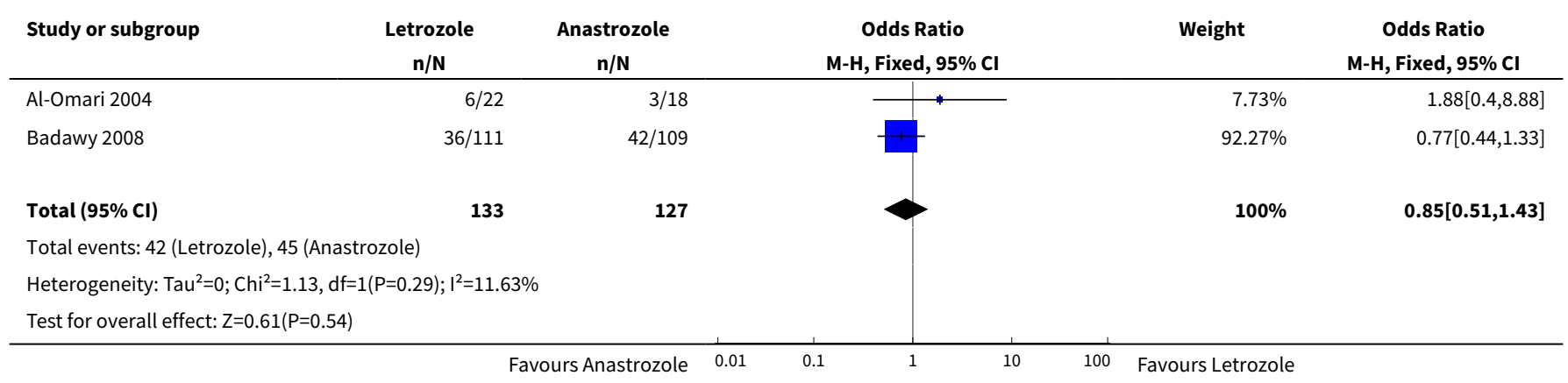

Analysis 6.3. Comparison 6 Letrozole compared to anastrozole, Outcome 3 Miscarriage rate by woman randomised.

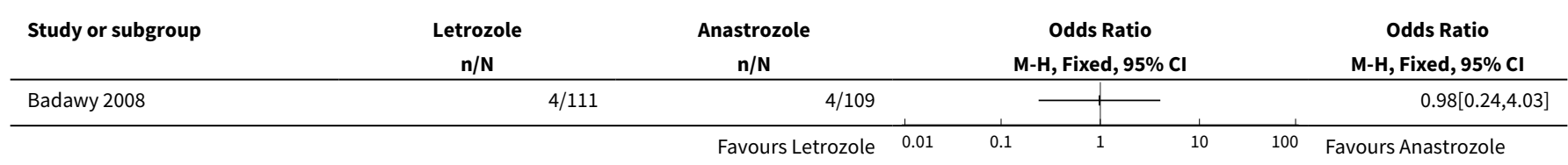


Analysis 6.4. Comparison 6 Letrozole compared to anastrozole, Outcome 4 Miscarriage rate by pregnancies.

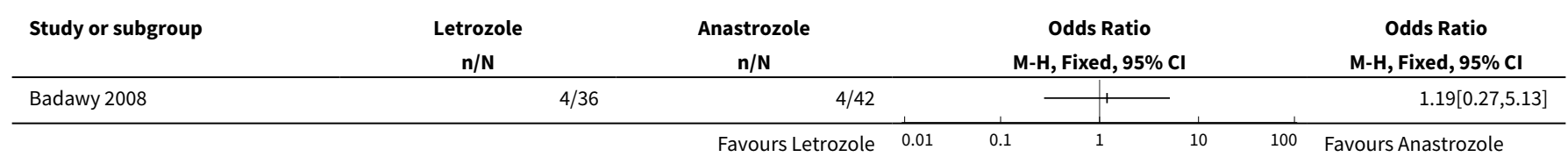

Analysis 6.5. Comparison 6 Letrozole compared to anastrozole, Outcome 5 Multiple pregnancy rate.

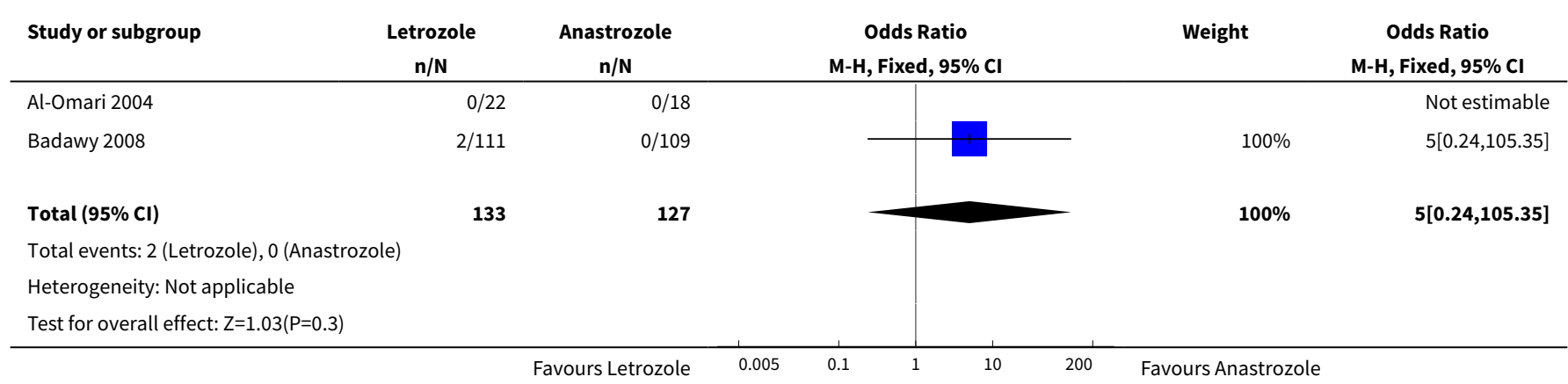

\section{Comparison 7. Different administration protocols of letrozole}

\begin{tabular}{|c|c|c|c|c|}
\hline Outcome or subgroup title & No. of studies & $\begin{array}{l}\text { No. of partici- } \\
\text { pants }\end{array}$ & Statistical method & Effect size \\
\hline $\begin{array}{l}1 \text { Ovarian hyperstimulation syndrome } \\
\text { rate }\end{array}$ & 1 & & $\begin{array}{l}\text { Risk Difference (M-H, Fixed, } \\
95 \% \mathrm{Cl})\end{array}$ & $\begin{array}{l}\text { Totals not select- } \\
\text { ed }\end{array}$ \\
\hline $\begin{array}{l}\text { 1.1 Five days compared to } 10 \text { days ad- } \\
\text { ministration protocol of letrozole }\end{array}$ & 1 & & $\begin{array}{l}\text { Risk Difference (M-H, Fixed, } \\
95 \% \mathrm{Cl})\end{array}$ & $0.0[0.0,0.0]$ \\
\hline 2 Clinical pregnancy rate & 2 & & $\begin{array}{l}\text { Odds Ratio (M-H, Fixed, 95\% } \\
\mathrm{Cl})\end{array}$ & $\begin{array}{l}\text { Totals not select- } \\
\text { ed }\end{array}$ \\
\hline $\begin{array}{l}2.1 \text { Five days compared to } 10 \text { days ad- } \\
\text { ministration protocol of letrozole }\end{array}$ & 1 & & $\begin{array}{l}\text { Odds Ratio (M-H, Fixed, 95\% } \\
\mathrm{Cl})\end{array}$ & $0.0[0.0,0.0]$ \\
\hline $\begin{array}{l}2.2 \text { Letrozole day 3-7 administratio ver- } \\
\text { sus day 5-9 administration }\end{array}$ & 1 & & $\begin{array}{l}\text { Odds Ratio (M-H, Fixed, 95\% } \\
\mathrm{Cl})\end{array}$ & $0.0[0.0,0.0]$ \\
\hline $\begin{array}{l}3 \text { Miscarriage rate by woman ran- } \\
\text { domised }\end{array}$ & 1 & & $\begin{array}{l}\text { Odds Ratio (M-H, Fixed, 95\% } \\
\mathrm{Cl})\end{array}$ & $\begin{array}{l}\text { Totals not select- } \\
\text { ed }\end{array}$ \\
\hline $\begin{array}{l}\text { 3.1 Five days compared to } 10 \text { days ad- } \\
\text { ministration protocol of letrozole }\end{array}$ & 1 & & $\begin{array}{l}\text { Odds Ratio (M-H, Fixed, 95\% } \\
\mathrm{Cl})\end{array}$ & $0.0[0.0,0.0]$ \\
\hline 4 Miscarriage rate by pregnancies & 1 & & $\begin{array}{l}\text { Odds Ratio (M-H, Fixed, 95\% } \\
\mathrm{Cl})\end{array}$ & $\begin{array}{l}\text { Totals not select- } \\
\text { ed }\end{array}$ \\
\hline
\end{tabular}




\begin{tabular}{lllll}
\hline Outcome or subgroup title & No. of studies & $\begin{array}{l}\text { No. of partici- } \\
\text { pants }\end{array}$ & Statistical method & Effect size \\
\hline $\begin{array}{l}\text { 4.1 Five days compared to } 10 \text { days ad- } \\
\text { ministration protocol of letrozole }\end{array}$ & 1 & & $\begin{array}{l}\text { Odds Ratio (M-H, Fixed, 95\% } \\
\mathrm{Cl})\end{array}$ & $0.0[0.0,0.0]$ \\
\hline 5 Multiple pregnancy rate & 1 & $\begin{array}{l}\text { Odds Ratio (M-H, Fixed, 95\% } \\
\text { Cl) }\end{array}$ & $\begin{array}{l}\text { Totals not select- } \\
\text { ed }\end{array}$ \\
\hline $\begin{array}{l}5.1 \text { Five days compared to 10 days ad- } \\
\text { ministration protocol of letrozole }\end{array}$ & 1 & Odds Ratio (M-H, Fixed, 95\% & $0.0[0.0,0.0]$ \\
\hline
\end{tabular}

Analysis 7.1. Comparison 7 Different administration protocols of letrozole, Outcome 1 Ovarian hyperstimulation syndrome rate.

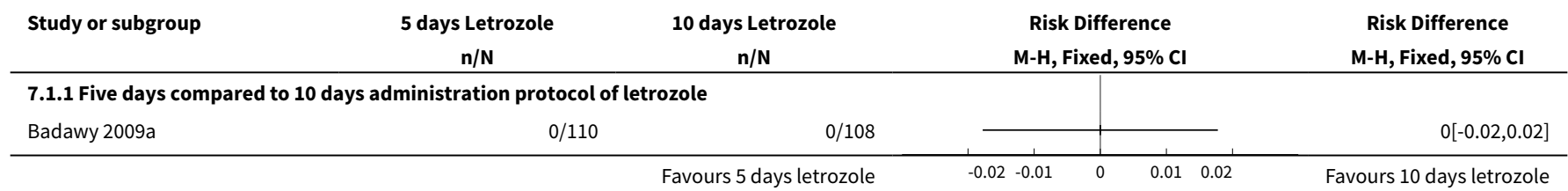

\section{Analysis 7.2. Comparison 7 Different administration protocols of letrozole, Outcome 2 Clinical pregnancy rate.}

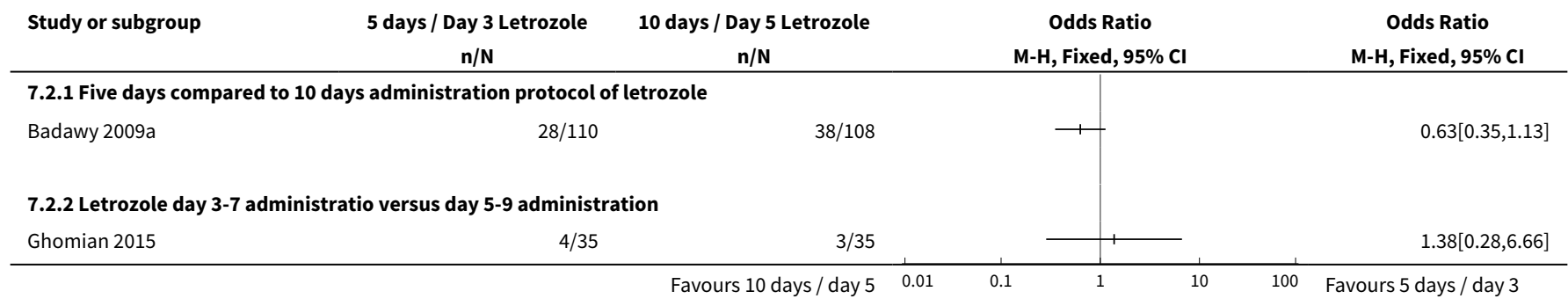

Analysis 7.3. Comparison 7 Different administration protocols of letrozole, Outcome 3 Miscarriage rate by woman randomised.

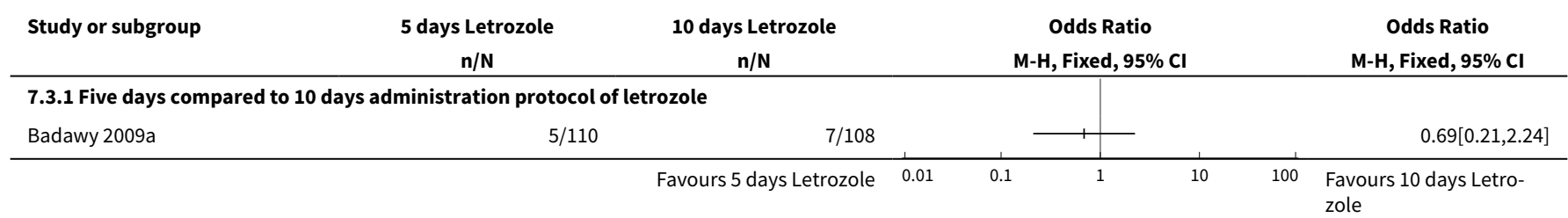




\section{Analysis 7.4. Comparison 7 Different administration protocols} of letrozole, Outcome 4 Miscarriage rate by pregnancies.

\begin{tabular}{|c|c|c|c|c|c|c|c|}
\hline Study or subgroup & $\begin{array}{c}5 \text { days Letrozole } \\
n / N\end{array}$ & $\begin{array}{c}10 \text { days Letrozole } \\
n / N\end{array}$ & & \multicolumn{2}{|c|}{$\begin{array}{c}\text { Odds Ratio } \\
\text { M-H, Fixed, } 95 \% \mathrm{Cl}\end{array}$} & & \multirow[t]{2}{*}{$\begin{array}{c}\text { Odds Ratio } \\
\text { M-H, Fixed, } 95 \% \mathrm{CI}\end{array}$} \\
\hline 7.4.1 Five days com & Iministration protocol o & rozole & & & & & \\
\hline Badawy 2009a & $5 / 28$ & $7 / 38$ & & & - & & $0.96[0.27,3.42]$ \\
\hline
\end{tabular}

Analysis 7.5. Comparison 7 Different administration protocols of letrozole, Outcome 5 Multiple pregnancy rate.

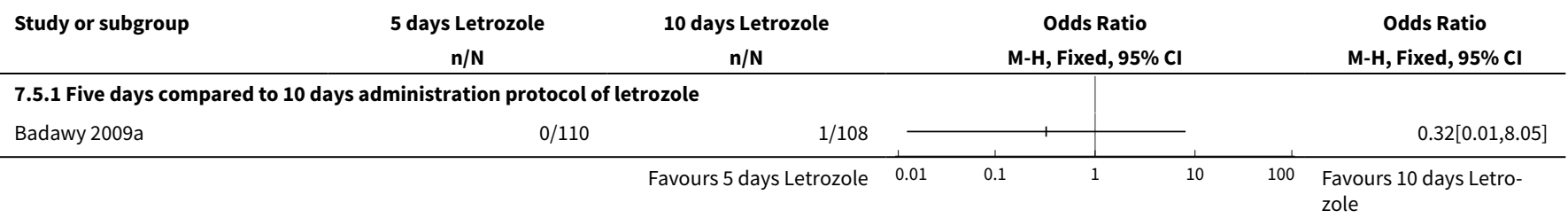

\section{Comparison 8. Dosage studies of letrozole}

\begin{tabular}{|c|c|c|c|c|}
\hline Outcome or subgroup title & No. of studies & $\begin{array}{l}\text { No. of partici- } \\
\text { pants }\end{array}$ & Statistical method & Effect size \\
\hline $\begin{array}{l}1 \text { Ovarian hyperstimulation } \\
\text { syndrome rate }\end{array}$ & 1 & & $\begin{array}{l}\text { Risk Difference (M-H, Fixed, 95\% } \\
\mathrm{Cl})\end{array}$ & Totals not selected \\
\hline $1.15 \mathrm{mg}$ vs $7.5 \mathrm{mg}$ letrozole & 1 & & $\begin{array}{l}\text { Risk Difference (M-H, Fixed, 95\% } \\
\mathrm{Cl})\end{array}$ & $0.0[0.0,0.0]$ \\
\hline 2 Clinical pregnancy rate & 1 & & Odds Ratio (M-H, Fixed, 95\% Cl) & Totals not selected \\
\hline $2.15 \mathrm{mg}$ vs $7.5 \mathrm{mg}$ letrozole & 1 & & Odds Ratio (M-H, Fixed, 95\% Cl) & $0.0[0.0,0.0]$ \\
\hline $\begin{array}{l}3 \text { Miscarriage rate by woman } \\
\text { randomised }\end{array}$ & 1 & & Odds Ratio (M-H, Fixed, 95\% Cl) & Totals not selected \\
\hline $3.15 \mathrm{mg}$ vs $7.5 \mathrm{mg}$ letrozole & 1 & & Odds Ratio (M-H, Fixed, 95\% Cl) & $0.0[0.0,0.0]$ \\
\hline $\begin{array}{l}4 \text { Miscarriage rate by pregnan- } \\
\text { cies }\end{array}$ & 1 & & Odds Ratio (M-H, Fixed, 95\% Cl) & Totals not selected \\
\hline $4.15 \mathrm{mg}$ vs $7.5 \mathrm{mg}$ letrozole & 1 & & Odds Ratio (M-H, Fixed, 95\% CI) & $0.0[0.0,0.0]$ \\
\hline 5 Multiple pregnancy rate & 1 & & Odds Ratio (M-H, Fixed, 95\% Cl) & Totals not selected \\
\hline $5.15 \mathrm{mg}$ vs $7.5 \mathrm{mg}$ letrozole & 1 & & Odds Ratio (M-H, Fixed, 95\% Cl) & $0.0[0.0,0.0]$ \\
\hline
\end{tabular}


Analysis 8.1. Comparison 8 Dosage studies of letrozole, Outcome 1 Ovarian hyperstimulation syndrome rate.

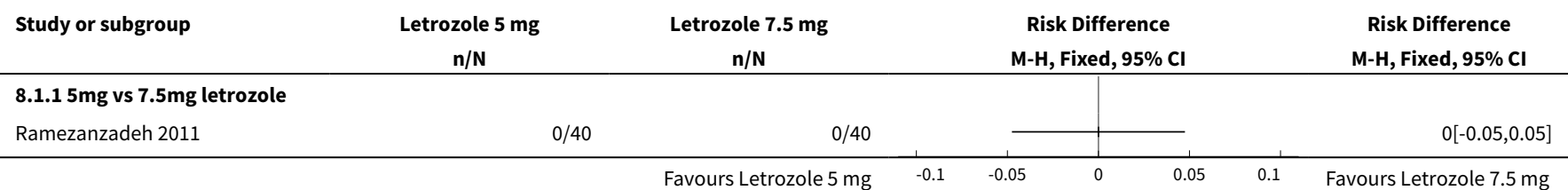

\section{Analysis 8.2. Comparison 8 Dosage studies of letrozole, Outcome 2 Clinical pregnancy rate.}

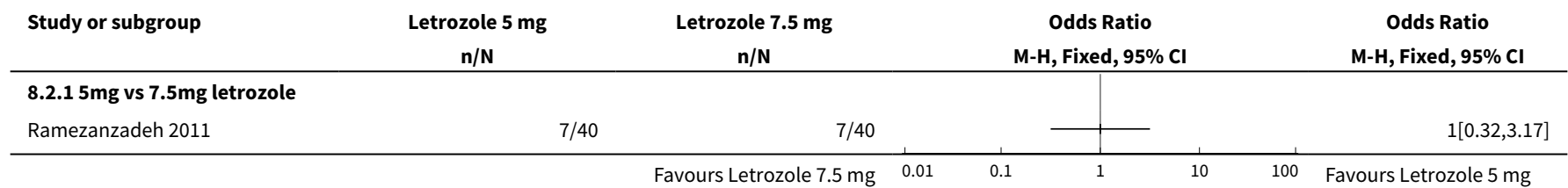

\section{Analysis 8.3. Comparison 8 Dosage studies of letrozole, Outcome $\mathbf{3}$ Miscarriage rate by woman randomised.}

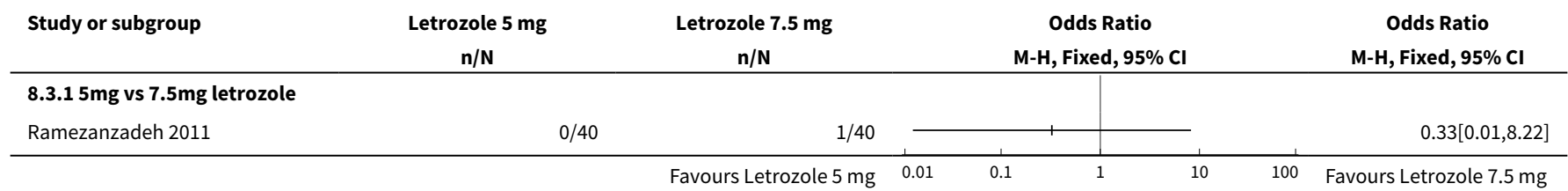

Analysis 8.4. Comparison 8 Dosage studies of letrozole, Outcome 4 Miscarriage rate by pregnancies.

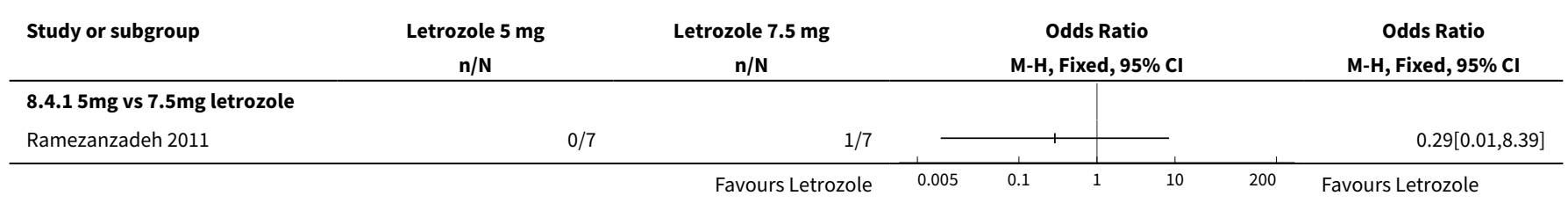

Analysis 8.5. Comparison 8 Dosage studies of letrozole, Outcome 5 Multiple pregnancy rate.

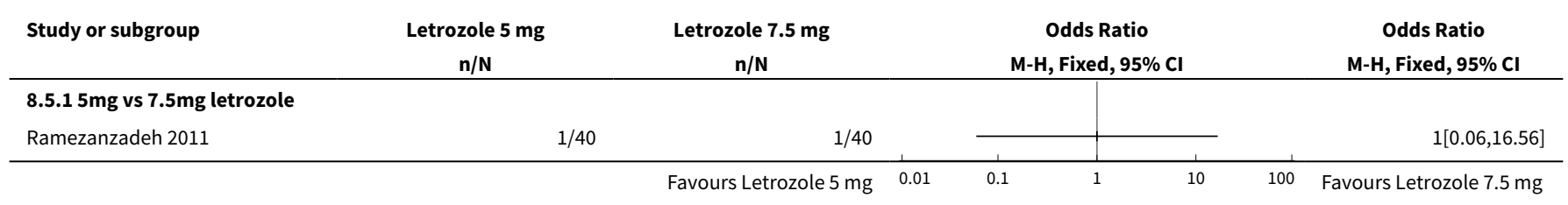




\section{APPENDICES}

\section{Appendix 1. CGFG search strategy}

Cochrane Gynaecology and Fertility Group (CGFG) specialised register search for SFR1820 06.11.16

Keywords CONTAINS "Polycystic Ovary Syndrome"or "PCOS"or "*Ovulation Induction"or"ovulation stimulation"or "ovarian hyperstimulation"or"superovulation"or Title CONTAINS"Polycystic Ovary Syndrome"or "PCOS"or "*Ovulation Induction"or"ovulation stimulation"or "ovarian hyperstimulation"or"superovulation"

AND

Keywords CONTAINS "aromatase inhibition"or"aromatase inhibitor" or "aromatase P450" or "Anastrozole" or "letozole" or "letrozole" or "Exemestane" or "arimidex" or Title CONTAINS "aromatase inhibition"or"aromatase inhibitor" or "aromatase P450" or "Anastrozole" or "letozole" or "letrozole" or "Exemestane" or "arimidex"

\section{Appendix 2. CENTRAL search strategy}

Database: EBM Reviews - Cochrane Central Register of Controlled Trials <August 2012>

Search Strategy:

1 exp Polycystic Ovary Syndrome/ (654)

2 Polycystic Ovar\$.tw. (950)

3 PCOS.tw. (648)

4 PCOD.tw. (23)

5 stein leventh\$.tw. (3)

6 (ovar\$ adj2 sclerocystic).tw. (0)

7 (ovar\$ adj2 degeneration).tw. (1)

8 PCO.tw. (309)

9 exp ovulation induction/ or exp superovulation/ (913)

10 (ovulat\$ adj2 induc\$).tw. (570)

11 superovulation.tw. (118)

12 (ovari\$ adj2 hyperstimulat\$).tw. (545)

13 (ovari\$ adj2 stimulat\$).tw. (725)

14 or/1-13 (2886)

15 exp aromatase inhibitors/ or exp aminoglutethimide/ or exp fadrozole/ (382)

16 aromatase inhibitor\$.tw. (413)

17 aminoglutethimide.tw. (153)

18 Anastrozole.tw. (294)

19 Arimidex.tw. (142)

20 Letrozole.tw. (349)

21 Femara.tw. (27)

22 Exemestane.tw. (161)

23 Aromasin.tw. (16)

24 Vorozole.tw. (16)

25 Rivizor.tw. (3)

26 Formestane.tw. (33)

27 Lentaron.tw. (7)

28 Fadrozole.tw. (28)

29 Afema.tw. (0)

30 or/15-29 (1094)

3114 and 30 (79)

This search was updated on 24 October 2013.

This search was again updated on 9 September 2014.

This search was again updated on 6 November 2017

\section{Appendix 3. MEDLINE search strategy}

Database: Ovid MEDLINE(R) In-Process \& Other Non-Indexed Citations, Ovid MEDLINE(R) Daily and Ovid MEDLINE(R) $<1946$ to Present $>$ Search Strategy: 
1 exp Polycystic Ovary Syndrome/ (9215)

2 Polycystic Ovar\$.tw. (9130)

3 PCOS.tw. (5069)

4 PCOD.tw. (251)

5 stein leventh\$.tw. (581)

6 (ovar\$ adj2 sclerocystic).tw. (82)

7 (ovar\$ adj2 degeneration).tw. (95)

8 PCO.tw. (3483)

9 exp ovulation induction/ or exp superovulation/ (9645)

10 (ovulat\$ adj2 induc\$).tw. (6375)

11 superovulation.tw. (1611)

12 (ovari\$ adj2 hyperstimulat\$).tw. (3473)

13 (ovari\$ adj2 stimulat\$).tw. (4369)

14 or/1-13 (30073)

15 exp aromatase inhibitors/ or exp aminoglutethimide/ or exp fadrozole/ (5470)

16 aromatase inhibitor\$.tw. (4418)

17 aminoglutethimide.tw. (1347)

18 Anastrozole.tw. (1141)

19 Arimidex.tw. (233)

20 Letrozole.tw. (1404)

21 Femara.tw. (76)

22 Exemestane.tw. (683)

23 Aromasin.tw. (27)

24 Vorozole.tw. (107)

25 Rivizor.tw. (5)

26 Formestane.tw. (121)

27 Lentaron.tw. (14)

28 Fadrozole.tw. (287)

29 Afema.tw. (4)

30 or/15-29 (7854)

3114 and 30 (311)

32 randomized controlled trial.pt. (335020)

33 controlled clinical trial.pt. (84917)

34 randomized.ab. (250120)

35 placebo.tw. (142679)

36 clinical trials as topic.sh. (161941)

37 randomly.ab. (183109)

38 trial.ti. (107599)

39 (crossover or cross-over or cross over).tw. (54410)

40 or/32-39 (820536)

41 exp animals/ not humans.sh. (3771273)

4240 not 41 (756998)

4331 and $42(90)$

This search was updated on 24 October 2013.

This search was again updated on 9 September 2014.

This search was again updated on 6 November 2017

\section{Appendix 4. EMBASE search strategy}

Database: Embase <1980 to 2012 August, week 28>

Search Strategy:

1 exp ovary polycystic disease/ (14819)

2 Polycystic Ovar\$.tw. (11706)

3 PCOS.tw. (6951)

4 PCOD.tw. (306)

5 stein leventh\$.tw. (538)

6 (ovar\$ adj2 sclerocystic).tw. (81)

7 (ovar\$ adj2 degeneration).tw. (97)

8 PCO.tw. (2819) 
9 exp ovulation induction/ (10176)

10 (ovulat\$ adj2 induc\$).tw. (7214)

11 (ovari\$ adj2 hyperstimulat\$).tw. (4638)

12 superovulation.tw. (1691)

13 (ovari\$ adj2 stimulat\$).tw. (5910)

14 or/1-13 (36936)

15 exp aromatase inhibitor/ (17443)

16 aromatase inhibitor\$.tw. (5958)

17 aminoglutethimide.tw. (1394)

18 Anastrozole.tw. (1668)

19 Arimidex.tw. (1489)

20 Letrozole.tw. (2124)

21 Femara.tw. (881)

22 Exemestane.tw. (1041)

23 Aromasin.tw. (423)

24 Vorozole.tw. (128)

25 Rivizor.tw. (27)

26 Formestane.tw. (159)

27 Lentaron.tw. (129)

28 Fadrozole.tw. (312)

29 Afema.tw. (25)

30 or/15-29 (18269)

3114 and 30 (696)

32 Clinical Trial/ (870009)

33 Randomized Controlled Trial/ (327258)

34 exp randomization/ (59096)

35 Single Blind Procedure/ (16267)

36 Double Blind Procedure/ (110342)

37 Crossover Procedure/ (34696)

38 Placebo/ (203094)

39 Randomi?ed controlled trial\$.tw. (77731)

40 Rct.tw. (9804)

41 random allocation.tw. (1170)

42 randomly allocated.tw. (17495)

43 allocated randomly.tw. (1825)

44 (allocated adj2 random).tw. (709)

45 Single blind\$.tw. (12431)

46 Double blind\$.tw. (129721)

47 ((treble or triple) adj blind\$).tw. (277)

48 placebo\$.tw. (177837)

49 prospective study/ (211224)

50 or/32-49 (1267084)

51 case study/ (16626)

52 case report.tw. (229076)

53 abstract report/ or letter/ (841093)

54 or/51-53 (1082122)

5550 not 54 (1231853)

5631 and 55 (281)

57 (2010\$ or $2011 \$$ or $2012 \$) . e m$. (2809950)

5856 and 57 (94)

This search was updated on 24 October 2013.

This search was again updated on 9 September 2014.

This search was again updated on 6 November 2017

\section{Appendix 5. PSYCINFO search strategy}

Database: PsycINFO < 1806 to June Week 4 2012>

Search Strategy:

1 exp Endocrine Sexual Disorders/ (825) 
2 Polycystic Ovar\$.tw. (221)

3 PCOS.tw. (128)

4 PCOD.tw. (5)

5 or/1-4 (979)

6 aromatase inhibitor\$.tw. (143)

7 Anastrozole.tw. (16)

8 Arimidex.tw. (2)

9 Letrozole.tw. (32)

10 Femara.tw. (0)

11 Exemestane.tw. (10)

12 or/6-11 (162)

135 and $12(3)$

This search was updated on 24 October 2013.

This search was again updated on 9 September 2014.

This search was again updated on 6 November 2017.

\section{Appendix 6. Trial registries and manual database search strategy}

Database: clinicaltrials.gov <Inception to January 7th, 2018>

1 polycystic ovary syndrome (490)

2 PCOS (560)

3 letrozole (438)

4 aromatase inhibitor ${ }^{\star}(897)$

5 (1 OR 2) AND (3 OR 4) (26)

Database: Pubmed <2017 to January 7th, 2018>

1 polycystic ovary syndrome (15040)

2 PCOS (8964)

3 letrozole (2703)

4 aromatase inhibitor ${ }^{\star}(10461)$

5 (1 OR 2) AND (3 OR 4) (260)

6 Limit 2017 - 2018 (33)

Database: LILACS < Inception to January 7th, 2018>

(tw:(polycystic ovary syndrome) OR (tw:(PCOS)) AND (tw:(letrozole) OR (tw:(aromatase inhibitor $\left.\left.{ }^{\star}\right)\right)$ ) (285)

\section{Appendix 7. Grey literature}

Database: google scholar <up to January 7th, 2018>

Keywords that has been searched for included: polycystic ovary syndrome, PCOS, letrozole, aromatase inhibitor, anastrozole, ovulation induction

\section{WHAT'S NEW}

\begin{tabular}{lll}
\hline Date & Event & Description \\
\hline 6 November 2017 & New search has been performed & $\begin{array}{l}\text { The review has been updated. We conducted a new search on } \\
\text { 6th November } 2017 .\end{array}$
\end{tabular}




\begin{tabular}{lll}
\hline Date & Description & \\
\hline & & We include 16 new studies in the 2018 update (Amer 2017; Chen \\
& 2016; El-Gharib 2015; El-Khayat 2016; Ghahiri 2016; Ghomian \\
& 2015; Hassan 2017; Hendawy 2011; Ibrahim 2017; Liu 2015; Liu \\
& 2017; Moussa 2016; Seyedoshohadaei 2016; Sharief 2015; Wu \\
& 2016; Zarei 2015) \\
& We added one study as ongoing (NCT03009838). \\
\hline \multirow{2}{*}{6 November 2017 } & New citation required but conclusions & There is no change in the conclusions of this review. \\
& have not changed & \\
\hline
\end{tabular}

\section{HISTORY}

Protocol first published: Issue 12, 2012

Review first published: Issue 2, 2014

\begin{tabular}{lll}
\hline Date & Event & Description \\
\hline 24 September 2014 & Amended & $\begin{array}{l}\text { This review has been amended. A new search was conducted on } \\
18.9 .14 \text { and new ongoing studies added. }\end{array}$ \\
\hline 17 July 2014 & Amended & $\begin{array}{l}\text { Addition of new data made available for Legro 2014. New sec- } \\
\text { ondary outcome has been added: Miscarriage rate per pregnancy }\end{array}$ \\
\hline 26 February 2014 & Amended & Correction of search date in Abstract and Methods sections \\
\hline
\end{tabular}

\section{CONTRIBUTIONS OFAUTHORS}

SF wrote the protocol and drafted the full review.

$\mathrm{JK}$ and CF acted as clinical experts and commented on the protocol and full review.

SF, SE and LK updated the 2018 version of the review.

CF acted as clinical expert and commented on the full review update in 2018.

\section{DECLARATIONS OF INTEREST}

No declarations of interest.

\section{SOURCES OF SUPPORT}

\section{Internal sources}

- Cochrane Gynaecology and Fertility Group, New Zealand.

editorial support

\section{External sources}

- None, Other.

\section{DIFFERENCES BETWEEN PROTOCOLANDREVIEW}

A new secondary outcome has been added as an amendment: Miscarriage rate by pregnancies. 


\section{N D EX TERMS}

\section{Medical Subject Headings (MeSH)}

Abortion, Spontaneous [epidemiology]; Anastrozole; Aromatase Inhibitors [ ${ }^{*}$ therapeutic use]; Birth Rate; Clomiphene [therapeutic use]; Coitus; Fertility Agents, Female [therapeutic use]; Infertility, Female [ ${ }^{*}$ drug therapy] [etiology]; Letrozole; Live Birth [epidemiology]; Nitriles [ ${ }^{\star}$ therapeutic use]; Ovarian Hyperstimulation Syndrome [epidemiology]; Ovary [surgery]; Ovulation Induction [methods]; Polycystic Ovary Syndrome [ ${ }^{\star}$ complications]; Pregnancy Outcome; Pregnancy, Multiple [statistics \& numerical data]; Randomized Controlled Trials as Topic; Triazoles [*therapeutic use]

\section{MeSH check words}

Female; Humans; Pregnancy 